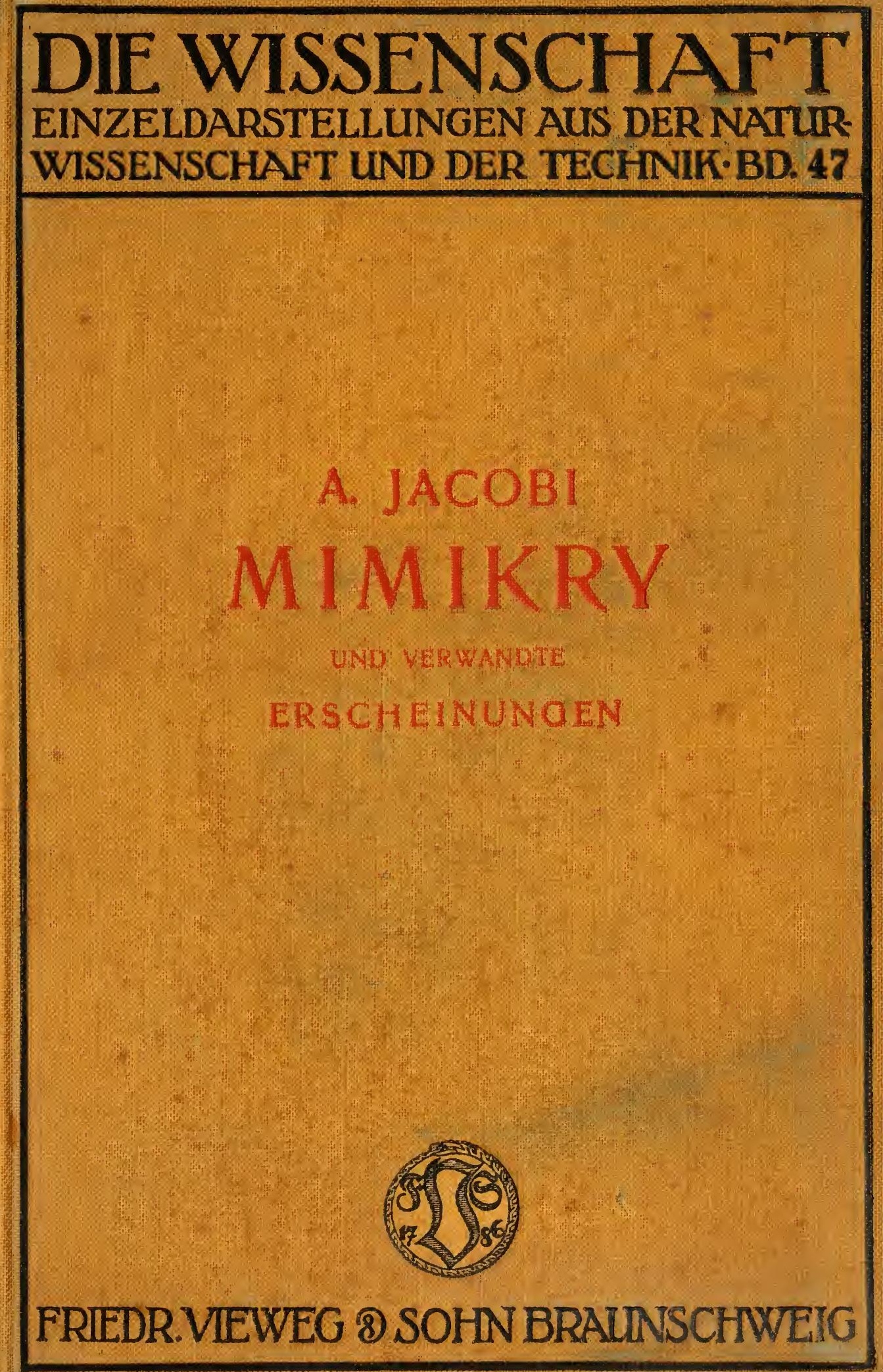




\section{A NKÜNDIGUNG.}

Die biologische Erscheinung der Mimikry zu kennen, gehört zur allgemeinen Bildung; gleichwohl sind sich nicht nur Laien, sondern oft auch Fachmänner darüber im Unklaren, welcher Begriff damit zu verbinden, auf welche Tatsachen und Erklärungen solcher er zu beschränken ist. Dem Mangel einer zeitgemäßen Zusammenstellung und kritischen Besprechung der in Betracht kommenden Erscheinungen will das vorliegende Heft der Sammlung "Wissenschaft" abhelfen. Der Verfasser begnügt sich jedoch nicht mit einer umfassenden Behandlung des eigentlichen Mimikryphänomens, sondern er führt auch in die oft damit zusammengeworfenen oder eine Vorstufe dazu bildenden Gebiete der Schutzfärbung, schützenden Ähnlichkeit und Warnfärbung ein. Man wird auch vieles in dem neuen Werke finden, das in den bisherigen Lehrbüchern und populären Aufsätzen unberücksichtigt blieb. Besondere Beachtung darf das Buch bei den Entomologen beanspruchen, da sein Stoff größtenteils auf deren Arbeitsfeld liegt; es bietet überdies durch reichliche literarische Nachweise umfassende Gelegenheit, sich über die erörterten Punkte eingehendere Kenntnisse zu verschaffen. Die Abbildungen stellen vielfach Gegenstände dar, die noch keine bildliche Wiedergabe gefunden haben und sind größtenteils in Farben ausgeführt.

Braunschweig, im Januar 1913.

Friedr. Vieweg \& Sohn. 


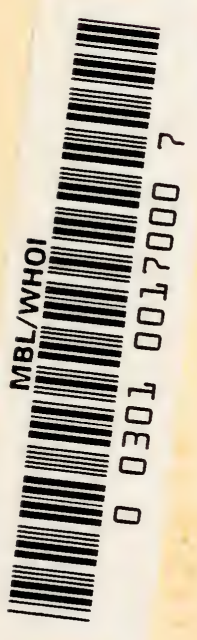






\title{
DIE WISSENSCHAFT
}

SAMMLUNG VON EINZELDARSTELLUNGEN AUS DEN GEBIETEN DER NATURWISSENSCHAF'T UND DER TECHNIK BA N D 47

\author{
A. J A C O B I \\ M I M I K R Y \\ UND VERWANDTE ERSCHEINUNGEN
}

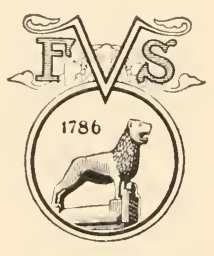

BRA U N S H W E I G

DRUCK UND VERLAG VON FRIEDR. VIEWEG \& SOHN

1913 


\title{
M I M I K R Y
} UND VERWANDTE ERSCHEINUNGEN

\author{
VoN
}

\section{DR. AR NOLD JACOBI}

DIREKTOR DES KÖNIGL. ZOOLOGISCHEN MUSEUMS IN DRESDEN

MIT 31 ZUM TELL FARBIGEN ABBILDUNGEN

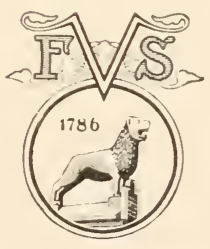

B R A U N S C HWEIG

DRUCK UND VERLAG VON FRIEDR. VIEWEG \& SOHN 1913 
Alle Rechte,

namentlich dasjenige der Übersetzung in fremde Sprachen, vorbehalten.

Copyright, 1913, by Friedr. Vieweg \& Sohn, Braunschweig, Germany.

$$
10907
$$




\section{VOR WORT.}

Das biologische Einzelgebiet der Mimikry darf um so mehr Anspruch erheben, in dieser Sammlung dargestellt zu werden, weil weder die deutsche noch die ausländische Literatur eine zusammenfassende und kritische Behandlung nach dem jetzigen Stande aufweist. Wer in dieser Richtung Belehrung sucht, muß zu älteren oder allgemein gehaltenen neueren Büchern greifen, die kaum aus Quellenverarbeitung hervorgegangen sind, und keine literarischen Hilfsmittel nennen. Ich war bemüht, alle Schriften von irgend einer Bedeutung für Mimikry in dem von mir angenommenen eigentlichen Sinne zu verarbeiten und habe versucht, die Früchte dieser mehrjährigen, oft recht weitläufigen Studien dem Leser in einer Gestalt zu bieten, die ihn nicht nur in großen Zügen über den Tatsachenschatz und seine Deutungen unterrichtet, sondern auch zu eigener Meinungsbildung den Boden ebnet. Freilich hat der Raum nur eine sehr enggezogene Stoffauswahl erlaubt, die zu der Fülle namentlich des in englischer Sprache erschienenen und schwer zu bewältigenden Materials in keinem Verhältnis steht, doch habe ich durch sorgfältige, fast immer auf eigene Bekanntschaft gegründete Quellenangaben dem weiteres verlangenden Benutzer zu helfen gesucht. Allerdings ließen selbst die reichen 
Hilfsmittel, über die ich hier verfüge, mich bei einigen Gelegenheiten im Stich.

Bei der Stoffeinteilung hielt ich es für angebracht, den weniger bekannten Gebieten, wie der Ameisennachäffung, reichlichen Raum zu gönnen, weil sie mir im ganzen gesicherter und der unmittelbaren Nachprüfung zugänglicher scheinen als die blendende, aber oft auf lockeren Stützen ruhende Mimikry der Lepidopteren. Meine eigene Stellungnahme zu der letzteren ist aus dem Schlußabschnitte zu entnehmen.

Auch in der Auswahl der Abbildungen, bei der ich das weitgehende Entgegenkommen des Verlags sehr dankbar empfunden habe, war ich darauf bedacht, manchen noch gar nicht oder an entlegener Stelle veröffentlichten Fällen zur Wiedergabe zu verhelfen.

Vielleicht kann ich mit dem dargebotenen kleinen Buche deutsche Naturbeobachter anregen, sich an der Lösung mancher noch offenen Fragen wieder etwas mehr und etwas unbefangener zu beteiligen.

Dresden, im Januar 1913.

A. Jacobi. 


\section{INHALTSVERZEICHNIS.}

Vorwort . . . . . . . . . . . . . . . V

Inhaltsverzeichnis . . . . . . . . . . . . VII

Einleitung. . . . . . . . . . . . . . . . . 1

I. Schutzfärbung . . . . . . . . . . . . . . . 4

II. Schützende Ïhnlichkeit . . . . . . . . . . 10

Bedeutung und Entstehung dieser Erscheinungen . . . 23

1. Die Nachahmung ist unbewußt . . . . . . . . 24

2. Entstehung durch Farbenphotographie... . . . . 24

3. Entstehung durch gleichgerichtete Entwickelung . . 26

4. Entstehung durch Einflüsse der Umgebung . . . . . 30

5. Viele Schutzfarben sind ursprünglich nur Pigmente . 32

6. Die lamarckistische Erklärung . . . . . . . . 33

7. Entstehung nach der Selektionstheorie . . . . . . . 34

Was spricht für die Schutzfärbungstheorie? . . . . . . . 39

Wirksamkeit der kryptischen Anpassungen . . . . . . 41

III. Warnfärbung . . . . . . . . . . . . 43

Schreckfärbung . . . . . . . . . . . . . 55

IV. Mimikry oder schützende Nachäffung . . . . . . . . 60

Erklärung des Begriffes Mimikry . . . . . . . . . 64

Einteilung der Mimikry . . . . . . . . . . . 66

1. Mimikry bei Wirbeltieren . . . . . . . . . 69

Mimikry unter Säugetieren ........ . 70

Mimikry unter Vögeln . . . . . . . . . 70

Mimikry unter Schlangen . . . . . . . . 72

Mimikry der Lurche .. . . . . . . . . . . 74

Mimikry unter Fischen . . . . . . . . 75

2. Mimikry der Spinnen. . . . . . . . . . 77

3. Mimikry von Insekten . . . . . . . . . . 79 
V. Nachäffung stechender Hautflïgler oder Sphecoidie . . 81

a) Durch Käfer . . . . . . . . . . . 82

b) Durch Schmetterlinge . . . . . . . . 86

c) Durch Fliegen . . . . . . . . . . 90

d) Unter Stechimmen selber . . . . . . . . . . 94

V. Yachäffung ron Ameisen oder Myrmecoidie . . . . . 95

1. Metöke Myrmecoidie . . . . . . . . . . . . 96

a) Spinnen als Nachäffer . . . . . . . . . . 96

b) Insekten als Nachäffer . . . . . . . . . 101

1. Myrmecoide Wanzen . . . . . . . . 102

2. Myrmecoide Geradflügler . . . . . . . 106

2. Synöke Myrmecoidie . . . . . . . . . . . . 114

a) Sehmimikry . . . . . . . . . . . . 115

b) Tastmimikry . . . . . . . . . . . . 117

VII. Nachäffung von Käfern . . . . . . . . . . . 124

1. Cicindelidae . . . . . . . . . . . 125

2. Curculionidae. . . . . . . . . . . 126

3. Phytophaga . . . . . . . . . . . . 127

4. Coccinellidae . . . . . . . . . . . 128

5. Erotylidae . . . . . . . . . . . . 129

6. Malacodermata . . . . . . . . . . 130

VIII. Nachäffung unter Schmetterlingen . . . . . . . . . 135

1. Danainae .. . . . . . . . . . 138

2. Ithomiinae . . . . . . . . . . . . . 140

3. Acraeinae . . . . . . . . . . . 146

4. Heliconiinae . . . . . . . . . . . 147

5. Papilionidae . . . . . . . . . . . 150

6. Uraniidae . . . . . . . . . . . . . 153

Dimorphismus und Polymorphismus in der Lepidopterenmimikıy . . . . . . . . . . . . . . 155

Nachäffung melırerer Vorbilder durch eine Art . . . . 161

Mimikry ausgestorbener Modelle . . . . . . . . 165

Beispiele für Müllersche oder synaposematische Mimikry 166 Zusammenstellung der mimetischen Gruppen von Schmetter. lingen ............... . . 167

Allgemeine Eigenschaften der mimetischen Schmetterlinge . 169

1. Eigenschaften, die gemieden machen. . . . . . 169

2. Eigenschaften der gemiedenen Falter . . . . . 172

3. Eigenschaften der Nachahmer. . . . . . . 176

4. Biologische Bedeutung der Müllerschen Mimikry . 180 
Beweise für die Richtigkeit der Schmetterlingsmimikry . . 182

Einwände gegen die Schmetterlingsmimikry . . . . 186

1. Unerhebliche, auf Unkenntnis oder Mißverständnis beruhende Einwände . . . . . . . . . 186

2. Sachliche Einwände . . . . . . . 187

A. Mimikry beruht nur auf menschlicher Vorstellung 187

B. Die mimetische Äbnlichkeit ist zu oberflächlich, um Täuschung zu bewirken....... 189

C. Warnfärbung und ihre Nachäffung dient nicht dazu, die Träger auffällig zu machen, sondern sie in der Ungebung verschwinden zu lassen . . 189

D. Die mimetischen Ähnlichkeiten haben überhaupt keine biologische Beziehung zueinander, sondern sind zufällige Ergebnisse einer gleichgerichteten Entwickelung. . . . . . . . 190

E. Mimikry ist keine durch natürliche Auslese hervorgerufene und weitergezüchtete nützliche Anpassung, sondern das Ergebnis teils von gleichen inneren Vorgängen im Tierkörper, teils von gleichen unmittelbaren Einflüssen der Umgebung 192

F. Die insektenfressenden Vögel sind überhaupt nicht nennenswert an der Vernichtung von Schmetterlingen beteiligt . . . . . . 194 



\section{Einleitung.}

Ton den Farben, die den Tierkörpern eigen sind, kommt den äußerlich sichtbaren eine biologische Bedeutung zu, sie sind lebenswichtig. Die Farben der inneren Teile und der Körpersäfte der Tiere werden nur von der physikalischen und chemischen Zusammensetzung ihrer Unterlagen bedingt, sie sind daher bald innerhalb großer systematischer Verbände sehr einförmig, bald können sie unter nahe verwandten Gruppen recht verschieden ausfallen, jedenfalls lassen sie kaum eine physiologische Erklärung dafür zu. warum gerade dieser oder jener Ton auftritt. Dagegen kann man vom äußeren Farbkleide gewisse Beziehungen zwischen dem Träger und seiner Umwelt, nämlich zu anderen Tieren oder zu den Daseinsbedingungen, ablesen. Zunächst ordnen sich beim Vorhandensein mehrerer Farben diese gewöhnlich in einer Weise an, die für die betreffende Tierart immer wiederkehrt, ihr die eigentümliche Zeichnung verleiht. Da sowohl Grundton wie Farbmuster oft bei Arten recht verschieden sein kann, die sich in ihrer sonstigen Organisation ganz nahe stehen, so läbt sich die Verteilung der Farben nicht von den Verhältnissen des inneren Baues und von den inneren Lebensvorgängen ableiten. Obwohl solche starken artlichen Unterschiede im Grunde auf unbekannte erbliche Veranlagungen zurückgehen dürften, ist es nicht schwer nachzuweisen, daß die äußeren Daseinsbedingungen starken Einfluß auf die Farben der ihnen unterworfenen Tierformen ausüben, und die vergleichende Betrachtung läßt nicht im Zweifel, daß den großen Lebensgebieten und Landschaftstypen auch gewisse Leitmotive in der Färbung entsprechen. So sind die altweltlichen Wüstentiere fast immer fahlgelb, die Bewohner der Hochsee entweder 
oben dunkel und unten silberweiß, oder aber ganz durchsichtig, d. h. farblos; in der Erde oder im Inneren von Pflanzen und Tieren hausende Tiere zeigen ein mißfarbiges Gelbweiß bis Trübrot; in den Baumkronen tropischer WValdgebiete sind Tögel und Kaltblüter meistens grün, und im hohen Norden tritt Weiß in den Tordergrund.

Jede Tierart pflegt eine Verteilung von Farben zu zeigen, die für sie bezeichnend ist, also ein Artmerkmal bildet. IVenn auch die einzelnen Angehörigen der Art sich in der Ausbreitung der und jener Farbe und in den Tonwerten kaum völlig gleich sind, bisweilen sogar sehr stark darin abändern, so schwanken doch diese Abweichungen nur innerhalb gewisser feststellbarer Grenzen ("Variationsbreite"), die eine Art von den Verwandten absondern. Jedenfalls tritt die Gesamtheit der Färbungsmerkmale wieder bei jeder neuen Brut auf, sie gehört zu den erblichen Eigenschaften der Art. Diese feste Übertragung von Artkennzeichen auf die Nachkommen kann aufgehoben werden, weun man ein Tier aus dem freien Zustand in denjenigen des Haustieres versetzt. Der Mensch kann dann durch geeignete Maßregeln der Züchtung erreichen, daß die Erscheinung der wilden Stammart sich im Körperbau und in der Färbung ganz erheblich wandelt, bis zu einem Grade, daß man in den so entstandenen Haustierrassen kaum noch die Nachkommen der freilebenden Stammform wiedererkennt. Es pflegt die Regel zu sein, daß die neu gewonnene Färbung im Gegensatz zu der ehemaligen unregelmäßig ist, und zwar oft schon beim Individuum als unsymmetrisches Auftreten der Farbenbezirke auf den Körperhälften, noch öfter aber als starke Verschiedenheiten zwischen Eltern und Kindern und zwischen Geschwistern. Wenn aber ein Haustier wieder zum freien Leben zurückkehren darf, verwildert, so verlieren sich nach wenigen Generationen alle unter der Domestikation angenommenen Äußerlichkeiten, an deren Stelle sich wieder die Artmerkmale der wilden Abnen einfinden. Allerdings wird auch in der Freiheit die regelmäßige Vererbung des artlichen Färbungstypus gelegentlich unterbrochen, indem einmal Individuen z. B. ganz weiß oder schwarz oder auch hier und da weißgefleckt sind, aber solche, übrigens seltenen, Ausartungen erhalten sich nicht - ihre Besitzer gehen entweder selber frühzeitig zugrunde, oder aber ihre Nachkommen schlagen wieder in die gewöhnliche Tracht zurück. 
Diese Tatsachen lassen sich kaum anders deuten als dahin, daß eine enge Beziehung zwischen der Färbung einer Tierart und ihren Lebensbeziehungen besteht. Wenn auch der Beweis schwer zu führen sein würde, daß jene ein unmittelbares Erzeugnis der umgebenden Natur ist, so weist doch alles darauf hin, daß die eigentümliche Färbung jeder Spezies einen Beharrungszustand darstellt, der keine raschen Änderungen verträgt, ohne die Lebensfähigkeit der Besitzer zu vermindern. Nur wenn der als "Kampf ums Dasein" verstandene Gefahrenkreis der Umwelt gebannt wird, indem der Mensch eine Art durch Aufnahme in seinen dauernden Schutz vor ihm sichert, kann sie es sich gestatten, andere Farben als die bisher getragenen und in freierer Wahl von der Palette der Natur zu entnehmen. Das jeder im Urzustand lebenden Form eigene Farbkleid ist also nichts $\mathrm{Zu}$ fälliges, sondern der gegenwärtige Abschluß eines lange bestehenden, den äußeren Einflüssen zugänglichen Entwickelungsweges, dessen Endziel die Erhaltung der Form ist, oder anders ausgedrückt: der durchschnittliche Färbungszustand jeder Art ist zurzeit eine für sie nützliche Eigenschaft. Dieses Ergebnis unserer Überlegung ist dem Einspruch ausgesetzt, daß es sich schwer denken läßt, warum jede Einzelheit der Zeichnung ihren Anteil an deren selektiver Bedeutung haben soll, wie denn tatsächlich viele Arten sich nur durch eine etwas andere Verteilung der Farben, etwas größere Ausdehnung der einen oder anderen voneinander unterscheiden. Solch eine weitgehende Bewertung der Einzelzüge, wie sie namentlich A. R. Wallace vertritt, ist allerdings nicht zu rechtfertigen, muß vielmehr dahin eingeschränkt werden, daß die auf Färbung bezüglichen Arteigenschaften ihren Besitzern wenigstens nicht zum Nachteil gereichen. Wenn also nicht alle Färbungserscheinungen arterhaltende Bedeutung im Daseinskampf haben dürften, kommt solche doch nach Ansicht vieler Naturforscher mehreren der Gruppen zu, in die man die Tierfarben vom biologischen Standpunkt aus gliedern kann. Von diesen Färbungstypen sollen drei näher besprochen werden, und zwar der dritte mit größerer Ausführlichkeit, weil er den Ausgangspunkt für die Erörterungen abgibt, welche Gegenstand dieser Schrift sind. 


\section{Schutzfärbung.}

Viele Tiere tragen ein Kleid, das sie in der Ruhestellung in ihrer Umgebung verschwinden läßt, also dem Auge anderer Lebewesen entziehen kann. Solche Schutzfärbung oder kryptische Färbung findet sich zu allermeist bei solchen Tieren, die, selber schwach oder wehrlos, des Schutzes gegen die Nachstellungen ihrer besonderen Feinde bedürfen und ihn finden, indem sie in der allgemeinen Umgebung aufgehen, so daß der Verfolger sie nicht so leicht findet; dies ist die protektive Schutzfärbung. Aber auch die Gegner machen sich diesen Kunstgriff zu eigen, indem sie dieselbe Ausstattung als Deckmantel benutzen, um unbemerkt ihre Beute zu beschleichen: aggressive Schutzfärbung. Man stellt sich gewöhnlich vor, daß für beide Fälle eine möglichst weitgehende Übereinstimmung mit dem Aussehen des Aufenthaltsortes den meisten Vorteil biete, allein das Ziel des Unsichtbarwerdens kann auch auf dem entgegengesetzten Wege erreicht werden, nämlich durch die sogenannte Körperauflösung [„Somatolyse $\left.{ }^{\text {" }}\right]^{1}$ ). Hierbei sind es gerade an sich auffallende, grelle Farben, die in einzelnen, gewöhnlich zu Querbäıdern angeordneten Flecken miteinander abwechselnd den regungslosen Träger verschwinden lassen, indem sie das körperliche Bild seiner Einheitlichkeit für das Auge berauben, in einzelne Teilstücke auflöselı. Weil das Auge sich daraus erst wieder die Gesamterscheinung vereinigen müßte, wird es sehr oft über die scheinbar zusammenhangslosen Farbenflecke hinweggleiten. Auf diese Weise entgehen so bunt gezeichnete Vögel wie unsere Buntspechte (Dendrocopus) mit ihrem Schwarz, Weiß, Rot leicht dem Späherblick, wenn sie regungslos in den Baumkronen hängen, und dasselbe berichtet H. O. Forbes ${ }^{2}$ ) von der großen Fruchttaube (Ptilopus cinctus

$\left.{ }^{1}\right)$ v. Lucanus, Journ. f. Ornith. 50, 358 (1902). — - ${ }^{2}$ ) Naturalists Wanderings 1885 , S. 460 . 
Temm.) auf Timor, die trotz ihrer grellen Färbung - weißer Kopf und Hals, schwarzer Mantel, gelber Bauch - frei auf Zweigen sitzend, selbst für den scharfsichtigen Eingeborenen schwer auszumachen ist.

Unser Wiedehopf führt dieselbe Wirkung instinktiv herbei, indem er sich bei drohender Überraschung durch einen Raubvogel mit ausgebreiteten Flügel- und Schranzfedern, die eine schwarzweiße Bänderung haben, platt zu Boden wirft. Die von den Reisenden oft hervorgehobene Schwierigkeit, eine Zebraherde aus der offenen Steppe, den Tiger aus dem Dschungeldickicht herauszuerkennen, dürfte ebenfalls auf Körperauflösung zurückgehen; wir sehen letztere also sowohl nach der protektiven, wie nach der aggressiven Seite hin wirksam.

Besonders häufig offenbart sich Schutzfärbung als eine Übereinstimmung mit dem allgemeinen Ton einer einförmigen Landschaft ron großer Ausdehnung und gleichartigem Kolorit: die Färbung der tierischen Bewohner ist sympathisch mit ihrer Umgebung.

In der Nordpolarzone und auf vielen Hochgebirgen der nördlichen Halbkugel mit ähnlichem Klima ist Weiß die vorherrschende Tracht der wenigen Landwirbeltiere, und zwar sowohl der schutzbedürftigen, z. B. Halsbandlemming, Hase, Schneehuhn und Schneeammer, als auch ihrer Verfolger, z. B. Eisfuchs, Hermelin, Eisbär, Schneeeule. Bemerkenswert ist dabei, da \$ die weiße Farbe sich in Pelz und Federkleid immer mehr ausbreitet, je länger mit dem Vorrücken nach Norden die Bedeckung des Bodens mit Schnee und Eis währt. In milderen Breiten, z. B. auf den Alpen und in Nordeuropa, sind Schneehase, Hermelin und Schneehuhn während des Sommers braun, im Winter weiø, im arktischen Nordamerika jedoch wird das Weiß auch im Sommer beibehalten. Andererseits wird das Bergschaf (Ovis cervina Desm.), das die Felsengebirge von Kalifornien an nordwärts bewohnt, an der Nordgrenze seines Verbreitungsgebietes in Alaska, der Wolf und das sonst braune Rentier im hohen Norden weiß. Alle diese Erscheinungen mögen auch physiologisch durch die Tatsache beeinflußt sein, daß eine weiße Körperbedeckung die Wärmeabgabe verlangsamt, aber der einzige Anla@ kann es nicht sein, weil der bis in die Polnähe vorkommende Moschusochse überall dunkel und das Rentier eben nur ganz hoch oben weiß ist; da nämlich beide 
Arten durch ihr herdenweises Zusammenhalten bei ziemlicher Wehrhaftigkeit geringerer Verfolgung ausgesetzt sind, so ist ein geringeres Bedürfnis auf Schutzfarbe da.

Auch bei den Wüstentieren ist sympathische Färbung häufig, ja bei den Vertebraten geradezu die Regel. Einer der frühesten Erforscher des Tierlebens der Sahara, H. B. Tristram, sagt darüber ${ }^{1}$ ): „In der Wüste, wo weder Bäume, noch Gebüsch, noch eine wellenförmige Bodenoberfläche den geringsten Schutz vor Feinden gewährt, ist eine Abtönung der Färbung, die der Umgebung gleicht, durchaus notwendig. Daher ist ausnahmslos die Oberseite der Vögel, gleichviel ob Lerche, Grasmücke oder Sandhuhn, ferner das Haarkleid aller kleineren Säugetiere und die Bedeckung aller Schlangen und Eidechsen von einer gleichmäßigen Isabell- oder Sandfarbe." Von Beispielen seien noch Gazellen, Springmäuse, Wüstenfuchs genannt; auch die Spinnen und die meisten frei auf dem Boden hausenden Insekten, besonders die Heuschrecken folgen der Regel, die sich sowohl protektiv wie aggressiv geltend macht.

Wenn in den großen Urwaldgebieten von Afrika, Indonesien und Brasilien so sehr viele Vögel, Eidechsen, Schlangen und Frösche, die sich ständig im Laubwerk der Bäume aufhalten, blattgrün gefärbt sind, so ist dies nur eine Abänderung der vorigen Fälle. Etwas anders liegt es bei den wirbellosen Tieren der Hochsee, gelegentlich auch des Süßwassers, weil bei ihnen das Aufgehen im Medium gerade durch den Wegfall jeder Farbe erzeugt wird. Alle die Quallen, Borstenwürmer, Krebse, Kielschnecken u. a. m., welche mehr oder weniger der Strömung und dem Wellenschlag preisgegeben als "Plankton" umhertreiben, sind farblos und glasartig durchsichtig, oft mit einem Stich ins Blaue, wie das sie tragende Meerwasser. Dadurch verschwinden sie in dem letzteren und entgehen wenigstens denjenigen ihrer Verfolger, welche mit dem Auge nach Beute suchen, aber nicht nur wahllos einschlucken, was ihnen die Woge in den Rachen spült. Auf die gleiche IVeise ist übrigens auch bei einer Gruppe von Schmetterlingen die Sichtbarkeit erschwert worden. In der südamerikanischen Unterfamilie der Ithomiinae greift eine Aufhellung der Flügel durch streckenweise Aufgabe des Schuppenbelages Platz,

1) The Ibis 1, 430 (1859). 
die bei einigen Gattungen zu beinahe völliger Durchsichtigkeit der Flugwerkzeuge geführt hat; eine äußerste Verschmälerung des Rumpfes trägt dazu bei, die Falter unkörperlich erscheinen zu lassen. In solcher geisterhaften Gestalt huschen sie im tiefen Waldesschatten herum, und die meisten Arten vermeiden es ängstlich, in die Sonne zu kommen. Daher nennen alle Beobachter es sehr schwer, den farblosen Tieren bei ihrem Fluge mit den Augen $\mathrm{zu}$ folgen.

Waren die vorstehenden Fälle solche von einförmiger Ausprägung und ausgedehnter Verbreitung, so handelt es sich im folgenden um Erscheinungen, wo Tiere in ihrer Färbung dem Kolorit ihres engeren Aufenthaltsortes angepaßt sind und wo oft dessen einzelnen Zügen durch bestimmte Zeichnung entsprochen wird, manchmal bis ins feinste. Auch hier wird die sympathische Färbung nur in der Ruhestellung des Trägers zur kryptischen, denn durch Bewegung wird nicht nur das Zusammenfallen von Lebewesen und Umgebung unterbrochen, sondern es werden vielfach auch Körperstellen mit gegensätzlicher Färbung enthüllt, die das Tier gerade recht auffallen lassen, z. B. die bunte Oberseite von Tagfalterflügeln oder der leuchtendweiße Unterrücken eines Togels. Einige Beispiele solcher besonderen Schutzfärbung sind die folgenden, zu denen die einheimische Tierwelt ausreichenden Stoff bietet. Wir haben Säugetiere und Vögel, die ohne Deckung auf dem Boden ruhen, wie Hase, Lerchen, Rebhuhn, Triel (Oedicnemus crepitans), und sämtlich eine aus unscheinbaren Tönen von Erdbraun, Grau, Schmutzigweiß usw. zusammengesetzte Färbung der Oberseite haben, die sie bei regungsloser Haltung röllig im Erdboden aufgehen läßt. Ton der Wirkung ihrer Deckfarbe machen die Tiere solchen Gebrauch, daß sie sich einer nahenden Gefahr erst dann durch die Flucht entziehen, wenn sie ihnen ganz nahe auf den Leib gerückt ist. Mehr dem Waldboden mit seiner vielgestaltigen Bedeckung aus Laub in allen Stufen des Moderns, aus Zweiglein, Fruchtkapseln usw. angepaßt sind die Hennen des Auer- und Birkhuhnes, die als Bodenbrüter ein kryptisches Federkleid bei der Brutpflege nötig haben, während die als Polygame daran unbeteiligten Hähne sich ein Schmuckgefieder leisten können; darum genießt der in Einehe lebende Haselhahn dieselbe Schutzfarbe wie seine Henne. Am höchsten ausgebildet ist jene Waldstreunachahmung bei der Waldschnepfe; eine "sich drückende" 
Schnepfe kann auch der geübteste Jäger allenfalls nur an den großen, schwarzglänzenden Augen herauserkennen, eine tote niemals. Andere Vogelgattungen zeigen eine bis ins feinste gehende Wiedergabe der Baumrinde mit ihrer rissigen, flechtentragenden Oberfläche; ihr Gefieder ist aus Rostgelb, Lohbraun, Aschgrau, Schwarz in ganz zerstreuter Verteilung, mit durchlaufenden Zickzacklinien und einzelnen Schmitzen, gebildet und kommt solchen Arten zu, die sich in der Ruhe an Baumstämme schmiegen; gewöhnlich sind es Eulen und Nachtschwalben, die also tagsüber stillsitzen, aber auch die Wendehälse aller Erdstriche.

Einige niedere Wirbeltiere von geringer Beweglichkeit haben die Fähigkeit, ihre Schutzfärbung dem Farbenton ihrer jeweiligen Umgebung entsprechend zu wechseln. Ein sehr bekanntes Beispiel hierfür sind die Chamäleons, die ihre Haut je nachdem grau oder blattgrün werden lassen; dann der Laubfrosch, dessen Grün auf der Erde dem Braun weicht, und die Plattfische (Flundern usw.), deren Pigment je nach der Beschaffenheit des Meeresbodens zwischen Hell und Dunkel wechselt.

Als Schutzfärbungen der oben umschriebenen Art deutbar sind die Zeichnungen sehr vieler Insekten in Heimat und Fremde. Wir müssen sagen "deutbar", denn wir leiten die Zweckmäßigkeit gerade dieser Einrichtungen fast nur aus unserem menschlichen Empfinden, unserem Unterscheidungsvermögen ab; wir wissen kaum von einem der zahlreich vorgebrachten Beispiele, ob die behauptete Schutzwirkung vorhanden ist, ob die kryptische Erscheinung wirklich vor dem Auge der Insektenfresser Bestand hat - ein Zweifel, der von mancher Seite gegen die Idee der Schutzfärbung überhaupt erhoben wird. Ohne fürs erste auf die Berechtigung solcher Zweifel einzugehen, sei nur auf einige erläuternde Fälle hingewiesen. Es gibt bei uns viele Nachtfalter, die ihre Tagesruhe nicht in Verstecken abhalten, sondern frei an Baumstämmen, Felswänden oder dem Erdboden, und sehr oft ist ihre Zeichnung sympathisch mit diesen Ruheplätzen - wenigstens an den Körperstellen, die von oben her sichtbar sind. Das unscheinbare Braun und Düstergrau, das der Rücken und die Torderflügel der Glucken (Gastropacha, Dendrolimus u. a.) zeigen, ist mit helleren Bändern und schwärzlichen Zickzacklinien in ein solches Muster gebracht, da@ eine Rindenähnlichkeit wie bei den oben erwähnten Nachtvögeln ader die Übereinstimmung mit dürrem 
Laub auf dem Boden bewirkt wird. Andere Arten (Halias prasinana, Tortrix viridana u. a. m.) sind grün wie ihr Ruhesitz, die grünen Blätter; ebenso unsere Laubheuschrecken (Locusta i. e. S.). Besonders bemerkenswert ist bei vielen Insekten eine derartige Anbringung der Schutzfärbung, daß bunte Körperteile in der Ruhestellung unter den sympathisch gefärbten versteckt werden. Bei manchen unserer Eulenfalter, besonders bei den schönen „Ordensbändern" (Catocala), sind die Hinterflügel mit leuchtend roten, blauen oder gelben Bändern geziert; bei manchen Feldheuschrecken der Gattungen Ocdipoda und Psophus machen sich ihre scharlachroten und himmelblauen Hinterflügel erst im Fluge bemerklich, ebenso bei vielen tropischen Zikaden (Fulgoridae), aber mit dem Augenblick des Niederlassens verschwinden diese bunten Flecke durch Zusammenfalten der Hinterflügel unter dem sie dachförmig überdeckenden vorderen Paare, das kryptisch ausgestattet ist. Von ähnlichen Erscheinungen bei Tagfaltern, die in abgeänderter Weise zustande kommen, wird später die Rede sein. 


\section{Schiitzende Ähnlichkeit.}

Während das von uns vermutete Ziel der Schutzfärbung ist, einem Tierkörper alle Züge zu nehmen, die ihn von der allgemeinen Umgebung unterscheiden, läuft es bei der schützenden Ïhnlichkeit darauf hinaus, daß die eigene Natur vor Feinden verborgen wird, indem man das Aussehen von Gegenständen annimmt, die jenen gleichgültig sind, ihre Aufmerksamkeit nicht auf sich lenken. Während es sich also in beiden Fällen um ein Versteckspiel handelt, arbeitet im einen nur das Deckmittel der Farbe, während im anderen, jetzt zu besprechenden außerdem die Form nachgeahmt wird. Modelle der Schutzfärbung sind im allgemeinen ganze Flächen, wie der Schnee, große Ansammlungen von Gegenständen, wie Blattwerk, Bodenstreu oder das Aufenthaltsmittel überhaupt (Wasser); dagegen richtet sich schützende Ähnlichkeit auf einzelne Naturkörper, deren bestimmte Umrisse, Oberflächengliederung und Farbe möglichst getreu wiedergegeben wird. Immer kommen dabei Vorbilder in Frage, die keine eigene Beweglichkeit haben, und das hat auch auf diesem Gebiet für den Nachahmer die Folge, daß er nur so lange der Entdeckung entgehen kann, wie er sich selber nicht von der Stelle rührt. Ein weiterer Unterschied von der allgemeinen Schutzfärbung ist der, daß die schützende Ähnlichkeit meistens protektiv ausgebildet ist, obwohl auch Fälle aggressiver Anwendung zu berühren sind. Der näheren Besprechung will ich vorausschicken, daß hier und künftig unter "Nachahmung" und ähnlichen Ausdrücken niemals eine bewußte Tätigkeit und Absicht zu verstehen ist, sondern nur die Erscheinung als solche; desgleichen sind Ausdrücke wie „die Nachahmung bezweckt", "zum Vorbild nehmen" usw. nur als Sprachbilder zu betrachten. Weiterhin werde ich öfter der Kürze wegen mit "Schutzfärbung" auch die kryptischen Züge in der Gestalt, nicht nur der Farbe, bezeichnen. 
Die niedrigste Form der schutzsuchenden Verähnlichung mit Gegenständen in der Umgebung ist die Maskierung, denn sie besteht nicht in einer entsprechenden Gestaltung des Körpers selber, sondern in der Verhüllung der dem Feindesblick zunächst ausgesetzten Oberfläche mit allerhand Fremdkörpern. Die Larven mehrerer zu den Neuroptera gehörenden Insekten, nämlich die des "Blattlauslöwen" (Hemerobius) und der Florfliegen (Chrysopa) kleben sich die Häute der von ihnen ausgesogenen Blattläuse als Deckschild auf; ähnliche Neigungen haben die Larven mancher Schreitwanzen (Reduviidae), z. B. unsere Kotwanze (Reduvius personatus [L.]), die sich mit Staub und Schmutz überziehen, während sich andere tropische Arten mit Holzstückchen oder sogar mit toten Ameisen bekleiden ${ }^{1}$ ). Im Neere zeigen sich die Krabben der Naskierung geneigt: die gemeine Wollkrabbe (Dromia vulgaris) hält mit Vorliebe gewisse häufige Schwämme der Gattung Suberites mit ihren nach oben gerichteten Bauchfüßen über sich; so kann sie für das ungenießbare Hohltier gehalten werden. Die Spinnenkrabben (Fam. Majidae) bekleben sich in dem kleineren und wehrlosen weiblichen Geschlecht ganz allgemein ihr Rückenschild mit Algenstückchen, Schwämmen, Polypen - und Moostierstöcken, wobei ihnen die besondere Beweglichkeit ihrer Scherenfüße ron Nutzen ist; immer sind diese maskierenden, weil für größere Räuber gleichgültigen, Bestandteile aus den jeweiligen Wohnplätzen des Krebses gewählt und werden bei einem Umzug ebenfalls gewechselt ${ }^{2}$ ). Bei Pflanzen hat man eine ähnliche, aber wesenseigene Anpassung in der Ähnlichkeit kapländischer Sukkulenten mit Steinen erblicken wollen ${ }^{3}$ ).

Manchmal sehen wir Gliedertiere die wertlosen tierischen Abgänge nachahmen. Bates ${ }^{4}$ ) erwähnt aus Südamerika einen kleinen, zu den Phytophagen gehörenden Käfer (Chlamys pilula), der für das Auge nicht von Raupenkot zu unterscheiden war; eine von H. O. Forbes im Malaiischen Archipel entdeckte Krabbenspinne (Ornithoscatoides decipiens) fand E. Haase auch in Siam wieder, wo sie auf einem Blatte sitzend durch die feinen Farbabtönungen des zarthäutigen Hinterleibes derart an frischen

1) Haase, S. 155. - $\left.{ }^{2}\right)$ L. A. Borradaile, Zool. Zentralbl. 14, 400 (1907); Hornell, Natural Science 3, 31 (1893). - 3) Marloth, Deutsche Tiefsee-Expedition 2, Teil 3, S. 336. - ${ }^{4}$ ) 1861, S. 509. 
gallertigen Vogelkot erinnerte, daß er zögerte, sie einzufangen, obwohl er längst auf sie zu achten beschlossen hatte ${ }^{1}$ ). Hier ist die Ähnlichkeit vielleicht außerdem aggressiv verwertet, denn frischer Vogeldung wird von Fliegen und Schmetterlingen gern saugenshalber aufgesucht, die dabei der lauernden Spinne zur Beute werden. Auch in Deutschland gibt es derartige Nachahmer, aber der trockenen Exkremente, in kleinen Motten der Gattung Citix. In der Ruhe auf Blättern sitzend und die Flügel, welche kreidigweiß und schwarzgescheckt sind, wie die Vorlage, um den Hinterleib wickelnd erhöhen sie den täuschenden Eindruck noch dadurch, daß sie aufgestört nicht wegflattern, sondern sich auf den Boden hinunterrollen lassen, wo sie ruhig liegen bleibend zwischen der Spreu verschwinden. So sehr diese Begleiterscheinungen für den Schutzwert der Ähnlichkeit sprechen, fehlt es doch hier wie anderwärts am Nachweis, daß sich Vögel dadurch täuschen lassen. An diese Gruppe schließt sich unter den Zikaden eine Art der an barock gestalteten Formen so reichen Buckelzirpen (Membracinae) an, die Oeda inflata (L.). Ihr Vorderrücken ist zu einer mächtigen, gelb durchscheinenden Blase aufgetrieben, die länger und höher ist als der ganze übrige Leib und ganz verblüffend in Form und Skulptur der leeren Puppenhülse eines Tagfalters gleicht, sogar die Flügelscheiden sind angedeutet. Im Gegensatz zu ihren meist gemeinen Verwandten ist die Art übrigens recht selten.

Die Nachahmung ungenießbarer oder doch wenig begehrter Körper scheint auch im Neere Anklang gefunden zu haben, und zwar namentlich seitens der Nacktschnecken, die in jenem Lebensbezirk wohl ebensolcher Verfolgung unterliegen, wie ihre Verwandten auf dem Lande. Die bereits vorhin (S. 10) als Vorbild erwähnten Schwämme, die ja in ihrer unbestimmten Form und Farbe anorganischen Gebilden ähneln und anderen Tieren wenig zur Nahrung dienen, werden von den nackten Hinterkiemerschnecken (Opisthobranchia) gern imitiert. In der Nordsee sitzt die kleine Archidoris tuberculata (L.) stets auf dem Schwamm Hatichondria panicea, dessen Oberflächenbildung und Farbe sie vollkommen gleicht und die orangerote Doris coccinea ähnelt der Spongie Mirociona atrosanguinea. Bei letzterer entsprechen feine braune Fleckchen den Auswurfsöffnungen (Oscula) des Schwammes;

1) Haase, S. 151 . 
beide Organismen haben oberseits gelbe Runzeln mit schwarzen Spitzen und die Gruben der zurückgezogenen Fühler können auf dem Schwamm lagernde Sandkörnchen vortäuschen ${ }^{1}$ ). Auch die harten Kalkalgen und die grünen Tange liefern Nacktschnecken der Gattung Hermaea solche Gelegenheit zur Nachahmung, aber auch Gehäuseschnecken suchen derartigen Schutz. An der amerikanischen Küste ist die orangerote Leptogorgia virgulata unabänderlich mit der gleichfarbigen Eischnecke Ovulum uniplicatum besetzt, nie findet man letztere in anderer Umgebung. Eine dunkelrosenrote Abart der Schnecke sucht sich wieder entsprechend gefärbte Korallen aus und verschmäht abweichend aussehende, was man im Aquarium beobachten kann ${ }^{2}$ ).

Ich habe diese Fälle von schützender Ähnlichkeit bei marinen Wirbellosen erwähnt, um zu zeigen, daß man sich bei der Betrachtung der Lebensgemeinschaften des Meeres Fragen nach der Bedeutung gewisser Farben und Zeichnungen vorlegen darf und soll. Der Versuche zu ihrer biologischen Beantwortung gibt es noch mehr, allein sie stehen meistens mehr auf dem Boden der Vermutung als der Beobachtung; wer sich näher darüber unterrichten will, möge zu Plateaus ${ }^{3}$ ) Abhandlung greifen. Ich kanı deshalb II'Intosh nur beipflichten, der nach kritischem Vergleichen aller irgendwie hierher gehörigen Fälle zu folgendem Urteil kam ${ }^{4}$ ): "Eine allgemeine Betrachtung der Färbung bei den Seetieren hinterläßt Zweifel an der Richtigkeit der Erklärungen, die man dazu erdacht hat. Einige dieser Erklärungen stimmen allerdings in verschiedenem Grade mit den Tatsachen überein, andere aber, soweit ich sehen kann, tun dies nicht, weisen vielmehr darauf hin, daß man mit solchen Deutungen äußerst vorsichtig sein muß. Ehe man ein Urteil darüber sprechen kann, ist eine viel größere Zahl von Beobachtungen nötig, die zudem viel genauer und auf längere Zeit hin durchgeführt werden müssen als bisher."

Die weitaus meisten Fälle von schützender Ähnlichkeit liefern indessen die Kerbtiere mit ihrem so veränderlichen Hautpanzer. Da ist zunächst die Gestalt dürrer Zweige und Holzstückchen ein oftmals angezogenes Vorbild, selbst ganzer systematischer Ein-

$\left.{ }^{1}\right)$ E. Hech t nach Zool. Zentralbl. 5, 98 (1898). - ${ }^{2}$ ) H. L. Osborn, Science 6, 9-10 (1885). - ${ }^{3}$ ) 1892. - $\left.{ }^{4}\right)$ S. 240 (1901). 
heiten. In der gemäßigten Zone sind es namentlich die Raupen der Spannerschmetterlinge (Geometrae), von denen viele Arten durch ihre besondere Gestalt und gefördert durch zweckmäbiges Verhalten einen Schutz vor Insektenfressern zu genießen scheinen. Ihr meist rindenbrauner Leib ist dünn und hat von den fünf Paaren Afterfüße der Falterraupen nur die letzten beiden; am Kopf, der Vorderbrust oder an bestimmten Hinterleibsringen finden sich oft Höcker und Zapfen, die Knospen oder Blattnarben sehr ähnlich sind. Sie sitzen stundenlang auf einem Fleck, ohne mehr als ihre Kinnladen zu rühren und nehmen bei der geringsten Beunruhigung eine ganz ungewöhnliche Haltung an, indem sie, nur mit den Afterfüßen sich anklammernd, den Körper in spitzem Winkel von der Pflanze abspreizen und stocksteif auf lange Zeit so verharren. Die Ähnlichkeit mit einem abgestorbenen Zweigrest oder einer Fruchtknospe ist dann eine verblüffende und wird auch durchgeführt, wenn man das Tier herunterschüttelt. Es gibt auch grüne Formen, von denen beispielsweise die vom Kiefernspanner (Bupalus piniarius) der Farbe der Kiefernnadeln gleichkommen, zwischen denen sie regungslos sitzen.

Noch schärfer ist die Zweiggestalt durchgeführt bei den phantastischen Stab- oder Gespenstheuschrecken (Phasmidae) der wärmeren Länder, deren Leib überaus dünn ausgezogen und vom Anfang bis Ende fast vom gleichen walzigen Querschnitt ist; bei der etwa $30 \mathrm{~cm}$ langen Phryganistria fruhstorferi ist er noch nicht kleinfingerdick. Dazu kommen kurze, meist in der Körperachse steif nach vorn gestreckte Fühler und fadendünne, in die verschrobensten Stellungen gebrachte Beine, während die Flügel ganz eng anliegen oder fehlen. Allerhand ungewöhnliche Auswüchse, die bald wie zerfressene Blattreste, bald wie ein Flechtenansatz aussehen, oder ein Stachelbesatz machen die Zweigähnlichkeit zu der vollkommensten. Die vollständige Ruhe, welche diese Tiere innehalten, läßt die 'Täuschung auch für erfahrene Sammler sich immer wieder erneuern, aber selbst aufgestört suchen sie ihre Rolle durchzuführen, indem sie bei Erschütterung der Unterlage ganz eigenartige pendelähnliche Bewegungen, gleich einem vom Windhauch getroffenen Zweige, ausführen, in die Hand genommen aber scheintot werden und solange wie möglich bleiben.

Andere pflanzliche Hartgebilde, wie Dornen, Stacheln, rauhe Fruchtschalen usw. spiegeln sich scheinbar in der äußerst barocken 
Gestalt vieler Buckelzirpen (vgl. S. 11) wider, und der im Deuten von Tierfarben sehr rührige Zoologe E. B. Poulton in Oxford hat dem Vergleich zwischen beiden eine lange Auseinandersetzung gewidmet ${ }^{1}$ ), aber es fehlt nicht nur an jeder Beobachtung über den Schutzwert dieser für die menschliche Anschauung freilich oft naheliegenden $̈$ Änlichkeiten, sondern die Lebensweise der Tiere spricht auch eher dagegen. Schützende Ähnlichkeit verlangt doch, um wirksam zu täuschen, daß der Träger sich still in der seinem Aussehen sympathischen Umgebung verhält, die Buckelzirpen aber sind für ihre Körpergröße gewaltige Springer, die sich beim Herannahen, wenigstens bei Erschütterung der Nährpflanze, nach Art der Flöhe unsichtbar machen. Diese Versuche und diejenigen Melichars (1904) dürften daher unter die "Museumsmimikry" zu rechnen sein. Dagegen könnte die ganz verblüffende Ähnlichkeit gewisser Rüsselkäfer, namentlich aus der Gattung Lithinus Coqu. (Madagaskar), mit der Baumflechte Parmelia crinita wohl kryptisch sein, wenigstens gibt der Entdecker Sikora an, daß der Käfer sich nur auf den jenes Gewächs tragenden Büschen aufhielte ${ }^{2}$ ).

Die Nachahmung von Blüten schreibt man einigen europäischen und tropischen Insekten zu, beispielsweise unserem Aurorafalter (Anthocharis cardamines), dessen Hinterflügel auf der weißen Unterseite zerrissene grüne Flecke tragen und beim Sitzen in der Art der Tagfalter die Vorderflügel bedecken; dadurch gleicht er in der Ruhe den besuchten kleinblütigen Doldenblumen. Ähnliches gibt Breddin ${ }^{3}$ ) von der Schildwanze Vitpiamus galii Wolff an. Einen verblüffenden Fall haben Gregory und Hinde aus Ostafrika bekannt gemacht. An den Zweigen eines dortigen Strauches sitzen dicht gedrängt zwei Arten der zur Zikadenfamilie gehörenden Gattung Ityraen, die I. speciosa Mel. und I. gregoryi Dist., im Larvenalter und erwachsen. Letztere haben über $2 \mathrm{~cm}$ Länge und leuchtend gelbe oder grüne Deckflügel, wodurch sie für jene Beobachter den Eindruck eines mit zahlreichen gelben Blüten und Knospen solcher besetzten Leguminosenstrauches hervorriefen ${ }^{4}$ ). Aber so überzeugend die Deutung der

$\left.{ }^{1}\right) 1903$, S. $\left.273-285 .-{ }^{2}\right)$ Stett. Ent. Ztg. 1891, S. 240 . $\left.{ }^{3}\right)$ Zeitschr. f. Nat. 69, 26 (1896). - ${ }^{4}$ ) Trans. Ent. Suc. 1902, S. 695; Taf. 26 und 27. 
englischen Beobachter scheint, kann ich sie doch nicht für richtig halten. Diese Flatinen sind in den Tropen in bedeutender Artenzahl vorhanden, manche Arten treten in Massen auf und machen sich durch die meist grellen Farben ihrer Deckflügel (weiß mit scharfen, schwarzen Zeichnungen oder gelb, grün, karminrot usw.), wie auch durch ihre Haltung auf den Pflanzen sehr bemerklich. Aber sie scheiden alle, im Larven- und erwachsenen Zustand, aus Hautdrüsen einen zottigen Wachsflaum aus, der erfahrungsmäloig Vögel, und jedenfalls auch die insektenfressenden Kaltblüter, von jedem Angriff abhält. Nach alledem ist die Färbung der Flatinae nicht ins Gebiet der schützenden Ähnlichkeit, sondern eher in dasjenige der Warnfarben einzubeziehen.

Wie die Blütennachahmung aggressiv verwendet wird, zeigt folgendes Beispiel. Die Fangheuschrecken oder Gottesanbeterinnen (Mantidae), durch die sonderbare Haltung ihrer zum Packen von Kerbtieren umgestalteten Vorderbeine wohl bekannt, beschleichen ihre Beute langsam unter dem Deckmantel ihres blattgrünen Kleides. Anders der seltene Hymenopus bicornis von Südostasien (Fig. 1). Das Tier sitzt im ungeflügelten Nymphenstadium regungslos auf seine Opfer lauernd auf Blüten, in Siam z. B. auf Melastoma polyanthum, und gleicht durch seine nelkenrote Farbe und entsprechende Gestalt diesen und anderen Blumen. Der eirunde, flach gedrückte Bauch entspricht der Lippe; die außergewöhnlich breiten und ebenfalls platten Schenkel der beiden hinteren Beinpaare, die im rechten Winkel abgespreizt sind, gleichen den Blumenblättern, während Vorderleib und Fangbeine die Geschlechtssäule wiedergeben. So wird der Räuber zu einem gefährlichen Köder für honiglüsterne Insekten, die sich arglos auf der vermeintlichen Blüte niederlassen, $\mathrm{um}$ in die Klauen der Mantide zu geraten. N. Annandale, der das wunderbare Wesen in Malakka beobachtete und davon die nebenstehende Aufnahme machte, wurde nur dadurch aufmerksam auf sein Dasein, daß sich auf einem blühenden Melastomabusch eine der Blumen in besonderer Weise hin und her bewegte, aber selbst nachdem er den betreffenden Zweig in der Hand hielt, konnte er sich keine genaue Rechenschaft darüber geben, wo die Grenze zwischen Tierkörper und Pflanzenteilen lag; trotzdem betont er, daß die Hymenopuslarve nicht etwa die Melastomablüte teilgetreu nachbilde, wohl aber in täuschendster Weise ihren Gesamteindruck. Auch beob- 
achtete er, da $B$ sie sich stets blütentragende Zweige als Anstandsplatz wählte, bloß beblätterte aber verschmähte $\left.{ }^{1}\right)$. Andere Arten der Familie (Gongylus) sehen ebenfalls gewissen Blüten mit weißer Blumenkrone so ähnlich, daß sogar ein Botaniker getäuscht

Fig. 1.

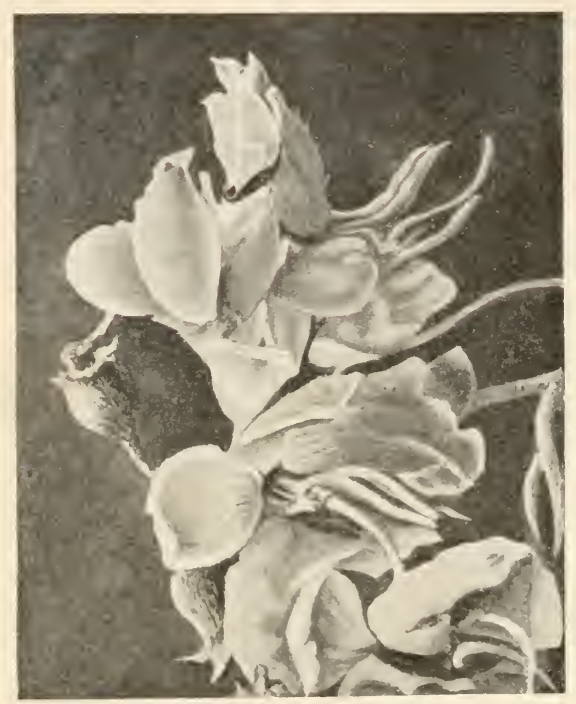

Hymenopus licornis im Nymphenzustande auf einem Blütenstande von Melastoma polyanthum.

Nach einem Photogramm von N. Annandale.

Das Tier sitzt ganz oben in fast senkrechter Haltung; man erkennt die kegelförmigen Augen und die $\mathrm{V}$-ähnliche schwarze Binde auf dem Brustabschnitt. Die Fangbeine sind vor dem Köper zusammengelegt, die Schenkel der anderen Beivpare kehren ihre deu Blütenblättern gleichende Verbreiterung dem Auge zu. Der Hinterleib ist über den Rumpf nach oben geschlagen, so da 3 er seine Bauchseite mit schwarzer Spitze zeigt. Der Fuß des linken Hinterbeins stützt sich auf eine Samenkapsel der Pflanze.

wurde, der eine davon in Pegu als Blume in die Hand nehmen wollte ${ }^{2}$ ).

$\left.{ }^{3}\right)$ Proc. Zool. Soc. 1900, S. 839 f. $-{ }^{2}$ ) Wood-M I son, Proc. Ent. Soc. 1878 , S. 53.

Ja cobi, Mimikry. 
Ähnlich meisterhafte Nachbildungen von Pflanzenteilen zeigen die "Blattnachahmer" unter verschiedenen tropischen Insektenfamilien, bei denen die Flügel, zum mindesten die vorderen, in Umriß, Aderverteilung und Farbe frische oder welke Laubblätter von Dikotyledonen wiedergeben; der flächenhafte Bau der Flügel macht sie bei mehreren Ordnungen der Kerbtiere dazu besonders geeignet. Zunächst gibt es Beispiele, wo jeder Flügel des vorderen Paares für sich ein Blatt darstellt. Bei Rio de Janeiro hat v. Langsdorff vor vielen Jahren eine mittelgroße

Fig. 2 .

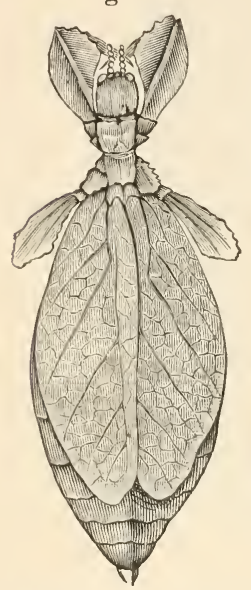

Phyllium siccifolium.

Aus Oels. $1 / 2$ natürl. Größe.
Singzikade (Hemidictya frondosa) gesammelt, deren hellgrüne Deckflügel eine ganz ungewöhnliche Verschmälerung und Zuspitzung nach hinten und eine reiche Auflösung des Geäclers wie die Nervatur vieler Baumblätter aufweisen; die Art ist außerordentlich selten, was vielleicht mit der erschwerten Sichtbarkeit zu erklären ist. Ähnliche Doppelblätter, aber mit engerem Anschluß an die Blattaderung stellen viele große Laubheuschrecken Südasiens vor, namentlich die Gattung Onomarchus; hier stehen die Vorderflügel senkrecht und berühren sich oben längs des Randes. Den Gipfel der Vollendung erreicht jedoch die Ähnlichkeit bei den berühmten "wandelnden Blättern" (Phyllium), einer Phasmidengruppe, die im Gegensatz zu der linear ausgezogenen Mehrzahl der Familienmitglieder ganz plattgedrückte, breite Körper und Gliedmaßen hat (Fig. 2). Wir sehen die starke Ader am Innenrand jedes Vorderflügels der Nachbarin so nahe gerückt, daß sie zusammen die Nittelrippe des vorgetäuschten Blattes ergeben, und die übrigen, jener sonst ungefähr parallel gehenden Adern sich in ganz getreuer Anschmiegung an die seitlichen Blattrippen nach außen kehren; diese Bildung schließt sich eng an die Gestalt der Blätter bei Psidium guiava, von dem die Heuschrecken fressen. Die abgeplatteten Flanken des Hinterleibes deuten perspektivisch entfernte andere Blätter an, während die 
ganz merkwürdig gebildeten Beine die Reste solcher wiederzugeben scheinen, die durch Insektenfraß zerstört wurden. Die Farbe dieser Heuschrecken ist ein echtes Blattgrün und erhält sich auch an gut behandelten Sammlungsstücken, so daß Linnés Artnahme siccifolium sich nur, auf vergilbte Iuseumstiere bezieht. Diese besondere Gestaltung kommt übrigens nur den Weibchen zu, was an anderer Stelle seine Erklärung finden soll (S.32).

Wir kommen nun zu den bei manchen Faltern zu findenden Nachahmungen dürrer Blätter, die ihren Trägern geradezu den Namen "Blattschmetterlinge" verschafft haben. Wer es will, kann schon unsere einheimische Kupferglucke (Gastropacha quercifolia) dazu rechnen, deren kupferrote Flügel durch besondere Ein-' kerbungen des Randes und durch die eigentümlich verschobene Ruhestellung an übereinander liegendes Laub gemahnen. Tiel schärfer und geradezu verblüffend getreu in den Einzelheiten ist aber die Blattähnlichkeit bei gewissen Gattungen der Tropen durchgebildet, und darunter steht die afrikanisch-indische Gattung Kallima an der Spitze. Ton den in Nordindien bzw. auf den Sundainseln sehr häufigen $K$. inachis und paralecta meint der große Naturforscher A.R. Wallace nach eigenen Erfahrungen, - daf sie der wunderbarste und zweifelloseste Fall von schützender Ïhnlichkeit bei einem Schmetterling seien und sagt darüber ungefähr folgendes ${ }^{1}$ ): „Die Flügeloberseite ist sehr auffällig, da sie von bedeutender Größe und mit einem breiten Band schön orangegelber Farbe auf tief bläulichem Grund geschmückt ist. Die Unterseite ist in der Färbung sehr verschieden, so daß man unter ๖0 Exemplaren nicht zwei genau gleiche findet, aber alle haben eine Schattierung von Aschgrau oder Braun oder Ockergelb, wie man sie bei toten trockenen und verfaulenden Blättern findet. Die Vorderflügel sind in eine scharfe Spitze ausgezogen, wie sie als sogenannte Träufelspitze - an den Blättern tropischer Gewächse sehr gewöhnlich vorkommt, und die Hinterflügel verlängern sich auch in einen kurzen, schmalen Schwanz. Zwischen diesen zwei Punkten läuft eine dunkle, gebogene Linie, die genau die Mittelrippe eines Blattes darstellt, und von dieser aus gehen auf jeder Seite einige schräge Linien ab: die Seitenadern des Blattes (Fig. 3). Es ist sehr merkwürdig, wie die seitlichen und

1) Wallace 1870 , S. $67 \mathrm{f}$. 
queren Streifen, die bei verwandten Gattungen vorkommen, hier derart gerichtet und verstärkt sind, daß jene Nachahmung erzielt ist. Aber die Blattnachahmung geht noch weiter, nämlich bis zur Wiedergabe jeder Stufe des Blattzerfalles: die Flügelspreite ist ver-

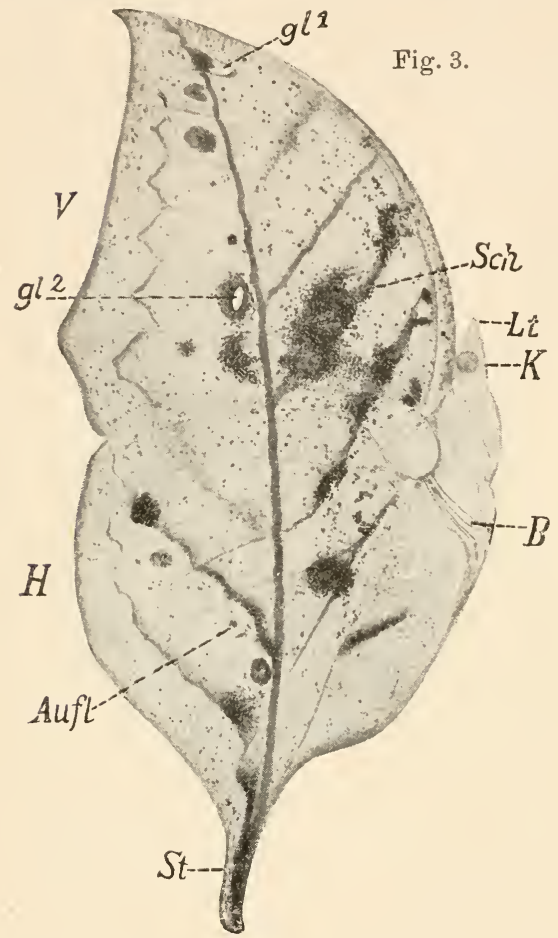

Kallima paralecta, rechte Unterseite des sitzenden Schmetterlings.

$\hbar$ Kopf. Lt Palpen. $B$ Beine. $V$ Torderflügel. $H$ Hinterflügel. St Schwänzchen der letzteren, den Blattstiel darstellend. $g l^{1}$ und $g l^{2}$ Glasflecke. Aufl Augenflecke. Sch Schimmelflecke. Aus Weismann. schiedenartig gefleckt, mit Schimmel bedeckt, von Löchern durchsetzt und in vielen Fällen unregelmäßig besät mit rußartig schwarzen Flecken, gleich Anhäufungen von Moderpilzen, die tote Blätter besiedeln, und zwar derartig getreu, da $\$$ man beim ersten Anblick unmöglich den Gedanken wehren kann, die Schmetterlinge seien von wirklichen Pilzen angegriffen. Aber diese Ähnlichkeit, so genau wie sie ist, würde von geringem Nutzen sein, wenn die Gewohnheiten des Insekts nicht damit übereinstimmten. Diese Falter halten sich in trockenen Wäldern auf und fliegen sehr schnell. Man sieht nie, daß sie sich auf eine Blume oder ein grünes Blatt niedersetzen, wohl aber auf Büsche mit abgestorbenen Blättern, und dabei verliert man sie gewöhnlich ganz aus den Augen. Nur ein-oder zweimal entdeckte ich zufällig eine Kallima in der Ruhe und konnte dann sehen, wie vollständig sie den umgebenden Blättern gleicht. Sie sitzt an einem fast senkrechten Zweige, die Flügel 
beider Seiten decken sich genau, Fühler und Kopf werden zwischen das vordere Paar eingezogen und sind daher unsichtbar. Die Anhänge der Hinterflügel berühren den Zweig und bilden einen vollkommenen Blattstiel. Der unregelmäßige Umriß der Flügel gibt genau die perspektivische Wirkung eines runzeligen Blattes. Wir finden auf diese Weise Größe, Farbe, Form, Zeichnung und Gewohnheiten zu einer Verkleidung vereinigt, die, wie man wohl sagen kann, ganz vollkommen ist, und der Schutz, den sie gewährt, zeigt sich hinlänglich in der Überfülle von Individuen, die solche Verkleidung tragen."

Eine Ähnlichkeit mit dürrem Laub ist auch bei anderen, wie Kallima zu den Nymphalinen gehörenden, Tagfaltern in der Alten und Neuen Welt vorhanden, und zwar in recht verschiedenem Ausbildungsgrad. Nicht immer liegen die Streifen und Linien der Schmetterlingszeichnung ganz entsprechend dem Adernetz des Pflanzenblattes, noch sind sie so vollständig ausgebildet, wie bei vielen Stücken einer Kallima inachis, vielmehr ist es oft nur eine, man könnte sagen impressionistische, Wiedergabe der überaus wechselvollen Tinten und Reflexe, in die sich die Oberfläche trockener, faulender, zerknitterter Blätter zerlegt. So kann es vorkommen, daß der Blattstiel nicht wie bei jener durch ein Schwänzchen des Hinterflügels gebildet wird, der sich beim Niederlassen des Falters an den Zweig fügt, sondern umgekehrt von der verlängerten Spitze des Vorderflügels, wobei dann auch die Seitenrippen den umgekehrten Terlauf nehmen; dergestalt ist Coenophlebia archidona von Ekuador. Solche und andere Abweichungen vom Blattschema, wie sie sich bei Doleschallia, Rhinopalpa, Anaea u. a. zeigen, will Eimer ${ }^{1}$ ) als Beweise auffassen, daß die hochgesteigerte Blattähnlichkeit von Kullima keine durch Anpassung an die Umgebung gewonnene schützende Ähnlichkeit sei, sondern nur das zufällige Endglied einer Entwickelungsreihe von Zeichnungen, die sich bei allen Tagschmetterlingen schematisch angelegt finden und aus denen nur die menschliche Phantasie durch die Brille des darwinistischen Nützlichkeitsprinzips den Vergleich mit Blättern gezogen habe. Ehe ich diesen und andere Einwände bespreche, sollen aber noch zwei weitere, sehr beachtenswerte Fälle Erwähnung finden.

1) 1897 , S. $116-128$. 
Zunächst kommt auch bei großen, zu den Noctuiden gehörenden Nachtfaltern die Blattähnlichkeit in feinster Durcharbeitung vor, nämlich bei der ebenfalls indischen Gattung Phy7lodes mit Ph. ornata, Ph. verhuelli und noch mehr Arten. Da sich bekanntlich die kryptische Erscheinung nur in der Ruhestellung äußert, diese aber bei den Nachtfaltern nur die Oberseite der Vorderflügel sehen läßt, so finden wir auch die Blattnachahmung dort ausgebildet. Die echt blattförmigen Flügel sind graubraun, rotbraun bis grünlich mit einem scharfen Blattgeäder, dessen Ursprung hierbei in der Flügelspitze liegt und in ganz regelrechter Ausbildung nach vorn bis über die Mitte reicht; dort, aber etwas nach innen verschoben, liegt die Fortsetzung des Rippensystems, durch dunkle Schatten bezeichnet. So ergibt sich das Bild mehrerer sich überschneidender Blätter mit streng sympathischem Grundton.

Endlich wissen wir neuerdings, daß auch bei Schmetterlingsraupen die Blattnachahmung vorkommt, aber entsprechend der Lebensweise diejenige des frischen grünen Laubes. Es handelt sich um eine Art der auch bei uns vertretenen Heterocerenfamilie der Notodontiden, die südafrikanische Hoplitis phyllocampa ${ }^{1}$ ). Bei der gedämpft grünen Raupe sind die Hinterleibsringe 7 bis 9 ganz merkwürdig umgewandelt; sie sind nicht allein länger und dicker als die drei vorhergehenden, sondern ihre Seitenränder sind auch sehr verbreitert, so daß sie zusammen eine Auftreibung bilden, die gegen $3 \mathrm{~cm}$ lang und an der breitesten Stelle $2 \mathrm{~cm}$ breit ist, der Rand blattartig verdünnt. Die abgeplattete Unterseite dieser gemeinsam erweiterten Ringe hat die Form eines spitz zulaufenden Blattes mit unregelmäßig gewelltem und eingebuchtetem Rand; ein mittlerer, erhabener Längsstreifen gibt die Mittelrippen wieder und etwa sechs Paare von etwas eingedrückten Querstreifen stellen die Seitenadern dar. Diese blattähnliche Fläche ist zudem mit feinen Grübchen bedeckt, wie ein Blatt mit Poren. Bei Beunruhigung schlägt die Raupe jene Auftreibung nach oben und vorwärts über den Rücken und behält diese Stellung bei, sie ahmt damit in vollendetem Grade die Blätter ihrer Nährpflanze Combretum gutinzii nach.

1) R. Trimen, Trans. Ent. Soc. 1909, S. 3 und 6; Taf. 1, Fig. 3. 


\section{Bedeutung und Entstehung dieser Erscheinungen.}

Wir haben bis jetzt eine Anzahl typischer Fälle von Farbkleidern kennen gelernt, die unter dem gemeinsamen Gesichtspunkt der Schutzwirkung in mehrere Gruppen zu bringen waren. Ich will nun versuchen, die verschiedenen Ansichten der Naturforscher über die biologische Bedeutung der geschilderten Erscheinungen und über ihre stammesgeschichtliche Entstehung wiederzugeben und kritisch zu bewerten, um aus der Gegenüberstellung des Für und Wider dem Leser eine Stellungnahme zu erleichtern. Unter der mächtigen Wirkung der Darwinschen Zuchtwahllehre hatten nämlich viele Beobachter und Schriftsteller aus jeder, oft nur entfernten Ähnlichkeit zwischen Tieren und ihrer Umgebung ohne schärfere Prüfung eine zweckdienliche Anpassung gefolgert, und die hierbei nicht seltenen Übertreibungen riefen bei Gegnern jener Anschauung Widerspruch hervor, der an und für sich eine gesunde Gegenäußerung bedeutete, gelegentlich aber in der Verneinung ebenfalls das Kind mit dem Bade ausschüttete. $\mathrm{Zu}$ denjenigen Anhängern der Nützlichkeitslehre, welche durch allzu großen Eifer im Aufspüren von Fällen der Kryptik diesen Gegnern Waffen geliefert haben, muß leider E. B. Poulton gezählt werden, ein Forscher, der sich der Bearbeitung dieses Problems und der Mimikryerscheinungen seit langer Zeit und mit großem Erfolg für die Erweiterung unseres Wissens gewidmet hat, aber freilich hier und da in der Deutung der Tatsachen zu weit geht. Wenn er schließlich "fast in jedem Strichelchen oder Fleckchen einer Raupe Nachahmung sieht, hier von diesem, dort von jenem 1)“, wenn er z. B. mit Herm. Müller bei der Raupe des Buchenspinners (Stauropus fagi) zwei seitliche Fleckchen als die Wiedergabe von Narben der Ichneumonstiche deutet, die solchen Feinden die Meinung beibringen sollen, daß der Platz schon besetzt sei ${ }^{2}$ ), wenn ron angeblicher Ähnlichkeit einer Zeichnung mit Schlangen- oder Raubtierköpfen die abschreckende IVirkung auf alle möglichen Insektenfresser erschlossen wird - so sind dies freilich Mißgriffe, die den gegnerischen Spott herausfordern. Andererseits gibt Piepers, ein Entomologe,

$\left.{ }^{1}\right)$ Piepers 1903, S. 13. - ${ }^{2}$ ) Poulton 1890, S. 281. 
welcher zur Widerlegung aller Theorien über Schutzfärbung und Mimikry mehrere ausführliche Schriften verfaßt hat, seiner anderen Meinung oft gradezu gehässigen Ausdruck und zeigt immer ein ausgesprochenes Vorurteil, das ihn des öfteren zu argen Mißverständuissen gegnerischer Behauptungen verleitet hat. Ich kamn deshalb seine Ausführungen nicht als eine unbefangene Beurteilung der vorliegenden Streitfragen gelten lassen und werde sie nur gelegentlich heranziehen.

1. Ein schwer begreifliches Mißverständnis der Gegner, das sich nur auf eine oberflächliche Bekanntschaft mit dem Gegenstand zurückführen läßt, betrifft den Ausdruck "Nachahmung." von artfremden Zügen durch ein Farbmuster. Man scheint ihn hier und da wörtlich verstanden zu haben, als wenn ein Tier, mit oder ohne Bewußtsein, bestrebt sei, sich einem Vorbild ähnlich zu machen. Für diesen Fehlschluß spricht es wenigstens, wenn Ribbe ${ }^{1}$ ) den Hinweis für nötig hält, daß die Schutzanpassungen bei Kallima, grünen Heuschrecken u. a. keine Nachahmung seien, "sondern es sind die betreffenden Formen und Farben den Tieren nur zum Schutz verliehen". Quod erat demonstrandum! Ebenso deuten mehrere, nicht immer klar gefaßte Äußerungen Piepers' ${ }^{2}$ ) an, daß er jene Auffassung bei seinen Gegnern voraussetzt. In Wirklichkeit dürfte niemand, der bei der Erörterung kryptischer Erscheinungen von "Nachahmung" spricht, damit etwas anderes gemeint haben, als schützende Ähnlichkeit; ersteres IVort ist eben nur eine bildliche Umschreibung des letzteren und darf hier wie sonst nur als unbewußte Nachahmung aufgefaßt werden.

2. Die Reihe wirklicher Erklärungsversuche möge derjenige beginnen, welcher die sympathischen Färbungen durch eine Art Farbenphotographie zustande kommen läßt. Danach würde die Körperbedeckung so gearteter Tiere für farbige Lichtstrahlen, die von ihrer dauernden Umgebung ausgehen, derart empfindlich sein, daß sie dieselben Töne, z. B. des Sandes oder des Laubes, annähme $\left.{ }^{3}\right)$. Es gibt außer einem spärlichen Versuch Poultons

1) Insektenbörse 1S, 300-301 (1901). - $\left.{ }^{2}\right)$ 1903, S. 20, 21, 25. 3) Daß Piepers (1903, S. 192) diese Ansicht Wallace zuschiebt, während dieser ebenso wie ein „anderer Ultravorfechter der Mimikrylehre", nämlich Weismann, sie ausdrücklich verwerfen (Wallace 1891, S. 292; Weismann 1904, S. 50), ist ein bedauerlicher Mißgriff. 
an Schmetterlingspuppen und theoretischen Schlußfolgerungen von Standfuß 1) nur die in der freien Natur gemachten Beobachtungen Vosselers ${ }^{2}$ ). Er stellte fest, daß bei den Heuschrecken der nordafrikanischen Wüsten die individuellen Abänderungen mancher Arten in strenger Abhängigkeit vom Lokalton des ron ihnen bewohnten und eigensinnig festgehaltenen Fleckes standen. Er konnte genau verfolgen, wie Tiere einer Eremobia-Art aus mehr steinigen Gebieten derbere Färbung und gröbere Zeichnung trugen, auf reinem Sand dagegen aufs vollkommenste mit dessen Tönen und zarter Struktur übereinstimmten, jeder ausgeprägten Zeichnung entbehrend; ebenso war Helioscirtus capsitanus in geradezu peinlich genauer Weise auf die Farbe des individuell bewohnten Wüstenfleckes, bald reiner Sand, bald rostbraunes, grauschiefriges oder selbst kupfriges Gestein abgestimmt, und ähnliches galt von Truxalis unguiculata. Aus diesen ganz engen Beziehungen zwischen Lokalton und Torkommen glaubt Tosseler schließen zu dürfen, daß die Farbstoffe in der Haut solcher Heuschrecken - oder wenigstens die einfacheren Grundlagen der Farbstoffe - unter dem Einfluß reflektierter Farbenstrahlen entsprechende Töne ausbilden können. Diese Annahme soll sich darauf stützen, daß die Pigmente der Geradflügler nicht, wie z. B. bei den Schmetterlingen, schon vor der letzten Häutung zur Imagostufe, während der Puppenruhe vorgebildet sind, sondern erst nach dem Abwerfen der vorletzten Körperbedeckung ihre bleibende Zusammensetzung und Umlagerung erfahren. Immerhin bleibt für die sympathische Beeinflussung der Körperfarben durch Reflexion von Naturfarben nur der kurze Zeitraum vom Abstreifen der letzten Larvenhaut bis zum Erhärten der neuen Chitindecke übrig. Wenngleich jener vorzügliche Beobachter die Häutung'svorgänge und die dabei stattfindenden Umfärbungen aufmerksam verfolgt hat, so fehlt doch die unumgängliche Stütze seiner Hypothese durch Versuche, ob sich denn bei Einwirkung andersartiger Lichtstrahlen im entsprechenden Zeitpunkt auch wieder sympathische Färbung ergeben würde; leider stellen sich solchem Vorhaben, wie Vosseler mitteilt, vorläufig unüberwindliche Schwierigkeiten entgegen, die in der Lebens- und Ernährungsweise der Wüstenheuschrecken beruhen.

1) $\left.1894 .{ }^{2}\right) 1903$, S. 34-38. 
3. Es gibt eine Form der Deszendenztheorie, deren Vertreter in den vielen Vorkommnissen von sogenannter schützender Ähnlichkeit bis zu jenen Fällen wunderbarer "Nachahmung" nichts weiter erblicken wollen, als ein Zusammentreffen von körperlichen Merkmalen, die ihre Träger durch einen bestimmten Verlauf ihrer Stammesentwickelung erworben hätten, mit anderen Worten, es sei nur Zufall, daß manche Raupen wie Zweigstücke gebildet seien, manche ruhende Falter dürren Blättern glichen. Jene Bekenntnisart des Transformismus ist die von Th. Eimer begründete und namentlich auf die Zeichnung der Tiere angewendete Lehre von der gleichgerichteten Entwickelung oder Orthogenesis, der sich mit in Einzelheiten abweichender Begründung Piepers anschließt. Auch er sieht in den kryptischen Anpassungen nichts weiter als die zufällige Ähnlichkeit gewisser gesetzmäßig entstehender Bildungsstufen mit anderen Naturgegenständen und in deren darwinistischer Auffassung stets Einbildung, Humbug usw. ${ }^{1}$ ). Eimer verwirft den Grundgedanken Darwins, daß die Umbildung der Lebewesen infolge von ihrer Veränderlichkeit nach zahlreichen Richtungen hin erfolge, unter denen die für das Bestehen des Daseinskampfes am besten passenden Varianten sich als Arten erhalten. Vielmehr geschieht die Umbildung von Arten in neue nur nach wenigen Richtungen hin nacl erkennbaren Gesetzen, sie ist eine bestimmt gerichtete Entwickelung, und die Ursachen dafür liegen in der Wirkung äußerer Einflüsse (Klima, Nahrung, Luft und Feuchtigkeit u. a. m.) auf die Organismen, indem jene Einflüsse an den Körpern Veränderungen hervorbringen, die sich auf die Nachkommen vererben. Zum Ausdruck kommen aber solche Veränderungen als ein Wachstum ("organisches Wachsen"), und zwar infolge der unendlich oft veränderten Bedingungen als ungleichartiges Wachsen ${ }^{2}$ ). Z.B. glaubt Eimer festgestellt zu haben, daß die Tagfalter ursprünglich eine Flügelzeichnung aus 11 Längsstreifen gehabt hätten, deren teilweises oder gänzliches Schwinden, Verbreitern und Verschmelzen, sowie die Auflösung in einzelne Flecke das mannigfaltige Nuster der zahlreichen Arten zuwege brachte. $\mathrm{Zu}$ diesen Abänderungen führt eben das bei den einzelnen natür-

1) 1903 , S. $25,262,264$ u. a. $-{ }^{2}$ ) Eimer 1888, S. 24; 1897, S. 13 f. 
lichen Gruppen verschieden starke, ungleiche Wachsen der Flügelfläche, wodurch einzelne jener Grundbinden verlagert werden und abweichende Verschmelzungen benachbarter Binden eintreten usw. Es braucht deshalb das organische Wachsen nicht immer eine Vervollkommnung bedeuten, sondern oft auch Vereinfachung oder Rückbildung. Ferner ist für die Zerspaltung einer Gruppe in mehrere neue Formen wichtig der Entwickelungsstillstand (Genepistase), d.h. Stehenbleiben einzelner Formen auf bestimmten Stufen der Entwickelungsrichtung, während andere fortschreiten. Andererseits können die oben aufgezählten Anlässe zur Artbildung auch bei verschieden gearteten, nicht unmittelbar verwandten Formen in derselben Richtung wirken und zu ganz ähnlicher Gestaltung führen: unabhängige Entwickelungsgleichheit (Homöogenesis).

Vorstehende ganz kurze Wiedergabe der Eimerschen Entwickelungslehre durch Orthogenesis war nötig, weil im IV. Abschnitt wiederholt auf sie zurückzukommen ist. Zunächst muß aber ihre Anwendung an einem Beispiel gezeigt werden, und zwar an den von Eimer selbst erörterten Blattschmetterlingen. Die landläufige Anschauung darüber geht bekanntlich dahin, daß deren Ähnlichkeit in der Ruhestellung mit trockenen Blättern eine schützende Anpassung ist, erzielt durch Einfluß der Naturauslese auf die Erhaltung der besten Nachahmer unter den Einzelwesen der betreffenden Art. Anders Eimer ${ }^{1}$ ): Er leitet zunächst die Blattrippenzeichnung aus den erwähnten Grundstreifen der Falterflügel $a b$ und zeigt an einem reichen IIaterial, daß nur eine gewisse Zahl von Individuen das typische Geäder wiedergibt, während bei den anderen nur ein Teil der Rippen zu sehen ist. Dieser Mangel soll durch ein Schwinden der Blattrippenzeichnung in der Richtung ron vorn nach hinten entstehen, wodurch die Unterseite einfarbig zu werden beginne; dadurch bilde sich bei vielen Exemplaren eine solche Terschiedenheit zwischen Vorderund Hinterflügeln heraus, daß der Eindruck ron einem Blatt ganz vernichtet würde. Weitere Untersuchung ron Gattungen, die mit Kallima verwandt sind, aber nur unvollkommene Blattnachahmung aufweisen, ergab Eimer, daß die ganze Erscheinung durch eine gesetzmäßige Verlagerung und Vereinigung einzelner

1) 1897 , S. $98 \mathrm{f} ., 245 \mathrm{f}$. 
Grundstreifen zustande komme und daß diese Verschiebungen, ebenso wie der blattähnliche Zuschnitt der Flügel, eine Folge von ungleichem Wachstum verschiedener Flügelteile seien. Außerdem gäbe es Gattungen aus derselben Familie der Nymphaliden, z. B. Doleschallia, wie auch Gattungen aus anderen Familien, bei denen zwar die zur Blattnachahmung nötigen Bestandteile der Zejchnung vorhanden, aber derartig umgelagert seien, daß die Ähnlichkeit ganz zerstört würde. Die so bestimmt behauptete hochgradige Blattähnlichkeit von Kallima ist also nach Eimer nur ein Zusammentreffen von Entwickelungsvorgängen, die nicht auf kryptische Anpassung hinzielen, sondern von verschiedenen Richtungen her unabhängig, homöogenetisch, wirkten und zufällig hier und da zur Blattähnlichkeit führten, sie jedoch ebensooft wieder zerstörten oder nur ein Zerrbild davon lieferten.

Durch diesen Gedankengang vermeidet die Lehre von der Orthogenesis die logische Klippe, an der sich der Darwinismus sehr leicht und oft festfährt, daß nämlich das Kausalverhältnis zwischen Ursache und Wirkung gleichgestellt wird dem Zusammentreffen mit einem an sich außerhalb dieser Kausalität stehenden Geschehen, mit einer Nebenwirkung. Die Darwinisten schließen nämlich so: Viele Tiere haben (durch natürliche Zuchtwahl) allmählich eine bestimmte Gestalt oder Farbe erlangt, die ihnen zum Schutz gereicht; folglich war der Schutz die Wirkung des Entwickelungsganges. Dieser Schluß kann richtig sein, wenn zwischen Entstehung und Tatsache eine unmittelbare kausale Verknüpfung besteht, doch wird die Gewißheit dafür in dem betreffenden Falle davon abhängen, daß jeder andere Weg ausgeschlossen ist. Dagegen ist folgendes Verhältnis weniger eng und wird von Eimer nebst der heutigen neolamarckistischen Schule vertreten: Eine Anzahl äußerer Reize haben den Entwickelungsgang vieler Tiere, so beeinflußt, daß gewisse eigentümliche Formen und Farben die Wirkung waren (Ka usalverhältnis); daran schloß sich mannigmal, vielleicht nur zufällig, die weitere Wirkung, daß diese Äußerlichkeiten einen Schutz boten (Effektualverhältnis ${ }^{1}$ ). Auf diese logische Voraussetzung muß man

$\left.{ }^{1}\right)$ Vgl. hierzu die beachtenswerten Auseinandersetzungen von Rothe; Zeitschr. f. wiss. Insektenbiol. 4, 262-266 (1908). 
Rücksicht nehmen, wenn man den Erklärungswert der einen oder anderen Theorie abwägen will; das eigentliche Urteil wird, da wir von der Ursache, nämlich dem Entwickelungsgang, keine unmittelbare Anschauung haben, immer auf Wahrscheinlichkeit beschränkt bleiben.

Unter dieser Einschränkung ist die Eimersche Theorie der bestimmt gerichteten Entwickelung sicher eine brauchbare Form der Deszendenzlehre, denn sie schaltet einerseits eine große Schwäche der Selektionstheorie aus, nämlich das Unvermögen, die Nützlichkeit der anfänglich so kleinen Tarianten für den Daseinskampf zu erklären, und das ist für das Problem der Entstehung nützlicher Färbungen eine Grundforderung. Andererseits erklärt sie das Vorwalten gewisser, häufig zu beobachtender Übereinstimmungen in der Organisation bei Gruppen von nur entfernter Verwandtschaft. Sie ist daher eine schätzenswerte Ergänzung zum Darwinismus und erringt sich mehr und mehr einen Platz auf dem Gebiet des Transformismus. Freilich ist der Terlauf der Orthogenesis gerade in der von ihrem Begründer am eifrigsten unternommenen Anwendung auf die Zeichnung der Tiere durchaus nicht so klar und unwiderleglich, wie er es immer behauptet hat. Nach Eimer gibt es ein allgemeines Umbildungsgesetz der Zeichnung, indem die Längsstreifung in Fleckung, Querstreifung und durch Zusammenfließen von Querstreifen schließlich in Einfarbigkeit übergeht. Aber andere Untersucher deuten seine von ihnen nachgeprüften Beobachtungen vielfach ganz anders, ja umgekehrt. Um nur bei der Zeichnung der Schmetterlinge zu verweilen, denen Eimer große Spezialwerke und ein ganzes Buch zusammenfassender Richtung gewidmet hat, so sieht z. B. L. v. Méhély ${ }^{1}$ ) die Aufeinanderfolge der Entwickelung gerade umgekehrt wie Eimer. Während dieser in den Längsbinden, d. h. dem parallel zur Körperachse verlaufenden Farbmuster, den stammesgeschichtlichen Ausgangspunkt erblickt, erinnert M[éhé y daran, daß die Pigmentablagerung allem Anschein nach hauptsächlich dem Terlauf der Tracheenstämme bzw. der Adern in den Flügeln folgt. Daher scheint es ihm naturwidrig, jene elf Binden, welche die Adern fast senkrecht schneiden und demnach in keiner unmittelbaren physiologischen Beziehung zueinander

') Verhand1. 8. internat. Zool.-Kongr. 1912, S. $343 \mathrm{f}$. 
stehen, für einen ursprünglichen Charakter und den Ausgangspunkt späterer Entwickelungen zu erklären. Noch viel weiter entfernt sich Piepers. Obwohl mit Eimer auf gemeinsamem Boden in bezug auf Orthogenesis und alle ihre einzelnen Äuberungen, will er von des ersteren Vorstellungen über die Falterzeichnung gar nichts wissen; er nennt sie eine jeder wissenschaftlichen Basis entbehrende Irrlehre und was der bei ihm üblichen Kraftausdrücke mehr sind ${ }^{1}$ ) und ersetzt sie durch eine Theorie der Farbenentwickelung, die er zuerst an der Schmetterlingsfamilie der Weißlinge (Pieridae) abgeleitet hatte ${ }^{2}$ ), aber auch an den anderen Familien bestätigt gesehen haben will.

Als ursprüngliches Pigment betrachtet er das Rot, aus dem durch Aufhellung und Verblassen allmählich Orange bis Gelb, Grün und endlich Weiß würde; in anderen Fällen wäre zuerst ein dunkles Pigment da, ein Melanin, das, allmählich verödend, jenen helleren Tinten und endlich wieder dem Weiß Platz machte. Diesen von Piepers für unwiderleglich erklärten Aufstellungen widerstreiten aber meiner Ansicht nach wieder Beobachtungen von Urech und Gräfin Linden - kurzum, es sprechen zwar immer wiederkehrende Beobachtungen durchaus dafür, daß die Entwickelung der tierischen Farbmuster nicht unendlich mannigfaltig, sondern auf verhältnismäßig wenigen Bahnen verläuft, aber die Ausgangs-, Zwischen- und Endpunkte sind durchaus noch nicht zweifelsfrei festgelegt. Darum kann auch den Einwänden der Vertreter des Orthogenesisprinzips gegen die Zweckmäßigkeit der sympathischen Farben und Zeichnungen nicht die von ihnen beanspruchte alleinige Gültigkeit beigelegt werden, sondern wir müssen dem von ihnen bekämpften Nützlichkeitsstandpunkt an späterer Stelle noch nähertreten.

4. Für das Vorkommen von schützender Erscheinung werden gelegentlich auch die Zustände und Einflüsse der Umgebung, als da sind Nahrung, Beleuchtung, Luftfeuchtigkeit, Wärme u. a. verantwortlich gemacht. Daß die Art der Kost mit im Spiel sein kann, läßt sich aus mancherlei älteren und neueren Fütterungsversuchen entnehmen, die da ergaben, daß die Farbstoffe der gereichten Nahrung sich in der Hautbedeckung ablagern können;

1) 1903 , S. 91 u. a.m. - ${ }^{2}$ ) Tijdschr. Nederl. dierkund. Vereen. (ser. 2), 5, 70-289 (1898). 
auch einige erfolgreiche Versuche Vosselers an Heuschrecken lassen sich herbeiziehen. Allzu groß kann jedoch dieser Einfluß nicht sein, sonst dürfte es keine Tiere mit Dimorphismus der Färbung geben, wo bei völlig gleicher Nahrung die Individuen oft ganz verschiedene Farben tragen; z. B. sind manche Raupen unseres Windenschwärmers (Frotoparce convolvuli) und des mittleren Weinschwärmers (Chaerocampa elpenor) auf derselben Futterpflanze braun oder grün. In den gleichmäßig fahlen Tönen der altweltlichen Wüstentiere wird die Wirkung der starken Lichtbestrahlung erblickt, die gleichsam zum Verschießen der ursprünglich dunkleren Schattierung führte; man könnte in der Tat zugunsten dieser Erklärung darauf hinweisen, daß auch die Nachttiere der Wüste (Eulen, Ziegenmelker), soweit sie während der Ruhe den Sonnenstrahlen ausgesetzt sind, so aussehen. Dem widerspricht aber, daß unter gleichen Breiten, z. B. in Mittelasien, wo zwar annähernd dieselben Lichtverhältnisse herrschen, aber die Natur nicht wüstenhaft ist, dunkle, kräftige Farben vorwiegen; ferner gibt es im Südwesten der Vereinigten Staaten Wüsten, die unter genau dem gleichen Sonnenstand liegen wie die Sahara, deren tierische Bewohner aber eine ganz andere Erscheinung haben als die nordafrikanischen, denn bei ihnen wiegen kontrastreiche Farbkleider vor - freilich tragen auch diese Gebiete von Colorado bis Neumexiko ein entsprechendes Aussehen: es ist die "bunte Wüste" mit vieler Abwechselung von leuchtenden, satten Farben und tiefem Schwarz. Ebensowenig kamn die Kälte der Polargegenden die wesentliche Bedingung für das vorherrschende Weiß der dortigen Landtiere sein, denn wir sahen einerseits, daß es unter ihnen auch dunkle Erscheinungen gibt, andererseits sind gewisse Vogelfamilien, wie die Möven, Reiher, Kakadus, gerade in den warmen Erdstrichen durch weiße Farbe ausgezeichnet.

Hierher gehört auch ein von F. Werner ${ }^{1}$ ) geäußerter Gedanke. Wenn bei den Gespenstheuschrecken (Phasmidae) so ungeheuerliche Verbreiterungen der Beine vorkommen, wie Phyllium und manche Stabheuschrecken sie zeigen, und damit an durch Insektenfraß zerstörte Blattreste gemahnen, so erklärt er dies für einen Wachstumsüberschuß, den die üppige, feuchte Tropennatur ins

1) 1908 , S. 597 . 
Werk setzt, und zieht die bizarren Kopfzierden der Chamäleone, die Kehlsäcke, Rückenkämme und Kapuzen vieler Eidechsen in denselben Ländern damit in Parallele. Dem muß aber entgegengehalten werden, daß z. B. die Männchen von Phyllium die Verbreiterung von Leib. Flügeln und Beinen in viel geringerem Grade als die Weibchen besitzen; warum ist also jener Einfluf des Klimas gerade bei dem Geschlecht unwirksam geblieben, das sonst ganz allgemein in der Ausbildung überflüssiger Zieraten den Vorsprung hat? Die naheliegende Antwort ist eben die, dab diese Umgestaltung des Körpers beim Weibchen, aus der die Blattähnlichkeit hervorgeht, wirklich eine kryptische Anpassung ist; damit erklärt sich auch obne Zwang ihre Beschränkung auf dasjenige Geschlecht, welches der Fortpflanzung wegen des Schutzes am meisten bedarf und ihn daher in so vielen Fällen allein genießt. Werner ist überhaupt geneigt, in den sogenannten Stab- und Blattheuschrecken nur mechanische Anpassungsformen zu sehen, indem nämlich die Typen von langausgezogenem Bau sich Äste zum Sitz wählen, die breit gedrückten aber Blätter, weil sie sich dadurch die Erhaltung des Gleichgewichtes erleichtern; er stützt sich dabei auf die Beobachtung, daß breite Formen beim Klettern an Ästen und stabförmige auf Blättern sich unsicher und unbehaglich zu fühlen scheinen. Könnte aber dieses Mißbehagen nicht eher psychisch als physiologisch zu deuten sein, insofern als die Tiere, wenn sie in eine kryptisch unwirksame Umgebung geraten, das instinktive Bestreben haben, aus dieser heraus in die für sie passende Deckung zu gelangen?

5. Derselbe Zoologe hat den beachtenswerten Hinweis gemacht' ${ }^{1}$ ), daß tierische Färbungen, die mit weit verbreiteten Naturtönen übereinstimmen, darum nicht erst durch Selektion zu Schutzfärbungen geworden $\mathrm{zu}$ sein brauchen, sondern es sind Pigmente von sehr regelmäßigem Vorkommen, deren Dasein in besonderen Fällen kryptische Bedeutung erlangt. Die erdfarbigen Tiere haben wohl die beste und verbreitetste Schutzfärbung, deshalb nämlich, weil die braunen und grauen Erdtöne die einfachsten, ursprünglichsten Farben sind, die ein Tier überhaupt haben kann. Es sind alles Abarten des häufigsten tierischen Pigmentes, des Melanins, von dem sich fast alle Töne

1) 1908 , S. $592-595$. 
ableiten, teils durch Verdünnung, teils durch chemische Veränderung, durch Überlagerung usw. Wenn aber diese ursprüngliche Pigmentierung, zu der das braune Chitin der Gliederfüßer gehört, sich so häufig erhält, so rührt dies davon her, daß kein Anlaß zur Teränderung durch natürliche Auslese vorliegt - die zweckmäßige Übereinstimmung mit dem Aufenthaltsort war ohnehin da. Auch das bei Landtieren so häufige Grün fällt nach Werner unter diese Betrachtung infolge direkten Hervorgehens aus dem Melanin oder durch Überlagerung mit anders brechenden Medien. Die Nachprüfung dieser Gedanken auf dem IVege des Versuches in einem weiteren Umfang als bisher muß um so eindringlicher empfohlen werden, als auch eine andere hörenswerte Stimme, nämlich F. E. Beddard in seinem Buch "Animal Coloration" 1), die Untersuchung der färbenden Bestandteile in der Tierhaut auf chemischem und physikalischem Wege als eine notwendige Unterlage aller weiteren, rein biologisch arbeitenden Schlußfolgerungen fordert.

6. Hier und da kann man der Meinung begegnen, dalo sympathische Färbung durch eine Art Sehnsucht der Tiere, ihrer Umgebung ähnlich zu werden, entstünde, wobei der individuell erreichte Erfolg durch Vererbung gesteigert würde: also eine ins Gebiet des reinen, alten Lamarckismus fallende Erklärung. Jenen Trieb hält $\mathrm{Hahnel}^{2}$ ) für halb unbewußt, halb bewußt, und Piepers ${ }^{3}$ ) möchte darin eine Autosuggestion sehen, die aus dem bei Tieren und Menschen stark vertretenen Nachahmungstrieb entspränge. Man kann für ein anderes von letzterem vorgebrachtes Beispiel, die Stabheuschrecken ${ }^{4}$ ), zugeben, daß für diese Insekten, die schon während ihrer Larvenzeit die betreffende Körperform zeigen, das Lamarcksche Entwickelungsprinzip anwendbar ist, nämlich in der Art, daß ein dauerndes Gestreckthalten des Körpers infolge der besonderen Lebensgewohnheiten (Anschmiegen an die Unterlage, Überbrücken der Abstände von Zweig zu Zweig usf.) eine allmählich gesteigerte Gebrauchswirkung gehabt hätte. Indem Piepers auf der ganz selbstverständlichen Voraussetzung fußt, daß die hierbei eintretenden körperlichen Leistungen durch Willensakte, wenn auch ganz geringer Stärke,

1) 1892. - $\left.{ }^{2}\right)$ Deutsche Ent. Zeitschr. Iris 3, 310 (1890). 3) 1903 , S. $148 \mathrm{f} .-{ }^{4}$ ) 1903 , S. 172.

Jacobi, Mimikry. 
also durch physische Vorgänge hervorgerufen werden, zieht er daraus den Schluß, daß auch jene chromatische Körperfunktion dem Willen, wenngleich nur einem unbewußten, unterworfen sei. An dieser Folgerung sind aber sowohl das Mittel wie der Zweck ganz hypothetisch und zudem gerade für die meisten reifen Insekten unwahrscheinlich, denn bei diesen handelt es sich nicht um Tiere, welche die Anordnung der Farbstoffe in ihren Hautschichten über Nervenbahnen hinweg beeinflussen können, wie Tintenfische und Chamäleone, sondern um Tiere mit einem festen, unveränderlich gefärbten Hautpanzer aus Chitin. Wollte man aber die autosuggestive Beeinflussung der eigenen Farbe in die plastische Larvenzeit verlegen, so käme wieder die Schwierigkeit, da die Larve sehr oft in andersfarbiger Umgebung lebt, als das farbige Kerbtier, also von dessen Farbensympathie noch nicht berührt wird. Kurzum, diese Hypothese ist, soweit sie sympathische Farbenübereinstimmung erklären will, unhaltbar und bei Hahnel eine Folge der unzureichenden naturgeschichtlichen Vorbildung dieses übrigens tüchtigen Beobachters, bei Piepers aber wohl aus seiner Abneigung entsprungen, der Zuchtwahllehre irgend einen Schritt entgegenzukommen. Vielleicht wird mir Piepers einwenden, daß ich ihn gar nicht verstanden hätte; ich will dies von vornherein zugeben, aber die Abfassung seines Buches in deutscher Sprache, die wir Deutschen als eine Ehrung seitens des holländischen Forschers empfinden müssen, hat seinen Stil etwas schwer faßlich, ja bisweilen fast unverständlich gemacht.

7. Da die kryptischen Erscheinungen zuerst von Darwin und Wallace ursächlich erklärt worden sind, so hat die Selektionstheorie der beiden großen Biologen auch darauf die meiste Anwendung gefunden, oft mit der Leichtherzigkeit, in der ihre Anhänger allen in größerer Tiefe der Probleme versteckten Schwierigkeiten aus dem Wege gingen und oft noch gehen; ich denke dabei namentlich an Weismann, der in der Zusammenfassung seiner entwickelungstheoretischen Ansichten, den "Vorträgen über Deszendenztheorie" (1904) und der "Selektionstheorie" (1909) im Außerachtlassen gegnerischer Einwände sich völlig treu geblieben ist. Man darf meines Erachtens dem Einflufo der Naturauslese auf die Erzielung von Schutzgestalten und -färbungen den weitgehendsten Einfluß unter allen Entwickelungs- 
reizen zugestehen, aber ihn zum allherrschenden $\mathrm{zu}$ stempeln, heißt manche Widersprüche totschweigen. Für die Ultradarwinisten gilt es bekanntlich ${ }^{1}$ ) als ausgemacht, daß die allgemeine Variabilität der Organismen eine Musterkarte von äußeren Eigenschaften bietet, von denen das geringste Mehr über dem Durchschnitt dem Besitzer schon einen Vorteil im Daseinskampf geben, hier also seine Feinde irreleiten kann. Jede kleine Übereinstimmung mit dem Aufenthaltsort wäre also ein Schritt auf dem Wege zur Schntzfärbung, und es genügte eben eine schrittweise Entwickelung aus kleinen Verbesserungen des Rassendurchschnittes, um ans Ziel, die vollkommene Schutzmaske, zu gelangen. Solch eine Voraussetzung verlangt aber die weitere, daß die besonderen Feinde der sich zur Kryptik wandelnden Arten sehr kurzsichtig gewesen sind, sonst hätten die kleinen Ansätze zu einer Verkleidung sie nicht ablenken können. Wenn Weismann ${ }^{2}$ ) es für selbstverständlich erklärt, daß die Anpassungen nicht aus dem Nichts entstehen, sondern aus dem, was schon da ist, so gibt el damit im Widerspruch mit der darwinistischen Grundanschanung zu, daß eine Selektion nur unter Material walten kann, das schon einen gewissen Grad von Ähnlichkeit besitzt, also zur Täuschung des Feindesauges einigermaßen geeignet ist. Damit gesteht er seinem Gegner Eimer indirekt zu, was dieser behauptet, daß die Veränderlichkeit in einer Formengruppe nicht unbegrenzt ist und der Selektion freiesten Spielraum gewährt, sondern daß schon vorläufige Ergebnisse einer oder einiger bestimmten Entwickelungsrichtungen vorhanden sein müssen, ehe sich die Fenerprobe des Daseinskampfes geltend machen kann. Forscher, die nicht nur am Schreibtisch oder vor dem Zuchtkäfig, sondern in der Natur tätig waren, betonen immer, daß auch die scheinbar vollendetste Schutzanpassung nicht vor Entdeckung sichert, daß die so ausgerüsteten Geschöpfe doch ihre besonderen Verfolger haben, die sie mindestens bei Hunger zu entdecken wissen ${ }^{3}$ ); um so eher muß die Erscheinung solcher Tiere, die sich in ein schützendes Gewand zu hüllen beginnen, bereits eine gewisse Möglichkeit zu dessen Ausgestaltung geben. Diese Stufe als Ausgangspunkt genommen,

$\left.{ }^{1}\right)$ Vgl. Weismann, 1904 , S. 50 und anderwärts. - ${ }^{2}$ ) Ebenda, S. 71. - ${ }^{3}$ ) Z. B. Heinroth, Journ. f. Ornith. 50, 428 (1902); Beal, Yearb. Dept. Agric. Washington 1908, S. 346; Werner, 1908, S. 574, 590. 
ist der Weitergang der natürlichen Auslese ganz verständlich und sogar von Eimer ${ }^{1}$ ) in Betracht gezogen worden. Es werden die in der Fortentwickelung zurückbleibenden Einzelwesen, Spielarten usf., am häufigsten von ihren Feinden - selbstverständlich den sehenden - entdeckt und vertilgt werden; dadurch wird die Fortpflanzung dieser ungenügend angepaßten Opfer verhindert, die Erhaltung ihres Zustandes erschwert, bis mehr und mehr ein Stamm solcher übrig bleibt, die sich der möglichst besten Anpassung nähern. Wenn es ein Beispiel gibt, das die Erzeugung kryptischer Tierfarben durch Selektion treffend belegt, so sind es die arktischen Landtiere mit ihrem vorherrschenden Weiß, weil es sich immer bei solchen Arten findet, die seiner als Deckfarbe benötigen, und zwar nur von der geographischen Breite an, wo es der Ausdehnung und Dauer der Schneedecke entspricht. In den ganz wenigen Fällen, wo das Weiß fehlt, läßt sich die Ausnahme unschwer biologisch erklären. Wenn Piepers ${ }^{2}$ ) diese Erscheinung wieder allein auf einen orthogenetischen Vorgang von Ausblassung zurückführt und dazu die fernliegendsten Gründe in einer sehr weitschweifigen Weise beibringt, so zeigt dies, in welche Fehlschlüsse ein ursprünglich logisch geschulter Kopf durch blinden Haß gegen eine wissenschaftliche Anschauung und durch Verallgemeinerung einseitiger Erfahrungen geraten kann; hier ist aber nicht der Ort zur Widerlegung im einzelnen. Auch Eimers Auffassung, daß die „Blattnachahmung" bei Schmetterlingen in keiner Weise durch die Zuchtwahl beeinflußt werde ${ }^{3}$ ), leidet unter Voreingenommenheit und ist nur einseitig begründet. Welche Beweiskraft kann man Ausführungen beimessen, die darin gipfeln, daß die Blattzeichnung von Kallima ungemein veränderlich, oder gelegentlich unvollkommen oder im Verschwinden sei ? ${ }^{4}$. Da nach den oben wiedergegebenen Äußerungen anderer Forscher die Aufeinanderfolge der Eimerschen Entwickelungsstufen durchaus nicht unbestritten ist, so darf ein Vertreter der Selektionstheorie wohl den Schluß ziehen, daß bei Kallima und vielleicht manchen anderen Fällen solcher Art - gerade ein Werdevorgang verkörpert ist, bei dem aus einer Fülle von kleinen Varianten mit beträchtlichem Spielraum der Abänderung die

1) 1897 , S. 14,16 usw. $\left.-{ }^{2}\right) 1903$, S. 113 f. $-{ }^{3}$ ) 1897 , S. $98-128$, 245 f., $470 .-{ }^{4}$ ) 1897 , S. 245 . 
weniger gut angepaßten ausgemerzt werden; mit anderen Worten, wir haben hier die Artbildung im lebendigen Gang vor Augen, von der wir gewöhnlich nur einzelne Ausschnitte zu sehen bekommen. Außerdem ist diese Mannigfaltigkeit der Zeichnung doch gerade etwas, das die Wirksamkeit der Blattnachahmung unterstützt, denn gerade das welke, dürre, halbvermoderte Blatt tritt in der Natur in tausend Farben und Formen auf, mit seinen Übergängen von Grün zu Gelb und Braun, seinen Einrissen und Sprüngen, den Nagespuren und dem Anflug von Schimmel- und Rußpilzen. Wer die "umgekehrte" oder "ganz verrückte" Blattzeichnung von Coenophlebia, Caerois u. a. für unvereinbar mit der Erklärung durch Kryptik hält ${ }^{1}$ ), der muß sich dürres Laub nur in einer einzigen Gestalt und in einer einzigen Stellung am Zweig vorstellen, aber nicht in den zahllosen Möglichkeiten des Naturbildes. Außerdem will ein Urteil, ob die toten Falter mehr oder weniger richtig dem Laub entsprechen, nicht viel besagen, die Wirkung im Leben ist nach Skertchly, der viele Arten Blattschmetterlinge auf Borneo beobachtete, oft ganz anders ${ }^{2}$ ): Obwohl Kallima die feinste Ausarbeitung zeigt, sind viel weniger blattähnliche Arten von Zeuxidia und Amathusia weit schwerer zu entdecken ${ }^{3}$ ). Der Abstufungen toter Blätter im Dickicht sind eben nach Umrissen, Aderung und Färburg so viele, daß nur eine ganz allgemeine, skizzenhafte Nachbildung des Durchschnittes völlig natürlich, also für das Späherauge täuschend wirkt. Wäre die Schutzzeichnung einer Art immer nach demselben Schema, so würde den Feinden das Wiedererkennen gerade erleichtert.

Wie die Beobachtung des Tierlebens in einem gut abgegrenzten Gebiete auf die Wirksamkeit der Naturauslese hinführt, zeigen wieder die trefflichen Untersuchungen Vosselers an den Heuschrecken der Sahara. Der Wohnraum dieser Kerfe ist in der Zeit, wo sie ihre letzte Entwickelung durchmachen, nahezu pflanzenlos dürr, er bietet kaum eine Gelegenheit zum Verstecken für die bei der großen Lichtfülle jedem Auge sichtbaren Tiere. „Also gerade während derjenigen Zeit, wo alles zusammenwirkt, um jeden nicht

$\left.{ }^{1}\right)$ Eimer, 1898, S. 118, 123 f. - ${ }^{2}$ ) Ann. Mag. Nat. Hist. (6) 4, 212 (1889). - ${ }^{3}$ ) M. Moszkowski, „Eine Kallima hebt sich deutlich von dem verfaulten Blatt ab, dem sie scheinbar nachgebildet ist." Sitzungsber. d. Ges. naturf. Freunde 1908, S. 77. 
dem Boden gleichgefärbten Gegenstand, vollends wenn er sich bewegt, einem lauernden Blick besonders deutlich zu machen, findet man die Acridier fast ausnahmslos auf dem nackten Boden, ihren zahlreichen Feinden unter den Reptilien und Vögeln wie auf dem Präsentierbrett preisgegeben. Mit vollstem Recht kann man in diesem Falle behaupten, daß alles, was nicht angepabt ist, dem Untergang verfällt $\left.{ }^{1}\right)$. "

Auch für die Bedeutung der unvollkommneren Stufen in der Artumwandlung zu einer kryptischen Erscheinung gibt es Hinweise, auf die der Selektionsgedanke Licht wirft. Wenn wir nämlich der an bestimmte Richtungen gebundenen Entwickelung auch gewissen Einfluß zugestehen dürfen, so ist doch die Weiterführung der dabei erzeugten Keime zu einer Schutzfärbung bis in den Bereich einer wirklichen Schutzanpassung nur denkbar, wenn die Besitzer solch geeigneter Kleider sie auch am richtigen Platz zur Geltung bringen, d. h. als Ruhesitze Orte wählen, mit denen ihr Äußeres sympathisch ist. Dazu veranlaßt sie der Instinkt, und daher bedeutet diese Lebensäußerung den anderen Weg, auf dem die Selektion arbeitet, indem sie die Vollbringer unzweckmäßiger Triebhandlungen aus dem Bestand der Art ausmerzt. Hierfür eine Tatsache als Beispiel: Auf Ceylon ist die Nymphalide Precis iphita ein häufiger Falter; braun von Farbe hat er auf der Flügelunterseite einen Diagonalstrich ähnlich wie bei den sogenannten Blattschmetterlingen. Er hat die Gewohnheit, bei Verfolgung nicht davon zu eilen, sondern ins tiefe Gebüsch zu tauchen und sich dort zwischen dürren Ästen niederzulassen. Er ist sozusagen ein werdender Blattschmetterling, denn er hat den passenden Instinkt, im Daseinskampf eine Stellung einzunehmen, auf der sein Geschlecht vorwärts kommen kann ${ }^{2}$ ). Dieselbe Art, sich möglichst rasch zu verbergen, haben nach Skertchly ${ }^{3}$ ) auch die anderen Blattnachahmer (Amathusia, Thaumantis, Discophora, Kallima); an Töne der engsten Umgebung angepaßte Heuschrecken (Helioscirtus) sah Vosseler nach dem Verscheuchen auf nicht sympathische Flecke so bald wie möglich auf ihre alten Plätze zurückeilen, während die Bewohner weiter, gleichartiger Sandflächen sich lange nach irgend einer Richtung hin forttreiben

1) 1903 , S. $42 .-{ }^{2}$ ) Dofle in 1908, S. 253. - ${ }^{3}$ ) Ann. Nat. Hist. (6) 4, 212 (1889). 
ließen $\left.{ }^{1}\right)$. Gegenüber diesen bestimmten Angaben über die zweckdienlichen Gewohnheiten solcher Tiere - auch die Krebse, Weichtiere und Wirbeltiere, wie Plattfische und Chamäleone, wären in diesem Zusammenhang zu nennen - kann ich vereinzelten abweichenden Beobachtungen keinen grundsätzlichen Wert beimessen, wonach z. B. Kallima auch mal zwischen grünen Blättern getroffen wird oder sich ganz frei hinsetzt ${ }^{2}$ ). Selbstverständlich bleibt der Falter ein Falter, er muß sich doch auch einmal rühren und hat wohl ein gewisses Gefühl dafür, ob er augenblicklich unter Verfolgung steht oder sich etwas gehen lassen darf. Andererseits soll nicht bestritten werden, daß der Deckungsinstinkt trotz kryptischer Anpassung mangelhaft sein kann, wofür Aigner-Abafi ${ }^{3}$ ) einige Beispiele aus der heimischen Schmetterlingswelt nennt, aber alles in allem möchte ich mit Doflein ${ }^{4}$ ) auf die Tatsache Wert legen, daß sich Schutzkleider nur bei Wirbellosen von höchster geistiger Fähigkeit (Gliederfüßer, wenige Weichtiere) und bei den Wirbeltieren finden, daß sich also Entwickelung der äußeren Erscheinung und der psychischen Leistung begegnen, wonach die Beteiligung des Instinktes an der Erlangung kryptischer Vorteile um so eher verständlich ist.

\section{Was spricht für die Schutzfärbungstheorie?}

Wenn man die große Menge von Fällen übersieht, die wir nach dem Urteil sehr vieler Naturforscher, und darunter solcher von hohem Rang, unter den Begriff der schützenden Anpassung an das Aussehen der Umgebung bringen, so treten mehrere allgemeine Gesichtspunkte heraus, die so oft wiederkehren, daß man sie als Regel betrachten kanı. Solch eine regelmäßige Verknüpfung gibt die Wahrscheinlichkeit, daß die Erklärung der sympathischen Erscheinungen als Schutzeinrichtungen richtig ist. Folgende Eigenschaften finden sich am häufigsten:

1. Kryptisch ausgestattete Tiere sind zur Nahrung für andere, räuberische geeignet, weil sie klein sind oder eine weiche, leicht $\mathrm{zu}$ zerbeißende oder $\mathrm{zu}$ verdauende Hautbedeckung haben und keine Waffen, keine ekelerregenden oder gar giftigen Körpersäfte

1) 1903, S. 40. - ${ }^{2}$ ) Hartert, Berl. Ent. Zeitschr. 33, 289-292 (1889); Piepers 1903, S. 200. - ${ }^{3}$ ) 1902, S. 372, 405. $-{ }^{4}$ ) 1908, S. 249. 
führen. Da so geartete Wesen der Verfolgung durch fleischfressende Tiere stark ausgesetzt sind, so ist ihnen jeder Umstand nützlich, der ihre Entdeckung durch Räuber erschwert.

2. Schützende Nachahmung wird im allgemeinen, bei Landtieren fast nur, in der Ruhestellung erreicht.

3. Kryptisch ausgestattete Tiere pflegen wenig Ortsveränderung zu haben oder gar festzusitzen; vielfach sind es solche, die beim Suchen nach Nahrung und bei deren Aufnahme keine Deckung genießen. Viele pflegen solange wie möglich regungslos zu bleiben, auch wenn sie zu geschwinder Ortsveränderung imstande sind; es gibt sogar welche, die derartige Sitten erst auf einer Lebensstufe annehmen, wo sie ein Schutzkleid erhalten ${ }^{1}$ ).

4. Ein kryptisches Aussehen ist namentlich den Tieren eigen, welche bei Tage ohne Deckung ruhen, daher sowohl wehrlosen Geschöpfen, wie auch nächtlichen Räubern, die von ihren tagsüber regen Opfern bei Entdeckung belästigt werden würden.

5. Eine Schutznachahmung zeigen nur diejenigen Körperteile, welche in der Ruhestellung sichtbar sind, während verdeckte Stellen abweichend, oft sogar lebhaft bis grell gefärbt sein können. Dies ist eine geradezu ausnahmslose Regel und sowohl bei Wirbeltieren (Vögel, Eidechsen), wie namentlich bei den Kerfen (Falter, Heuschrecken, Zikaden) wahrzunehmen. Besonders bezeichnend sind die Schmetterlinge, wo die verschiedene Ruhehaltung der Flügel den Sitz der kryptischen Zeichnung bedingt ${ }^{2}$ ), ferner die häufig vorkommende Tatsache, daß da, wo der Flügel eines Paares den anderen deckt, nur die freiliegenden Stellen kryptisch, die verdeckten aber gegensätzlich gefärbt sind. Diese Farbenverteilung kann durch Selektion leicht, durch andere Einflüsse wie Belichtung ${ }^{3}$ ) nur gezwungen erklärt werden.

Kurz gesagt ist eine kryptische Färbung und Gestalt bei solchen Tieren zu bemerken, die für ihre Lebensgewohnheiten davon Vorteil haben dürften; sie beschränkt sich fast immer auf die Ruhestellung und dann noch auf die sichtbaren Körperteile. Ein sehr starker Hinweis darauf, daß ein Schutzbedürfnis als

1) Vosseler 1909, S. 180-181. - 2) Ausführliches zu Punkt 5 findet man hinsichtlich der Schmetterlinge bei StandfuB 1893. 3) J. Oudemans, Verh. Koningl. Ak. Wetensch. Amsterdam (2) 10, No. 1. 
Folge von Genießbarkeit und Wehrlosigkeit durch die Erlangung von Schutzfärbung oder schützender Ähnlichkeit befriedigt wird, besteht darin, daß ungenießbare oder wehrhafte Tiere kein schützendes, sondern vielfach ein geradezu auffallendes Äußere haben.

\section{Wirksamkeit der kryptischen Anpassungen.}

Bei der Erklärung aller Erscheinungen, die uns bisher beschäftigten, läßt man sich völlig von der menschlichen Anschauung leiten, d. h. wir finden irgend ein Tier ähnlich irgend einem Teil seiner Umwelt und ziehen daraus den raschen Schluß, daß die Feinde jenes Tieres denselben Eindruck haben. Da eine unmittelbare Prüfung auf die Richtigkeit dieser Annahme ausgeschlossen ist, so müssen wir uns damit begnügen, zu beobachten, ob der an uns selber erfahrenen Täuschung durch die Schutztracht auch Tiere anheimfallen; unsere Schlußfolgerung soll also mittelbar durch Erfahrung bestätigt werden. Wer aber erwartet, daß wir über einen Schatz von Beobachtungen verfügten, der einigermaßen der Fülle von Deutungen jener Art entspräche, wird nicht befriedigt werden, vielmehr ist unsere nachgewiesene Kenntnis von der Bedeutung der Schutzanpassungen im Naturhaushalt äußerst ärmlich. Innerhalb des Insektenreiches allein sind mir keine Fälle von Für oder Wider bekannt, doch hat hier die bloße Schlußfolgerung auf Schutzwirkung gegen Feinde, die ihre Beute wesentlich mit dem Auge suchen, noch am meisten Berechtigung, weil man es als erwiesen ansehen darf, daß das Sehvermögen der Kerbtiere gegenüber bewegungslosen Dingen sehr schwach ist. Auch für die Wirkung gegen Wirbeltiere gibt es, wenigstens im Hinblick auf Insekten mit kryptischer Ausstattung, nur wenig stützende Beobachtungen, und sie sind an Käfigtieren gemacht worden, was die Beweiskraft schwächt ${ }^{1}$ ). Andererseits sind negative Beobachtungen, dahingehend, daß Tiere mit protektiver Schutzfärbung entdeckt und gefressen werden, leichter und deshalb häufiger gemacht worden; sie betreffen wohl immer Vögel als Verfolger, deren Sehfähigkeit freilich am höchsten steht.

1) Zum Beispiel Poulton 1890, S. 40 (Eidechsen-Spannerraupen); Prochnow 1907, S. 18 (Vögel-Stabheuschrecken). 
Der so spärliche Vorrat an wirklichen Beobachtungen wird von den Gegnern zur allgemeinen Ablehnung der Schutzfärbungstheorie benutzt, wozu sie schlechterdings kein Recht haben. Die Anhänger verteidigen ihre Lehre zunächst durch den Vorbehalt, daß keine kryptische Anpassung unfehlbaren Erfolg haben könne, da sich sonst die geschützten Arten ins Unendliche vermehren würden; ferner wenden sie ein, daß ohne Schutzfärbung usw. die Verfolgung noch viel heftiger sein würde und daß der Mißerfolg gegen die eine feindliche Art durch die Täuschung anderer ausgeglichen würde. Letzterer Verteidigungsgrund stützt sich auf die verbreitete Meinung, daß jeder Tierart eine Mannigfaltigkeit von Feinden gegenüberstünde, von denen einige die Verkleidung durchschauten, andere sich von ihr irreführen ließen. Dagegen behauptet Werner ${ }^{1}$ ), daß die Zahl der Verfolger - natürlich der mit dem Auge suchenden - ganz beschränkt sei und will dies durch Beispiele aus verschiedenen Klassen belegen. Ich kann nicht zugeben, daß seine Beweismittel hinreichend sind, um jene Annahme der "Protektivisten“ als völlig unbegründet hinzustellen, glaube vielmehr, daß sich eine ebenso große Zahl von Gegenbelegen aus dem einschlägigen Tatsachenbereich beibringen lassen würde. Im ganzen scheint mir die Frage, ob die kryptischen Ähnlichkeiten ihren Trägern einen ausschlaggebenden, arterhaltenden Nutzen bringen, in letzter Hinsicht also, ob es sich wirklich um Anpassungen handelt, bisher weder von den Verfechtern der Bejahung, noch von den Gegnern hinreichend geklärt zu sein; solange aber die letzteren nicht den Nachweis liefern, daß. die 'Täuschung durchschnittlich öfter ausbleibt, als sie eintritt, muß ich aus den allgemeinen Feststellungen des vorigen Abschnittes den Schluß ziehen, daß die Theorie der schützenden Anpassungen durch Farbe und Gestalt die Wahrscheinlichkeit für sich hat.

1) 1908 , S. 572 . 


\section{Warmüärbung.}

In scharfem Gegensatz zu den bisher erörterten Schutzmitteln steht ein anderes, das sich zwar auch der besonderen Gestaltung oder Färbung des Körpers bedient, aber nicht dahin zielt, ihn zu verbergen, sondern gerade sichtbar, insbesondere leicht wiedererkennbar zu machen: die Warnfärbung (Trutz-, Schreckfärbung). Die so gezeichneten Tiere sind aber trotz geringer Körperstärke und oft trotz Langsamkeit nicht wehrlos, sondern besitzen irgend welche Abwehrmittel, seien es nur ein unangenehmer starker Geruch oder schlecht schmeckende Körpersäfte, seien es wirkliche Gifte oder Waffen, von Dornen und Brennhaaren an bis zu Giftzähnen und -stacheln, oder auch ein besonders starker Panzer. Würde ein Tier dieser Art nur unscheinbar oder auch kryptisch ausgestattet sein, so liefe es immerhin Gefahr, daß ein Raubtier es entdeckte und bei dem Versuch, es zu verzehren, beschädigte oder tötete, wenn der Feind auch dabei die Ungeniebbarkeit der Beute wahrnähme; die Unscheinbarkeit des Aussehens würde aber bei dem Feind keine Erinnerung an seine unangenehme Erfahrung hinterlassen, die Art wäre beständig probeweisen Angriffen ausgesetzt und in ihrem Bestand gefährdet. Daher tragen solche irgendwie ungenießbaren oder bewehrten Geschöpfe sehr oft ein Kleid aus lebhaften, ja grellen Farben oder mit großen Gegensätzen in der Zeichnung, um damit den Gegnern ins Auge zu fallen. Eine derartige Tracht gibt nämlich die Veranlassung, daß ein unerfahrener Gegner, wenn er einige Male rersucht hat, solche Speise zu verzehren, das auffallende Bild in seinem Gedächtnis mit der Erfahrung von dessen Unverwendbarkeit verbindet und künftig nicht daran rührt. Diese Erscheinung, die eben zumeist durch Farben ausgedrückt ist, stellt also ein warnendes Zeichen dar, das feindlichen Angriffen vorbeugt; daher die Benennung. 
Wenn auch die Erziehung der gewöhnlichsten Verfolger immer wieder einer Anzahl Artangehörigen das Leben kostet, so hat doch die Art im ganzen weniger Einbuße an ihrem Bestand, und deshalb ist die Warnfärbung ein Schutzmittel. Tiere mit Warnfärbung scheinen ein instinktives Bewußtsein des darin liegenden Schutzes zu haben, denn sie pflegen eine Lebensweise zu führen, die sie leicht sichtbar macht; sie verschmähen Deckung, lieben das helle Licht oder fliegen frei umher, ihre Bewegungen sind langsam, und alle diese Äußerungen stehen manchmal in auffallendem Gegensatz zum Gehaben nah verwandter Arten, die kein Warnkleid besitzen. Ich werde künftig nach dem Vorgang E. Haases für den Besitz aller genannten Verteidigungsmittel der Kürze halber den Ausdruck Immunität verwenden, mit dem Zugeständnis, daß er dem Wortsinn entgegen nur eingeschränkte Geltung hat, ferner für Warnerscheinungen die von. Poulton ${ }^{1}$ ) erdachte Bezeichnung Aposem, aposematisch verwenden.

Es ist Wallace, dem nach Darwins Zeugnis ${ }^{2}$ ) das Verdienst zukommt, die biologische Beziehung zwischen Immunität und A posemen erkannt zu haben. Als D ar w in bei seinen Untersuchungen über die geschlechtlichen Auszeichnungen der Tiere in Verlegenheit war, wie die auffallende Zeichnung mancher Raupen zu deuten sei, wies ihn sein Freund auf den Umstand hin, daß für diese zarten Tiere schon ein Bif oder Schnabelhieb eines Vogels verderblich sein, also selbst ein Ekelgeschmack nur einen ungenügenden Schutz bieten würde, wenn nicht auffallende Merkmale der Raupe die Sicherheit brächten, sofort und mit Bestimmtheit von alien Vögeln und anderen Tieren als ungenießbar erkannt zu werden. Diese Theorie wurde alsbald an den grell gezeichneten Raupen vom Blausieb (Diloba coeruleocephala), Ringelspinner (Malacosoma neustria L.), Widderchen (Zygaena filipendulae) und anderen Arten durch Entomologen erprobt, indem man sie Käfigvögeln vorsetzte, zum Teil auch das Verhalten freilebender Insektenfresser daraufhin beobachtete, und mit wenigen Ausnahmen bestätigt gefunden; Poulton und spätere haben bei zahlreichen Versuchen mit Fröschen und Eidechsen dieselbe Erfahrung gemacht ${ }^{3}$ ). Die aposematische Tracht der Raupen zeigt gewöhnlich eine abwechselnde Verteilung

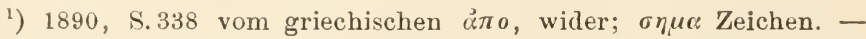
2) Die geschlechtliche Zuchtwahl, deutsch von H. Schmidt, S. 83 (1909). - ${ }^{3}$ ) Poultons Zusammenstellung in Proc. Zool. Soc. 1887, S. $191 \mathrm{f}$. 
von leuchtendem Gelb bis Orange und tiefem Schwarz auf weißlichem Grund; ähnliche Gegensätze bietet auch die Oberfläche der sehr sichtbar lebenden Afterraupen gewisser Blattwespen (Lophyrus), die meines Wissens kein Vogel behelligt. Hier wie dort ist es bemerkenswert, daß gerade solche immunen Raupen durch geselliges Leben, Massenansammlungen an der Fraßpflanze usw. die Sichtbarkeit ihrer Aposeme zu steigern scheinen. Geselliges Vorkommen scheint auch gänzlich die Stelle der Warnfarbe vertreten zu können - man denke an die von den meisten Tieren gemiedenen Ameisen!

Der Gegensatz von Gelb und Schwarz dient überhaupt häufig als Warnfarbe immuner Tiere unter den Insekten und Wirbeltieren. Als Beispiele der ersteren sei die Käferfamilie der Weichkäfer (Malacodermata) genannt, wofür schon unsere hiesige Gattung Telephorus Belege liefert, dann namentlich deren tropische Unterfamilie der Lycinae, die größtenteils gelbes Halsschild und gelbe Flügeldecken mit scharf abstechenden schwarzen Binden haben (Fig. 14 a bis 16 a). Ähnliches gilt von vielen Blasenkäfern (Cantharidae), z. B. der Gattung MIylabris, und den Erotylidae; auch die Blattkäfer (Phytophaga) und Marienkäfer (Coccinellidae) zeigen häufig diese Farbenzusammenstellung neben anderen Mustern von aposematischer Bedeutung ${ }^{1}$ ). Dab diese auch ihre Wirkung tut, lehren viele Beobachtungen an gefangenen Insektenfressern ${ }^{2}$ ). Hierher gehört auch die Bindenzeichnung so vieler stacheltragender Hautflügler - Bienen, Wespen und größerer Schlupfwespen namentlich in der Alten Welt, und auch bei den Wirbeltieren kommt sie vor. Wir haben bei uns einen sehr bezeichnenden Fall im Feuersalamander (Salamandra maculosa), der auf tiefschwarzem Grund mit großen dottergelben Flecken gezeichnet ist; er sucht zwar nur bei feuchtem Wetter das Freie, kriecht dann aber mit sehr langsamen Bewegungen ohne Scheu umher - alle diese Eigenschaften im Einklang mit seiner Giftigkeit, die auf der Absonderung zahlreicher Hautdrüsen beruht und ihn vor Angriffen aller größeren Feinde Sicherheit gibt. Unter den Froschlurchen der Tropen haben Darwin und Belt ganz entsprechende Fälle beobachtet (vgl. S. 74). Dem Feuersalamander recht ähnlich in

$\left.{ }^{1}\right)$ Aufzählung der immunen Käferfamilien bei Donisthorpe 1901, S. 354 f. und Poulton bei Marshall 1902, S. 393. - ${ }^{2}$ ) Marshall 1902, S. 377 f.; Poulton, Proc. Zool. Soc. 1887, S. 191 f. 
Gestalt und Farbe, nur bedeutend größer, ist die mexikanische Krustenechse (Heloderma in zwei Arten) und dadurch von allen Eidechsen ihrer Heimat scharf unterschieden; daß es sich hier, im Einklang mit der Lebensweise, ebenfalls um ein Aposem handelt, beweist der Umstand, daß sie die einzige Eidechse mit Giftzähnen ist.

Eine andere bei immunen Insekten häufige Kontrastzeichnung wird von Schwarz und Karminrot gebildet. Wir finden sie bei manchen Coccinelliden und anderen Käfern der bereits aufgezählten Familien, namentlich aber bei gewissen Schmetterlingen, die alle

Fig. 4.

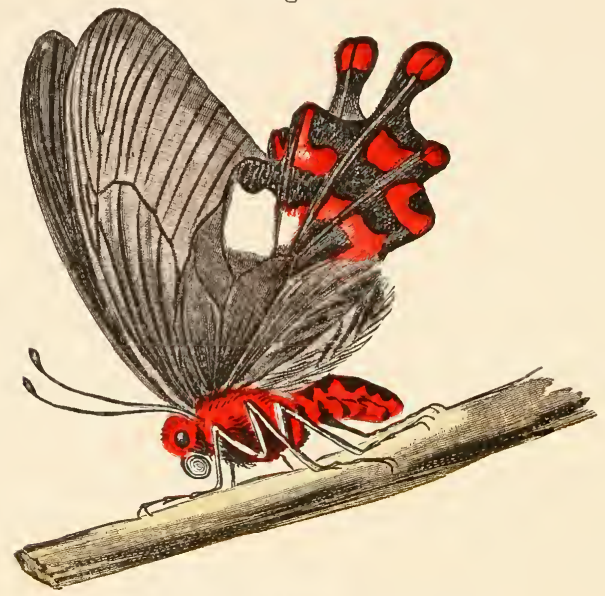

Pharmacophagus desaratu.

Original, verkl.

Züge der Immunität aufweisen und an ihren Plätzen häufig bis gemein sind. Bei uns zählen dazu die Widderchen (Zygaena L.), kleine, tagfliegende Heteroceren, z. B. das gemeine "Blutströpfchen" (Z. filipendulae) und gewisse Bärenspinner, z. B. der Kreuzkrantspinner (Euchelia jacobaeae I.) mit schwarzen, karminrot gegezeichneten Vorder- und ganz roten Hinterflügeln. Obwohl sie in der hellsten Sonne frei umherflattern oder an Blüten sitzen, zeigen sie nicht die geringste Scheu, da ihre scharfen Körpersäfte sie vor Feinden schützen. In den Tropen gibt es eine ganze artenreiche Gruppe der Schwalbenschwänze (Papilio L., Subg. Pharmacophagus 
Haase), die bei sonst rorwiegend schwarzen Tönen an Leib und Hinterflügeln leuchtend rote Abzeichen tragen und im Sitzen und Fliegen zur Geltung bringen (Fig 4, 24a); man vermutet, daß die nachgewiesene Immunität dieser Falter auf die Nahrung ihrer Raupen zurückgeht, die von giftigen Aristolochien leben. Zu diesen Aposemen liefert eine formenreiche Gattung Singzikaden (Huechys Am. u. Serv.) von Südasien ein treffendes Gegenstück. Ihre Arten sind ungefähr von der Größe einer Hornisse, haben schwarze oder weiß und schwarz gestreifte Flügel, schwarze Brust mit blutroten Flecken und ganz roten Hinterleib; die Körpersäfte sind so scharf, daß man in China Zugpflaster daraus bereitet, ein Schutzmittel, auf das sich jedenfalls ihr sehr häufiges Torkommen stützt. Annandale ${ }^{1}$ ) sagt über die Gattung, daß sie auf Malakka in Gegensatz zur Mehrzahl der Singzikaden ein Tagleben führe und sich namentlich zur Mittagszeit frei auf Büschen herumtriebe; ergriffen zirpen die Huechys nicht, wie es andere Cicadiden zur Abwehr des Feindes tun. Also Lebensgewohnheiten, die ganz in die Regel passen. Um die anderen Gliederfüßer des Festlandes nicht ganz zu übergehen, sei auf den Bericht Armits ${ }^{2}$ ) von einer Spinne in Queensland hingewiesen, deren giftiger Biß bei Mensch und Tier gefürchtet ist; dem durch einen roten Fleck auf schwarzem Körper gekennzeichneten Tier weichen selbst die spinnenraubenden Grabwespen aus. Auch unsere großen, nackten Wegschnecken (Limas cincreus und Arion empiricorum) fallen unter diesen Gesichtspunkt, nur sind sie entweder gläuzend schwarz oder ziegelrot; so leicht sie bei ihrer tagliebenden Lebensweise einen stattlichen Bissen für Tögel, Dachs, Fuchs usw. ergeben würden, rührt sie doch kein solcher Schneckenliebhaber zum zweiten Male an. S'chließlich sei eines Säugetieres gedacht, dessen ungewöhnlich kontrastreiche Zeichnung im Einklang mit seinem Benehmen wohl eine echte Warnfarbe darstellt. des Stinktieres (Mekhitis). Diese Marderart ist schwarz mit zwei breiten weißen Streifen an den Flanken und trägt ihren besonder's buschigen Schweif bei Beunruhigung hoch aufgerichtet, eine Erscheinung, die sie auch in der Dämmerung und in mondhellen Nächten sehr hervortreten läßt. Durch seinen fürchterlich stinkenden Drüsensaft im Besitz einer fast unfehlbaren Verteidigungswaffe, kann das Tier alle Tor-

1) Proc. Zool. Soc. 1900, S. 839 f. - "2) Nature 18, 642 (1878). 
sicht entbehren und durch sein Warnsignal auch unvorsichtige Gegner von einem unüberlegten Angriff fernhalten.

Wie im letzten Beispiel, so können auch in anderen Fällen Schwarz und Weif durch ihren Gegensatz aposematisch wirken, was uns im IV. Abschnitt wiederholt begegnen wird, doch können im Bereich des Insektenlebens auch viele anderen Farbenzusammenstellungen diesem Zweck dienen, soweit sie grell genug hervortreten, um sich leicht dem Gedächtnis einzuprägen. Wenn trotzdem, im Vergleich mit der sonstigen Mannigfaltigkeit der Zeichnung, bei dieser Tierklasse immer wiederkehrende aposematische Muster verhältnismäßig selten sind, so läßt sich die Erklärung dafür nach Poulton ${ }^{1}$ ) von den Voraussetzungen der Warnfärbung biologisch ableiten. Ehe diese ihren Inhabern nützen kann, muß in dem betreffenden Gebiet jeder junge Insektenfresser mit dem Verzehren schlechte Erfahrungen gemacht haben, bis sich ihm die Verbindung von Ekel oder Schrecken mit gewissen Gesichtseindrücken ins Gedächtnis geprägt hat. Wenn nun jedes immune Beutetier sein besonderes Aussehen hätte, so würde das Sammeln von Erfahrungen sehr lange dauern; wenn dagegen nur eine beschränkte Anzahl Typen vorhanden ist, damn werden jedenfalls viel weniger Eindrücke hinreichen, um ein Vorurteil gegen jedes Kerbtier zu befestigen, das eine ähnliche Erscheinung hat.

Nachdem Poulton die Farbmuster aller Insektenarten verglichen hatte, die sich durch Versuche als immun erwiesen, kam er $\mathrm{zu}$ folgenden Ergebnissen:

Stärkste Gegensätze und demzufolge die stärkste Wirkung auf das Auge kerbtierfressender Wirbeltiere erzielen Schwarz und Weif, demnächst Schwarz — oder sehr dunkle Tinten anderer Farben - und Gelb bis Rot; diese Zusammenstellungen bilden die meisten warnenden Trachten. Auch die Anordnung pflegt sehr gegensätzlich und übersichtlich zu sein; es sind Ringe von verschiedener Farbe oder Längsbinden, die miteinander abwechseln, beiderlei Zeichnung besonders der zylindrischen Körperform von Raupen usw. angepaßt; ferner Flecke auf kontrastierendem Grund einer großen Fläche, wie den Schmetterlingsflügeln. Endlich scheinen bei Insekten auch einfache, glänzende Metallfarben als Warnsignal zu dienen, wenn sie nämlich mit einem

1) 1890 , S. $184-186$. 
besonders harten Chitinpanzer als Bedingung für die Ungenie@barkeit verbunden sind; dahin würden mehrere Käferfamilien, besonders aus den Lamellicorniern (Cetoniidae und Rutelidae) und die Curculionidae, gehören; vielleicht auch viele tropische Wanzen (Scutellerinae und Graphosomatinae). Magenuntersuchungen freilebender Vögel liefern jedoch hierfür keine Bestätigung ${ }^{1}$ ). Aus dieser Einfachheit und regelmäßigen Triederkehr des äußeren Bildes gehen folgende Vorteile hervor: 1. eine beschränkte Zahl ron Farben und Mustern lenkt wirksam die Aufmerksamkeit von Feinden auf sich und prägt sich ihrem Gedächtnis bald ein; 2. deren Verständnis für die Bedeutung dieser Warnfarben wächst rasch, wenn sie nur wenige Typen kennen zu lernen brauchen: 3. einer immunen Art von seltenem Vorkommen erwächst daraus noch der Nutzen, daß sie mit solchen verwechselt werden kann, die wohlbekannt und besonders gemieden sind.

Da die Beschreibung weiterer Fälle als der schon genannten für die allgemeine Betrachtung wenig Neues herzutragen würde, so möge sich gleich eine Zusammenfassung der Erfahrungen über Immunität und Warnfarben anschlie@en, die sich zwar nur auf die Insekten bezieht, aber dadurch den Anspruch für sich hat, auf dem reichsten Stoff und den zahlreichsten Angaben zu beruhen. Wir verdanken sie wiederum Poulton ${ }^{2}$ ), der die Ergebnisse zahlreicher eigener und fremder Versuche zusammengestellt hat, um daraus für allerhand Insekten ihre anlockende oder abstoßende Stellung in den Augen insektivorer Wirbeltiere (Tögel, Eidechsen und Frösche) zu ermitteln; die Beobachtungen wurden meistens an Käfigtieren, aber unter möglichst natürlichen Bedingungen gewonnen. Daraus ergaben sich folgende Schlüsse:

1. Sehr auffallend gefärbte Insekten besitzen fast immer eine für Räuber unangenehme Eigenschaft, indem ihren Geweben und Säften ein unangenehmer Geruch oder Geschmack anhaftet oder indem sie Waffen, wie Gifthaare und Wehrstacheln, tragen oder dem Terzehren mechanische Hindernisse (Dornen, sehr harten Panzer) bieten.

2. Die auffallende Erscheinung wird hervorgebracht durch starke Kontrastfarben, lange Behaarung oder Haarbüschel, Körper-

\footnotetext{
1) Vgl. Dahl. - ${ }^{2}$ ) 1887, S. 266. 
haltung, geselliges Auftreten, heftige Bewegungen bei Bedrohung durch einen Feind.

3. Nur in wenigen Ausnahmen ist eine auffallende Erscheinung nicht von abstoßenden Eigenschaften begleitet.

t. Bei den verschiedensten aposematischen Arten wiederholen sich immer ein und dieselben Farbmuster. Auf diese Weise brauchen die Feinde nur wenige Typen kennen zu lernen, und zwar sind diese 'Typen leicht kenntlich.

5. Auch bei den Insektenfressern ist der Geschmack sehr verschieden, und ein hungriger Räuber scheut sich vor keiner Warnerscheinung und vor keinem ekelhaften Geschmack.

6. Kerbtiere, die sich Nachstellungen durch kryptische Eigenschaften oder durch Schnelligkeit oder durch verborgene Lebensweise entziehen, sind im allgemeinen nicht immun.

7. Auch bedeutende Körpergröße dürfte ein Schutzmittel gegen kleinere Feinde sein.

Wenn wir aus den bisherigen Anführungen von Tatsachen und allgemeinen Schlußfolgerungen über Warnfärbung die Summe ziehen, so ergibt sich nach meinem Dafürhalten, daß die Anschauungen darüber sich auf einen viel höheren Grad von Wahrscheinlichkeit stützen, als ihn die Schutzfärbungstheorie beanspruchen kann. Diese ruht bis heute wesentlich auf dem menschlichen Standpunkte und auf deszendenz-theoretischen Voraussetzungen, dort aber gruppieren sich die Fälle unter eine sehr beschränkte Zahl von Erscheinungsformen; die Probe aufs Exempel ist durch den Versuch leicht gemacht und nicht viel schwerer durch Beobachtung im Freien, und der biologische Vorteil ist positiv und dauernd, nicht wie bei der Schutzfärbung nur auf den Zufall, nämlich die Unaufmerksamkeit des Gegners gegründet. Es liegt deshalb die Frage sehr nahe, warum sich die aposematische Bekleidung verhältnismäßig viel seltener findet als die kryptische Verkleidung? Wenn wir im Auge behalten, daß Warnfärbung als solche irgend eine Art Immunität zur Grundlage hat, so schränken die aposematischen Arten im allgemeinen den Ernährungsbereich der räuberischen Tiere ihres Wohngebietes ein, und zwar desto mehr, je größer ihre Zahl ist und je häufiger die eine oder andere ist. Dadurch, daß gerade eine individuenreiche Art durch ihre Entwickelung zu einer aposematischen Tracht gelangt, muß sie die Befriedigung des Nahrungsbedürfnisses ihrer 
Feinde auf andere, nicht geschützte Arten lenken. Falls diese nun auch durch irgend welchen Entwickelungsanlaß auf den Weg zur Immunität kämen, so könnten die Räuber in die Nötigung versetzt werden, unter Überwindung ihres Ekels die unangenehme Kost anzunehmen (siehe oben Punkt 5), und damit würde der Torteil der Warnfärbung als eines auffallenden Kennzeichens in das Gegenteil verkehrt, sie würde die Entdeckung der Beute gerade erleichtern. Demnach ist es für den Daseinskampf in einem umgrenzten Gebiete wichtig, daß seine Lebensgemeinschaft nur eine mäßige Anzahl aposematischer Arten enthält.

Es gilt jetzt, den Einwänden gegen die Anschauung von der Warnfärbung näherzutreten. Ich war bis jetzt von der gewöhnlichen Voraussetzung ausgegangen, daß die aposematischen Trachten sich als Folge eines Grades von Immunität entwickelt hätten, indem die Naturauslese nur die auffallend gefärbten Einzelwesen und Arten unter der Menge der Immunen übrig ließ. Wie bei der Schutzfärbung, so ist auch bei diesem Gegenstande eine derartige Kausalität weder denknotwendig, noch der einzig mögliche Entwickelungsweg. Es ist ebensowohl denkbar, dab rein physiologische Torgänge in der Tierhaut gewisse Stoffe ablagern, die erstens für andere Tiere ekelhaft oder giftig, zweitens aber grell gefärbt sind. Daß lebhafte Pigmente als Nahrung aufgenommen unverändert in die Körperdecken gelangen können, ist längst erwiesen: Kanarienvögel mit spanischem Pfeffer gefüttert bekommen rotes Gefieder; bei einem Borstenwurm (Syllide) enthält nach Eisig die Haut dasselbe orangegelbe Pigment wie der Schwamm (Reniera aurantiaca), von dem er lebt ${ }^{1}$ ); von Capitella wird verzehrter und verdauter Karmin in der Haut aufgespeichert ${ }^{2}$ ), und weitere Fälle dieser Art sind bei Beddard und Tosseler ${ }^{3}$ ) vermerkt. Aber auch der eigene Stoffwechsel kann eine derartige Verknüpfung herbeiführen. Haben wir doch weitere Beobachtungen von Eisig, wonach die gelben Nierenexkrete von Capitella als gelbes Pigment in die Körperbedeckung gelangen, und nach Untersuchungen von F. G. Hopkins und von Urech können die lebhaften Farben von Schmetterlingsflügeln aus Harnsäureverbindungen herrühren; $\mathrm{Ha}$ ase endlich hat viele Hinweise gebracht ${ }^{4}$,

1) Fauna u. Flora d. Golfs v. Neapel 16, 2. Stück, 775 (1887). $\left.{ }^{2}\right)$ Ebend., S. 767. — ${ }^{3}$ ) Beddard, S. 126 f. (1892); Vosseler, S. 185 (1909). - $\left.{ }^{4}\right) 1893$. 
wonach die Immunität ganzer Gruppen von aposematischen Falteru mit der Ernährung ihrer Raupen von Giftpflanzen, wie Aristolochien und Solaneen, zusammenhängen soll. Dann ist der nächste Schritt, daß solche Pigmente für Feinde widrig oder schädlich sind, bei ihrer überaus mannigfaltigen chemischen Zusammensetzung ohne besonderes Walten des Zufalls leicht getan und damit die Ends tufe, der Effekt, einer Verbindung von Vorgängen erreicht, welche Endstufe der Darwinismus mit umgekehrter Schlußfolgerung für den Ausgangspunkt erklärt und damit eine ungerechtfertigte Verallgemeinerung begeht. WVenn man also den oben dargelegten Torgang als die nächstliegende Grundlage betrachtet, so ist dadurch der Wirksamkeit selektiver Entwickelungseinflüsse durchaus noch nicht der Weg versperrt. Sobald nämlich eine rein physiologische, unabhängig von äußeren Bedingungen entstandene Färbung sich so weiter entwickelt, daß sie im Daseinskampfe Bedeutung gewinnt, dann kann ihr Ausbildungsgrad bei den einzelnen Trägern Selektionswert erhalten und sich unterm Einflusse der Naturauslese in zweckmäßiger Weise weiter entfalten. Dagegen dürfte eine unmittelbare Abhängigkeit zwischen dem Besitze eines Giftstachels bei weiblichen Hautflüglern und der Tatsache bestehen, daß solchen meistens eine Warnfärbung eigen ist, denn die Immunität dieser Insekten ist ganz anderer, aktiver Art als ein auf der Zusammensetzung von Organen oder Körperflüssigkeiten fußender passiver Schutz. Gleiches gilt von den Aposemen bei Giftschlangen usf.

Allerdings müssen wir im Auge behalten, daß der Nutzen der Warnfärbung nicht unbeschränkt ist. Im Hinblick zunächst auf die Kerbtiere ist sie wohl größtenteils ${ }^{1}$ ) wirkungslos gegen die Schmarotzerinsekten, wie Schlupfwespen und Raupenfliegen, die durch Unterbringung ihrer Brut im Körper von Insektenlarven oder in den Eiern allein schon die Vermehrung in hohem Grade einschränken. Während z. B. die Raupen des Kohlweißlings (Pieris brassicae L.) von Vögeln nicht verzehrt werden, fallen sie den Ichneumoniden in solchem Umfange anheim, daß Poulton von 533 Raupen 424 umkommen sah ${ }^{2}$ ). Auch die vor

$\left.{ }^{1}\right)$ Dieser Punkt bedarf noch genauerer Untersuchung. Haase stellte fest (1893, S. 100, Anm.), daß die Raupen der immunen Pieride Delias hirta Cram. sämtlich zu Faltern wurden, wenn Loranthus die Futterpflanze war, während die von Anona squamosa L. gesammelten Puppen sämtlich angestochen waren. - ${ }^{2}$ ) 1890, S. 182. 
Wirbeltieren ziemlich geschützte Schmetterlingsfamilie der Danaidae stellt den Schmarotzern einen großen Anteil ihrer Artbestände als Opfer ${ }^{1}$ ).

Gegen Raubinsekten scheint die Warnfärbung ebenfalls wenig zu leisten, erstens deshalb, weil das Sehvermögen der Insekten nach Plateaus Versuchen weniger auf der Wahrnehmung von Farben und Umrissen als auf der von Bewegungen, vom Verhältnis zwischen Licht und Schatten u. dgl. beruht; zweitens, weil ihre Geschmacks- und Geruchsempfindung ron widrigen Eigenschaften weniger berührt wird. Hierüber liegen schon manche Beobachtungen vor. Die großen Raubfliegen (Asilidae) verzehren ebensowohl Blatt- und Blasenkäfer (Galerucidae, Cantharidae) wie sonst gemiedene Schmetterlinge aus den Familien der Danainue, Acracinue und Pievidae, sie scheinen geradezu alle Kerfe, die sie der Größe nach bewältigen können, zu verzehren, ohne sich an Ekelsäfte, harten Panzer und selbst Wehrstachel zu stoßen; auch die Fangheuschrecken (Mantidae) sind für Warnfarben unempfänglich ${ }^{2}$ ), doch scheinen die Libellen gelegentlich wählerischer zu sein ${ }^{3}$ ). Doch auch die Wirbeltiere, selbstverständlich sind nur "Augentiere" beteiligt, zeigen Unterschiede in der Empfänglichkeit. Die insektenfressenden Tögel, die im allgemeinen viel Raupen verzehren, sind wohl am heikelsten, da sie nach Beobachtungen, die J. Weir im Freien und in der Gefangenschaft machte ${ }^{4}$ ), behaarten und bedornten Raupen ausweichen (eine Ausnahme macht der Kuckuck); andererseits werden Raupen, die von ihnen im allgemeinen nichts zu fürchten haben, wie die des Ringelspinners (Mulacosoma neustria L.), gelegentlich ohne Umstände angenommen ${ }^{5}$ ). Über das Verhalten gegen aposematische Schmetterlinge gibt es zahlreiche Erfahrungen, die im vierten Abschnitt Besprechung finden werden. Eidechsen sind nach Prochnows Versuchen i) gegen Raupen mit obiger Ausstattung nicht so ablehnend wie Tögel. Endlich sei der Schlangen gedacht, von denen nachweislich nicht wenige Gattungen (z. B. Tropidonotus, Heterodon, Leptodira) sich auch durch die schärfsten Hautsekrete nicht abhalten lassen, Lurche wie Kröten

$\left.{ }^{1}\right)$ Marshall 1902, S. 337. - ${ }^{2}$ ) Poulton 1906, S. 363; Marshall 1902, S. 322, 336. - $\left.{ }^{3}\right)$ Hahnel, Iris 3, 161 (1890). - ${ }^{4}$ ) Trans. Ent. Soc., S. 337-339. — $\left.{ }^{5}\right)$ Slevogt nach Insektenbörse 1S, 89 (1901). 6) 1907 , S. 35 . 
und den Feuersalamander regelmäßig zu verzehren. Wrerner zieht aus diesen und ähnlichen Tatsachen wieder die weitgehende Folgerung ${ }^{1}$ ), daß es nur nebensächliche Feinde seien, die den von uns für geschützt angesprochenen Tieren ausweichen; dagegen hätten sich die wirklich auf sie angewiesenen Gegner längst an die Abwehrmittel gewöhnt. Allerdings sind große Raubfliegen der Gattung Laphria die ärgsten Verfolger der Marienkäfer, die u. a. von Fröschen verschmäht werden; ebenso werden die Raupen von Cladius, einer Gattung Blattwespen, zwar von Wirbeltieren nicht genommen, begierig aber von Fangheuschrecken trotz der kräftigen Abwehrbewegungen, und eine ganze, in warmen Ländern heimische Togelfamilie, die Bienenfresser (Meropidae), hat ihren Namen davon bekommen, daß sie die bestachelten Hautflügler ohne Bedenken verschlingt - wie es unter den Kerbtieren die Raubfliegen tun. Auf der anderen Seite kam Marshall2) bei seinen ausgedehnten Fütterungsversuchen mit aposematischen Faltern Südafrikas bei Eidechsen zu keinem klaren Ergebnisse, weil sie Schmetterlinge überhaupt verschmähten; die dortigen Eidechsen scheinen sich vielmehr auf eine bestimmte, noch unbekannte Nahrung zu beschränken.

In der scharfen Fassung und spärlichen Beweisführung, in der Werner seiner Geringschätzung der Warnfärbung Ausdruck gibt, kann ich ihm nicht beipflichten. Wenn man nur die Insekten als zahlreiche Träger dieser Eigenschaft ins Auge faßt, aber die räuberischen Insekten außer Betracht läßt, so bleiben immer mehrere große Gruppen von Wirbeltieren als wichtige Kerbtierjäger übrig: Frösche, Eidechsen und namentlich Tögel. Über diese haben wir zahlreiche Erfahrungen aus Freiheit und Gefangenschaft, Heimat und Fremde, die sich vielfach auf das sehr zuverlässige Verfahren der Magenuntersuchung stützen. Wenn nämlich Vertreter einer gemeinen Gattung, sagen wir von Käfern, massenhaft in Vogelmägen vorkommen, so ist anzunehmen, daß diese Gattung keine abstoßenden Eigenschaften hat. Wenn aber eine andere ebenso gemeine Gattung an derselben Örtlichkeit zur gleichen Zeit verschont bleibt, so ist der Rückschluß gestattet, daß sie immun ist und höchstens aus Hunger verzehrt wird. Zum Beispiel sind die Singrögel, zu denen die meisten

1) 1908 , S. $\left.574 .-{ }^{2}\right) 1902$, S. 338. 
Togelarten zählen, so eifrige Raupenfresser und vernichten bei ihrer Häufigkeit und ihrem starken Nahrungsbedürfnis so viele, daß man sie nicht für nebensächliche Gegner erklären darf. Wenn aber die alltägliche Beobachtung zeigt, daß gemeine Raupenarten gleich familienweise bei öffentlicher Lebensweise ungeschmälert heranwachsen, und wenn diese Arten Merkmale von Immunität tragen, so ist der Schluß naheliegend, daß sie nur diesen ihre Verschonung durch die Vögel verdanken. Dasselbe gilt für manche Käfer, wobei Ausnahmen wenig besagen. Ich kann mich aus diesen und den schon vorher besprochenen allgemeinen Gründen nicht zu der Meinung Werners bekennen, daß die Terbindung von Immunität und auffallender Farbe für die Träger eine nebensächliche Eigenschaft bedeute, halte diese Meinung vielmehr so lange für anfechtbarer als die Warnfärbungstheorie, bis sie zahlreichere Gegenbeweise als bisher vorbringen kann.

Zum Schluf noch eine Gegenüberstellung der unterscheidenden Merkmale von Schutzfärbung nebst schützender Ähnlichkeit und von Warnfärbung:

Die kryptische Erscheinung ist wehrlosen, genießbaren, viel verfolgten Tieren eigen, die ihr Dasein dadurch zu verbergen trachten: die aposematische Erscheinung solchen, die durch passive oder aktive Eigenschaften ihre an sich stärkeren Feinde abhalten und sich probeweiser Angriffe dadurch erwehren, dab sie eine leicht kenntliche Tracht zur Schau tragen, indem sie Deckung verschmähen.

Im Anschlu@ an diesen Abschnitt sei eines weiteren auf gewisser Färbung beruhenden Schutzmittels gedacht, das zwanglos weder unter Schutzfärbung noch unter Warnfärbung gerechnet werden kann: die Schreckfärbung. Sie ist wie die erstere wehrlosen Geschöpfen eigen und dient wie die zweite zur Abwehr ron Angriffen, aber sie kommt im Unterschied ron beiden nicht dauernd zur Geltung, sondern tritt nur vor übergehend in Wirksamkeit mit dem Ziele, einen Feind durch plötzliches Entgegenstellen einer für ihn ungewöhnlichen, absonderlichen Erscheinung $\mathrm{zu}$ verscheuchen. Um dies $\mathrm{zu}$ veranschaulichen, will ich das von Japha ${ }^{1}$ ) gut durchgearbeitete Beispiel unseres bekannten Abendpfauenauges, Smerinthus ocellata, wiedergeben.

1) 1909 . 
Tagsüber verharren diese Falter unbeweglich in ihrer Ruhestellung am Stamme, oder noch häufiger an Zweigen von Bäumen, meistens an Weiden als der Nährpflanze ihrer Raupen. Die Flügel sind etwas schräg nach hinten vom Körper abgespreizt, die Fühler werden nach hinten gelegt und unter den Vorderflügeln versteckt. Seine Hinterflügel schiebt der Falter so weit unter die vorderen, daß nur die Spitzen, ein kleiner Teil des Außenrandes und fast der ganze Vorderrand zu sehen sind, das sind aber die mit der Färbung des vorderen Paares fast übereinstimmenden Teile, während der rosenrote Bezirk und der Augenfleck völlig verdeckt sind. Von unten gesehen erscheint es umgekehrt, da verbergen die unscheinbar getönten Hinterflügel die große rosenrote Fläche der vorderen. In dieser Haltung gleicht der Schmetterling außerordentlich einem Büschel vertrockneter Weidenblätter, und zwar auch auf der Unterseite, was nicht unwesentlich ist, weil er meistens frei an Zweigen hängt. Wie täuschend der so erzielte Eindruck ist, weiß jeder Sammler, wie denn bereits der alte Roesel von Rosenhof in seinen "Insektenbelustigungen" sagte ${ }^{1}$ ): "Durch diese Stellung betrügen sie unser Auge dergestalt, daß man sie bei ohngefährer Erblickung öfter vor ein vertrocknetes Blatt als vor einen Papilion ansiehet, und daher am Tage, da sie sonst am leichtesten zu erhaschen wären, ihrer hundert übersehet, ehe man einen davon erkennet." Zum Aufgeben dieser Stellung ist das Abendpfauenauge durch schwache Reize, wie geringe Erschütterung, nicht so leicht $\mathrm{zu}$ bewegen wie andere Schwärmer; freiwillig fliegt es bei Tage überhaupt nicht, auch noch nicht während der Dämmerung. Erst bei Berührung seines Körpers, etwa bei einem leichten Stoß gegen Kopf oder Brust, tritt folgende, äußerst bezeichnende Wirkung ein: Blitzschnell werden die Vorderflügel in dachförmige Lage gebracht und gleichzeitig die Hinterflügel aus der Deckung gezogen, so daß ihr leuchtendes Rot und die Augenzeichnung zum Vorschein kommen; außerdem werden die Fühler nach vorwärts gerichtet und der Kopf eingezogen. Hand in Hand damit geht ein ganz eigentümliches, sehr kräftiges, mäßig rasch wiederholtes Wippen mit dem Vorderkörper; zum Fortfliegen bringt man den Falter durch eine derartige Störung niemals. Diese Körperstellung und -bewegung wird einige Sekunden bis eine halbe Minute beibehalten.

1) 1747 , Bd. 1, 3. Sammlung, Nr. 1, Taf. 1. 
Über die Wirkung dieser Schreckerscheinung auf Vögel hat Standfuß $\beta^{1}$ ) folgende Tersuche vorgenommen: Eine Anzahl Pfauenaugen wurde einer Nachtigall, einem Sprosser, einer Mönchsgrasmücke und zwei Rotkehlchen, alle in besonderen Käfigen befindlich, dargeboten; die Tögel waren schon mehrere Jahre in Gefangenschaft, aber in erwachsenem Alter eingebracht worden. Alle hackten sofort nach dem Falter, der alsbald die Schreckstellung einnahm, worauf fast alle Vögel die Flucht ergriffen und sich dem Insekt nicht wieder zu nähern wagten. Nur der Sprosser ließ sich nicht irre machen, sondern packte und verzehrte sein Exemplar; allerdings war er schon seit Jahren mit lebenden Kerbtieren, auch mit großen Schmetterlingen gefüttert worden. Dagegen wurden Lindenschwärmer (Smerinthus titice L.) ohne Umstände zerrissen und verzehrt: aber es.genügte, ein Pfauenauge beizugeben, um die erstere Art auf Stunden gegen jeden Angriff zu schützen.

Man hat bei diesem seit länger bekannten, aber ron Japha ungenau geschilderten Vorgange die auffallende Augenzeichnung für das wirksame Schreckmittel gehalten, was jener Beobachter dahingestellt sein läßt; jedoch scheinen Wahrnehmungen von Prochnow ${ }^{2}$ ) zu ergeben, daß die ähnliche Zeichnung des Tagpfanenauges (Vanessa io L.) im Freien den Meisen ebenfalls einige Furcht einflößt, obwohl sie nicht in Schreckstellung gezeigt wird. Daß letztere Erscheinung, also das plötzliche Auftauchen der grell hervortretenden Zeichnung, doch das Ausschlaggebende ist, scheint mir aus einer Erfahrung Slevogts hervorzugehen, dem ein Paar Spechtmeisen die toten Abendpfauenaugen auf dem Spannbrette vorm Fenster zerpickten - die unbeweglichen Flecke flößen also keine Furcht ein.

Andere derartige Fälle sind bei Raupen beobachtet worden. Diejenige des großen Weinschwärmers (Chaerocampa elpenor L.) hat oben auf dem vierten und fünften Leibesringe ein paar große augenähnliche Flecke; bedroht zieht sie den Kopf und die vorderen Ringe ein, so daß gerade der vierte dick aufgebläht wird und die Augen auf einem dicken Kopfe zu stehen scheinen (Fig. 5). Die verwandte $C h$. osiris wird erwachsen gegen $15 \mathrm{~cm}$ lang und hat große blaue Augenflecke, was ihr nach Marshall³) große Ähn-

$\left.{ }^{1}\right)$ Mitteil. Schweiz. entom. Ges. 11, 155 (1906). — ${ }^{2}$ ) 1907, S. 56. 3) 1902 , S. 397 . 
lichkeit mit einer Schlange, z. B. der Puffotter (Bitis arietans), gibt. Als er die Raupe einigen gefangenen Pavianen vorsetzte, die viel Insektenlarven verzehren und sich wie alle Affen vor Schlangen sehr fürchten, gerieten sie in fürchterliche Angst. (Veismann ${ }^{1}$ ) deutet an, daf die Weinschwärmerraupe mit ihrer Trutzstellung „kleinere Vögel, Eidechsen und andere Feinde" in die Flucht jage, führt aber nur seine dahingehörigen Beobachtungen an Haushühnern und einem Sperling an. Man könnte noch mancherlei Beispiele solcher zeitweiliger "Schlangenmimikry" heranziehen Pieper's hat für die Liebhaber solcher Vergleiche eine ziemliche Auswahl zusammengestellt ${ }^{2}$ ) - , aber sie bleiben so lange verdächtig, bloße Kinder der menschlichen Einbildungskraft zu sein, wie man ihre Wirkung auf die beteiligten Verfolger nicht kennt.

Fig. 5.

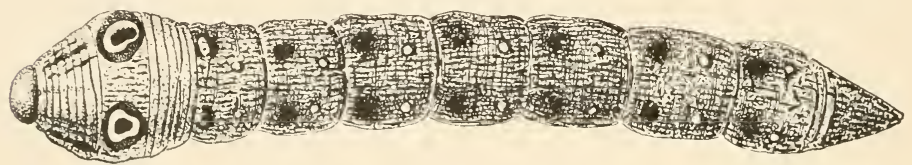

Erwachsene Raupe des großen Weinschwärmers, Chaerocampa elpenor, in Schreckstellung.

Aus Weismann.

Lies gilt namentlich für Weismanns Deutung der großen Augenflecke auf der Flügelunterseite von Caligo Hübn., einer Faltergattung, die gleichzeitig kryptisch geschützt sein soll, und man möchte lächeln, wenn Seitz - allerdings wohl noch in seiner Sturm- und Drangzeit — aus der Schreckstellung des Abendpfauenauges die Wiedergabe des Kopfes einer kleinen Marderart oder einer Katze samt Nasenrücken und spitzen Ohren heraus(leutet $\left.{ }^{3}\right)$ !

Da auch die phantasiereichsten Entdecker von Schreckstellungen, die auf plötzlichem Vorzeigen besonderer Zeichnungen beruhen, bisher nur eine ganz beschränkte Zahl Fälle aufweisen konnten, von denen erst die wenigsten durch Versuche gestützt sind, so darf man schließen, daß die Schreckfarben nur ein vereinzelt angewendetes Schutzmittel der Tiere sind. Wahrscheinlich

1) 1904 , S. $\left.57 .-{ }^{2}\right) 1903$, S. 8, 13. $-{ }^{3}$ ) Zool. Jahrbüch., Abt. f. Syst., :, 95-96 (1887). 


\section{$-\quad 59-$}

gehört ihre Anwendung unter die vielen reflektorischen Bewegungen, welche Tiere bei Bedrohung machen, und erlangen ihre Wirkung nur dadurch, daß dabei an und für sich vorhandene auffallende Zeichnungen besonders zur Geltung kommen; Piepers ${ }^{1}$ ) hat darüber beachtenswerte Ausführungen gemacht. Also auch hier können Eigenschaften, die sich vielleicht in ganz fernliegendem Zusammenhange entwickelt haben, nachträglich in den Bereich des Nützlichen getreten sein, aber dabei gleich wieder die Naturauslese als die alleinig treibende, "allmächtige" Ursache hinzustellen, wie es $\mathrm{W}$ eismann ${ }^{2}$ ) tut, ist reine Dogmatik.
1) 1903 , S. $216 \mathrm{f}$
2) 1903 , S. 59. 


\section{Mimikry oder schiitzende Nachäfflung.}

Es war der hervorragende englische Forschungsieisende und Wandergefährte IVallaces in Südamerika, Henry Walter Bates, der die Lehre von der schützenden Nachäffung oder Mimikry begründet hat; sie besagt kurz folgendes: Es gibt Tiere, die weder durch Schnelligkeit, WVaffen, Gift oder ekelhaften Geschmack, Ähnlichkeit mit der Umgebung usw. geschützt sind, aber anderen aus irgendwelchem Grunde gemiedenen Arten sehr ähnlich sehen, ohne mit ihnen verwandt zu sein. Da sie von ihren Feinden mit den ohnehin gemiedenen Tieren leicht verwechselt werden, weil beider Ähnlichkeit die Verfolger täuscht, so genießen sie den Schutz der immunen Arten mit, haben also von ihrer "Scheinwarnfärbung“ im Daseinskampfe Vorteil. Solche „mimetic analogies", wie Bates sie nennt, waren schon früher vou Entomologen bemerkt worden, so von IV. S. Mac-Leay ${ }^{1}$ ), der auf die Ähnlichkeit einiger Fliegen mit stechenden Hautflüglern hinwies und für reine Analogien ohne nähere systematische Verwandtschaft erklärte. Etwas tieferen Einblick nahmen Kirby und Spence ${ }^{2}$ ), als sie die Mimikry der Hummelfliegen (Volucella) nach Hummeln mit dem Vorteil in Verbindung setzten, unter solchem Deckmantel ihre Eier unentdeckt in die Nester jener einbringen zu können. Die beiden englischen Bahnbrecher der wissenschaftlichen Entomologie hatten übrigens den Ausdruck "Mimicry" schon etwas früher ${ }^{3}$ ) geschaffen, aber auf die schützende Ähnlichkeit beschränkt. Bates aber und seine Nachfolger auf diesem Sondergebiete der Tierbiologie verstanden darunter nur Ähnlichkeiten

$\left.{ }^{1}\right)$ Horae Entomologicae, Part 2, S. 365 (1819-21). - *) An introduction to entomology, 2. ed., 2, 223 (1817). - ${ }^{3}$ ) Nach einem anscheinend nachgeschriebenen Zitate Haases (S. 1) 1816, d. h. in der 1. Auflage der "Introduction", S. 5; mir ist nur die deutsche Übersetzung Okens (1823-33) zugänglich. 
in Form und Farbe zwischen Tieren verschiedener systematischer Stellung, und clieser Lesart mul jetzt alleinige Gültigkeit beigelegt werden, da die Weiterbehandlung des Phänomens durch maßgebende Forscher nur mit dieser Fassung rechnet. Die genaue Erläuterung der Merkmale folgt später, nur sei im voraus bemerkt, daß ich auf die Tersuche, auch bei Pflanzen Mimikry nachzuweisen, nicht eingehe, weil ich kein Urteil habe, wieweit sie begründet sind. Eine Zusammenstellung hat Stäger ${ }^{1}$ ) geliefert, dabei aber schützende Ähnlichkeit und Mimikry vermengt.

Die Tatsachen, auf die sich Bates in seiner grundlegenden Abhandlung ${ }^{2}$ ) stützte, waren folgende: Es gibt in Südamerika mehrere Unterfamilien von Tagfaltern - B. faßte sie damals sämtlich als Familie der Heliconiden zusammen -, die trotz ihrer schmucken, auffallenden Zeichnung so reich an Arten und diese an Einzelwesen sind, daß er daraus schloß, sie müßten ror den Angriffen der falterraubenden Tögel durch widrige Eigenschaften geschützt sein. An denselben Plätzen finden sich aber Arten aus anderen Familien, besonders der Weißlinge oder Pieridae ( "Leptaliden" bei B.), die den „Heliconieren" ungemein ähneln, so daß auch der Sammler manchmal getäuscht wird. Da die Farbenverteilung unter den Heliconiern für die einzelnen Abteilungen durchgängig dieselbe charakteristische ist, während die ähnlichen Arten der Pieriden rom Typus ihrer Gruppe sehr abweichen, so liegt die Folgerung nahe, daß erstere die Vorbilder, letztere die nach ihnen gemodelten Nachahmer sind. Diese Ähnlichkeiten sollten nach Bates in Würdigung der dabei auftretenden biologischen Gesetzmäßigkeiten nicht auf Zufall oder Konvergenz der Eigenschaften beruhen, sondern durch natürliche Zuchtwahl erworben sein mit dem Erfolge, daßs die nachahmenden Arten von Verfolgern leicht mit den Vorbildern verwechselt und wie diese gemieden werden. Er hob endlich besonders die Häufigkeit der nachgeahmten Arten im Verhältnis zu den oft sehr seltenen Nachahmern hervor.

Wenn man von einer inhaltreichen, aber in den Schlußfolgerungen allzu zurückhaltenden Arbeit Gerstäckers ${ }^{3}$ ) absieht, so ist der weitere Ausbau der Mimikrytheorie zunächst Bates' Lands-

1) Natur u. Offenbarung 45, 274-287, 341-348 (1899). - ${ }^{2}$ ) 1861.

- ${ }^{3}$ ) Stett. Ent. Zeitschr. 24, 308 (1863). 
leuten zu verdanken, und zwar wandte sie in klassischen, ebenfalls in den "Transactions of the Linnean Society" niedergelegten Arbeiten A. R. Wallace ${ }^{1}$ ) auf die Schmetterlinge der östlichen Tropen und R. Trimen ${ }^{2}$ ) auf die von Südafrika an. Dem ersteren gelang dabei die wichtige Feststellung, daß manche Arten von Schwalbenschwänzen (Papilio) polymorph sind, d.h. im weiblichen Geschlecht eine und selbst mehrere vom Männchen in Tracht und Gestalt abweichende Erscheinungen besitzen, und er zog daraus die fruchtbare Folgerung, daß diese abweichenden Weibchenformen das Ergebnis einer zur Mimikry führenden (mimetischen) Anpassung seien. Ein Jahrzehnt später trat der deutsche, in Brasilien lebende Naturforscher Fritz Müller mit der scharfsinnigen Erklärung einer bisher unbehobenen Schwierigkeit der Theorie auf ${ }^{3}$ ). Es war Bates nicht entgangen, daß auch zwischen Angehörigen durchaus immuner Gruppen Ähnlichkeiten desselben Grades vorkommen wie in den von ihm behandelten Mimikryverbänden, ohne daß dort ein Schutzbedürfnis als Entwickelungsreiz vorliegt. Von der damals unbestrittenen Annahme ausgehend, daß insektenfressende Vögel die Hauptfeinde der Falter seien, führte Müller aus, daß die jungen Vögel zunächst durch eigene Erfahrung die widrigen Falter ihres Wohngebietes am Aussehen kennen lernen müßten; wenn dann mehrere immune Arten ein und dasselbe Kleid trügen, so verteilte sich von den Opfern der Unerfahrenheit ihrer Gegner die gleiche Zahl auf mehrere Parteien, die bei abweichender Tracht von einer zu bringen wären. Je mehr immune Arten also auf einem Platze ein ähnliches Kleid tragen, desto mehr Angehörige einer jeden haben Aussicht durchzukommen.

Müllers geistvolle Äußerung hat infolge ihrer alsbald von Ifeldola besorgten Übersetzung ins Englische ${ }^{4}$ ) alle Beachtung gefunden und gerade durch die englischen Nachfolger von Bates, Wallace und Trimen eine Verallgemeinerung erhalten, die den ursprünglichen Gedanken der Mimikrylehre fast in den Hintergrund drängt. Dies Verfahren geht wesentlich auf Poulton zurück, der seit $1887^{5}$ ) umfangreiche Untersuchungen über den Eindruck aposematischer Insekten auf kerbtierfressende Wirbeltiere und Wirbellose angestellt hat oder von Schülern und Freunden in Heimat und

1) 1864. $\left.-{ }^{2}\right)$ 1868. $\left.-{ }^{3}\right)$ 1879. $-{ }^{4}$ ) Trans. Ent. Soc. 1879, S. 20 f. $-{ }^{5}$ ) Siehe dort. 
Fremde anstellen ließ. Der Ausbau der Theorie auf systematischer und experimenteller Grundlage ist fast ausnahmslos englischen Forschern unter Führung des Oxforder Professors zu verdanken, unter denen die Namen von Belt, Dixey, Eltringham, Finn, W. Fowler, Kaye, G. Marshall, Shelford, Swinhoe ${ }^{1}$ ) Hervorhebung verdienen; auch Wallace hat in seinen allgemeinen darwinistischen Werken ${ }^{2}$ ) die Grundgedanken weiter ausgeführt und wesentlich vertieft. Dennoch war es ein Deutscher, der früh verstorbene Erich Haase, der mit seinem 1893 erschienenen Buche in Zusammenfassung alles bekannten Stoffes und in geistiger Durchdringung der Mimikrylehre eine Darstellung auf breitester Grundlage gab; ihr hat sich bis heute noch keine Veröffentlichung des In- und Auslandes nur annähernd zur Seite stellen können. Haase war von einem begrenzten Gebiete, dem System der Papilioniden, ausgegangen, hatte aber durch die mit außerordentlicher Formenkenntnis durchgeführte Idee, die sehr verwickelten Verwandtschaftsverhältnisse dieser und anderer Familien von Tagfaltern durch Herauslösung der mimetischen Umwandlungen zu erklären, eine ganz neue Einsicht geliefert, die durch Nachuntersuchungen auf anderer Unterlage vollauf bestätigt worden ist ${ }^{3}$ ). Wenn der Terfasser, ganz im Bannkreise des noch alleinherrschenden Darwinismus, mannigmal etwas kühne Schlüsse gezogen, auch wohl für einzelne Entdeckungen, die schon anderen gelungen waren, sich die Urheberschaft zuerkannt hat, so darf man diese Mißgriffe wohl hinter den Gesamtwert seiner, übrigens in Siam fern ron allen wissenschaftlichen Hilfsmitteln vollendeten, großen Leistung treten lassen. Jedenfalls war die Kritik, welche die Engländer Poulton ${ }^{4}$ ) und Trimen ${ }^{5}$ ) daran geübt haben, ebenso kleinlich wie unangebracht, denn sie stützte sich nur auf Einzelheiten des allein, und dazu äußerst mangelhaft, ins Englische übertragenen zweiten Teiles, dessen äußerst wichtiger Vorgänger, weil zur nichtenglischen Literatur gehörig, den Tadlern wie gewöhnlich unbekannt war. Unbekanntschaft mit $\mathrm{H}$ a a ses Mimikrywerk kann allerdings auch fast allen denen vorgeworfen werden, die mit Befähigung oder ohne sie, das sind die meisten, in deutscher Sprache gegen die Theorie geschrieben haben; es muß nämlich

1) Siehe diese alle. $\left.-{ }^{2}\right) 1870,1891 .{ }^{3}$ ) E. Reuter, Acta Soc. Scient. Fennicae 22 (1896). - ${ }^{4}$ ) Nature 57 1 f., (1897). - $\left.{ }^{5}\right) 1897$, S. 79 . 
hervorgehoben werden, daß unsere Literatur seit $\mathrm{H}$ aase sich so gut wie immer die Bekämpfung der Mimikrylehre zur Aufgabe gemacht hat. Da hierbei die Insekten, die ja den überwiegenden Stoff liefern, den Ausgangspunkt abgeben, will ich die geguerischen Meinungen erst bei dem betreffenden Abschnitt aufzählen.

\section{Erklärung des Begriffes Mimikry.}

Da man sich für die Verwendung des Wortes "Nimikry" leider nicht so oft, wie eigentlich nötig war, um die maßgebenden Quellen kümmerte, haben in der Folge viele Schriftsteller ohne Trteil unter dieses Wort alle Fälle von Schutzfärbung, schützender Ähnlichkeit und schützender Verkleidung, ja jelbst von zufälliger Ähnlichkeit von Tieren mit irgend welchen Dingen gebracht, wodurch Zweideutigkeit und Mißverständnissen Tür und Tor geöffnet worden ist und wird. Bates und die bedeutenden Fortbildner der Batesschen Theorie, namentlich Wallace, Darwin, Fritz Müller, Meldola, Ha se verbanden damit nur den Sinn, welchen Bates, als der Begründer des Gedankens, hineingelegt hatte, jedoch mit der Erweiterung, daß auch zwischen Arten, die beide gemieden sind, Nimikry möglich ist. Ich kann deshalb nicht scharf genug betonen, daß die Ausdehnung auf andere biologische Beziehungen überflüssig, ja eine ungehörige Begriffsverwirrung ist und lege ein für allemal fest: Mimikry bedeutet die schützende Nachäffung gemiedener Tiere durch andere Tiere desselben Wohngebietes, und nichts anderes!

Wenn Piepers seine umfangreiche Kampfschrift mit der Behauptung einleitet ${ }^{1}$ ), daß sich die Begriffe Mimikry, Warnfärbung und schützende Ähnlichkeit "schwer" oder gar "wissenschaftlich nicht" voneinander trennen ließen, so beweist er damit, wie flüchtig. er um den Kern des Problems herumgegangen ist; daß seine Definition des Begriffes, wie er ihn versteht, ganz verschwommen und unbrauchbar für die logische Ordnung der aus dem Gegenstand entspringenden Fragen ist und die Heraushebung der einzelnen soziologischen Bedingungen aufs äußerste erschwert, ist also des Terfassers eigene Schuld, die um so schwerer wiegt, als jemand nur ein dickes Buch mit einseitig scharfer Stellungnahme zu

1) 1903 , S. 3-4. 
schreiben braucht, um für eine Menge oberflächlicher Parteigänger die Sache abgetan sein zu lassen. In denselben Fehler des Zusammenwerfens ganz getrennter Erscheinungen ist leider - unter vielen anderen - auch Prochnow in seiner sonst recht belehrenden Arbeit verfallen ${ }^{1}$ ).

In Wirklichkeit läßt sich der Begriff in der eben von mir aufgestellten Fassung völlig eindeutig, unmißverständlich benutzen. Das Wesen der Mimikry ist nur eine Weiterbildung der Warnfärbung, daher ihre Erörterung an diese anzuschließen. Voraussetzung ist also, daß ein Tier da ist, das wegen irgendwelchen Eigenschaften von natürlichen Feinden seiner Sippe gemieden und an seiner auffallenden Erscheinung leicht von ihnen erkannt wird. Wenn eine andere harmlose Art der ersteren sehr ähnlich sieht, sie gleichsam nachäfft, so trägt sie scheinbar auch ein Warnsignal, das aber nur den Eindruck der Gefährlichkeit usw. auf Gegner macht, in Wirklichkeit des Zusammenhanges mit immunisierenden Eigenschaften entbehrt. Die Wirkung solcher Ähnlichkeit besteht in einer Verwechselung mit den immunen Vorbildern, die den Gegnern unterläuft, und deren Unaufmerksamkeit ist die Ursache. Aus diesem Kausalverhältnisse entsteht der Erfolg, daß die Nachahmer vor jenen Gegnern geschützt sind. Wenn man als das Mittel zur Erzielung jener falschen Warnfarbe, also der Nachäffung, die Entwickelung unter natürlicher Zuchtwahl ansieht - wir werden sehen, daß die Wahrscheinlichkeit dafür spricht —, so darf als Zweck der Nachäffung bezeichnet werden, daß die mimetische Art einen Grad von Schutz erlangt. Unter derselben Annahme würde das Ergebnis des Entwickelungsganges die Anpassung der nachahmenden Art, des "Mimetikers", an die durch Immunität mehr als jene geschützte ("Modell") sein, und zwar vielfach nicht die Anpassung nur an deren äußere Erscheinung, d. h. morphologisch, sondern auch an ihren besonderen Aufenthalt, die Körperhaltung und Bewegungsart, also in biologischer Hinsicht. Stets aber sind Modell und Nachahmer Bewrohner desselben engeren Gebietes, was ja für den Anpassungsvorgang überhaupt Toraussetzung sein muß. Schließlich sei der Unterschied zwischen schützender Ähnlichkeit und Mimikry in knapper Fassung gegeben:

1) 1907 .

J a cobi, Mimikry. 
Ṡchützende $\ddot{A} h n l i c h k e i t$ täuscht die Erscheinung eines Gegenstandes ohne Eigenbewegung vor, der die Aufmerksamkeit eines Feindes nicht auf sich lenkt - das Schutzmittel ist Terborgenheit.

Schützende Nachäffung oder Nimikry läßt das Tier einem beweglichen Gegenstande ähneln, der seinen Feinden bekannt ist und von ihnen gemieden wird - das Schutzmittel ist Sichtbarkeit.

Übergänge, Grenzfälle zwischen beiden Anpassungsformen, die einigermaßen aus den Lebensbedingungen der angezogenen Arten begründet wären, kenne ich nicht, sie lassen sich vielmehr entweder der einen oder der anderen Abteilung zuordnen, wenn man die obige Begriffsbestimmung der Mimikry und jene Unterscheidungsmerkmale anwendet. Beispielsweise ist das von ( $i$ iard ${ }^{1}$ ) geistreich ausgeführte Beispiel der Nachahmung eines Schnecken - oder Sackmottengehäuses durch eine abgestorbene Raupe, die eine Schlupfwespenpuppe verhüllt, sehr anfechtbar und im besten Falle keinerlei Mimikry. Auch ein anderes Beispiel ${ }^{2}$ ), wo kleine, wegen ihrer harten Schale angeblich von Vögeln verschmähte Landschnecken das Modell für Spinnen (Cyclosa) sein sollen, gehört besser zur schützenden Ähnlichkeit, demn Gehäuseschnecken - namentlich die Clausilien und Bulimiden, an die hierbei wohl gedacht ist - liegen tagsüber so oft in ihrem sozusagen unorganischen Hause versteckt oder haben beim Fressen eine so unbedeutende Eigenbewegung, daß man sie von unserem Standpunkte aus besser zu den leblosen Vorbildern der schützenden Ähnlichkeit zählt. Allenfalls könnte man die glasartige Aufhellung der Flügel bei gewissen Tagfaltern des südamerikanischen Urwaldes (S.6) als einen Übergang zur Schutzfarbe, besser wohl "schützenden Farblosigkeit" rechnen.

\section{Einteilung der Mimikry.}

Was Bates und Wallace in ihren grundlegenden Arbeiten unter Mimikry verstanden, ging zunächst nur von dem genossenschaftlichen Verhältnis zwischen Schmetterlingen aus. Sowohl diese Zoologen wie ihre Nachfolger lehrten aber bald die Erscheinung bei anderen Tiergruppen kennen, doch kam man mit

$\left.{ }^{1}\right)$ Bull. Soc. Ent. France 1894, S. 124-126. - ${ }^{2}$ ) Pocock, S. 257. 
der Zeit an urteilsfähiger Stelle, d. h. in England, zu der Einsicht, daß gewisse Fälle eine abgesonderte Behandlung zu beanspruchen haben. Während man früher alle mimetischen Anpassungen ungeschützter Arten an gemiedene die "Batessche Mimikry", diejenige von gemiedenen an andere gemiedene die Müllersche Nimikry nannte, hat der erstere Sammelbegriff eine Aufteilung durch Poulton erfahren ${ }^{1}$ ).

Er faßt zunächst die große Zahl der Mimikryfälle, die angeblich zum Schutze des Nachahmers vor seinen Feinden dienen, als "protektive Nimikry" zusammen; für deren Erscheinung als „Scheinwarnfärbung“ er die Ausdrücke „Pseudaposem, pseuda posematis ch " verwendet. Diese Kunstausdrücke werde ich übernehmen, weil sie viel biegsamer sind als "Bates sche Mimikry" usw., nur muß beachtet werden, daß die in Betracht kommende Ähnlichkeit vielfach nicht nur in der Färbung, sondern wesentlich in der Gestalt zutage tritt. Eine andere Gruppe nennt Poulton „aggressive Mimikry“ („Pseudepisem“), weil gewisse Angreifer die Tracht ihrer Beute tragen, was ihnen gestattet, sich dieser zu nähern, ohne Verdacht zu erwecken. Hierfür haben Poulton ${ }^{2}$ ) sowohl wie $\mathrm{Haase}^{3}$ ), der sie „mimetische Anpassungen seitens der Angreifer" nennt, nur ganz wenige Beispiele herbeibringen können, wovon eins überhaupt nicht dahingehört. Es betrifft die Hummelfliegen (Volucella), die ihre Eier in Hummel- und Wespennester tragen, damit ihre Larven sich von denen der Hummeln nähren können; ihre Ähnlichkeit mit letzteren soll sie vor Erkennung und Abtun mit dem Giftstachel schützen. Abgesehen davon, daß diese Erklärung stark angezweifelt worden ist ${ }^{4}$ ), bedeutet die Einbeziehung des Falles nach meiner Meinung einen Mißgriff. Denn das Wesentliche an dem ganzen Geschehen ist vom Mimikrygedanken aus der Schutz eines schwachen Tieres vor einem Feinde, nämlich der Schutz der Fliegenimago vor der Hummel, nicht aber der Larve vor dieser oder ihrer Larve; daß dieser Schutz den weiteren Effekt hat, das Einschmuggeln der Fliegeneier ins Hummelnest zu erleichtern, steht erst an zweiter Stelle. Sonach ist der Nachahmer und nicht das Vorbild der Angegriffene, weshalb dieser und ähnliche Fälle unter die

1) Poulton, 1890, S, 265 f. und Tabelle nach S. 340. - ${ }^{2}$ ) 1890, S. $266 .-{ }^{3}$ ) S. $138 .-{ }^{4}$ ) Vgl. S. 91. 
protektive Mimikry gehören. Auch von den zwei oder drei (!) anderen Beispielen für "aggressive Nimikry" können einige mindestens ebensogut der protektiven Art zugezählt werden, was übrigens Poulton selber zugibt ${ }^{1}$ ). Ich halte es daher für überflüssig, ein so ungenügend belegtes Einteilungsmerkmal festzuhalten und dadurch die allgemeine Regel zu durchbrechen, daß die Nachahmer unter ihrer Verkleidung Schutz genießen; somit ist jede Mimikry "protektiv" und braucht nicht erst als solche hervorgehoben zu werden.

Endlich sei erwähnt, daß Stecher ${ }^{2}$ ), Distan $\mathrm{t}^{3}$ ) und Sajó ${ }^{4}$ ) eine Reihe von Umschreibungen des Mimikrybegriffes versucht haben, wobei sie nicht nur in der schon beklagten Weise Schutzfärbung und Mimikry vermengen, sondern auch jeder mit des anderen Fassung in Widerspruch gerät; die analytischen Arbeiten der englischen Schule sind dabei gänzlich außer Berücksichtigung geblieben. Eine vergleichende Übersicht dieser Wortbildungen findet man in der "Insektenbörse" 21,58 (1901). Es bleibt nach alledem nur

a) die von Bates aufgestellte, durch pseudaposematische Erscheinung ungeschützter Arten verkörperte, schlechthin Mimikry zu nennende Form; dabei hat also der Mimetiker falsche Warnfarbe:

b) die von F. Müller erläuterte Form, wo zwei oder mehr immune Arten dasselbe warnende Kleid tragen, die häufigste darunter aber das Modell ist; da hierbei jeder Partner echte Warnfarbe trägt, so benennt Poulto ${ }^{5}$ ) die hierbei auftretenden Merkmale als synaposematische, worin ich ihm ebenfalls zu folgen gedenke.

In der Folge werde ich, um zwei Tierarten als mimetisch verbunden zu bezeichnen, öfters das Zeichen $\rightarrow$ anwenden, wobei die Pfeilspitze immer auf den Namen des Modells hinweist.

Wir wollen jetzt die großen Abteilungen des Tierreiches auf das Vorkommen von Mimikry hin durchgehen, doch will ich die Insekten zuletzt vornehmen, weil sie den reichsten Stoff bieten und zu besonders vielen Fragestellungen Anlaß geben.

1) 1890, S. 256-257; ein ebenso zweifelhafter Fall 1906, S. 368. $\left.{ }^{2}\right)$ Ber. d. naturw. Ges. Chemnitz 13 (1895). — ${ }^{3}$ ) Zoologist 1901. $\left.{ }^{4}\right)$ Prometheus 12, 710 (1901); 13, 367 (1902). - ${ }^{5}$ ) Trans. Ent. Soc. 1897, S. 29. 


\section{Mimikry bei Wirbeltieren.}

Wenn man die Anzahl von angenommenen Mimikryfällen bei den einzelnen Tierklassen durchmustert, so ist das Verhältnis zum Artenreichtum äußerst ungleich, und zwar zu ungunsten der Wirbeltiere. Man kann dafür eine gewisse Erklärung geben, wenn man erwägt, wodurch die Insekten dazu im Gegensatz stehen. Hier haben wir eine ungeheure Artenzahl und einen fast unbegrenzten Spielraum in der Ausbildung der Körperform, die sich in Gestaltungsfähigkeit des Hautskeletts sehr frei ausgeben kann, ohne daß die Leistungen der lebenswichtigen inneren Teile davon in Mitleidenschaft gezogen werden müssen. In der wohl auf Millionen Arten $\mathrm{zu}$ schätzenden Formenmenge ist bei der Entwickelung der äußeren Kennzeichen die Wahrscheinlichkeit einer zufälligen Annäherung eines Tieres an das Aussehen des anderen leicht gegeben, und die Lebensbedingungen geben für sehr große Gruppen dieselbe Entwickelungsbasis her, so daß der Weg für die weitere Angleichung durch Naturauslese offen liegt. Dagegen besteht bei den Wirbeltieren eine so starke Abhängigkeit der äußeren Gestalt von dem sehr einförmig gebildeten Innenskelett, und die Hautbedeckung ist im allgemeinen so weich und nachgiebig, daß selbst innerhalb solcher großen Abteilungen wie der Ordnungen die Möglichkeit zur vielseitigen Formgestaltung sehr beschränkt ist. Wo dies aber trotzdem an und für sich möglich wäre, weil gewisse Hautgebilde von den physiologischen Ansprüchen des Körperinneren sehr unabhängig sind und darin dem Chitinpanzer der Insekten nahekommen, nämlich bei den Vögeln, da ist wieder in einem beschränkten Wolıngebiete die Artenmannigfaltigkeit zu gering, um genügend viele Möglichkeiten für mimetische Anpassung zu gewähren. Daher sehen wir, daß auch das eifrigste Suchen der Mimikrytheoretiker aus den Wirbeltieren nur eine winzige Zahl von Beispielen herzutragen konnte, und davon haben meines Erachtens nur die zu den Kriechtieren gehörenden einen gewissen Anspruch auf Glaubwürdigkeit. Indessen sollen auch die anderen wenigstens nicht unerwähnt bleiben. 
Mimikry unter Säugetieren.

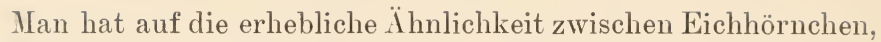
die im indischen Tiergebiete sehr formenreich und häufig sind, und einer dortigen kleinen Gruppe von Insektenfressern, den Tıpaiidae, hingewiesen. Diese haben Gestalt und Größe eines kleinen Eichhorns, auch den langen buschigen Schwanz, nur einen spitzeren Kopf; auch in dem Vorkommen auf Bäumen, der Körperhaltung beim Fressen und im Tagleben treten die "Spitzhörnchen " neben jene Nager. Wallace ${ }^{1}$ ) nahm daher an, daß die außer Insekten auch Vögel raubenden Tiere von ihrer Áhnlichkeit mit den harmlosen (?) Eichhörnern den Vorteil hätten, ihre Beute unter der Verkleidung leichter beschleichen zu können. Daß es sich damit um einen weiteren Fall "aggressiver" Mimikry handle, ist jedoch um so unwahrscheinlicher, als es auf den Sundainseln wieder ein Eichhörnchen gibt (Rhinosciurus tupajoides), das in Größe, Behaarung, Farbe und Kopfform sich der dortigen Tupaja ferruginea zugesellt. Wenn man hierbei überhaupt an eine Nachäffung denken soll, so kann sie im Einklang mit den regelmäßigen Erscheinungen von Mimikry nur von den Nagern auf die Insektivoren zielen, da diese in ihrem üblen Geruche ${ }^{2}$ ) einen gewissen Schutz vor Verfolgern haben mögen. Solange hierüber keine Feststellungen vorliegen, bleibt die Frage ganz ungeklärt.

\section{Mimikry unter Vögeln.}

Nach einem alten Volksglauben rührt das zeitige Verschwinden unseres Kuckucks aus dem sommerlichen Vogelleben davon her, daß er sich in einen Sperber verwandelt. So hat die in der Tat große Ähnlichkeit beider Vogelarten in Größe, Gestalt und Farbe schon Schriftsteller verführt, im Kuckuck einen Mimetiker des Raubvogels zu erblicken, in dessen Erscheinung er beim Einschwärzen seines Eies in die Nester der Krleinvögel weniger Widerstand begegnen soll. In Wirklichkeit macht dieser Umstand auf andere Vögel keinerlei Eindruck; wohl aber gilt dies von dem indischen Hierococcyx sparverioides, dessen habichtsähnliches Flugbild den kleinen Vögeln große Furcht einflößt; auch der Bericht-

1) 1870 , S. $122 .-{ }^{2}$ ) Nach Beobachtungen Haases, S. 81. 
erstatter Davison ${ }^{1}$ ) wurde oft dadurch getäuscht. Noch mehr Wahrscheinlichkeit für wirklich mimetischen Zusammenhang hat die Ähnlichkeit gewisser Pirolarten mit den Höckerschnäbeln (Philemon), Tögeln von Drosselgröße aus der Familie der Honigfresser (Meliphagidae), wofür namentlich spricht, daß jedes mimetisch verbundene Paar auf der gleichen Insel der Molukken zusammenlebt. Die Verteilung ist folgende:

\section{Buru: Oriolus bourouensis $\rightarrow$ Phitemon moluccensis, Ceram: Oriolus forsteni $\rightarrow$ Philemon subcorniculatus, Timorlant: Oriolus decipiens $\longrightarrow$ Philemon timorlaoensis.}

Die Vertreter der beiden Gattungen scheinen auf den ersten Blick ron ein und derselben Art zu sein, und dieser Eindruck gründet sich nicht nur auf die Allgemeinfärbung, sondern auch auf Einzelheiten; z. B. wird der Ring von nackter, dunkler Haut um das Auge des Höckerschnabels bei dem Pirol durch schwarze Federn wiedergegeben, und selbst die Erhöhung auf der Schnabelwurzel des Modells ist durch eine ähnliche Anschwellung angedeutet. Da die Pirole ein Kleid tragen, das von der sonstigen Tracht ihrer Familie abweicht ${ }^{2}$ ), während es für Philemon das normale ist, so ist in Anwendung einer bei Mimikry immer wiederkehrenden Regel der Schluß berechtigt, daß erstere die Nachahmer sind. Hierfür sprechen auch die Lebensverhältnisse, denn die Pirole sind schwächer im Bau und kommen einzeln vor, so dals es ihnen Vorteil bringen dürfte, mit den kräftigen, streitlustigen und geselligen Philemons verwechselt zu werden, die zu zweien oder dreien jede Krähe und sogar einen Sperber in die Flucht jagen.

Zweifelhaft ist mir dagegen die Mimikry zweier Habichte des südlichen Brasiliens (Cooperastur pileatus $\longrightarrow$ Harpagus diodon). Ersterer hat weite Terbreitung, trägt aber dort ein abweichendes Kleid, das sich dem des Harpagıs nähert. Da dieser wesentlich Kerbtiere verfolgt, soll die Verkleidung jenes Sperbers seine Beute, die Kleinvögel, veranlassen, ihn mit jenem wenig gefährlichen Verwandten $\mathrm{zu}$ verwechseln ${ }^{3}$ ), für meinen Geschmack etwas sehr ausgeklügelt!

$\left.{ }^{1}\right)$ Stray Feathers 6, 157 (1878). - ${ }^{2}$ ) Man hatte sie sogar als eigene Gattung Nimeta abgesondert. $-{ }^{3}$ ) Wallace 1870, S. 121 . 
Einige andere in der Literatur ${ }^{1}$ ) verzeichnete Fälle scheinen mir ebenfalls in biologischer Hinsicht zu wenig gesichert zu sein, um dabei zu verweilen.

\section{Mimikry unter Schlangen.}

Unter den Nattern (Colubridae) kennt man eine mit den Brillenschlangen verwandte Gattung Elaps, deren sehr giftige Mitglieder eine ausgesprochene Warnfärbung haben. Die Grundfarbe ist lebhaft korallenrot ( Korallenschlangen“), unterbrochen durch Ringel von Schwarz und auch Gelb, die oft noch von hellen Säumen eingefaßt werden; es ist eine besonders angeordnete, für die Elaps arten charakteristische Zeichnung und findet sich nirgends anders als im wärmeren Amerika. In demselben Gebiete leben ungiftige Schlangen aus mehreren anderen Familien, die eine Nachäffung der Elaps, manchmal sehr vollkommenen Grades, sind, und zwar kommen bisweilen mehrere mimetische Arten auf ein IIodell. Als solche Anpassungen nenut Wallace ${ }^{2}$ ):

Mexiko: Elaps corallinus Guatemala: Elaps fulvius $\leftarrow$ Homalocranium semicinctum,

$\leftarrow$ Pliocercus aequatis und Coronella

tricincta,

\section{Brasilien: Elaps lemniscatus $\longleftarrow$ Oxyrrhopus trigeminus.}

Zahlreiche andere Fälle aus verschiedenen Familien, die alle elapsähnlich sind, wissen Haase und Werner ${ }^{3}$ ) anzugeben, ohne einige weitere zu rechnen, wo die Mimikry von harmlosen Nattern nach giftigen Arten anderer Gattungen angenommen wird; es gehören dazu auch wasserbewohnende Formen.

Bemerkenswert ist jedoch die von Sternfeld ${ }^{4}$ ) hervorgehobene bedeutende Ähnlichkeit südafrikanischer harmloser Nattern, z. B. der eierfressenden Dasypeltis und des kleinen Rhamphiophis multimaculatus mit der gefährlichen Puffotter (Bitis caudalis); es kommt hierbei namentlich die für Giftschlangen bezeichnende, bei den Nachahmern jedoch sehr ungewöhnliche Verkürzung des Schwanzes in Betracht. Außerdem ist das Modell die häufigste Giftschlange des Gebietes, jeder Nachahmer aber verhältnismäßig selten.

1) A. Newton, A Dictionary of Birds 1893, S. 574; Haase, S. 81. - $\left.{ }^{2}\right)$ 1891, S. 397. - ${ }^{3}$ ) S. $80 .-{ }^{4}$ ) Sitzber. d. Ges. nat. Freunde 1908 , S. $89-91$. 
Hierbei liegt die Versuchung nahe, auch in unserer spärlichen Schlangenfauna einen Mimikryfall zu finden, worauf Thallwitz ${ }^{1}$ ) die Aufmerksamkeit lenkt. Wir haben in der Kreuzotter (Vipera berus) und der harmlosen Glattnatter (Coronella laevis) zwei Schlangen, die sich in der Größe, Körperform und Zeichnung so ähneln, daß nur ein geübter Kenner, keinesfalls der Laie, sie unterscheiden kann, ohne die Tiere in der Hand zu haben. Die Natter besitzt nämlich das Merkmal sehr vieler Giftschlangen, den verbreiterten Kopf und kurzen Schwanz, in nur wenig geringerem Grade als die Kreuzotter, und unter den vielen Spielarten in der Färbung unserer Giftschlange gibt es welche, denen die wenig. veränderliche Erscheinung der Nachahmerin völlig entspricht. In den dichter besiedelten Gegenden Mitteleuropas, wo man die Kreuzotter auszurotten sucht, dürfte diese Mimikry der Coronella freilich eher verhängnisvoll sein als schützend. Aber die beiden Schlangen lebten ja längst vor der menschlichen Besiedelung ihrer Heimat nebeneinander, und da die giftige Art ohne ständige Terfolgung an ihren Wohnplätzen sehr häufig ist, die Glattnatter dagegen viel sparsamer, so treffen die allgemeinen Mimikryregeln hier sämtlich zu.

Eine zum synaposematischen Verhältnis sich erhebende Anpassung will A. B. Meyer zwischen mehreren sich um Callophis gruppierenden Gattungen von sehr giftigen Schlangen aus den indischen Tropen aufgefunden haben 2). Im allgemeinen sind alle dazu gehörigen Arten sich äußerlich ganz ähnlich, sie unterscheiden sich aber durch die Länge ihrer an und für sich schon riesig entwickelten Giftdrüsen, die bei Adeniophis fast die halbe Körperlänge erreichen, während sie bei Callophis s. str. kleiner bleiben. Daher soll die Ähnlichkeit z. B. von C. gracilis mit A. intestinalis eine mimetische Anpassung der weniger geschützten Art an eine besonders gemiedene sein.

Zur Bestätigung dieser und anderer Annahmen verlangte schon $\mathrm{Haase}^{3}$ ) vor allem wirkliche Erfahrungen, ob gewisse Feinde der harmlosen Nattern die Elaps unbehelligt lassen, so daß deren Nachahmer dadurch vor ihren Gattungsgenossen eineu höheren Grad der Sicherheit erlangen. Daß solch ein Nachweis

1) Sitzber. u. Abh. Naturw. Ges. Isis, Dresden 1890, S. 21. 2) Proc. Zool. Soc. 1870, S. 368. - ${ }^{3}$ ) S. 80 u. 143. 
geliefert worden wäre, ist mir nicht bekannt. An und für sich sind ja die Bedingungen, welche erfahrungsgemäß für Mimikry sprechen, durchaus gegeben, aber man darf doch nicht außer acht lassen, daf diejenigen Feinde, die wesentlich von Schlangen leben, wie Ichneumone und manche Raubvögel, auch die giftigsten angreifen, was wieder darauf hinausläuft, daß die gewohnheitsmäßigen V'erfolger sich um keine Warnfärbung kümmern. Die letzterwähnte Callophis-Gruppe hat übrigevs nicht einmal eine besondere Zeichnung, die als Warnsignal in Betracht kommen könnte.

Mimikry der Lurche.

In einer Naturaliensendung aus Costarica fand O. Boettger ${ }^{1}$ ) eine zu den Engmäulern oder Ameisenfröschen (Engystomatidae) gehörende, sehr schlanke Froschart [Phryniscus varius] ${ }^{2}$ ), die auf tiefschwarzem Grunde abwechselnd mit lebhaft roten und leuchtend gelben queren Fleckenbinden gezeichnet ist und dadurch auffallend den oben erwähnten Elıps gleicht. Noch größer ist nach Boettgers Meinung die Täuschung, wenn zwei Individuen während der Begattung in ihrer Umklammerung auf- und teilweise hintereinander zu liegen kommen, wobei die roten und gelben Farbenringel in größerer Anzahl und auf längere Erstreckung hin in ganz regelmäßiger Anordnung grell hervortreten. Diese Erklärung ist an sich nicht ganz von der Hand zu weisen, da es sich um den mimetischen Schutz eines Tieres handelt, dessen Sippe unbehilflich und wehrlos zu sein pflegt, und auch der Hinweis auf die Bedeutung der Zeichnung während der Paarung ist nicht allzu gesucht, denn dieser Torgang dauert bekanntlich bei den Froschlurchen oft tagelang und ist der wichtigste für die Erhaltung der Art, sonach vom selektiven Standpunkte aus für die Herausbildung der Schutzzeichnung nicht außer Betracht zu lassen. Allein die Farbenähnlichkeit mit einer Korallenschlange kann immer nur einem kleinen Bruchteil vom Artangehörigen zugute kommen, denn Boettger läßt außer acht, daß Atelopus varius seinem Artnamen durch die Veränderlichkeit der Färbung alle Ehre macht: sie schwankt zwischen reinem Schwarz mit Spuren von Rot und der

1) Nach Haase, S. 78. - ${ }^{2}$ ) Neuerdings heißt die Gattung Atelopus und gehört zu der nahverwandten Familie der Brachycephalidae. 
umgekehrten Zeichnung; gewisse Stücke sind sogar hellblau und schwarz gefleckt, und das Gelb ist so zufällige Beimengung, daß vielfach jeder Anklang an die Elaps-Zeichnung fehlt. Andererseits darf die Frage nicht unterdrückt werden, ob denn die Gattung Phryniscus nicht vielleicht widrige Eigenschaften hat, so daß jenes Kleid ihre eigene Warnfärbung, statt der von einer anderen Tierart erborgten pseudaposematischen wäre? Berichtet doch Darwin ${ }^{1}$ ) von dem schwarz und rot gefärbten Phryniscus nigricans, "der auffallendsten Kröte, die ich je gesehen habe", daß sie auf den kahlen Ebenen von La Plata unter einer glühenden Sonne herumkriechen und das Auge jedes vorbeikommenden Wesens anziehen muß. Dieselbe offene Lebensweise führt ein kleiner, "grell mit Rot und Blau gezeichneter" Frosch in Nicaragua, dessen Ungenießbarkeit für die so gern seinesgleichen verzehrenden Enten Belt erproben konnte ${ }^{2}$ ). Ich mu daher glauben, daß die einfachere Deutung als Warnfärbung für den Boettgerschen Fall näher liegt als seine Hypothese.

\section{Mimikry unter Fischen.}

Ob mimetische Anpassungen unter Fischen vorkommen, ist bisher kaum beachtet worden. Die Bedingungen dafür wären schon gegeben, da einerseits eine ganze Anzahl Arten mit immunisierenden Eigenschaften, wie Giftstacheln und giftigem Hautschleim, bekannt sind, andererseits die Arten der tropischen Uferzone, des Litorals, großenteils in grelle Kontrastfarben gekleidet sind. Natürlich scheidet das Süßwasser mit seiner schlammfarbigen Lebewelt für die Möglichkeit von Mimikry so gut wie ganz aus, und in der See kann nur die geringe vom Sonnenlicht erhellte Schicht in Frage kommen. Alles in allem ist mir nur ein von Masterman ${ }^{3}$ ) erörterter Fall bekannt. Unsere beiden Arten von "Petermännchen" (Trachinus draco und T. vipera) haben vor der ersten Rückenflosse und dicht dabei auf dem Kiemendeckel

1) Geschlechtl. Zuchtwahl, übers. von H. Schmidt, 1909, S. 98. $\left.{ }^{2}\right)$ The Naturalist in Nicaragua 1874 , S. 321 (nach Haase). Die wissenschaftliche Zugehörigkeit dieses als "Belts Frosch" in allen darwinistischen Büchern herumhüpfenden Batrachers festzustellen, hat sich bisher kein Berufener veranlaßt gesehen. Es kann aber weiter niehts sein als der erwähnte, in Mittelamerika äußerst gemeine Atelopus varius. 3) 1908 . 
Giftstacheln von einer, wenigstens für den Menschen, empfindlichen Wirkung. In den Sand vergraben, so daß nur der Oberkopf und der Saum der Rückenflosse hervorgucken, belauern sie ihre kleinen Beutetiere, Krebschen und Fischbrut. Die erste Rückenflosse beider Arten hat ein Gerüst aus sechs bis sieben starken Strahlen, verbunden durch eine tiefschwarze Haut. Bei Beumruhigung richten sie die Flosse auf und spreizen jene Strahlen, so daß die schwarze Fläche gegen den hellbraunen Sandboden scharf hervortritt. Im Hinblick auf die Giftigkeit könnte dieses Gebilde ein Warnsignal sein, wofür auch das schwarmweise Vorkommen der Fische spricht. Hiervon soll die Seezunge (Solea solea) eine Nachäffung abgeben. Ebenfalls gesellig liegt sie in ähnlicher IVeise in den Sand eingewühlt, dessen Farbe ihre veränderliche Hautfärbung kryptisch wiedergibt. Bei unmittelbarer Bedrohung schwimmt der Plattfisch aber davon und spreizt dabei die rechte, d. h. obere, Brustflosse in eigner Weise im rechten Winkel vom Körper ab. Auf der Oberseite dieser Flosse befindet sich aber ein großer schwarzer Fleck, der auch in der Entfernung sehr auffällt und bei den anderen Zungen wie den übrigen Plattfischen ebensowenig vorhanden ist, wie jene besondere Haltung der Brustflosse. Aus diesen Umständen folgert Masterman eine Mimikry des wohlbewehrten Petermännchens durch die wehrlose Seezunge und weist dazu auf das Gemeinsame des Vorkommens und der Lebensweise hin. Freilich gehört dazu noch die Feststellung, ob sich Raubfische wirklich durch Zeichnung und Gebaren des Nachahmers davon abhalten lassen, ihn anzufallen.

Von Mimikry bei Weichtieren (Mollusca) hat man einige Fälle berichtet ${ }^{1}$ ), aber sie sind rein erdacht, nicht durch Beobachtungen dafür belegt, daß wirklich ein Schutz zustande kommt. Indem ich, soweit Meeresformen in Betracht kommen, wieder auf die von M'Intosh ${ }^{2}$ ) geäußerten Bedenken verweise, ziehe ich vor, von einer Wiedergabe der zitierten Beispiele abzusehen.

1) C. Semper, Existenzbedingungen der Tiere 2, 241 (1880); Breitenbach, Kosmos 1, 20 (1884); Hecht, Zool. Centr.-Bl. 1898, S. 98. $-{ }^{2}$ ) S. 13 . 


\section{Mimikry der Spinnen.}

Man hat nicht selten behauptet, daß Spinnen die Modelle für mimetische Nachahmung durch Insekten lieferten, aber dafür liegt weder eine Beobachtung vor, noch findet diese Annahme irgendwie in den natürlichen Verhältnissen eine Stütze. Die weichhäutigen Arachniden, insbesondere die Lauf- und Springspinnen, sind nämlich eine bevorzugte Nahrung der kerbtierfressenden Vögel, wie man sie denn sehr oft in deren Mägen findet; ein bezeichnendes Beispiel sind die altweltlichen Sonnenvögel (Nectariniidae), von denen eine Gattung geradezu "Spinnenjäger" (Arachnothera) heißt, und die Kolibris. Der Biß von Spinnen ist andererseits für diese Feinde wie auch für die Mordwespen, die große Mengen als Nahrung für die Larven in ihre Nester eintragen, kein Abschreckungsmittel, so daß für die Entwickelung von Warnfarben als Vorbedingung für mimetische Anpassung im allgemeinen kein Grund vorliegt ${ }^{1}$ ). Eine Mimikry innerhalb der Klasse selber ist nicht festzustellen ${ }^{2}$ ). Somit ist mindestens die Nachahmung auf seiten der Spimnen, wenn Fowler ${ }^{3}$ ) die Ähnlichkeit von Bockkäfern, wie Echthistatus spinosus, von Australien und Gerania sp. von Java, mit solchen hervorhebt; er hätte dann auch die sehr spinnenähnliche Erscheinung der artenreichen papuanischen Rüsselkäfergattung Arachnopus mit ihren langen Beinen oder den eine mächtige Kreuzspinne vorstellenden Ectatorhinus magicus von Neuguinea erwähnen können. Damit kommen wir auf das Verhältnis der Nachahmung gemiedener Tiere (Insekten) durch Arachniden, wofüı' Dahl ${ }^{4}$ ) einen Belegfali in Deutschland gefunden haben will. Er fing auf Gebüsch mehrfach eine kleine Springspinne (Ballus depressus), deren große Ähnlichkeit mit einem daselbst sehr häufigen kleinen Rüsselkäfer (Strophosomus obesus) sogar ihn, den geübten Spinnenkenner, irreleitete. Er konnte sich dadurch erklären, warum sich jene Arachnide in auffallender Weise von allen anderen einheimischen Springspinnen unterscheidet, indem

$\left.{ }^{1}\right)$ Die einzige mir bekannte Annahme wurde S. 47 erwähnt. 2) E. Peckham, Occas. Papers Nat. Hist. Soc. Wisconsin, p. 103 (1889). -

$\left.{ }^{3}\right)$ S. 52 (1901). - ${ }^{4}$ ) Sitzungsber. Ges. Naturf. Freunde Berlin, S. 273 bis 278 (1903). 
der Vorderteil ihres Kopf'bruststückes, der bei den anderen Arten sonst vorn sehr breit endet, sich hier sehr merklich verengt, und auch der Hinterteil eine recht auffallende Form hat. Dahl folgert eine Mimikry aus der Ähnlichkeit, weil beide Tierarten zusammen vorkommen, weil das Modell, der Käfer, weit häufiger war als die Spinne, und weil die Nachäffung auf ein Tier ginge, das von den meisten Singvögeln verschmäht würde. Die Richtigkeit der übrigen Gründe zugegeben, muß ich den letzteren doch für unzulänglich gestützt erklären. Einerseits ist mir gänzlich unbekannt, auf welche ausgedehnten Untersuchungen Dahl seine Behauptung aufbaut, daß man Käfer der Gattung Strophosomus "niemals im Magen unserer meisten Singvögel findet"; ist der nahverwandte $S$. faber doch schon in der Vogelkost entdeckt worden ${ }^{1}$ ). Fast möchte ich glauben, daß er dies nur vermutet, weil der erwähnte Rüßler einen sehr festen Panzer hat. Indessen werden von unseren Vögeln, namentlich den Spechten und den Rabenarten, aber auch verschiedenen anderen, z. B. vom Rebhuhn, mancherlei Rüßler, wie Pissodes-, Cleonus- und Otiorrhynchusarten recht häufig gefressen, deren Hautbedeckung mindestens so hart ist wie bei Strophosomus. Übrigens würde die Härte eines so kleinen Bissens wie dieser Käfer auch für schwächere Singvögel kaum abstoßend sein, denn sie verschlucken auch Gehäuseschnecken und harte Samenkörner vielfach. im ganzen. So anziehend der Dahlsche Fall wäre als einer der wenigen aus dem Nimikrygebiete in der gemäßigten Zone, müssen doch die mir aufgestiegenen Bedenken nachgeprüft werden, was ja auf dem Wege des Tersuches nicht zu schwer sein würde.

Dagegen hat die von Pocock ${ }^{2}$ ) angeführte Mimikry von Epeiriden nach Coccinelliden von vornherein für sich, daß die als Modell dienende Käferfamilie alle Kennzeichen der Immunität besitzt. Die Nachäffung zeigt bei den Spinnen kurzeiförmige und gewölbte Körper und eine Zeichnung von gelben Flecken auf schwarzem Grunde oder umgekehrt, wie bei den Vorbildern. Derartig ahmt in Natal Paraplectana thorntoni den Käfer Chitomenes Tunata, eine andere Art in Borneo die Caria ditatata nach. Hier kommt die Ähnlichkeit neben der Färbung zustande durch eine Verkürzung der Beine und Überwölbung des Kopf-

$\left.{ }^{1}\right)$ Rey, Ornithol. Monatsschr. 35, 231 (1910). - ${ }^{2}$ ) S. 257 (1908). 
bruststïcks durch den aufgetriebenen Hinterleib, wodurch die sonst so bezeichnende Einschnürung zwischen beiden Körperabschnitten zum Terschwinden gebracht wird.

Auf gesicherterem Boden stehen die zahlreichen Nachäffungen, durch die Spinnen die Erscheinung von Ameisen annehmen. Da jedoch die Ameisennachahmung eine Seite des Mimikrygegenstandes ist, die sich besonders einheitlich erfassen läßt, so ist es vorteilhafter, die Beteiligung der Spinnen in dem dafür bestimmten Kapitel zu behandeln.

Soeben kommt mir eine jüngst erschienene Teröffentlichung von E. G. Green ${ }^{1}$ ) vor Augen, die uns mit der Nachäffung ron "Bienenameisen" (ILtillinae) auf Ceylon bekannt macht. Diese auch bei uns vorkommenden Hautflügler aus der Familie der Doldwespen (Scoliidae) sind im weiblichen Geschlechte (die eine dort vorbildliche Art auch beim Männchen) ungeflügelt und mit einem sehr wirksamen Giftstachel bewehrt; ihre Erscheinung ist sehr kenntlich durch den breiten Kopf, walzenförmigen Brustabschnitt und die Färbung, die auf dem letzteren rotbraun, sonst aber schwarz mit leuchtend weißen oder gelben Abzeichen auf dem Hinterleibe ist. Die mimetische Arachnide (Coenoptychus pulchellus) gehört zu den Springspinnen (Salticidae), die sonst zur Nachäffung von Ameisen neigen. Sie ist schon durch die Form des annähernd rechteckigen Kopfbruststückes und des ovalen Hinterleibes einer Nutilla recht genähert, aber verblüffend ähnlich ist die Färbung des rotbraunen Torderkörpers und schwarzen, hellgefleckten Abdomens. Merkwürdigerweise sind aber die Geschlechter verschieden gefärbt, und zwar entspricht das Männchen der weilgefleckten Spilomutilla eltola, während sich das Weibchen die Mutilla subintrans mit gelber Fleckung des Hinterleibes zum Muster genommen hat. Green und andere Beobachter heben hervor, daf das Aussehen der wie die Modelle auf dem Boden herumlaufenden Spinnen sehr irreleitend ist, so daß sie aus Furcht vor dem Stich nicht zuzugreifen wagten.

\section{Mimikry von Insekten.}

Es war im Eingang zur Behandlung der Wirbeltiere bereits darauf hingewiesen worden, daß die reiche Zahl der mimetischen

1) Spolia Zeylanica S, 92-93, 1 Taf. (1912). 
Anpassungen unter den Kerbtieren sich auf die leichte Wandelbarkeit ihres Hautpanzers und ihre riesige Formenmenge stütz, die gleichgerichtete Entwickelungsverläufe bis zum Ähnlichwerden von Angehörigen sehr verschiedener Stämme erleichtert. Weitere Anlässe biologischer Art sind, wie schon Darwin hervorhob, die durchschnittliche sehr geringe Größe, die dadurch eingeschränkte Geschwindigkeit, die leichte Verletzbarkeit vieler Arten und die Seltenheit aktiver Verteidigungsmittel, was alles ein ausgesprochenes Schutzbedürfnis hervorruft. Wie dieses in der großen Fruchtbarkeit vieler Kerfe und in der raschen Folge ihrer Bruten eine Befriedigung und für die starke Verfolgung durch Feinde aus den Wirbel- und Gliedertieren einen Ausgleich findet, so öffnen jene Vorteile auch eine weite Bahn für Umbildungen im Äußeren, die unter dem Druck irgendwelcher Entwickelungsreize zu Angleichungen ursprünglich verschiedener Typen führen, und befördern das Zeitmaß solcher Vorgänge. Da ich mir nicht die Aufgabe stellen kann, die sämtlichen innerhalb einer Ordnung mit oder ohne Begründung aufgestellten Mimikryfälle zu nennen und zu erörtern, brauche ich auch den Stoff nicht immer unter ein und derselben Abteilung des Systems zu behandeln, was für den Leser den Vorteil bringt, daß ihm öfters eine Zusammenfassung nach weiter gezogenen biologischen Gesichtskreisen geboten werden kann. Es soll nämlich mehr die Bedeutung gewisser Familien als häufig benutzte Nodelle für einzelne Angehörige aus allen möglichen anderen Gruppen hervorgehoben werden, als die Mannigfaltigkeit der Täuschung, welche schutzbedürftige Arten anstreben. 


\section{Nachäffung stechender Hautflïgler oder Sphecoidie.}

Unter den Hymenopteren haben die Weibchen bei einer Anzahl Familien einen Wehrstachel oder auch eine Legeröhre mit Giftdrüse; erstere wurden in der Systematik früher als Aculeata oder Stechimmen zusammengefaßt. Dazu gehören viele Bienen (Apidae), die Faltenwespen (Vespidae), Grabwespen (Sphegidae), Wegwespen (Pompilidae), Dolchwespen (Scoliidae), Goldwespen (Chrysididae) und Ameisen (Formicidae); letztere sollen Gegenstand eines besonderen Kapitels werden. Diejenigen, welche eine oft mit Giftdrüse versehene Legeröhre haben, gehören zu den größeren Familien der "Schlupfwespen“ (Ichneumonidae, Braconidae). Für die erwachsenen Weibchen dieser Familien kommen als Feinde im ganzen nur die Radspinnen und einige wenige Vögel in Betracht; erstere wagen sich aber nicht an die in ihre Netze geratenen heran, sondern lassen sie schleunigst durch Abbeißen von Fäden frei. Herumfliegende Stechimmen werden wohl nur von einigen Raubvögeln, die aber vor dem Verschlucken den Stachel entfernen, namentlich aber von den Bienenfressern (Meropidae) gefangen, einer an das ungestrafte Verzehren dieser für andere Vögel todbringenden Kerbtiere angepaßten Familie; bei uns hat auch der Tannenbäher (Nucifraga caryocatactes) dieselbe Unempfindlichkeit ${ }^{1}$ ). Merkwürdigerweise wissen manche Singvögel. z. B. Schwalben, die stachellosen Drohnen der Honigbiene von den durchaus gemiedenen Weibchen zu unterscheiden (ob am Flugtone?) und rerschlingen sie öfters. Kröten sollen, vor Wespennestern lauernd, einen Bewohner nach dem anderen wegschnappen, desgleichen indische Eidechsen ${ }^{2}$ ), aber im allgemeinen genießen die Stechimmen, wie ich sie weiter zusammenfassend

1) Naumann, Naturgeschichte der Vögel Mitteleuropas 4, 340. 2) Beddard, S. 227 (1892).

Jacobi, Mimikry. 
nennen will, eine ausgesprochene Immunität, was meines Wissens von keinem Naturbeobachter bestritten wird ${ }^{1}$ ). Nur die Schlupfwespen hält man befremdenderweise fast allgemein für wehrlos, da sie weder einen Stachel noch eine andere widrige Eigenschaft besäßen ${ }^{2}$ ). In Wirklichkeit können die größeren Arten mit ihrer spitzen Legeröhre auch uns an zarteren Hautteilen empfindlich stechen, also vollends die Mundschleimhaut eines Wirbeltieres verletzen, ferner sind schon bei einer ganzen Anzahl Giftdrüsen nachgewiesen (R. du Buysson) und den größeren (z. B. Pimpla) ist sowohl ein unangenehmer Geruch eigen wie ein bitterer Geschmack, der vom Tanningehalt der Körpersäfte herrühren soll ${ }^{3}$ ). Es liegt also sehr nahe, den vielen Fällen von Ähnlichkeit zwischen Aculeaten und allerlei anderen Insekten die Bedeutung schützender Nachäffung zu geben, zumal auch die Flugweise und die dabei entwickelten Geräusche vielfach denen der Modelle nahekommen, wie überhaupt die Unterdrückung abweichender Einzelheiten im Flugbilde die Täuschung des Gegners befördert.

Ich will jetzt ein gedrängtes Bild der mimetischen Nachbildungen zu geben suchen, indem ich diese in den größeren systematischen Abteilungen zusammenfasse, vereinzelte Vorkommnisse jedoch übergehe, wofür Haases großes Werk Ersatz bietet.

a) Unter den Käfern beschränkt sich die Sphecoidie, wie ich das zu besprechende Erscheinungsgebiet kurz nennen möchte, auf zwei Familien, deren Mitglieder großenteils auf Blüten leben und gern herumfliegen, also in der Lebensweise gewisse Ähnlichkeit mit Immen haben. Von der ersten, den Buntkäfern (Cleridae), haben wir bei uns wenig Vertreter, von denen aber die Gattung Clerus selber den flügellosen Weibchen der „Bienenameisen" Mutilla (Fam. Scoliidae) durch Größe und Färbung recht ähnelt; dazu kommt die entsprechende Neigung des Kopfes und die Form des haarigen Halsschildes. Mutilla europaea hat einen roten Brustabschnitt und zwei weiße Haarbinden auf dem Hinter-

1) Nur Ribbe [Insektenbörse 18, 300-301 (1901)] glaubt das Gegenteil, denn "nicht selten fand ich in Indien in dem Magen von Vögeln Wespen, die bei Lebzeiten recht herzhaft stechen können". Mit derart unbestimmten Angaben (wahrscheinlich handelt es sich eben um Meropiden) sollte man nicht versuchen, die Mimikrytheorie zu bekämpfen! - ${ }^{2}$ ) Z. B. E. E. Austen, Proc. Zool. Soc. S.777 (1896). $\left.{ }^{3}\right)$ Nach Giard, Bull. Soc. Ent. France, S. 125 (1894). 
leibe - Clerus formicarius ahmt dies durch die Zeichnung seiner Flügeldecken nach, die am Grunde rot und dahinter zweimal weißgebändert sind. Auch in Amerika finden sich solche Anklänge und über die indischen Arten sagt Hartert ${ }^{1}$ ): "Alle Clerusarten sind treffliche Nachahmer von bös stechenden Hymenopteren, Iutillen, eine Nachahmung, die der sehr wohl begreift, der wie ich einmal solchen Hautflügler für einen Clerus ansah und den außerordentlich schmerzhaften Stich empfand."

Von den Bockkäfern (Cerambycidae) beschränken sich die Anlehnungen auf die Unterfamilien der Necydalinae, Rhinotraginae, Esthesinae und Calichrominae, von denen eine große Anzahl Formen in allen Tropengebieten ihre sphecoide Erscheinung durch Verkümmerung der Flügeldecken und lebhafte Färbung bei entsprechender, für Käfer dann ganz ungewöhnlicher Haltung der Unterflügel erlangen. Auch in unserer Tierwelt ist eine derartige Nachäffung in den "Wegböcken" (Necydalis) vertreten, die in der Tat großen Schlupfwespen, wie Anomalon heros, oder auch den Wegwespen (Ammophila) sowohl in der ganzen Erscheinung wie im Betragen, dem schwächlichen Fluge und Herumtreiben am Boden usw. recht ähneln, auch haben sie das gewöhnliche negative Merkmal der Mimetiker, die Seltenheit. Bisher wurde diese Mimikry vielfach für Phantasie erklärt, da Ichneumoniden nicht gemieden seien, was bekanntlich doch der Fall sein kann. Und für ein ganz beschränktes Gebiet, Sarawak auf Borneo, weiß der gut beobachtende, leider jüngst verstorbene, Shelford allein 11 Arten Bockkäfer zu nennen ${ }^{2}$ ), die großen Braconiden ähneln.

Besonders ausgeprägt ist die Sphecoidie der Gattung Nothopoeus des indischen Faunengebietes und einer mit ihr nahe verwandten von Westafrika. Der erste Fall betrifft $N$. (Coloborhombus) fasciatipennis von Borneo, dessen verblüffende Ähnlichkeit mit der Pompilide Mygnimia aviculus von Pryer ${ }^{3}$ ) entdeckt und durch Wallaces "Darwinismus"4) sehr bekannt geworden ist. Wie aus Pryers hier wiedergegebenen Abbildungen (Fig. 6) ersichtlich, hält der Bock, ganz dem Gebrauche seiner Verwandten entgegen, die Hinterflügel ausgebreitet, während die Flügeldecken zu kleinen Schuppen geworden sind; außer den Verhältnissen des

1) Berl. Ent. Ztschr. 33, 291 (1889). — ${ }^{2}$ ) S. 237 u. f. (1902). ${ }^{3}$ ) Trans. Ent. Soc., S. $369-373$, Tab. 10 (1885). - ${ }^{4}$ ) S. 392 , Fig. 26 (1891). 
Rumpfes undider Beine entsprechen sich Vorbild und Nachahmer auch in der dunkelblauen Farbe und dem großen weißen Fleck nahe der Flügelspitze. „Die Wespe und der Käfer sind häufig,

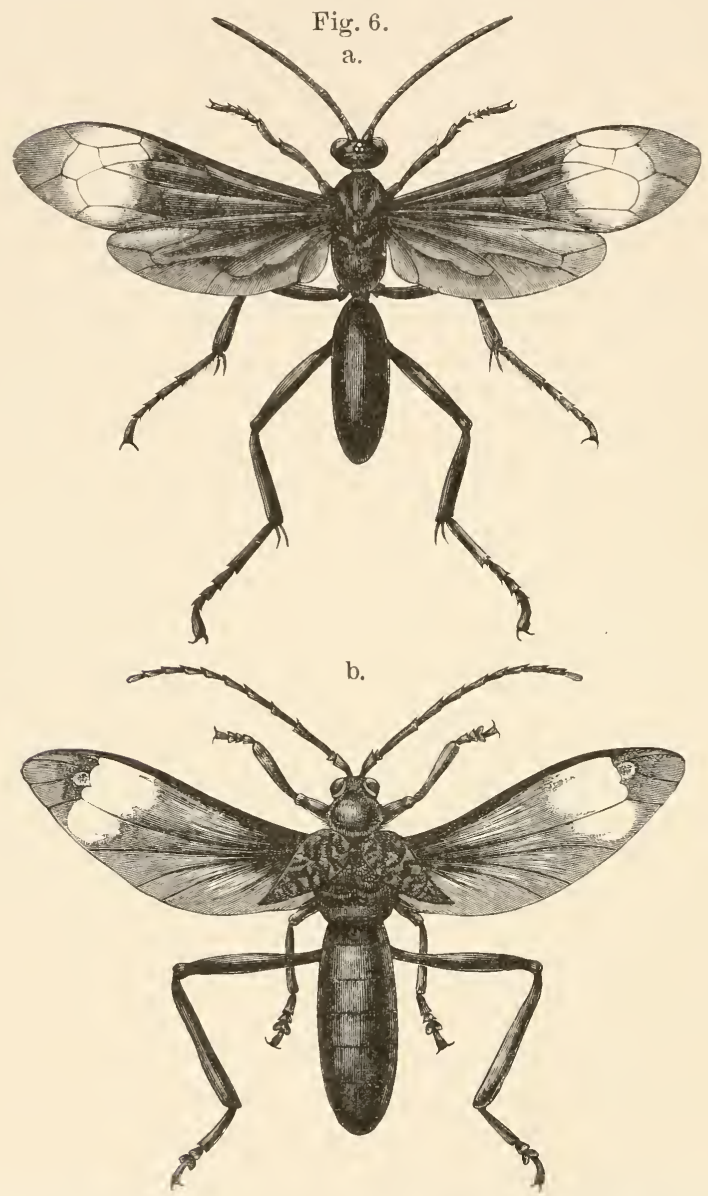

a. Mygnimia aviculus(Wespe). - b. Coloborhombus fasciatipennis (Käfer). Aus Wallace.

aber schwer zu fangen. Beim Fluge oder auch im Sitzen ist es auf eine Entfernung von 6 Zoll ganz unmöglich, beide zu unterscheiden." Da es Pryer nur ein Stück von jeder Art zu fangen 
gelang, konnte er nicht feststellen, welche von beiden die häufigere ist. Aus der folgenden Tatsache zu schließen, dürfte aber, wie gewöhnlich, das Modell häufiger sein. Später hat nämlich Shelford ${ }^{1}$ ) ein anderes mimetisches Artenpaar in Nordborneo entdeckt. Dieser noch unbenannte Nothopoeus ist ebenfalls groß und schwarz, aber mit einfarbig braunen Flügeln, und ähnelt erstaunlich der gemeinen, fürchterlich stechenden Mygnimia anthracina. Den summenden Flug und die anderen Bewegungen beider Käferarten, namentlich ein rhythmisches Senken des Hinterleibes im Sitzen, nennt Shelford außerordentlich wespenähnlich, und es täuschte die dajakischen Sammler des Sarawakmuseums - die sich als Naturkinder doch scharf unterscheidender Augen erfreuten derartig, daß sie die gefangenen Tiere nur mit der größten Vorsicht $\mathrm{zu}$ behandeln wagten. Auch der im indischen Gebiete weit verbreitete $N$. hemipterus scheint seine Wespenmodelle zu haben, da C. Ritsema in einer Käfersammlung von der Insel Nias neben einem Pärchen jener Art auch mehrere Stücke der äußerst ähnlichen Pompilide Macromeris splendida erhielt, die also der Sammler für die Käfer gehalten hatte ${ }^{2}$ ). Auch der Entomologe J. Tuillet wagte sich des nahe verwandten, im Senegalgebiete lebenden Bockkäfers Guitelia vuilleti nur mit größter Vorsicht zu bemächtigen, weil er ihn für eine dortige, sehr gefürchtete Grabwespe hielt ${ }^{3}$ ).

Eine besondere Beurteilung muß der Unterfamilie Clytinae, (Widderböcke) zugewandt werden. Unser schwarz und gelb gebänderter Clytus arietis sieht im Leben einer Wespe nicht unähnlich, besonders in der Art seines vielen Herumfliegens und Niederlassens, sowie in den raschen, zuckenden Bewegungen der Beine beim Laufen. Shelford möchte jedoch aus seinen Beobachtungen auf Borneo schließen ${ }^{4}$ ), daß die dortigen Clytinen selber immun sind. Der häufigste Käfer auf allen Höhen des ohnehin insektenreichen Mount Penrissen ist der mittelgroße, durch seine scharfe Zeichnung aus Gelb und Schwarz äußerst auffallende Chlorophorus ammularis; er schwärmt geradezu um manche Büsche und zeigt ein auffallendes Gebaren. In der Ebene wiederum gehören Verwandte von ihm, wie Clytanthus sumatrensis und

1) S. 240 (1904). — $\left.{ }^{2}\right)$ Notes Leyden Mus. 34, 22 (1911). 3) Insecta, Revue ill. d'Entom. 1, 183, Fig. 1-2, herausgegeben von Oberthür. - ${ }^{4}$ ) S. 251 (1902). 
Demonax viverra, zu den gemeinsten Bockkäfern. Diese Umstände - die auffallende Farbe, die freie Lebensweise und die Häufigkeit - berechtigen allerdings zu der Annahme, daß die Widderböcke an und für sich gemieden werden, daß also ihre passive und aktive Ähnlichkeit mit Wespen mehr eine synaposematische Gleichheit im Sinne F. Müllers ist als eine schützende Nachäffung. Shelford und Poulton knüpfen daran die weitere, reichlich kühne Folgerung, daß jene Käfer wieder, vorläufig wenigstens auf Borneo, die Vorbilder pseudaposematischer Nachahmung für andere Bockkäfer aus den Gruppen der Lamiinae, Phytoeciinae und Glaucytinae seien.

b) Die Schmetterling e weisen sehr gelungene Nachäffungen auf, die aber auf die sogenannten Nachtfalter (Heterocera) und darunter auf wenige, bezeichnenderweise aber völlig als Tagtiere lebende Familien beschränkt sind. Unter den echten Schwärmern (Sphingidae) sind es die $\mathrm{Hu}$ m mels chwär mer, namentlich Hemaris bombyliformis, deren Größe, die bis auf den dunkleren Rand fast durchsichtigen Flügel und der gedrungene, dickpelzige Hinterleib mit schwarzen und rotbraunen Binden sehr der allgemeinen Erscheinung von Hummeln ähneln. Wie diese fliegen sie im Sonnenschein von Blüte zu Blüte, freilich in viel rascherem Fluge und vor den Blumenkelchen schwebend. Viel mehr noch erinnern die Glasflügelschwärmer (Sesiidae) durch ihre Erscheinung und das Benehmen an Stechimmen. Die schmalen Flügel sind mehr oder weniger glashell, der gestreckte Hinterleib hat bei den nahe angepaßten Arten die Form und die Abwechselung schwarzer und gelber Binden der Wespen, auch die Beine und Fühler erinnern an diese. So gleichen unsere Hornissenschwärmer ('Trochilium apiforme und spheciforme) einer kleineren Hornisse (Fig. 7), während andere Arten trotz ihrer von anderen Kerbtieren abgeleiteten Namen an Lehm- und Grabwespen gemahnen (Sciapteron tabaniforme, Bembecia hylaeiformis und Sesia cynipiformis $\longrightarrow$ Odynerus; Sesia asiliformis $\longrightarrow$ Cerceris). Wo die meist wenig häufigen Nachahmer vorkommen, zeigen sie die unruhige Beweglichkeit von Wespen, und Tr. apiforme brummt auch ganz wie eine Hornisse; im Netz gefangen, können sie sogar den Schmetterlingssammler täuschen. Auch in den Tropen findet man diese Mimetismen, von denen Pryer ein schönes Beispiel auf Borneo zusammen mit dem vorhin beschriebenen sphecoiden Bockkäfer 
entdeckte. Auch hier sind die Tiere blauschwarz, und zwar wird Triscolia patricialis, eine stark bewaffnete große Dolchwespe, von Scotiomima insignis in der auffallenden Färbung und dem körperlichen Zubehör nachgeahmt. Eine ähnliche, ihn zuerst irreführende Mimikry fand Austen ${ }^{1}$ ) am unteren Amazonas in einer kleinen Sesie, die sogar die orangegelben und schwarzen Binden auf dem Brustschilde ihres Modells, der Wespe Polybiaphthisica, wiedergibt. In beiden Vorkommnissen werden die Mimetiker als selten bezeichnet.

Die feinsten Anpassungen werden im neotropischen Faunengebiete ron der Familie der Srntomiden (früher Glaucopiden genannt) fertig gebracht. Mit schönen Metallfarben und bunten Bändern geschmückt haben diese Falterchen noch hier und da besondere sphecoide Züge, z. B. auffallend lange Hinterbeine bei

Fig. 7 .

a.

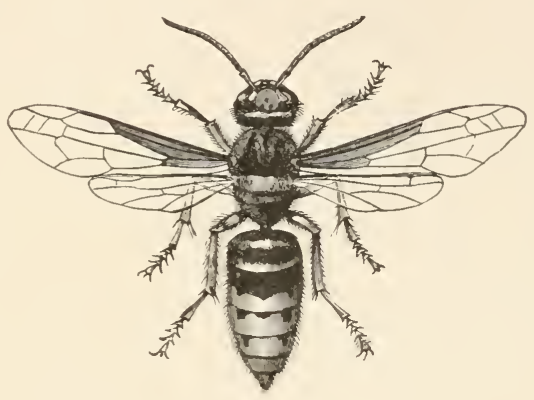

b.

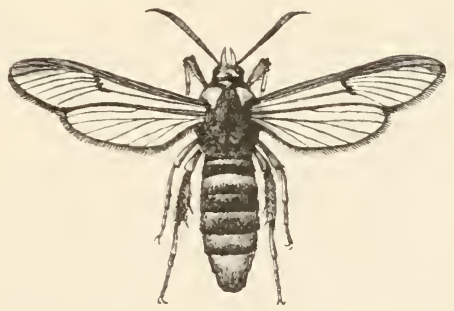

a. Vespa cabro. - b. Trochitium apiforme. Aus Claus.

Macrocneme, die durch abstehenden, federartig angeordneten Borstenbesatz die bei vielen Holzbienen und Raubwespen Südamerikas vorhandenen "Bürsten" imitieren. Bei manchen Arten wird der plumpe Hinterleib des Nachtfalters zur "Wespentaille" retuschiert, indem die schwarze Grundfarbe von leuchtend weißen Flanken eingefaßt wird, so daß durch diese Übermalung der Leib verengt erscheint - eine auch bei der Ameisennachahmung (s. folgenden Abschnitt) oft wiederkehrende Umbildung. Endlich

1) Proc. Zool. Soc., S. 777 (1896). 
kommt es wirklich zur stielartigen Einschnürung des Hinterleibes (Sphecosoma, Myrmecopsis), wo dann das Aussehen des Schmetterlings so verwischt ist, dab nur genauere Untersuchung noch die Zugehörigkeit zu den Lepidopteren nachweist. Hören wir nunmehr zwei Kenner sich zur Sphecoidie der Syutomiden äußern, die sie in ihrer tropischen Heimat kennen gelernt haben. Dr. Seitz ${ }^{1}$ ) sagt von ihnen: "Hier öffnet sich der Mimikry ein weites Feld. In den wunderbarsten Verkleidungen treffen wir solche Nachtfalterchen, von denen manche Raubwespen, andere Käfer, die meisten aber Hymenopteren kopieren. Die stärksten Hautflügler der Erde, die Pepsis-Arten ..., werden von den überaus zahlreichen (in den Laplatastaaten allein 31) Syntomidenarten kopiert. Unter dem Namen "Marimbondo" ist diese Wegwespe wegen ihres fürchterlichen Stachels in Amerika von Mensch und Tier gefürchtet, und so könnte man tatsächlich kein geeigneteres Modell für Schutzverkleidungen erfinden. Ganze Syntomidengattungen, wie die Macrocneme, kopieren fast ausschließlich solche Riesenwespen." Der andere Gewährsmann, Schrottky, führt die mimetischen Züge der von ihm in Paraguay beobachteten Syntomiden nur deshalb an, weil er als Gegner der Mimikrytheorie von einer schützenden Bedeutung jener Ähnlichkeiten nichts wissen will. An und für sich wäre solch ein aus unmittelbarer Naturbeobachtung geschöpfter Widerspruch hoch einzuschätzen, aber Schrottky ist einer der vielen "Entomologen", die zwar auf einem engen Einzelgebiete schätzenswerte Kenntnisse haben und in dieser Einschränkung die Wissenschaft fördern, aber daraufhin befugt zu sein glauben, über wichtige Allgemeinfragen der Biologie entscheidende Kundgebungen zu äußern und über die Stellungnahme angesehener Naturforscher dazu ein Urteil zu fällen. Solche Übergriffe, die an dieser Stelle ein für allemal zurückgewiesen werden sollen, sind dann um so weniger berechtigt, wenn der Kritiker es nicht einmal für nötig hält, sich vorher über die längst angenommenen Grundlagen der angegriffenen Lehrmeinung zu unterrichten. Da sich Schrottky über das eigentliche Wesen der Mimikry, ihre Voraussetzungen und den darüber erlangten Erfahrungsschatz völlig im unklaren ist, sind seine Einwände gänzlich verfehlt; er hat mit seinen Ausführungen nicht, wie

1) Die Großschmetterlinge der Erde 5, 6 (1907). 
beabsichtigt, Waffen gegen, sondern Stützen für die Anwendung der Mimikrytheorie auf unsere Falterfamilie geliefert.

Was sagt nun Schrottky ${ }^{1}$ )? "Obschon nicht sämtliche Arten "mimetische" sind, besitzt doch ein weit größerer Teil Ïhnlichkeit mit anderen Insekten, namentlich Wespen, als es bei einem Blick auf die schön präparierten Tiere scheinen möchte; es soll damit gesagt sein, daß sich diese irreführende Ähnlichkeit nach dem Tode mehr oder minder verändert, ja, bei einigen Arten wird die Täuschung überhaupt nur durch das fliegende Tier hervorgebracht, während es sitzend leichter als Schmetterling erkennbar ist. Die größte Wespenähnlichkeit hat Pseudosphex ichneumonea H.-S. und P. noverca Schaus; Rhynchopyga meisteri Berg gleicht im Fliegen einer Braconidae-Art; Macrocneme lades (Cram.) zeigt die ungefähre Gestalt und Farbe der Pepsis; Argyroeides braco (H.-S.) und A. sanguinea Schaus täuschen beim Fliegen die Vespidae-Gattung Megacanthopus vor. Daf die Ïhnlichkeit besteht, ist unmöglich zu leugnen; sie ist bei manchen Arten so groß, daß nicht nur Laien, sondern auch geübte Entomologen sich nur durch scharfes, wiederholtes Hinblicken nach den Fühlern davon überzeugen können, es nicht mit einer Wespe zu tun zu haben, vorausgesetzt natürlich, daß das Tier still in einer Blüte sitzt und sich aus nächster Nähe genau betrachten läßt; ist es dagegen in Bewegung oder beträgt die Entfernung mehr als einen Meter, so kann der geübteste Hymeno- oder Lepidopterologe nicht angeben, ist das in Frage kommende Tier Wespe oder Schmetterling" 2). Ferner erfahren wir, daßs gerade die vollkommensten Nachahmer am seltensten sind, woraus Schrottky unrichtige Schlüsse zieht, z. B. waren unter Tausenden gefangener Wespen der Polybia angulata, Pachymenes ater und anderen Arten nur zwei Stück des Mimetikers Pseudosphex ichneumonea, die der Verfasser trotz ihrer sehr weiten Verbreitung als aussterbend ansieht. Einige weitere Angaben sind für ihn die Hauptbeweise, dalo die Sphecoidie der Syntomiden keinerlei Schutz bedeutet; sie fallen aber keineswegs aus dem Geltungsbereich der Nachäffung heraus. So erfahren wir, daß die Familie unter allen „immunen“ Insekten am meisten gemieden würde, und erhalten als einzigen

1) 1909 , S. 127-130. - 2) Ganz Ähnliches berichten Kaye und Bertoni aus jener Gegend: Proc. Ent. Soc. 1910, S. 54. 
Beweis die Angabe, daß ihm einmal Schaben je einen toten Heliconius und eine Mechanitis (als immun bekannte Tagfalter) auffraßen, eine Cyanopepla jedoch in ihrer Papierdüte unberührt liefien. War die Düte möglicherweise besser verschlossen? Ferner seien die Pepsis-Nachahmer keineswegs träge und voller Vertrauen auf ihre Schutzfärbung, sondern sehr flüchtig. Es ist aber meines Wissens von keinem Verteidiger der Mimikry behauptet worden, daß Trägheit und Vertrauensseligkeit durchweg eine Grundeigenschaft der Mimetiker sei, ja kaum solcher, die zu Modellen mit solchem Betragen gehören; sind aber nicht im vorliegenden Falle die Modelle ebenfalls flüchtig? Kurz, Schrottky greift in seiner Kritik stets daneben, weil er sich über die Unterlagen nicht klar ist; seine tatsächlichen Angaben sind nützlich, aber seine Schlüsse sprechen nicht einmal dagegen, daß die Mimikry der Syntomiden noch zu der gewöhnlichen pseudaposematischen gehört, geschweige denn, daß sie Zweifel an der Bedeutung des synaposematischen Schutzes bekräftigen könnten. Was er über Verfolger von Syntomiden vorbringen kann, ist ebenso spärlich wie zweifelhaft oder es hat nichts mit der Sache zu tun.

c) Für die Sphecoidie der Fliegen (Diptera) will ich an die Modelle der letzten Gruppe, die gefährlichen Grab- und Dolchwespen der heißen Zone, anknüpfen. Sie werden von einer Familie stattlicher Fliegen, den Mydasidae, nachgeahmt, die auf beiden Halbkugeln, aber stets selten, vorkommen. Einen Fall gibt Fig. $S$ wieder. Das Vorbild ist Pepsis ruficornis, eine auf den Antillen und in Südamerika verbreitete Sphegide von nicht weniger als $6,5 \mathrm{~cm}$ Spannweite, mattschwarzem Körper und Beinen, stahlblauen Flügeln und gelbroten Fühlern. Dazu gehört Mydas praegrandis, eine mächtige Fliege von ähnlichem Bau und Färbung, aber noch größerer Flugweite; sie lebt in einem großen Teile des Wohngebietes der Wespe an denselben Orten und ist nach A usten ${ }^{1}$ ) lebend sowohl im Fluge wie im Netz schwer von ihr zu unterscheiden. Für die wissenschaftliche Betrachtung ist natürlich die Ähnlichkeit nur oberflächlich, wie denn die ebenso stattliche II. ruficornis auf Ceylon im Leben mit gewissen wehrhaften Dolchwespen äußerst leicht verwechselt wird, ohne daß ihre Erscheinung eine bestimmte Scoliide wiedergäbe ${ }^{2}$ ).

1) Novitates Zool. 16, 129-131 (1910). - ${ }^{2}$ ) Fletcher, Proc. Entom. Soc. 1909, S. 26. 
Mimetische Dipteren sind auch in unserer Fauna verhältnismäßig reichlich anzutreffen, vor allem in der Familie der Schwebfliegen (Syrphidae). Diese oft zierlichen und bunt gezeichneten Fliegen sieht man sehr häufig vor Blüten herumschwirren und Fig. 8.

a.

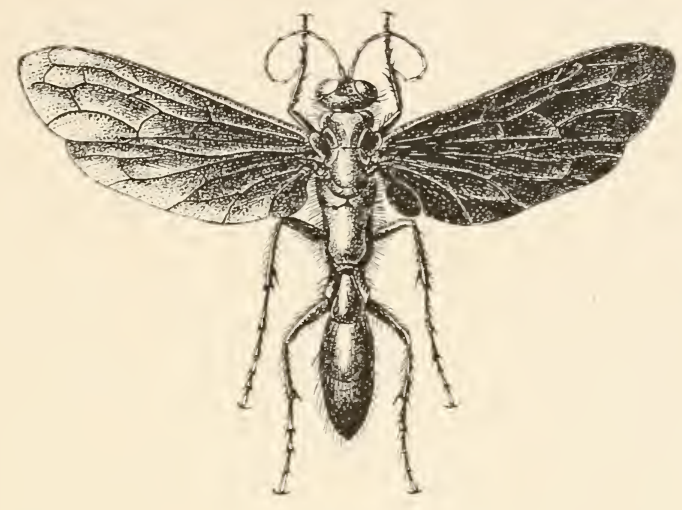

b.

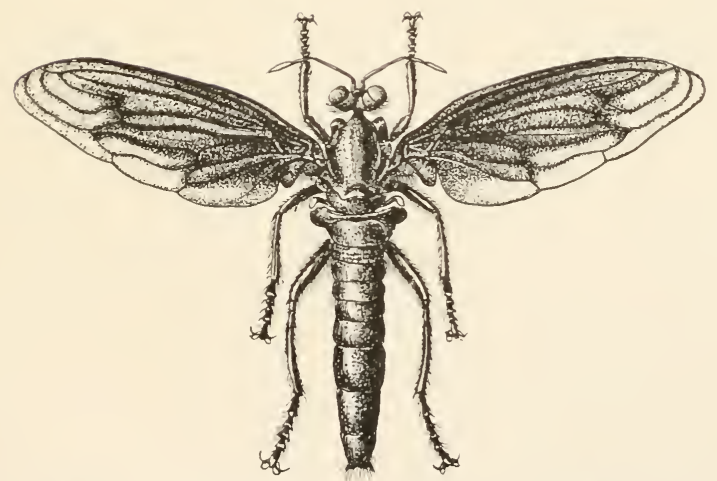

a. Pepsis ruficornis, eine Wespe. - b. Mydas praegrandis, eine Fliege. Original.

schweben, dabei vielfach mit den dort ebenfalls verkehrenden Immen mancherlei Art zu verwechseln. Beispiele solcher Ähnlichkeit bieten Syrphus corollae mit der Schmuckbiene Nomada succincta, die Bogenfliege (Chrysotoxon succinctum) und die Stielhorn- 
fliege (Ceria conopsoides) mit der Lehmwespe (Odynerus parietum), durch besondere Häufigkeit aber die "Schlammfliege" (Eristalis tenax) mit unserer Honigbiene. Das 'Tier hat nicht nur deren Größe, Form und Pelzfarbe, sondern auch ganz ihren summenden Laut und die Art des Herumsuchens an Blüten; man kann einen Laien nicht überreden, sie anzufassen, und auch der Naturkundige muf zunächst genau hinsehen, um Vorbild und Nachahmer nicht zu verwechseln. Wie die Ähnlichkeit auf Fliegenfresser wirkt, ist nur an Gefangenen probiert worden, und da mit widersprechendem Ergebnis: ein Frosch, der beim Verschlingen von Bienen deren Stich gekostet hatte, ließ kurze Zeit danach eine Schlammfliege unberührt ${ }^{1}$ ), A. G. Butlers Käfigvögel verzehrten sie dagegen ohne weiteres ${ }^{2}$ ).

Fermer hat die Gattung Hummelfliegen (Volucella) ihren Namen von der Ähnlichkeit ihrer stattlichen Angehörigen mit Hummeln und Faltenwespen und ist auch in Amerika mit solcher Sphecoidie vertreten "). Wie früher ${ }^{4}$ ) angedeutet wurde, ist es die herkömmliche Auffassung, daß die mimetischen Volucella ihre Verkleidung tragen, um ihre Eier unerkannt und unangegriffen in die Nester der Stechimmen befördern zu können. Diese Deutung hat aber mehrfachen Widerspruch erfahren. Beddard5) gibt erstens zu bedenken, daß wir gar nicht wissen, ob Wespen oder Hummeln sich überhaupt um das Aussehen von Eindringlingen kümmern, da alle staatenbildenden Hautflügler sogar Artgenossen aus anderen Verbänden sofort erkennen - und nicht durchs Auge - und nicht im eigenen Neste dulden; warum sollten ihnen die ganz anders beschaffenen (riechenden?) Fliegen ein Blendwerk vormachen können? Zweitens verkehren in Wespennestern ungestraft noch zahlreiche andere Insekten ohne jede Verkleidung, darunter vier Arten Dipteren einschließlich der überhaupt nicht sphecoiden Volucella pellucens. Diese Zweifel haben Latter ${ }^{6}$ ) und Speiser ${ }^{7}$ ) fortgeführt. Bei $V$. bombylans ist die Ähnlichkeit mit Bombusarten nicht nur ausgeprägt, sondern geht so weit, daß

$\left.{ }^{1}\right)$ Nach Prochnow in Landois „Tierstimmen “ 1874, S. 26, aber für mich unauffindbar (flüchtiges Zitieren!). - ${ }^{2}$ ) Trans Ent. Soc. 1910, S. 153. - ${ }^{3}$ ) V. facialis $\longrightarrow$ Bombus juxtus nach Cockerell, Ann. Nat. Hist. (7) 5, 401 (1900). - ${ }^{4}$ ) S. $67 .-{ }^{5}$ ) 1892 , S. 226-228. $\left.{ }^{6}\right)$ Natural Scien. 2, 54-56 (1892). - ${ }^{7}$ ) Kranchers Entom. Jahrb. 17, 163-167 (1908). 
sie in mehreren Abarten vorkommt, deren jede wieder einer Hummelart gleicht. Kann der Fliege aber diese Ähnlichkeit in dem einen kritischen Augenblick, wo sie sich in die Höhle des Löwen wagt, etwas nützen, da dort mindestens Halbdunkel herrscht? Auch halten sich von den beiden Abarten der $V$. bombylans, von denen die eine der Mooshummel (Bombus muscorum), die andere der Steinhummel (B. Tapidarius) ähnlich sieht, durchaus nicht jede $\mathrm{zu}$ ihrem besonderen Modell ${ }^{1}$ ), sondern nach Bateson ${ }^{2}$ ) trifft man sowohl beide Varietäten in ein und demselben Hummelnest zusammen, wie jede bei einer ihr unähnlichen Hummel. Es ist also viel wahrscheinlicher, daf die starke Behaarung, welche $V$. bombylans im Gegensatz zu den fast kahlen V. inanis, pellucens, inflata besitzt, ihr dazu verhilft, den Tastsinn der Nestinhaber zu täuschen, wenn beide einander darin begegnen. Dafür spricht auch, daß jene unbehaarten Arten sich gerade bei unbehaarten Faltenwespen aufhalten, ron denen sie nur die allgemeine Erscheinung, nicht aber die jeweiligen Artmerkmale nachahmen. Freilich hat man auch Anzeichen, daß die Einkehr ron Hummelfliegen den Wirten überhaupt gleichgültig ist, wie in der Tat die Volucella-Larven gar keine eigentlichen Schmarotzer sind, sondern Commensalen, die rom Abfall der Nestinhaber, höchstens ron deren abgestorbenen Larven und Puppen leben. Dagegen fallen dieselben Wespen, die z. B. V. inanis ruhig durchlieben, Artgenossen aus einem anderen Neste wütend $a^{3}{ }^{3}$ ). Latter meint deshalb, daß die Mimikry ron Volucella keine Anpassung an das Brutschmarotzertum sei, sondern mehr zur Täuschung eigentlicher Feinde diene, und machte darauf eine Probe mit sechs Eidechsen, denen er sowohl $V$. inanis wie mehrere Tarietäten von $V$. bombylans im Käfig vorsetzte. Die Fliegen wurden nur aus der Entfernung besichtigt, aber nicht angerührt, und wenn sie anfingen herumzusurren, so gerieten die Eidechsen in erhebliche Aufregung. Ob aber die Sphecoidie der Volucellen allgemein eine pseudaposematische Mimikry zum Schutz vor Insektenfressern, namentlich vor insektenjagenden Vögeln ist, wurde noch nicht unmittelbar beobachtet; in Vogelmägen sind sie meines Wissens noch nicht gefunden worden.

Endlich sei noch mehrerer Fälle gedacht, die als Nachahmung von Schlupfwespen durch Dipteren gedeutet worden sind; den einen

') Poulton 1890, S. 267. - ${ }^{2}$ ) Natural Scien. 46, 588 (1892). $\left.{ }^{3}\right)$ Speiser, Kranchers Entom. Jahrb. 17, 166 (1908). 
mir bekannten schildert Townsend ${ }^{1}$ ) aus Europa, den anderen A usten ${ }^{2}$ ) vom Amazonas. Beidemal sind die Vorbilder Ichneumoniden von so geringer Größe, daß ich mir eine nennenswerte Immunität nicht recht vorstellen kann, und deshalb dürfte es sich eher um zufällige Ähnlichkeiten handeln, denn um mimetische Angleichung.

d) Endlich ist auch eine Reihe von Ähnlichkeiten unter Stechimmen selber bekannt geworden, die als Mimikry, und da diese alle gemieden werden, als solche synaposematischer Art betrachtet werden können. Schon unserem entomologischen Altmeister Ratzeburg fiel es auf ${ }^{3}$ ), daß sich bisweilen Schlupfwespen verschiedener Art und selbst Gattung, die sich in demselben Wirte entwickeln, ungemein ähneln, und er erklärte sich dies als eine durch gleiche Nahrung und sonstige Bedingungen hervorgerufene Konvergenz, eine bei diesem strenggläubigen Anhänger der Artbeständigkeit bemerkenswerte Berührung mit dem Entwickelungsgedanken. Giard ${ }^{4}$ ) sieht darin Synaposeme, für die er den nicht gerade nötigen Begriff des "Mimétisme isotypique" aufstellt; Voraussetzung ist aber wiederum, daß die Träger bei Insectivoren wirklich Respekt genießen. Eher wahrscheinlich ist Bewertung für eine Reihe solcher Paarungen, die Gerstäcker ${ }^{5}$ ) und Handlirsch ${ }^{6}$ ) unter südamerikanischen Stechimmen aufgefunden haben. Die Grabwespe Gorytes politus gleicht der Faltenwespe Polybia chrysothorax, G. robustus dem Odynerus parredesi, die schmarotzende Erzwespe Polistomorpha surinamensis ist „eine in der Tat vollendete Nachbildung von Polistes testacea, und Chalcis emarginata und punctata sind ebenso vollkommene Kopien von Polybia cayennensis". Die Mimetiker sind in diesen Fällen jedoch wesentlich schwächer bewehrt als die Vorbilder. Endlich erinnert die südeuropäische Pompilide Stizus tridentatus an die Dolchwespe Scolia hirta auch in der Veränderlichkeit der gelben Hinterleibsbinden. Da die aufgezählten Grabwespen von der Erscheinung ihrer zahlreichen Gattungsverwandten abweichen, während die vorbildlichen Vespiden und Scoliiden normale Typen sind, so ist für Handlirs ch die Folgerung gegeben, daß erstere die Gattungseigenschaften zugunsten einer mimetischen Umgestaltung aufgegeben haben.

1) Ann. Nat. Hist. (6) 20, 21 (1897). - ${ }^{2}$ ) Proc. Zool. Soc. 1896, p. 777. $-{ }^{3}$ ) Die Ichneumonen der Forstinsekten 3, 7 (1852). - ${ }^{4}$ ) Bull. Soc. Entom. France 1894, p. 126. - ${ }^{5}$ ) Stett. Entom. Ztg. 24, 411 (1863). $-{ }^{6}$ ) Nach Haase, S. 10. 


\section{Nachäffung von Ameisen oder Myrmecoidie.}

Eine sehr gut umschriebene Form der Mimikry zielt auf Wiedergabe der eigentümlichen Form des Ameisenkörpers und gesellt dazu eine Nachahmung der Lebensweise und des besonderen Gebahrens der Vorbilder; erstere Seite nennt Wasmann ${ }^{1}$ ) die passive, letztere die aktive Mimikry, eine nicht gerade nötige Unterscheidung. Für die körperliche Nachahmung kommt nur der ungeflügelte Zustand von Ameisen in Betracht, und zwar die weitaus häufigste und gewöhnlich wehrhafte Form jeder Art, der Arbeiter. Die wichtigsten Züge der Ameisenerscheinung sind der etwas abgeflachte und schief nach vorn gerichtete Kopf mit den vorstehenden Vorderkiefern und den geknickten Fühlern, der dünne, sehr bewegliche Hals, der schmale Brustabschnitt und der gegen ihn etwas aufgetriebene, gewöhnlich rundliche bis eiförmige Hinterleib, der am Grunde stielartig verengt ist und dort öfters in ein bis zwei Knoten anschwillt; die drei Paar Beine sind dünn und von mittlerer Länge. Auch die Bewegungen von Ameisen zeichnen sich durch Eile und Planmäßigkeit aus.

Die "Nyrmecoidie" (Wasmann) tritt in zwei, ihrer biologischen Bedeutung nach wohl unterschiedenen Formen auf, von denen übrigens Wasmann nur die zweite behandelt hat. Bei der ersten kommt nur das gewöhnliche Ziel der mimetischen Nachäffung in Betracht, für eine gemiedene Tierart gehalten zu werden, wozu hier noch das Aufsuchen enger Gemeinschaft mit dem Vorbilde; tritt da ein Ausdruck von bezeichnender Kürze und ausreichender Biegsamkeit sich im Deutschen nicht recht bilden läßt, möge das Fremdwort Metökie dafür eintreten.

1) 1909 , S. 44 . 


\section{Metöke Myrmecoidie.}

Die metöken Ameisennachahmer verkehren im Freien, da, wo ihre Vorbilder viel zu sehen sind, womöglich mitten in deren Getriebe, ohne aber ein näheres Verhältnis zu ihnen zu unterhalten, wie dies bei manchen anderen Gliederfüßern der Fall ist, die als Einmieter und Gäste in Ameisennestern vorkommen. Der Vorteil der Nachäffung besteht hier in der Möglichkeit, mit Insekten verwechselt $\mathrm{zu}$ werden, die sehr wehrhaft sind und durch massenweises Vorkommen ihre Kräfte vervielfachen. Was die Waffen der Ameisen belangt, so bestehen diese zunächst in den starken Kiefern, die durch ihre oft kolossal entwickelten Kaumuskeln als Beißzangen benutzt werden, und in einem Giftapparate. Dieser besteht aus einer, das eigenartige Ameisengift absondernden Drüse, deren Saft bei mehreren Familien durch einen Stachel in den Körper des Feindes eingeführt, bei anderen mit verkümmertem Stachel in eine mit den Beißzangen erzeugte Wunde gespritzt wird. Aber auch ohne den Feind selber zu verwunden, können ihn Ameisen sich vom Leibe halten, indem sie ihm die Absonderung der eigentlichen Giftdrüse oder - bei der Unterfamilie Dotichoderinae - diejenige zweier beim After ausmündenden Analdrüsen auf den Leib spritzen ${ }^{1}$ ).

\section{a) Spinnen als Nachäffer.}

Zur Abteilung der metöken Myrmecoiden stellen zunächst die Spinnen einen beachtlichen Beitrag; von den Beobachtungen, die dazu Peckham, Simon, Shelford und Pocock lieferten, hat letzterer eine Anzahl zusammengestellt ${ }^{2}$ ). An sich ist die Durchschnittserscheinung einer Spinne von der einer Ameise bis auf den eingeschnürten und runden bis eiförmigen Hinterleib recht verschieden, denn der Kopf ist mit dem Brustteil in eins verschmolzen und trägt ganz andersartige Fühler; ferner haben die Spinnen vier Paar meist recht langer Beine. Die Ähnlichkeit wird im vollkommensten Grade erzielt durch eine deutliche Einschnürung an den Seiten des Kopfbruststückes, so daß der vordere Abschnitt den

1) Escherich, Die Ameise 1906, S. 26-28 (Verlag von Friedr. Vieweg \& Sohn in Braunschweig). - ${ }^{2}$ ) 1908. 
Kopf, die Einschnürung den Hals und der Hinterabschnitt die Brust des Kerbtieres wiedergibt; bisweilen wird die Täuschung erhöht durch einen Streifen weißer Behaarung längs der Einschnürung, der jene Strecke bedeutend schmäler erscheinen läßt. Um die "Taille" einer Ameise darzustellen, ist der Hinterrand des Kopfbruststückes und öfters auch der Anfang des Hinterleibes in einen dünnen Stiel verschmälert. Ton den dünnen Beinen wird eins der vorderen Paare in der Art der Ameisenfühler über den Kopf emporgereckt.

Einige der besten Fälle von Myrmecoidie zeigen mehrere Tertreter der Sackspinnen (Clubionidae), namentlich das weitgehend angepaßte Myrmecium nigrum aus Südamerika, wofür Pachycondyla villosa das Torbild ist. Das Kopfbruststück hat hinter dem Ansatz des zweiten Beinpaares eine tiefe Einschnürung, so daß der vor ihr liegende Abschnitt den Ameisenkopf darstellt, der hintere aber durch seine Länge, Schmalheit und eine doppelte Anschwellung den Brustabschnitt; ebenso zweckmäßig ist der Hinterleibsstiel nachgeformt. Die Farbe ist dem Torbilde entsprechend schwarz mit feinem gelblichgrünen Haarflaum, und die Ringelung des Hinterleibes wird ron einer Reihe Querbinden angedeutet. Besondere Hinneigung zu dieser Art Mimikry zeigt aber die Familie der Springspinnen (Salticidae), was durch rerschiedene Umstände begünstigt wird. Einmal sind es frei lebende Bodentiere, also den Nachstellungen der Spinnenliebhaber unter den Kerbtierfressern besonders ausgesetzt, des weiteren aber ist ihr langgestreckter Körperbau schon ein Ausgangspunkt für die mimetische Umgestaltung nach dem myrmecoiden Schema. Die Brücke dahin dürften aber gewisse Lebensgewohnheiten dieser Spinnen geschlagen haben, denn wir verdanken dem vorzüglichen entomologischen Reisenden Burchell eine in Brasilien gemachte Beobachtung, die einen Hinweis auf die Entstehung dieser besonderen Angleichung und der Spinnenmyrmecoidie überhaupt gibt. Er bezeichnete nämlich eine von ihm eingeschickte Salticide ausdrücklich als in ihrem Gebahren ameisenähnlich, obwohl die Art im Aussehen eigentlich nicht gerade myrmecoid war. Wenn man auf diesem Gebiete der Naturauslese gestaltenden Einfluß zugestehen will, so könnte somit diese Lebenserscheinung die Unterlage abgegeben haben, auf der sich auch die körperliche Ähnlichkeit entwickelte. 
Dementsprechend hat man auch beobachtet, daß echt myrmecoide Spinnen überraschend genau die Bewegung und das Gebahren der Ameisen nachahmen, z. B. die Clubionide Micaria scintitlans dasjenige der schwarzen Waldameise Formica rufibarbis, $\mathrm{zu}$ der sie sich gesellt. Ton den nordamerikanischen Springspinnen Peckhamia picata und Synemosyna formica, die schon in Form und Farbe sehr gut angepaßt sind, berichtet Miss E. Peckham, daß ihre Art sich zu bewegen ganz von der ihrer Familie abwiche. Sie springen weder, noch rennen sie gerade aus, sondern laufen im Zickzack bald rechts, bald links wie eine beutesuchende Ameise. Während freilich letztere nur bei jener Verrichtung sich derart, unter anderen Umständen aber in gerader Linie bewegt, tut die Nachahmerin es beständig. Auch das Verhalten beim Fressen ist anders gegenüber dem Stillsitzen, das Spinnen dabei beobachten, denn $P$. picata stellt sich dabei an wie eine Ameise, die sich abmüht, einen eroberten Schatz in tragbare Stücke zu zerlegen. Die Beobachterin sah ein Weibchen jener Art eine erlegte Mücke beim Aussaugen mit den Vorderbeinen beklopfen und hin und her stoßen, wobei sie unausgesetzt mit dem Hinterleibe nach Ameisenart zuckte.

Ein Nutzen aus dieser Nachäffung mag den Salticiden nicht nur gegen die allgemeinen Feinde von Arachniden erwachsen, die nicht gleichzeitig vorzugsweise Ameisenfresser sind, z. B. gegen Erdspechte und gewisse Erdkuckucke, deren es in allen Tropen bestimmte Arten gibt, sondern auch gegen größere Angehörige der eigenen Familie, da ja Spinnen bekanntlich arge Kannibalen sind, und gegen die Wegwespen, die für ihre Brut vorzugsweise Laufspinnen eintragen. Spinnen wagen sich nämlich nach Peckham ebensowenig wie jene Stechimmen an Ameisen! Endlich gleicht, wie Haase mit Recht hervorhebt ${ }^{1}$ ), die schützende Nachäffung einen für die Arterhaltung bei den Salticiden ungünstigen Umstand aus: die geringe Fortpflanzungsziffer. So hat die stärkste Art, Phidippus morsitans, 180 Eier, die schon geschilderte Peckhamia (s. Synageles) picata gar nur drei. „Die kleine S. picata ist verteidigungslos und nur durch ihre Ameisenähnlichkeit geschützt. Eine Form mit so niedriger Geburtsziffer kann sich nur erhalten, wenn ihre Sterblichkeit entsprechend gering ist."

$\left.{ }^{1}\right)$ S. 5 . 
(E. Peckham.) In diesem Zusammenhang wird uns das auch für die Salticiden zutreffende, immer wiederkehrende Nerkmal der Mimetiker, ihre geringe Individuenzahl, erklärlich, andererseits aber auch ihr Artreichtum, denn 1889 waren bereits etwa 100 Arten aus den wärmeren Zonen bekannt, wovon die meisten auf Südamerika und Indonesien kommen.

Um eine Vorstellung von diesen Tieren zu geben, wähle ich die Gattung Nyrmarache (Fig. 9). Sie lebt an den Orten, wo Ameisen stark verkehren, z. B. findet man auf Ceylon M. plataleoides in Gemeinschaft mit der merkwürdigen, ihr Nest aus Blättern zusammenspinnenden Oecophylla smaragdina. Hier ist die Myrmecoidie besonders dadurch vervollständigt, daßauch der Ameisenkopf vorgetäuscht wird. Dies besorgen die in eigenartiger Weise ausgebildeten Kieferfühler, die wagerecht über den Kopfrand nach vorn gestreckt und in der Grundhälfte dünn, in der Endhälfte aber gleichmäßig angeschwollen sind (vgl. besonders Fig. 9 b). Von einer anderen Salticide, die

Fig. 9.

a.

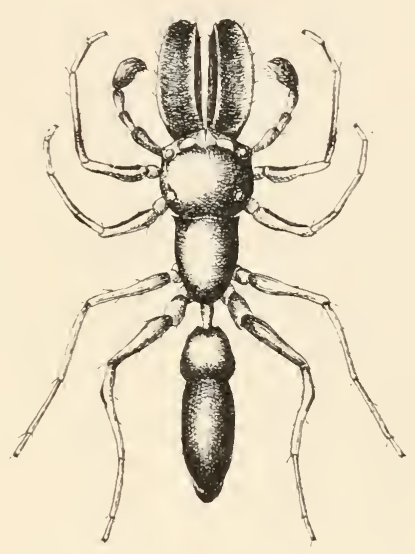

b.

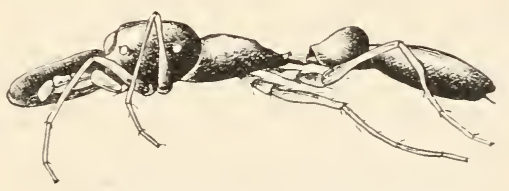

Myrmarache formosana.

a. von oben, b. von der Seite.

Original, etwa zehnmal vergr.

Vosseler mit mehreren myrmecoiden Insektenarten an ein und derselben Örtlichkeit in Ostafrika vorfand, nennt er die Nachahmung so wundervoll — auch in der Fühlerhaltung und in der Bewegung des Tieres überhaupt - durchgeführt, daß ihm die Unterscheidung vom Vorbilde im Leben unmöglich $\operatorname{war}^{1}$ ).

1) 1909 , S. 192 . 
Endlich sei noch ein besonderer Fall erwähnt, der bei Mimikry unter Schmetterlingen viel Gelegenheit zu Erörterungen geben wird, des Inhaltes nämlich, daß bei ein und derselben Art die Geschlechter verschieden gestaltet oder gefärbt sind. Diese Erscheinung, dieman geschlechtlichen (sexuellen)Dimorph ismus nennt, findet sich bei mehreren amerikanischen Argiopiden (1ldibaha mutilloides und myrmicaeformis) im Hinblick auf Myrmecoidie verkörpert. Die Weibchen sind mit Dornen bewaffnet und leben für gewöhnlich schon unterm Schutze ihres Netzes, von wo aus sie einem besonders zudringlichen Gegner leicht durch einen Sprung auf den Boden oder ins Blattwerk entgehen können; die Männchen sind dagegen unbewehrt und bei ihrer Suche nach dem anderen Geschlecht mehr Gefahren ausgesetzt. Sie haben wohl aus diesem Grunde eine ganz andere, myrmecoide Erscheinung. Der Fall ist eigenartig, weil der mimetische Geschlechtsdimorphismus sonst gewöhnlich das weibliche Geschlecht betrifft, wo er durch das größere Schutzbedürfnis des von der Bruterzeugung und Brutpflege stark gefährdeten Weibchens hervorgerufen seiı dürfte.

An diese Einzelschilderungen sei eine Betrachtung über das Wesen der Ameisennachahmung durch Spinnen überhaupt geknüpft. Shelford ${ }^{1}$ ) hat die Ansicht geäußert, daß diese Erscheinung den Trägern zu Angriffszwecken diene, um nämlich unentdeckt zwischen den Ameisen verkehren und sich von ihnen selber nähren zu können. Er hat in der Tat solche Beobachtungen bei Amiciaea lineatipes, einer Thomiside, gemacht, während die von Peckham gehaltenen Salticiden stets Ameisen verschmähten, obwohl sie andere Insekten gern annahmen. Allein das Vorkommen ganz ähnlicher Anpassungen bei einer Reihe von Kerbtieren aus sehr verschiedenen Gruppen, die sich nicht gut anders als nach dem Bedürfnis des Schutzes deuten lassen, spricht doch dafür, daß für die viel verfolgten Spinnen dieselbe Erklärung am nächsten liegt. Eine mittelbare Stütze findet sie auch in der erwähnten geringen Vermehrung der Salticiden, wobei ich aber dahingestellt lassen möchte, ob diese Tatsache die Veranlassung zur schützenden Anpassung gewesen ist oder ihre nutzbringende Folge, mit anderen Worten, ob die Mimikry früher vorhanden

1) 1902 , S. 266 . 
war oder die geringe Fruchtbarkeit. Indessen dürfte der Hinweis auf das Verhältnis der räuberischen Weg- und Grabwespen (Pompitidae, Sphegidae) und einsamen Faltenwespen (Vespidae solitariae) einerseits zu Ameisen, andererseits zu Spinnen die Entscheidung erlauben, ob die Myrmecoidie protektiven Vorteil bringt. Jene Wespen meiden aber Ameisen fast durchweg, ja sie fürchten sich vor ihnen. Andererseits versorgen viele Pompyliden, Odynerus u. a. ihre in Erd- oder Lehmnestern untergebrachte Brut zur Nahrung ausschließlich mit Spinnen, von denen sie zu diesem Behufe ungeheure Mengen zur Strecke bringen: Sphex cyanea

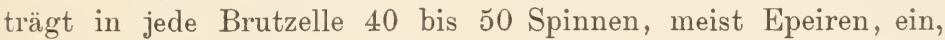
Pompilus polistoides von Nicaragua jagt sie sogar aus den Netzen heraus. Da Raubwespen und Spinnen außerhalb der kalten Zonen überall zusammen vorkommen, so liegt der Schluß nahe, daß diejenigen Arachnidenformen, welche in Gestalt und Lebensweise eine Annäherung an den Ameisentyp eingingen, durch Naturauslese darin weitergefördert worden sind. Jedenfalls kommt nach Pococks Ansicht weder den Schlupfwespen noch den spinnenfressenden Wirbeltieren so viel Beteiligung an dieser Naturauslese zu, wie den Raubwespen.

\section{b) Insekten als Nachälfer.}

An der metöken Ameisennachäffung beteiligen sich, soweit die Beispiele einige Wahrscheinlichkeit für sich haben, nur zwei Familien der Gradflügler (Orthoptera) und zwei bis drei der Wanzen (Heteroptera). Für die Herausbildung der charakteristischen Ameisenform ist hier, da Vorbild und Nachahmer schon dieselbe Körpergliederung haben, in der Hauptsache nur die Verschmälerung des Körpers zwischen Brustabschnitt und Hinterleib nötig. Dies kann durch eine wirkliche Verkleinerung des Durchmessers erreicht werden, aber mehrfach wird durch eine ganz besondere Zeichnung nur der Eindruck eines Hinterleibsteiles hervorgerufen, der sich am toten Sammlungsstück oft kaum geltend macht, desto mehr aber an der Erscheinung des lebendigen, in rascher dem Vorbilde ähnlicher Bewegung befindlichen Tieres, und dessen Wirkung von den Beobachtern immer sehr hervorgehoben wird. Fiebrig ${ }^{1}$ ) will diesen Zug der Maskierung geradezu als

1) Zeitschr. f. wiss. Insektenbiol. 3, 101-106 (1907). 
typisch für die metöken Myrmecoiden unter den Insekten ansehen. Überhaupt muß man im Auge behalten, daß die Verwechselungsfähigkeit mit Ameisen allen Angaben nach mindestens ebensoviel von der Lebensweise und Körperhaltung der Nachahmer bedingt wird wie von der gestaltlichen Modelung. Die rein biologische Anpassung geht sogar bis zur Aufgabe von Gewohnheiten, für die der Bau eigentlich ausgebildet ist und die für die Familie des Nachahmers bezeichnend sind.

\section{Myrmecoide Wanzen.}

Es muß hervorgehoben werden, daß die Mehrzahl von Fällen im gemäßigten Gebiete vorkommt, was für die Mimikryerscheinung an und für sich eine Ausnahme bedeutet; dies schließt nicht aus, daß in den Tropen noch weit mehr dieser kleinen und unscheinbaren, dazu im Gewimmel der Ameisenscharen so leicht aufgehenden Mimetiker zu entdecken sein werden. Die europäischen Beispiele hat größtenteils Bred din ${ }^{1}$ ) zusammengestellt, dem ich darin folge. Eine körperlich schon sehr genaue Nachäffung bietet eine kleine, im nördlichen Europa heimische Blindwanze (Myrmecoris gracilis), deren Rumpf ganz ameisenähnlich ist, indem die hinteren beiden Brustringe stark verengt sind, so daß die bei Ameisen so häufige Verschmälerung der Brust nach hinten zu herauskommt; auch der Ansatz des eiförmigen Hinterleibes ist sehr verdünnt und dazu sind, mit seltenen Ausnahmen, die Flügel zu unbedeutenden Schüppchen verkümmert. Obwohl die Fühler, dem Familientypus ganz entsprechend, lang und dünn sind, kommt ihre mehrfache Knickung immerhin der Bildung beim Modell entgegen. O. Reuter hat noch die hübsche Entdeckung gemacht, daß die Art in zwei Farbenstufen auftritt, wovon die eine, mehr gelbrot gezeichnete unter der entsprechend gezeichneten Formica rufa, die andere mehr schwarzbraun getönte unter der dunkeln F. fusca vorkommt. Eine andere myrmecoide Capside (11yrmecophyes alboornatus) wurde nach 0 . W. Reuters Mitteilung ${ }^{2}$ ) von Poppius in denselben Breiten mit einer schwarzen Lasiusart vereinigt gesammelt, und zwar in Menge auf dürren grasigen Hügeln. Sie war im Laufe und in den Bewegungen den Ameisen so ähnlich, daß der geübte Sammler sich mehrmals irrte, als er

1) 1896, S. 31-35. $-{ }^{2}$ ) Horae Soc. Ent. Ross. 39, 10 (1910). 
die im Streifnetze vereinigten beiden Arten sortieren wollte. Obwohl die verdickten Hinterschenkel der Wanze auf ihre Zugehörigkeit $\mathrm{zu}$ den springenden Blindwanzen hinweisen, übt sie diese Bewegung bezeichnenderweise nicht aus, weil, wie man wohl sagen möchte, sie sich dadurch von ihren Modellen abheben würde.

Mimetiker wie die Myrmecoris sind auch von anderen Familien hervorgebracht worden. Eine zu den Feuerwanzen (Pyrrhocoridae) gehörende, ganz einzeln stehende Form, die Mryrmoplasta mir $a^{1}$ ), wurde von Stuhlmann in Ostafrika in einem Stücke gesammelt und zusammen mit den Ameisen Polyrhachis gagates, der sie täuschend ähnlich sieht, und Ponera tarsata als "Ameise" eingesendet. Auch hier beruht die Nachäffung besonders auf dem kurzen, kugeligen und gegen die Brust tief abgeschnürten Hinterleibe. Dieselbe Gattung Polyrhachis dient einer ganzen mimetischen Gattung von Randwanzen (Coreidae) zum Vorbilde. Dieses aus zwei afrikanischen und einer indischen Art bestehende Genus Dulichius (Formicoris Kirby) ist den zahlreichen anderen Randwanzen sehr unähnlich. Über den indischen $D$. inflatus sagt Wroughton ${ }^{2}$ ), daß er ziemlich häufig unter Steinen in Gesellschaft von Polyrhachis spiniger vorkäme und sie sehr schön nachäffe, sogar in der Bildung des Hinterleibstieles und der für jene Ameise bezeichnenden Rückenstacheln. Dazu bemerkt Rothney ${ }^{3}$ ), daß er Torbild und Nachahmer auch dann vereinigt gefunden habe, wenn die Ameise ihr Nest auf Bäumen anbringe, beide liefen dann zusammen am Stamme herum. Die mimetische Bedeutung dieser Genossenschaft will Bergroth ${ }^{4}$ ) mit dem Hinweise darauf anzweifeln, daß Wroughton die Art nur in einer kurzflügeligen Form gefunden liabe; wenn sich aber noch eine Form mit normaler Flügellänge finden sollte, so würde sie wahrscheinlich keine Myrmecoidie zeigen. Mir scheint dieser Einwand nach jeder Richtung anfechtbar. Erstens kann, wie wir mehrfach sehen werden, auch ein geflügeltes Insekt einem ungeflügelten Ameisenarbeiter täuschend gleichen; zweitens liegt die Vermutung sehr nahe, daß sich, wenn Dulichius inflatus je dimorph gewesen ist, die kurzflügelige Form als die besser angepaßte allein erhalten hat, und an diesem Entwickelungsgange würde drittens das

$\left.{ }^{1}\right)$ Jahrb. Hamburg. wiss. Anstalten 9, 9 (1892). — ${ }^{2}$ ) Proc. Ent. Soc. 1891, S. 17-18. - ${ }^{3}$ ) Ebend. - ${ }^{4}$ ) Entom. Month. Mag. 1892, S. 107 . 
gelegentliche Auftreten der geflügelten Form wenig ändern, denn es gibt unter Heteropteren und Homopteren viele in diesem Punkte dimorphe Arten, wo der Flügelschwund die Regel, das ausnahmsweise Erscheinen geflügelter Bruten vielleiclıt nur ein Rückschlag ist.

Es sei nunmehr ein Fall erwähnt, wo die im Grunde oberHächliche Nachäffung durch bestimmte Färbung einer Stelle mit der früher hervorgehobenen Wirkung entsteht. Die Larve einer bei uns häufigen kleinen Raubwanze, der Nabis lativentris, hat im Körperumriß mit einer Ameise nur die gestreckte Figur gemeinsam. "Aber durch einen wahren Geniestreich der Natur", sagt Bred din ${ }^{1}$ ), , wird das Tierchen wunderbar verkleidet. An der Basis des Hinterleibes tritt beiderseits ein weißlicher, schwach durchschimmernder Fleck auf, der sich über den Rücken hin so weit ausdehnt, daß die dunkle Grundfärbung bis auf einen schmalen Mittelstreifen, der den bekannten stielförmigen Bauchgrund der Ameisen nachahmt, wegretuschiert wird. Um die Maskerade vollständig zu machen, werden auch die plump und eckig hervortretenden Hinterecken des Vorderrückens durch ein weißes Fleckchen unsichtbar gemacht, und die Verwandlung des ziemlich plump gebauten Tieres in eine schlanke Ameise ist fertig." Die Erscheinung der Larve ist von der des fertigen Insektes erheblich verschieden, wie denn ein älterer Beschreiber (Costa) sie als besondere Art mit dem Namen Nabis myrmicodes bekannt gemacht hatte. Dieser Verschiedenheit geht eine tatsächliche Gewöhnung an das Treiben der Ameisen zur Seite, in dem unsere Art von ihren auf Gesträuch und Stauden lebenden Verwandten erheblich abweicht - sie ist ein versteckt lebendes Bodentier, das die Nachbarschaft von Ameisen sucht, wurde sie doch sogar im Inneren der Bauten von Lasius fuliginosus gefunden.

Vir kennen auch ein Gegenstück zu der myrmecoiden Spinne, bei der nur das eine Geschlecht die Myrmecoidie zeigt, in der Blindwanze Systellonotus triguttatus, nur kommt hier in der gewöhnlichen Weise das weibliche in Frage. Das Männchen, durch seine schwarzen, mit silberweißen Querbinden gezierten Deckflügel leicht sichtbar, lebt häufig auf Wiesen und Waldrändern und ist ein längst bekanntes Insekt. Das Weibchen dagegen blieb lange

1) 1896 , S. 34 . 
völlig unbekannt, bis Kirschbaum es 1855 in einem völlig ameisenähnlichen, flinken, kleinen Wesen entdeckte. Man hat es, aber außerordentlich selten, in den Gängen der schwarzen Hügelameise Formica fusca gefunden, etwas häufiger und in einiger Anzahl beobachtete es $\mathrm{O}$. Reuter in den Kolonien des gleichgefärbten kleinen Lasius niger.

Als Beleg für die Erzielung von Ameisenähnlichkeit wesentlich durch das Gehaben eines im übrigen wenig an Formiciden gemahnenden Tieres sei noch ein von Breddin erlebtes Beispiel geschildert. Er hatte jahrelang an einem alten Weinstocke zarte, bräunliche geschwinde Kerfe bemerkt, die den Stamm hinauf und hinab eilten, sie aber nach Größe, Farbe und den emsigen, gleichmäßig schnellen Bewegungen immer für Ameisen gehalten. Ganz zufällig fand er einmal, daß es sich jedoch $\mathrm{um}$ die kleine Capside Pilophorus clavatus handelte, die in Bau und Färbung gar keinen besonderen Anlaß zur Verwechslung mit Ameisen bietet. Wenn ein besonderer Kenner und Sammler der Schnabelkerfe, wie der verstorbene Breddin es war, dennoch irregeleitet wurde und sich darin mit engsten Fachgenossen wie Puton und O. II. Reuter teilte, so zeigt diese Tatsache, daß zur mimetischen Täuschung "durchaus nicht immer ein genaues körperliches Übereinstimmen nötig ist, sondern dal dasselbe Ziel, bei sich sehr schnell bewegenden Tieren, durch ein genaues Kopieren der Bewegungen ihres Nodells in Verbindung mit einer ungefähren Übereinstimmung der Grundfarben rollkommen erreicht werden kann". Nur die eine Bedingung muß erfüllt sein, wenn die Deutung einer Ähnlichkeit als Mimikry Berechtigung haben soll, daß nämlich beide Partner auch in der Natur ökologische Beziehungen zueinander haben, wenn auch nur örtliche. In China gleicht die Randwanze Riptortus linearis im Larvenzustande zuerst erheblich einer dortigen kleinen, gelben Ameise, als Nymphe einer größeren Art, die schwarz und weiß gefärbt und sehr gemein ist. Da aber die auf Leguminosen lebende Wanze keinerlei Gemeinschaft mit diesen Ameisen unterhält, so kann man nicht von Mimikry sprechen ${ }^{1}$ ).

Von den Wanzen sei noch ein Seitenblick auf die verwandte Gruppe von Schnabelkerfen, die Zikaden (Homoptera), geworfen.

$\left.{ }^{1}\right)$ Kershaw und Kirkaldy, Trans. Ent. Soc. 1908, S. 59-62. 
Es gibt unter ihnen eine, namentlich in Amerika äußerst formenreiche Familie, die Buckelzirpen oder Membracidae. Poulton hat mehreren Gattungen dieser ganz wunderlichen Insekten eine mimetische Deutung als Myrmecoide gegeben ${ }^{1}$ ). Es sind die (iattungen Heteronotus und Hemiconotus, deren blasig aufgetriebener und hinten fast bis zur Spitze der Flügel reichender Vorderrücken eine bei manchen Arten wirklich verblüffende Ähnlichkeit mit dem Ameisenkörper hat und von oben gesehen den übrigen Rumpf fast verschwinden läßt. Sogar die Terdickungen am Hinterleibstiele der Knotenameisen (Myrmicidae) werden wiedergegeben. Allein es handelt sich hier nur um eine "Pseudomimikry". Wie mir Ohaus mitteilte, der diese Tiere im südlichen Brasilien beobachtete, läßt ihr Betragen gar keinen Tergleich mit der unruhigen Geschäftigkeit von Ameisen $\mathrm{zu}$; sie sitzen wie alle Zikaden meistens still auf einem Fleck und bringen sich bei Beunruhigung durch ihr vorzügliches Springvermögen in Sicherheit. Allerdings besitzen die Tiere noch ein unmittelbar wirkendes Schutzmittel - sie haben an dem Rückenfortsatze kräftige Stacheln, die sich bei raschem Zufassen empfindlich in die Haut bohren; vielleicht hatte schon Germar, als er eine Art "vulnerans" benannte, von dem ebenfalls bei Rio de Janeiro arbeitenden Sammler Bescke Hinweise auf jene Schutzwaffe erhalten.

\section{Myrmecoide Geradflügler.}

Aus der eigenartigen Unterordnung der $\mathrm{F}$ angheuschrecken (IIantoidea) sind zwei Fälle überliefert, die beide die Larvenstufe betreffen. Nach einer Mitteilung ${ }^{2}$ ) des ausgezeichneten Erforschers der indischen Schmetterlingswelt L. de Nicéville an Poulton hatten die neu ausgeschlüpften Larven einer von ihm aus dem Ei erzogenen Mantide (unbekannter Artzugehörigkeit) bemerkenswerte Ähnlichkeit mit einer kleinen schwarzen Ameise; es gehörte schon eine genaue Untersuchung dazu, um beide unterscheiden zu können. Auch waren die Larven im Gegensatze zu dem trägen, aufs Beschleichen von Beute ausgehenden Gehaben erwachsener Mantiden äußerst beweglich, sie liefen unaufhörlich herum wie die Ameisen, die Nicéville für das Vorbild hielt. Der zweite Fall

1) 1898 , S. $593 ; 1903$, S. $275,281 . \quad{ }^{2}$ ) Veröffentlicht bei Shelford 1902, S. 232 . 
gehört unter diejenigen, welche die Nachäffung durch eine besondere Körperhaltung erzielen. Pocock ${ }^{1}$ ) beschreibt die Larve einer ebenfalls unbenannten Mantide von der Goldküste, die in der Ruhestellung ihren Hinterleib in der gewöhnlichen Weise wagerecht nach hinten gerichtet hält und die Fangbeine unterm Körper verbirgt. Beim Laufen wird dagegen der Hinterleib vollständig nach oben geschlagen, so daß seine Spitze den Hinterrand des Bruststückes erreicht; dadurch verdeckt sie die hellere Zeichnung des Hinterleibsrückens und kehrt dessen gleichmäßig schwarze Bauchseite nach oben, zugleich scheint er die langovale, am Grunde eingeschnürte Form des Abdomens einer Ameise zu haben. Ferner streckt das Geschöpf seine Vorderbeine über den Kopf hinaus und bewegt sie in der Weise, daß die langen Fußglieder den immerzu tastenden Ameisenfühlern ähneln.

Die Familie der Grillen ist durch ein Tierchen (Fhylloscyrtus macilentus) vertreten, dessen Lebensweise Fiebrig ${ }^{2}$ ) in Paraguay beobachtet hat. Die kleine, 7 bis $8 \mathrm{~mm}$ lange Grille hat zur Erzielung der Iyrmecoidie eine ganze Reihe bezeichnender Familienmerkmale abgelegt; besondere Beachtung verdient es im Hinblick auf die Zeichnung von Nabis lativentris und der gleich zu behandelnden Myrmecophana fallax. dab auch hier die stielartige Einschnürung des Ameisenabdomens durch einen hell ockergelben Fleck beiderseits am Grunde der Deckflügel erzielt wird, den die helle Basis der nahe dabei eingelenkten Hinterbeine verstärkt. Die Täuschung tritt dadurch auch bei seitlicher Betrachtung ein. Die Lebensweise der Grille entspricht ihrer Erscheinung, denn sie verweilt besonders an Orten, die von ihren Vorbildern, z. B. Camponotus rufipes, häufig besucht werden. So fand Fiebrig sie in deren Gemeinschaft auf Blättern, die reich mit Schildläusen, diesen Zuckerspendern für Ameisen, besetzt waren, einmal auch am Nesteingange jener Art.

Am besten bekannt unter den myrmecoiden Geradflüglern ist die Larve einer zu den Laubheuschrecken gehörenden Phaneropteride, der Eurycorypha fallax. Das Tier wurde schon vor 30 Jahren im Sudan entdeckt und von Brunner von Wattenwyl für ein reifes Insekt gehalten, das er zum Vertreter einer

$\left.{ }^{1}\right)$ Proc. Zool. Soc. 1910, S. 37. - ${ }^{2}$ ) Zeitschr. f. wiss. Insektenbiol. 3, $101-106,350-352(1907)$. 
besonderen, wegen ihrer auch im trockenen Zustande verblüffenden Ameisenähnlichkeit Myrmecophana genannten Gattung erhob. Viel später fand sie Vosseler im deutschen Ostafrika wieder auf und erkannte durch Feststellung der Imagostufe ihre Zugehörigkeit zu der Gattung Eurycorypha. Er hat durch eingehende Verfolgung der Lebensweise auf allen Entwickelungsstufen die biologische Bewertung dieses Mimikryfalles so vorzüglich geklärt, daß er zu den lehrreichsten und für die Beurteilung der metöken Ameisennachäffung wie der Mimikryfrage überhaupt ergiebigsten Beispielen gerechnet werden muß; ich glaube deshalb nichts Besseres tun zu können, als von den sehr eingehenden Mitteilungen Vosselers ${ }^{1}$ ) das Wichtigste wiederzugeben. Nach seinem Torgange wird die myrmecoide Larve zur Unterscheidung von der erwachsenen Eurycorypha als "Hyrmecophanastufe" bezeichnet.

Unser Gewährsmann fand mehrere der Tierchen im Usambaragebirge auf einem Busche zwischen Ameisen, erkannte sie aber nur daran heraus, daß sie am Grunde des Hinterleibes smaragdgrüne Fleckchen trugen, was ihm bei einer Ameise auffällig schien, aber erst die Untersuchung getöteter Stücke enthüllte ihm die wahre Natur als Orthopteren. Sie sind je nach dem Alter 6 bis. $8 \mathrm{~mm}$ lang und heller oder dunkler braun, während die Nymphen- und Imagostufe ein laubgrünes Kleid tragen. Die Larven kletterten mit der gemächlichen Ruhe einer honigsuchenden Ameise ebenso öffentlich umher, wie die beiden häufigsten Arten der dortigen, Blattläuse besuchenden Ameisen, Myrmicaria cumenoides und Camponotus rufoglaucus; von ihrer Springfähigkeit machten sie dabei nur im Notfalle Gebrauch. Bei der geringsten Störung läßt Myrmecophanı die langen fadenförmigen Fühler in so schnell zitternder Bewegung spielen, daß nur die Basis sichtbar bleibt, wodurch die Länge auf diejenige einer Ameisenantenne verkürzt erscheint; dieser Täuschung kommt zu Hilfe, daß eine Anzahl hellgefärbter Glieder den sonst schwarzen Fühler unterbricht, ohne freilich die so bezeichnende Knickung des Vorbildes nachzubilden. Jene zitternde Bewegung üben freilich auch die Eurycorypha-Stufen aus, die damit keinen mimetischen Eindruck erwecken können - ein zweckloses Beibehalten von Larvengewohnheiten, das auch in anderen Fällen das schöne

1) 1909 . 
Anpassungsschema stört ${ }^{1}$ ). Beziehungen zu den Ameisen ihrer Aufenthaltsorte unterhalten die MIyrmecophana nicht, weichen ihnen vielmehr aus, obwohl sie keine Angriffe von ihnen erleiden. Man findet Vorbild und Nachahmer zu der gleichen Jahreszeit und meist an den gleichen Stellen beieinander, nur sind letztere viel seltener, es kommen nur drei Heuschrecken auf 50 bis 100 Ameisen.

Die Myrmecoidie unserer Heuschrecke ist, wie Tosseler im einzelnen nachweist, eine der vollkommensten Nachbildungen einer Ameise in Form, Färbung und Betragen (Fig. 10). Die körper-

Fig. 10.
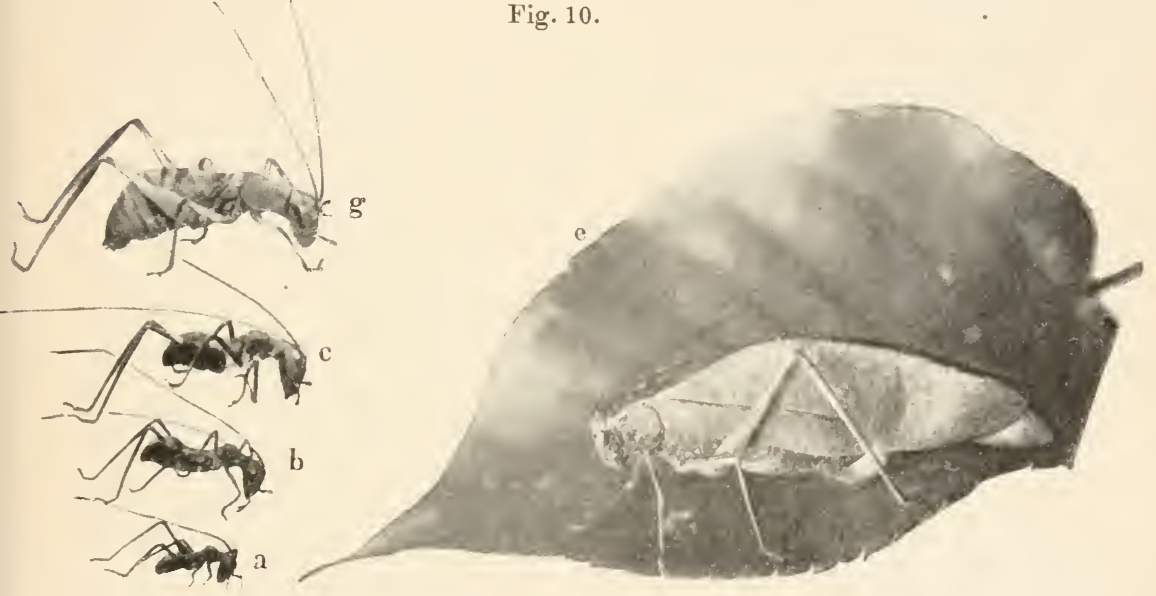

"-y die vier ersten Larvenstadien von Eurycorypha fallax (2:1),

$e$ weibliche Imago $(1,45: 1)$.

Aus Vosseler.

liche Ähnlichkeit beruht auf der Form des Kopfes und seiner Breite im Verhältnis zur Schmalheit des Brustabschnittes, auf dem schlanken Halse und der verengten Vorderbrust; dazu der kugelige, vorn etwas eingeschnürte Hinterleib und nicht am wenigsten die auffallend geringe Ausbildung der Sprungbeine. Sehr wesentlich ist auch, daß die grüne Farbe des Bauches auf die Rückenseite der ersten Hinterleibsringe übergreift, wodurch eben die

1) So nach Werner (1908, S. 600) bei der Mantide Empusa cyanea, die Vosseler für blütennachahmend gehalten hat. 
Täuschung entsteht, als ob jener in dem Grade eingeschnürt sei, wie bei Ameisen. Ich erwähnte schon, daß eine derartige Zeichnung geradezu bezeichnend ist für myrmecoide Verkleidung vieler Gliederfüßer. Wie fein durchgebildet diese Nachäffung bei Myrmecophana auch ist, so will Vosseler doch keinen der angenommenen Züge als entbehrlich zugeben, wenn die Nachäffung - wie es allem Anschein nach geschieht - Vorteil bringen soll; es könnten vielmehr einige Feinheiten noch kräftiger aufgetragen sein. Von einer „hypertelischen“, d. h. unnötig weit durchgeführten, Angleichung, wie sie Brunner an seinem trockenen Sammlungsstück erschien, kann also nicht gesprochen werden. Trotzdem betont Vosseler, daß keine einzige Entwickelungsstufe jener Art der genaue Abklatsch eines dortigen Vorbildes sei, sondern nur einen Durchschnittstyp wiedergebe, dessen Erscheinung nur auf die Täuschung eines rasch darübergleitenden Blickes hin ausgearbeitet sei, allerdings wesentlich unterstützt durch zweckentsprechend verändertes Gebahren. Auch wäre hervorzuheben, daß die Farbe der Larven zwar sehr veränderlich ist, worauf die Ernährung nach Fütterungsversuchen des Beobachters erheblichen Einfluß hat, veränderlich aber nur innerhalb solcher Töne, die bei Ameisen vorkommen. Freilich verschweigt Vosseler nicht, daß dazu die beiden Arten, in deren Mitte die Myrmecophana bei Amani lebt, nicht gerade zählen, allein das Vorkommen von E. fallax reicht ja erheblich weiter, vom Kap bis zum Sudan über die ganze Breite Afrikas weg. Als Möglichkeit für diese weite Verbreitung sieht jener Zoologe gerade die aufs Allgemeine gehende Ähnlichkeit an, denn der Myrmecophana-Typ würde in allen Erdteilen, selbst in den gemäßigten Zonen von Europa für eine Ameise gehalten werden und damit nur denjenigen Gefahren unterliegen, die auch seine Vorbilder bestehen.

Ganz besondere Beachtung darf die Veränderung beanspruchen, die nach der vierten Häutungsstufe mit der Myrmecophana vor sich geht, insofern sie nach Vosseler das Vertauschen der mimetischen Schutztracht mit einer kryptischen bedeutet. Von jenem Entwickelungsgrade an verändern sich nämlich Aussehen und Betragen der Larve, indem ihre Färbung ein Gemisch von Braun und Grün wird und sie selber für gewöhnlich ruhig auf Blättern sitzt; sie stimmt dann sowohl mit den lebenden Modellen wie mit den umgebenden Pflanzenteilen gleichzeitig so gut überein, daß 
man sie nur mit gro@er Mühe entdeckt. Mit Erreichung der geflügelten Imagostufe wird Eurycorypha fallax endlich zu einer vollendeten Blattnachahmerin und gibt ihre ameisenartige Regsamkeit auf, um wenigstens tagsüber ruhig an beblätterten Zweigen angedrückt zu sitzen. Wie Vosseler es zusammenfaßt, ändert unsere Art mit ihrer körperlichen Umbildung fortschreitend auch ihr Benehmen, indem sie es jederzeit mit der jeweilig getragenen Maske im Einklange hält: sie wird aus einem Tagtier ein Nachttier, aus dem Nachäffer beweglicher Tiere zum steifen Pflanzennachahmer, und den Übergang von den myrmecoiden Ständen zu den blattähnlichen verkörpert eine regelrechte Zwischenform.

Für die schützende Bedeutung aller bisher mitgeteilten Fälle von metöker Myrmecoidie ist Voraussetzung, daß die Vorbilder, also Ameisen insgemein, von Insektenfressern gemieden werden. Ist diese Annahme in weitem Umfange richtig? Für seinen besonders durchstudierten Fall äußert sich Vosseler, daß die beiden zur Lebensgemeinschaft gehörenden Formiciden außerordentlich wenig von Feinden heimgesucht werden, solange sie sich auf Büschen bewegen, mehr dagegen auf der Erde und in ihren Erdnestern, wo ihnen mehrere Reptilien und Hautflügler nachstellen; was mit Reptilien gemeint ist, läßt er in der Schwebe, während er sich unter letzteren wahrscheinlich Raubwespen denkt; jedoch wird, wie schon erwähnt ${ }^{1}$ ), von anderen Beobachtern deren Beteiligung verneint. Auf $\mathrm{Zweigen}$ fallen die Ameisen bisweilen Lauf- und Springspinnen zur Beute (also Tieren, die angeblich selber in der myrmecoiden Verkleidung Schutz suchen), doch ist die Vertilgung durch solche selbst in der trockenen, insektenarmen Zeit höchst spärlich. Weitere oberirdische Verfolger gibt es nach Vosselers genauen Beobachtungen bei Amani kaum, da Eidechsen und Laubfrösche die betreffenden Sträucher nicht besuchen und insektenfressende Vögel jene Ameisen verschmähen. Es steht deshalb für ihn außer Zweifel, daß ihre Nachäffung der Euryc. fallax Vorteil bringt, und zwar erklärt er sich das Bedürfnis dazu aus ihrer Fortpflanzungsweise. Die Entwickelung der Eier im weiblichen Körper geht nämlich sehr langsam vor sich, dazu zieht sich die Eiablage über das halbe Jahr hin, auch

1) S. 98 . 
die Weiterentwickelung ist von klimatischen Einflüssen sehr abhängig. So wäre es denkbar, daß diese Vermehrungshindernisse durch die Myrmecoidie ausgeglichen werden, was freilich die Нypothese verlangt, daß es für die Art leichter war, sich im Larvenleben eine schützende Verkleidung zuzulegen, als während des Geschlechtslebens eine raschere und sicherere Eierzeugung und -unterbringung.

Wenn wir ganz allgemein die Ameisenfeinde in Betracht ziehen, so dürften solche aus den Gliederfüßern wenig besagen. Die kräftigen Abwehrmittel der Ameisen, nämlich die Säureabsonderung, der Wehrstachel und die scharfen Kiefer, ihre Kopfzahl, Kampflust und das Mitteilungsvermögen geben ihnen vor der weitaus größten Mehrzahl der in Betracht kommenden Gegner die Überlegenheit. Aber wie jede mimetische Nachäffung soll ja die Myrmecoidie wesentlich vor „Augentieren " als Feinden schützen, und als solche sind hauptsächlich die Landwirbeltiere zu bewerten. Darunter gibt es freilich eigene Ameisenvertilger, die durch die Massenbewältigung in den Bauten auf die Bilanzierung des Naturhaushalts Einfluß üben, so unter den Säugetieren die am Boden spürenden Zahnarmen, wie Ameisenbären (Myrmecophaga) Gürteltiere (Dasypodidae), Schuppentiere (Manis), Ameisenbeutler (Myrmecobius) und Schnabeligel (Echidna). Freilich muß man im Auge behalten, daß mehrere dieser Säuger mehr Termiten- als Ameisenverzehrer sein dürften, worauf auch ihre durchweg mächtigen Klauen als Grabscheite zum Eröffnen der steinharten Termitenbauten hinweisen; zudem ist die Bezeichnung der Termiten als "Ameisen" in allen Tropenländern so eingebürgert, daß man bei der Frage nach der Ernährung jener Vierfüßer stark damit rechnen muß. Auch unter den Vögeln führen mehrere Familien von teilweis großer Artenzahl einen Namen, der sie zu großen Ameisenfressern stempelt, z. B. die Ameisendrosseln (Formicariidae) Südamerikas und die indoaustralischen Glanzdrosseln (Fittidae), die "Ant-Thrushes" der Engländer. Wenn man aber der Nahrungsfrage nähertritt, so kommt man auf ganz befremdende Ergebnisse negativer Art. Von den Formicariiden muß der kenntnisreiche $\mathrm{Newton}{ }^{1}$ ) berichten, daß über ihre Lebensweise kaum etwas bekannt sei, und in einem der besten Werke über süd-

1) A Dictionary of Birds 1893, S. 21. 
amerikanisches Vogelleben findet sich nicht mehr ${ }^{1}$ ). Мan muß bis auf eine um 90 Jahre zurückliegende Äußerung des deutschen Naturforschers v. Kittlitz ${ }^{2}$ ) aus Brasilien zurückgehen, um wenigstens über eine Art, die Pyriglena leucoptera Vieill., die überraschende Tatsache zu erfahren, daß der Vogel zwar den Wanderzügen ron Ameisen mit dem größten Eifer folgt, in den Magen geschossener aber diese Kerfe fast völlig fehlen. "Es scheint also, daß die Ameisen mehr Leckerbissen als regelmäßige Nahrung für diese Vögel bilden." Und die Pittas, welche als reine Bodenvögel es mit der Ameisenjagd gerade am bequemsten haben müßten, haben Wallace und $\mathrm{Dahl}^{3}$ ) nie damit befaßt gesehen und auch keine im Magen gefunden.

Dennoch bestreiten in der warmen wie gemäßigten Zone einige Vogelformen ihr Nahrungsbedürfnis vorzugsweise mit jenen Hautflüglern, dann aber auch durch Ausbeutung der Nester. Dazu zählen bei uns der Schwarzspecht und die beiden Grünspechte anderwärts entsprechende Gattungsvertreter und gewisse Kuckucke So erklärt es sich, daß G. L. Bates ${ }^{4}$ ) unter den Insekten, welche er in den Magen von Vögeln Kameruns fand, die Ameisen im engeren Sinne zwar die dritte Stelle nach Käfern und Geradflüglern einnehmen, aber so gut wie allein von Dendromus, einer Cuculidengattung, verzehrt werden. Außerdem verzehren bei uns nachgewiesenermaßen die kleinen Insektenfresser, wie Nachtigall, Rotund Blaukehlchen, Star, auch die Hühnervögel gelegentlich welche, und die Notizen Dahls berichten von Eisvögeln, Bienenfressern, Fliegenschnäppern, Schwalben, Würgern u. a. m. Aber dabei wiegen augenscheinlich die geflügelten, das will heißen wehrlosen, Stufen vor, während die den eigentlichen großen Verkehr auf der Erde, an Stämmen und im Blattwerk stellenden Arbeiter in den Hintergrund $\mathrm{zu}$ treten scheinen.

Im ganzen genommen erlauben unsere jetzt noch äußerst dürftigen Kenntnisse über den Anteil von Ameisen an der Ernährung anderer Tiere nur die Feststellung, daßs sie als Nestbewohner einer kleinen Anzahl von Feinden blindlings in gewaltigen Mengen geopfert werden. Außerhalb der Bauten dürften namentlich die geflügelten Geschlechtstiere von Vögeln weggeschnappt

1) Sclater and $\mathrm{Hudson}$, Argentine Ornithology 1889. 2) Brehms Tierleben 4, 538 (1891). — ${ }^{3}$ ) 1899, S. 187. — ${ }^{4}$ ) Ibis (9) 5, 630-631 (1911). 
werden. Was aber die unausgesetzt in Heeressäulen hin und her ziehenden Arbeiter belangt, so scheinen räuberische Gliederfüßer sie durchaus zu meiden und Vögel im Durchschnitt wenig darauf zu geben. Diese Stufe ist es aber gerade, die von einigen Spinnen und Insekten nachgeäfft wird, so daß die Annahme einer wirklichen Schutzanpassung bis auf weiteres Berechtigung hat.

\section{Synöke Myrmecoidie.}

In den Bauten von Ameisen lebt eine Anzahl Kerbtiere oder ihre Larven, die aus diesem Aufenthalte entweder einseitigen Vorteil ziehen (Wohnstätte, Gelegenheit zum Raube oder Schmarotzen) oder aber den Wirten für genossene Duldung und Pflege gewisse Leckereien spenden. Dieses Myrmecophilie genannte Verhältnis teilt Wasmann ${ }^{1}$ ) je nach dem Verhalten der Ameisen zu diesen Eindringlichen in vier Gruppen:

1. Feindlich verfolgte Einmieter oder Synechthren, die als Raubtiere von Ameisen oder ihrer Brut leben.

2. Geduldete Einmieter oder Synöken.

3. Echte Gäste oder Symphilen, die von den Ameisen eine wirklich gastliche Pflege genießen.

4. Schmarotzer.

Aus den ersten drei Gruppen gibt es Mitbewohner, die eine Angleichung an die Körperform, bisweilen auch an die Farbe ihrer Wirte, und zwar in weiten Grenzen aufweisen; da das unter 2. genannte Verhältnis das biologisch allgemeinste ist, sei davon der Sammelname für diese Art von Myrmecoidie als der synöken entnommen. Sie hat zum besonderen Merkmal, daß die Nachäffung sich nicht gegen Feinde richtet, die das Vorbild fürchten oder verschmähen - wozu alle bisher behandelten und fast alle in den weiteren Abschnitten vorkommenden Beispiele gehören -, sondern sie soll vor Angriffen der nachgeäfften Form selber schützen. Die hierzu gehörenden Erscheinungen hat der erste Kenner der Myrmecophilie, E. Wasmann, in scharfsinniger Weise gesondert und ihre Bedeutung für das Leben der betroffenen Insekten mit gewohnter Gründlichkeit behandelt, so daß ich mich auf eine kurze, aber an seine Ausführungen möglichst eng anschließende Wiedergabe der Ergebnisse beschränken darf.

$\left.{ }^{1}\right)$ Vgl. Escherich, Die Ameise, S. 163. 
a) Sehmimikry. Für die Art der körperlichen Nachäffung ist es bedingend, ob die Mimiker von ihren Wirten gesehen werden können, wozu gut entwickelte Netzaugen gehören, oder ob die Wirtsameisen blind oder nahezu blind sind. "Bei ersteren beginnt die Myrmecoidie mit Ähnlichkeit der Färbung und schreitet fort zu einer Ähnlichkeit der Gestalt, die ineistens nicht auf wirklicher Formähnlichkeit, sondern hauptsächlich auf täuschenden Lichtreflexen beruht. Bei letzterer beginnt die Mimikry mit Ähnlichkeit der Skulptur und Behaarung, schreitet fort zu einer Ähnlichkeit der Gestalt, welche auf einer wirklichen Formähnlichkeit der betreffenden Körperteile mit jener der Wirte beruht, und gipfelt endlich in der Gleichheit der Fühlerbildung von Gast und Wirt." Auf die Lebensbeziehungen übertragen bedeutet dies: die körperliche Verähnlichung von Gästen gut sehender Ameisen bezweckt hauptsächlich die Täuschung des Gesichtssinnes der Wirte, gegenüber Wirten mit schlechtem oder fehlendem Gesicht aber Täuschung des Fühlertastsinns. Beide Arten mögen weiter als "Seh-" und "Tastmimikry" gesondert behandelt werden.

In Europa findet sich nur die Sehmimikry vertreten. $\mathrm{Zu}$ den Synöken im engeren Sinne gehören die Dinardinen, eine Gruppe kleiner Kurzflügel-Käfer (Staphylinidae), die von ihren Wirten nicht gerade gern gesehen, hier und da sogar verfolgt und angegriffen werden. Die einzige einfarbige Art, Chitosa nigrita, lebt denn auch bei der eintönig schwarzen Aphaenogaster testaceopilosa im Mittelmeergebiet; zweifarbige dagegen, wie Dinarda dentata, D. mürkeli u. a. m., hausen sämtlich bei zweifarbigen, rot und schwarzen Formica-Arten. Wenn die Dinarden auch einen sogenannten "Trutztypus" besitzen (eine Körperform, welche die Bisse von Ameisen wirkungslos macht), so bringt ihnen doch die Ähnlichkeit mit den unwilligen Gastgebern den weiteren Vorteil, daß sie deren mißtrauische Aufmerksamkeit ablenkt und über die Anwesenheit dieser „indifferent geduldeten " Gäste gleichsam beruhigt. Noch besser ausgebildet ist die auf Formähnlichkeit mit Beigabe von gleicher Farbe gestützte Sehmimikry bei den symphilen Atemeles und Lomechusa. Obwohl nämlich, wenn man IVirt und Gast außerhalb der IVohnstätte nebeneinander hält, nur eine ganz geringe Ähnlichkeit besteht zwischen der schlanken, scharf gegliederten Ameise und dem plumpen, gar nicht eingeschnürten Käfer, so stellt doch an Ort und Stelle die eigen- 
artige Verteilung der Farben des letzteren eine so täuschende Ähnlichkeit her, daf selbst das geschulte Auge des Ameisenforschers irregeführt wird. Die rotbraunen Atemeles sind nämlich um die Mitte etwas heller, vorn und hinten dagegen dunkel genau wie ihre Wirte Myrmica rubra. Die dunkle Färbung von deren Hinterleib wird am Käfer dadurch hergestellt, daß sich vor die Spitze ein dunkles Querband legt, das bei der aufgerollten Normalstellung des Abdomens nach hinten und oben sichtbar wird und daraus scheinbar eine dunkle Kugel wie den Hinterleib der Ameise macht. Bei Lomechusa strumosa ist der Gegensatz der Färbung zwischen den hellroten Flügeldecken und dem übrigen Körper viel stärker ausgeprägt als bei Atemeles, entsprechend der lebhafteren Färbung des Wirtes Formica sanguinea mit seiner hellroten Körpermitte. Allerdings ergeben diese Zeichnungen nur an Ort und Stelle eine Ähnlichkeit, also wenn die Käfer im Neste zwischen ihren Wirtsameisen sitzen. Dann ist die Umgebung zu beiden gleichgestimmt und gibt den täuschenden Lichtreflexen Raum, welche die Erscheinung von Wirt und Gast einander zum Verwechseln ähnlich macht. „Die jene Täuschung bewirkenden Reflexe gehen hauptsächlich vom Hinterleibe und Halsschilde des Käfers aus. Ersterer gleicht - wie erwähnt - in seiner aufgerollten Haltung einer glänzenden Kugel von der Größe des Hinterleibes einer Formica- bzw. Myrmica-Königin. Die tief ausgehöhlten und am äußersten Rande aufgebogenen Seiten des Halsschildes dagegen bewirken, daß das Mittelstück der Halsschildfläche durch starken Glanz hervortritt und durch diesen Lichtreflex als ein selbständiges, schmal gewölbtes Stück von der Breite eines Ameisenrückens erscheint. Auf das Sehvermögen der Netzaugen von Ameisen muß eine derartige, auf Lichtreflexen beruhende, optische Täuschung noch viel wirksamer sein als auf unser weit schärferes Auge." Daß die Rechnung stimmt, wonach solche, auf Zeichnung durch Farben oder Lichtreflexe beruhende Ähnlichkeit wirklich Nimikry bedeutet, ergibt sich aus dem Fehlen derartiger Nachahmer in der Gesellschaft von Ameisenarten, die verkümmernde Netzaugen oder nur noch Punktaugen haben. Es läßt sich aber der Beweis auch vom Gegenteil her führen. Von der Staphylinidengattung Myrmedonia leben sechs myrmecophile Arten als feindlich verfolgte Einmieter (Synechthren) bei Lasius fuliginosus und Myrmica rubra, die mittels einer ähnlichen Nachäffung wie die 
vorhergehende die Angriffe der Hausbesitzer von sich ablenken. Dagegen gibt es unter den sehr zahlreichen in Termitenbauten lebenden "termitophilen" Myrmedonien Ostasiens keine einzige, deren Färbung derjenigen von Termiten auch nur im geringsten entspräche, obwohl die Polizeidienst tuenden Indiviauen des Termitenstaates, die Soldaten, nicht weniger wehrhaft und bissig sind als Ameisen, aber sie sind eben völlig blind, so daf eine termitenähnliche Färbung den Gästen keinen Vorteil bringen würde. Die auch unserem Auge auffallende Ameisenähnlichkeit der myrmecophilen Myrmedonien muß also auf den Gesichtssinn der Wirte berechnet sein und für die Träger die biologische Bedeutung von Mimikry haben.

Hier wäre der Platz, um einem Einwande zu begegnen, den sich Wasmann in der Fassung denkt: wie können Ameisen die Färbung und Gestalt ihrer Gäste in dem gewöhnlich dunklen Nestinneren erkennen? Nun, die Myrmedonien zunächst pflegen sich am Nesteingange aufzuhalten, begegnen den Ameisen also häufiger außerhalb als innerhalb des eigentlichen Nestes. Atemeles, Lomechusa und Dinarda findet man dagegen gewöhnlich nur im Nestinneren. „Aber selbst hier herrscht in den oberen Teilen der Erdnester und Haufen, wo das Licht durch die Eingänge Zutritt hat, kein wirkliches Dunkel. Ferner erfolgt die Aufnahme neuer Gäste in der Nähe der Nestoberfläche oder sogar vor dem Neste unter Laub usw., wo sich eine Anzahl Ameisen um die neu ankommenden Gäste versammelt." Bevor ein derartiger Besucher in das dunkle Nestinnere kommt, ist er schon von Ameisen bemerkt und mit den Fühlern untersucht worden, eine Prüfung, die um so sorgfältiger erfolgt, je fremdartiger der erste Eindruck von der Erscheinung des Gastes auf die Ameisen ist. Während dieser Untersuchung können sie den Gast auch sehen. Daher kann der Einwand des Lichtmangels die schon vorgebrachten, für eine mimetische Bedeutung der Ähnlichkeiten in Gestalt und Färbung sprechenden Gründe nicht entkräften.

b) Tastmimikry. Im Gegensatze zu den bisher beschriebenen Fällen ist die Myrmecoidie der Gäste von Ameisen mit ungenügenden oder geschwundenen Sehwerkzeugen auf Täuschung des Fühlertastsinns der Wirte berechnet. In dieser Richtung sind die Gäste der Wanderameisen (Dorylini) ausgerüstet, räuberischer Insektenfresser, die keine dauernden Nester errichten. „Die 
Mimikry der Dorylinengäste beginnt mit Gleichheit der Skulptur und Behaarung bei Gast und Wirt, schreitet fort zur Nachahmung der Körpergestalt des Wirtes und gipfelt in der Gleichheit der Fühlerbildung." Alle diese Anpassungen sind darauf berechnet, dem mit seinem Fühler prüfenden Wirte das Äußere seiner Artgenossen zu unterschieben. $\mathrm{Zu}$ dieser passiven gesellt sich noch eine aktive Mimikry, die auf Ähnlichkeit der Bewegungen, insbesondere der für Ameisen so wichtigen Fühlerverständigung fußt. Wo die Wirtsameisen noch ein gewisses Sehvermögen haben, wie bei einigen Eciton mit gut entwickelten Punktaugen, da weisen deren Gäste auch noch eine nebensächliche Gesichtsmimikry auf.

Am vollkommensten ist die reine Tastmimikry bei Mimeciton pulex, ebenfalls einem Kurzflügler, entwickelt, der in Brasilien bei Eciton praedator lebt (Fig. 11a). Er sieht hell rostrot aus, die Wirtsameise schwarz, also von Farbengleichheit keine Spur, was aber im Einklange damit steht, daß letztere ganz verkümmerte Nebenaugen hat, die höchstens noch Unterschiede von Hell und Dunkel zu empfinden scheinen. Desto vollkommener ist dafür gesorgt, daß die Betastung des Gastes dem Wirte die Erscheinung von seinesgleichen unterschiebt, indem ersterer in Körperbau und Behaarung der kleinsten Arbeiterform angepaßt ist. Die Nachahmung gibt jedoch nicht so sehr die Körperform im ganzen wieder, weshalb sie für unseren Vergleich nicht überraschend ähnlich ist, als daß die einzelnen Körperabschnitte einander gleichen; in diesen Einzelheiten springt die Anlehnung deutlich ins Auge, und der dem Käfer ursprünglich eigene Bau ist in weiter Ausdehnung abgeändert. Der Kopf gleicht dem schmalen Eciton-Kopfe, der erste Brustring mit seinen Einschnürungen ahmt genau den Rücken und der gestielte kugelige Hinterleib den der Ameise nach. "Die größte morphologische Schwierigkeit bestand in der Kopierung der beiden Stielchenglieder von Eciton an der Verbindungsstelle von Thorax und Hinterleib, aber auch sie ist erfolgreich überwunden: die gewölbten, knotenförmigen Flügeldecken des Käfers sind verwachsen und stellen das erste Stielchenglied dar, während das zweite durch das frei vortretende Metanotum des Käfers gebildet wird. Den Höhepunkt der Mimikry finden wir in der Fühlerbildung von Mimeciton, wo das erste Fühlerglied durch Streckung den Schaft des Ameisenfühlers ersetzt. ebenso getreu ist die Nachbildung der Geißel. An den langen Beinen des Käfers ist durch 
einen langen Sporn an den Vorderschienen die bei Eciton an derselben Stelle sitzende kammförmige Bildung wiedergegeben.

Neuerdings ist bei der Treiberameise Dorylus (Anomma) nigricans in Kamerun ein Gast entdeckt worden (Mimanomma spectrum Wasmann), der nach Wasmann ${ }^{1}$ ) das weitgehendste aller Beispiele von Tastmimikry der Dorylinengäste darstellt und

Fig. 11.
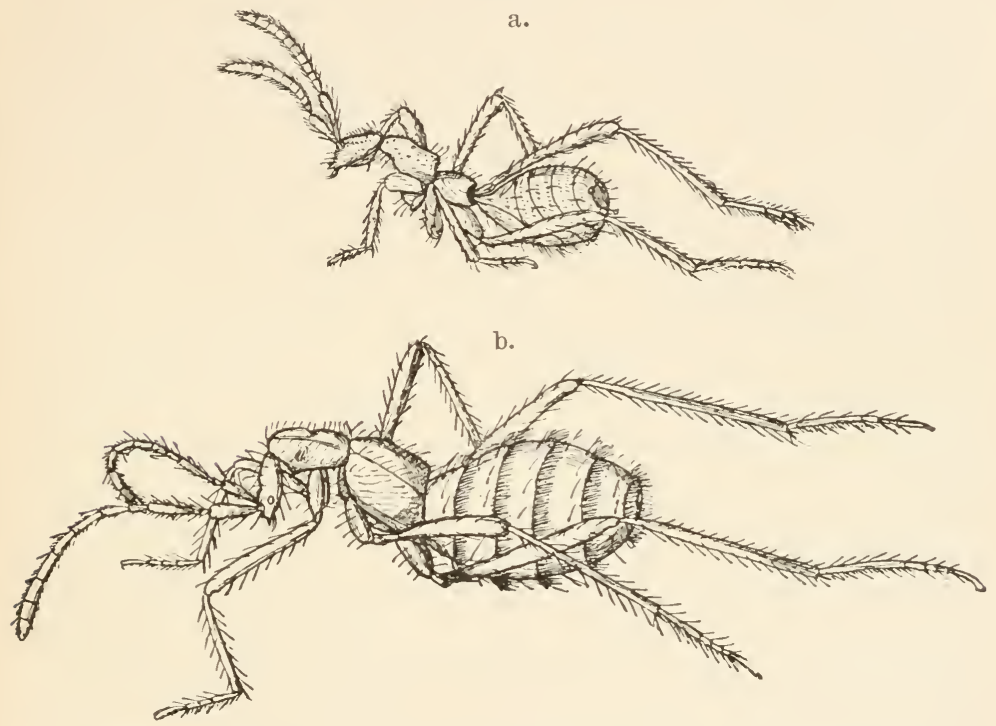

a. Nimeciton pulex. b. Ecitophya simulans (acht- bis zehnmal).

Nach Wasmann aus Lotsy.

darin die vorige Art noch übertrifft. Es ist wieder ein Kurzflügler, dessen ursprüngliche Organisationsmerkmale durch die mimetische Anpassung markiert werden. Dieser Nimetiker geht „in der Nachahmung der Körperformen des Originals weit über dasselbe (!) hinaus und übertreibt die Eigentümlichkeiten desselben (!) in raffinierter Weise".

Ferner will Wasmann an einem anderen Eciton-Gaste außer der Tastmimikry eine Sehmimikry erkennen. Es handelt sich um

1) Zool. Anz. 39, 473-481, 8 Fig. (1912). 
Ecitophya simulans, der als größter aller myrmecoiden Käfer bei Eciton burchelli haust (Fig. 11 b). Die Nachbildung der Ameisengestalt ist keine so feine wie bei Mimeciton, aber dafür ist die Färbung zur vollkommenen Gleichheit entwickelt. Nun hat aber E. burchelli mehrere Arbeiterformen, wovon die größte wie auch die Soldatenform wesentlich heller, von gelbbraun bis gelb, gefärbt sind; dagegen sind die mit dem Käfer gleichgroßen (6 bis $7 \mathrm{~mm}$ langen) Arbeiter matt schwarzbraun, nur der Hinterleib, namentlich gegen die Spitze hin, ist meist braun, und genau dieselbe Farbenverteilung findet sich auch bei Ecitophya. Die Erklärung sucht Wasmann im Zustande der Sehorgane jener Ameisenart, deren Arbeiter für die verschwundenen Netzaugen gut entwickelte, ziemlich große und gewölbte Punktaugen besitzen, so daß die Myrmecoidie der Ecitophya außer auf Irreleitung des Tastgefühls auch auf eine Augentäuschung abzielen dürfte.

Bemerkenswert ist endlich, daß in den Gastverbänden, die uns zuletzt mehrfach beschäftigten, auch Stufen vorkommen, die dem Metökentum nahekommen, da sie mindestens auf Schutz gegen äußere Feinde berechnet zu sein scheinen. Bei den schon erwähnten afrikanischen Treiberameisen (Anomma), die sich ihre Nahrung durch oberirdische Jagdzüge auf andere Insekten verschaffen, gibt es sowohl Nestgäste, die den unterirdischen Bau nicht verlassen, wie Jagdgäste, welche die Raubzüge ihrer Ameise begleiten. Sie haben eine allgemeine, unbestimmte Färbungsähnlichkeit mit dem Wirte, die aber nur den Nutzen haben kann, die Aufmerksamkeit insektenfressender Vögel usw. von den wehrlosen Käfern abzulenken.

Zu den synöken Ameisennachäffern zählen nicht nur Käfer, sondern auch Hautflügler, z. B. kleine Schlupfwespen (Proctotrupidae), aber die geschilderten Beispiele dürften ein genügendes Bild der Erscheinung vermitteln.

Um seine Bearbeitung der synöken Myrmecoidie abzurunden, hat Wasmann es sich angelegen sein lassen, auch den Einwänden zu begegnen ${ }^{1}$ ), die man der Mimikrytheorie im allgemeinen gegenübergestellt hat oder die für jenes Einzelgebiet besonders vorgebracht worden sind. Es käme zunächst die Gegentheorie Eimers in Betracht, die bekanntlich für keinerlei äußere Ïhnlichkeit die

1) 1903 . 
Erlklärung als zweckdienliche Nachahmung gelten läßt, sondern sie als zufälliges Ergebnis unabhängiger Entwickelungsgleichheit (Homoeogenesis) erklärt. Um die Irrigkeit dieser anderen Deutung darzutun, genügt es, auf das mimetische Verhältnis zwischen Mlimeciton pulex und Eciton praedator hinzuweisen. Es hätte sich dazu zunächst jene hochgradige Formähnlichkeit zwischen einem Käfer und einer Ameise, also Angehörigen zweier verschiedener Ordnungen, entwickeln müssen, weiterhin aber hätten diese beiden, zufällig einander täuschend ähnlichen Tiere sich auch als Gast und Wirt zusammenfinden müssen; das sind wohl mehr als billige Forderungen an den Zufall, zumal es eine große Anzahl solch merkwürdiger "Zufälle" gibt.

Auch Piepers ${ }^{1}$ ) hat Anlaß genommen, eine "ruhigere, nicht von der Mimikrysuggestion befangene" Beurteilung unserer Tatsachen zu liefern, die darauf hinausläuft, daß eine $\ddot{C}$ bereinstimmung in Lebensweise und Lebensbedingungen, also äußere Einflüsse, die Ähnlichkeit zweier Partner zustande gebracht habe. Wasmann sagt hiergegen: Bei denselben Wirten und unter denselben, Bedingungen, wie sie die Gäste des Mimikrytypus umgeben, hausen auch solche aus derselben Verwandtschaft, aber vom "Trutztypus", die das gerade Gegenteil von einer Nachahmung der Ameisengestalt zeigen - also müßten ein und dieselben Umstände auf gleichartige Organismen in ganz verschiedener Weise einwirken. Allerdings kommen auch Konvergenzerscheinungen dieser Art vor, indem Gäste vom gleichen biologischen Typus, aber ohne systematische Verwandtschaft, die bei verschiedenen Wirten und in verschiedenen Erdteilen leben, einander auffallend ähnlich werden, z. B. Mimeciton pulex aus Brasilien und Dorylomimus Kohli aus Afrika. Dergleichen Konvergenz hat ihren Ausgangspunkt nicht bei den Nachahmern, sondern in der nahen Verwandtschaft der vorbildlichen Ameisenarten, die also ihren Gästen die gleichen Ziele für die Verähnlichung bieten. Piepers' andere Erklärung ${ }^{2}$ ), daß myrmecoide Ähnlichkeiten durch suggestive Umbildung der nachahmenden Partner entstehen, ist für die wissenschaftliche Zoologie überhaupt zu keiner Erörterung geeignet.

Endlich hat $\mathrm{Brues}^{3}$ ) der Myrmecoidie von Dorylinengästen die gleiche Bedeutung wie der von Metöken gegeben, daß sie also

1) 1903 , S. 126 u.f. - ${ }^{2}$ ) 1903 , S. $167 . \quad{ }^{3}$ ) Americ. Naturalist 36, 367 (1902). 
nicht zum Schutze gegen die eigenen Wirte, sondern gegen äußere Feinde diene. Gegen diesen, nicht die Tatsache der Nachäffung leugnenden, sondern nur ihre Wirkung verschiebenden und verallgemeinernden Einwurf bringt Was man n folgende Gründe bei ${ }^{1}$ ):

1. Auf der höchsten (WVasmann damals bekannten) Stufe des myrmecoiden Typus, bei Mimeciton pulex, ist gar keine Färbungsähnlichkeit von Gast und Wirt vorhanden - der Käfer ist hellrot, die Ameise schwarz; jener müßte also unter den häufig am Tageslichte marschierenden Eciton-Ameisen für das Auge von Ameisenfressern sofort auffallen und von seiner Terkleidung gar keinen Nutzen haben.

2. Man muß sich erinnern, daß Mimeciton nicht so sehr den Gesamteindruck einer Ameise wiedergibt, sondern nur die Oberflächenbildung einzelner Körperteile. Diese kann aber nur für die Tastmimikry der Ameisen, für ihre Fühlertätigkeit als Veranlassung von Myrmecoidie in Frage kommen, während sie für die Wahrnehmung durch das Auge eines Verfolgers wegen ihrer Kleinheit nicht irreführend sein kann, was auch die auffallende Farbe des Käfers verhindern würde.

3. Die täuschende Ähnlichkeit zwischen Gast und Wirt gipfelt bei den mimetischen Dorylinengästen in der Gleichheit der Fühlerbildung. Diese Vervollkommnung eines Nebenorgans bei kleinen, nur 3 bis $6 \mathrm{~mm}$ langen Tieren bleibt auch für das schärfste Sehvermögen eines Insektenfressers außer Betracht. Seine biologische Bedeutung kann sich eben nur auf den irrezuleitenden Tastsinn des Wirtes beziehen.

Bei der scharf umrissenen Eigenart der Myrmecoidie von synöken Ameisengästen ist es angebracht, auch Gedanken über ihren stammesgeschichtlichen Werdegang etwas Raum zu gönnen, wobei ich gebührenderweise wieder dem besonderen Kenner der Erscheinung, Wasmann, das Wort lassen möchte ${ }^{2}$ ). Wenn wir ihn vorhin als Gegner von Deutungen kennen lernten, die bald den Einfluß gleicher äußerer Bedingungen, bald das Zusammenlaufen gleicher Entwickelungsgänge zur Grundlage erheben, so gewährt es einen gewissen Reiz, zu erfahren, dab auch jener Forscher die Wirksamkeit dieser beiden Entwickelungsanlässe zum Ausgangspunkte seines evolutionistischen Gedankenganges

1) 1903 , S. $\left.584 .-{ }^{2}\right) 1903$, S. 588. 
macht, freilich nur in dem Umfange, wie die Mehrzahl sich auf der Mittelstraße deszendenztheoretischer Überlegungen haltender Forscher ihn zuläßt - als Unterbau für die Entfaltung der natürlichen Zuchtwahl. Jedenfalls will $\mathrm{W}$ asmann ron einer Bedeutung der letzteren in der Ausdehnung wie Weismanns "Allmacht der Naturzüchtung" nichts wissen; denn diese kann nie die erste Entstehung eines Mimikryrerhältnisses angeben, also auch nicht deren "primärer Faktor" sein; vielmehr ist sie nur eine Erklärung dafür, weshalb die durch schützende Nachäffung besser ausgerüsteten Formen überlebten und sich in der eingeschlagenen Richtung weiter entwickelten, während andere, schlechter geschützte ausstarben. Für die nähere Begründung sei auf Wasmanns Arbeit verwiesen.

Anmerkung. Der biologische Zusammenhang erlaubt es, noch auf eine wenig geklärte Mimikry hinzuweisen, die Nachäffung der ebenfalls staatenbildenden, aber einer ganz anderen Insektenordnung (Corrodentia) angehörenden Termiten durch $\mathrm{K}$ äfer ${ }^{1}$ ). Die wenigen bekannten Fälle sind nicht gleichwertig. Wo wiederum Staphylinen (Corotoca, Spirachtha, Termitomimus) in Betracht kommen, ist die "Termitoidie" durch den riesig aufgetriebenen Hinterleib recht ausgesprochen, aber alle anderen Gesichtspunkte sprechen dagegen, daß dies eine Schutzanpassung, auf Täuschung des Tastgefühls der Wirte zielend, bedeute. Da nämlich das Verhältnis beider ein auf gegenseitigen Vorteil gegründetes ist (Symphilie Wasmanns), so haben jene Nestgäste gar keine Veranlassung, eine Maske anzulegen. Ich halte deshalb diese Termitenähnlichkeit mit Wasmann für ein zufälliges Beiwerk, eine Pseudomimikry. Anders liegt der Fall mit dem stark umgewandelten, durch viele Einzelheiten einer geflügelten Ternite täuschend ähnlichen Atractocerus termiticola, einem Lymexyloniden. „Es handelt sich hier zweifellos um eine Schutzmimikry, die dazu bestimmt ist, die Termiten über die wahre Natur des Käfers zu täuschen." (Escherich.)

1) Escherich, Die Termiten oder weißen Ameisen. Leipzig 1909, S. $134-136,146$. 


\section{Nachäffung von Küfern (Coleoptera).}

Von den sehr zahlreichen Familien der Käfer sind es verhältnismäßig wenige, die wegen bestimmter Eigenschaften keine geeignete Nahrung für andere Tiere, namentlich die Vertebraten, liefern und deshalb von Insektenfressern unbehelligt bleiben. Sie sind in verschiedenem Grade Gegenstände mimetischer Verähnlichung. Es müssen dabei solche Gruppen außer Betracht bleiben, die vorwiegend Arten von bedeutender Körpergröße umfassen, denn diese ist an sich und wegen der damit verbundenen Dicke des Panzers ein Schutzmittel wider jene Feinde, kann aber naturgemäß nicht zum Zwecke der Täuschung nachgeäfft werden. Vielmehr handelt es sich nur um solche Familien, die entweder in ihren starken Kiefern Trutzwaffen besitzen oder durch äußere Drüsenabsonderungen, scharfe bis giftige Körpersäfte usw. Nachstellungen abwehren. Meistens findet sich damit eine Warnfärbung verbunden, die innerhalb der Familie demselben Schema zu folgen pflegt, und diese Kundmachung von Immunität ist es, welche die Ähnlichkeit mancher ungeschützten Typen sowohl von Käfern wie von anderen Ordnungen als Nachäffung deuten läßt. Jene Tatsache, daß hier wie anderwärts die Widrigkeit durch auffallende Erscheinung angekündigt wird, hat Poulton ${ }^{1}$ ) und einige seiner Mitarbeiter dazu verleitet, den umgekehrten Schluß zu ziehen, daß bunte Farben und gegensätzliche Zeichnung immer auf den Besitz widriger Eigenschaften hinweisen, wenn auch über diese noch nichts bekannt ist. Wenn man seiner sich immer steigernden Neigung, überall in der Insektenwelt Müllersche Mimikry oder, nach seiner Erweiterung dieses Begriffes, "gemeinsame

$\left.{ }^{1}\right)$ Siehe Marshall, 1902, S. 393 und manche von Poultons späteren Aufsätzen. 
Warnfarben" aufzusuchen, folgen wollte, so müßte man bald glauben, daß jedes lebhafter gefärbte Kerbtier gemieden würde, während durch die Befunde aus Vogelmagen schon recht viele Beweise vom Gegenteil geliefert worden sind - wenigstens für die Ordnungen der Coleoptera und Rhynchota $\left.{ }^{1}\right)$. Die Nagenuntersuchungen sind aber neben der viel schwierigeren Beobachtung in der freien Natur das Ausschlaggebende, während der von den englischen Entomologen einseitig bevorzugte Weg des Fütterungsversuches an Käfigtieren widerspruchsvolle Ergebnisse zu liefern pflegt, die deshalb nur mit Vorsicht verwendet werden dürfen. Unter Ausschlu@ der ganz unsicheren Fälle würden etwa die folgenden Familien als immune Vorbilder für Angehörige der Ordnung und einige andere Hexapoden in Frage kommen.

1. Die Sandlaufkäfer (Cicindelidae) sind schon bei uns mittelgroße, äußerst flinke Läufer und für Käfer sehr gute und scheue Flieger, aber in den Tropen erlangen sie neben beträchtlicher Größe und stahlhartem Panzer auch gewaltige, äußerst spitze Beißzangen; ibre Wehrhaftigkeit und Raubgier hat ihnen nicht umsonst die englische Bezeichnung "Tigerkäfer" eingetragen. Somit ist es nicht unwahrscheinlich, daß sie wenig Verfolgung erleiden, wozu das Fehlen in Vogelmagen paßt. Nachahmer sind bis jetzt fast nur unter den Orthopteren gefunden worden. Ton den Grillen, einer Familie, die mit den Cicindelen das Leben am Boden und die wesentlich laufende Ortsbewegung gemeinsam haben, wird die eigenartig umgebildete Gattung Phylloscyrtus aus Südamerika genannt; in geringerem Grade mimetisch ist das südeuropäische Trigonidium cicindeloide. Ganz betörend ist dagegen die Ähnlichkeit der Laubheuschrecken des weit verbreiteten Genus Condylodera mit Sandkäfern (Tricondyla); sie haben die Flügel verkümmert, einen vorgequollenen Kopf mit den großen abstehenden Augen ihrer Modelle, lange Beine und blauschwarze Farbe mit roten Oberschenkeln, wie sie jenen oft zu eigen ist. Die immer nur selten vorkommende Cond. tricondyloides täuschte selbst den großen Entomologen Westwood so, daß er sie in der Sammlung zu den Cicindelen steckte, ja Duponchel beschrieb sie im ersten Eifer sogar als eine nene Art von Tricondyla. Beide

I) Als Quellen dienten mir Arbeiten von Dahl, Rörig, Baer, Rey, Jablonowski. 
Insekten leben auf den großen Sundainseln, und zwar gemeinschaftlich am Boden zwischen trockenem Laub und Moder ${ }^{1}$ ).

Eine andere Angleichung besteht zwischen Peridexia fulvipes und der Grabwespe Pogonius venustipennis von Madagaskar ${ }^{2}$ ). Beide sind $12 \mathrm{~mm}$ lang und gleichen sich besonders in den schwarzen, durch zwei chromgelbe Binden verzierten Vorderflügeln. Nach dem Sammelbericht teilt diese schlankbeinige Wespe Örtlichkeit und Gebaren mit dem Käfer, indem sie bald mit gefalteten Flügeln dahinläuft, bald kurze Strecken dicht über dem Boden fliegt, so daß sie wenigstens das menschliche Auge täuscht. Hier könnte man, trotz Hellers gegenteiliger Ansicht, wohl an II üllersche Mimikry denken, da ja beide Partner Abwehrmittel besitzen.

2. Den Rüsselkäfern (Curculionidae) wird manchmal Unverletzbarkeit infolge ihres in der Tat oft sehr harten Panzers nachgerühmt. Da die Härte und Dicke des Chitins der Körpergröße einigermaßen folgt, so müßten namentlich die großen tropischen Rüßler unbehelligt bleiben; dies ist aber durchaus nicht der Fall nach Dahls ${ }^{3}$ ) Magenuntersuchungen papuanischer Vögel, die das Verzehren von so mächtigen und äußerst harten Tieren wie Rhynchophorus und Rhinoscapha ergaben. Danach dürften die von Wallace ${ }^{4}$ ) aufgenommenen Fälle, wo die Gattung Heilipus von anderen Curculioniden nachgeahmt werden soll, ebensolch zufälliges Zusammentreffen von Zeichnungsentwickelung sein wie die von Heller ${ }^{5}$ ) mit ähnlichem Zweifel erwähnten Parallelen. Eher noch wäre an die Gültigkeit der Mimikry nach einigen nahe verwandten Gattungen - Pachyrhynchus und Apocyrtus - von den Philippinen zu denken, denn diese erreichen bei nur mittlerer Größe wohl das Äußerste an Hartschaligkeit und haben außerdem eine so glatte, kugelige Oberfläche, daß wenigstens kein Vogelschnabel Angriffspunkte finden möchte. Die Käfer sind rot oder grün metallglänzend und haben als sehr auffallende Zeichnung große hell umrandete Augenflecke auf der Oberseite. Diese besondere Erscheinung findet sich bei mehreren dortigen Bockkäfern, z. B. Doliops curculionides, nachgeäfft, bemerkenswert aber wieder bei einer Grille, dem Scepastus pachyrhynchoides ${ }^{6}$ ). In Wiedergabe

1) Shelford, 1902, S. 233. - 2) Heller, Entom. Nachr. 18, 183 (1892). - $\left.{ }^{3}\right)$ 1899. — $\left.{ }^{4}\right)$ 1891, S.394. — ${ }^{5}$ ) Entom. Nachr. 17, 185 (1892). - ${ }^{6}$ ) Gerstäcker, Stett. Entom. Ztg. 24, 424 (1863). 
der gedrungenen Käfergestalt sind Halsschild und Flügeldecken stark halbkugelig gewölbt und letztere nach hinten birnförmig geweitert; von den Beinen ist das erste Paar ganz nach Käferart gestaltet und auch das letzte mehr käfer-als grillenähnlich (Fig. 12). Zu der für Geradflügler schon sehr seltenen Metallfarbe kommt noch das Augenfleckenmuster als etwas für alle bekannten Mitglieder der Ordnung Fremdartiges. Wenn jene Rüßler wirklich geschützt sind, so ist diese Maske für die weichhäutige Grille sicher ein Vorteil.

3. Den Blattkäfern (Phytophaga) wird vielfach Anziehungskraft für Nachäffung zugeschrieben ${ }^{1}$ ). Viele haben auffallend metallbunte Farben oder gegensätzliche Fig. 12.

a.

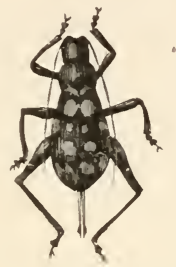

a. Scepastus pachyrhynchoides.

b. Pachyrhynchus sp. Aus Wallace.

Zeichnung, sie leben frei sichtbar auf Gewächsen, bewegen sich langsam und sondern gelegentlich samt ihren ähnlich gearteten Larven scharfe Stoffe ab (bei den Larven von ILelasoma populi und ihren Verwandten riecht das Exkret stark nach Nitrobenzol). Während nach Poultons Meinung die Unterfamilien Galerucinae und Hispinae besonders von Käfern anderer Familien, also pseudaposematisch, nachgeäfft werden, soll innerhalb der Chrysomelincie und Eumolpinae die synaposematische Mimikry herrschen, weil deren Mitglieder vielfach in ungeheuren IIengen auftreten und Ekelsäfte führen. In der Tat scheinen die öfters an Kulturpflanzen Verheerungen anrichtenden Melasoma im Freien auf Vögel keinerlei Anziehung auszuüben, was mir wichtiger scheint als eine Beobachtung, daß sie im Zwinger nicht verschmäht werden ${ }^{2}$ ).

Beachtenswerte Angaben über die Mimikry beiderlei Gestalt macht Gahan ${ }^{3}$ ). Die weit verbreiteten Igelkäfer (Hispa) sind wohl durch ihren dichten Stachelbesatz immun; ihnen gleichen auf Borneo drei Arten von Lema, einer sonst unbewehrten Gattung,

$\left.{ }^{1}\right)$ Haase, S. 12; Donisthorpe, 1901, S. 367; Poulton bei Marshall, 1902 , S. 393 f. - ${ }^{2}$ ) Donisthorpe, S. 367. - ${ }^{3}$ ) Trans. Ent. Soc., 1891, S. $367-374$; Taf. 17 . 
und scheinen im Gegensatz zu den Modellen von der gewohnten Seltenheit zu sein. Andererseits gleichen sich von den beiden äuBerst formenreichen Gattungen Lema und Diabrotica etwa 15 Arten in Farbe, Zeichnung und Größe bis zum Verwechseln, während sie durch feinere Gattungsmerkmale durchaus gesondert sind; das Vorkommen der Doppelgänger deckt sich jedesmal. Obwohl Lema ein hartes Chitinkleid hat, Diabrotica aber weichhäutig ist, dürfte letztere Gruppe doch der Ausgangspunkt für die Nachäffung durch jene sein, weil mehrere große Arten Südamerikas beim Anfassen eine scharfe Flüssigkeit aus dem Mund und den Beingelenken hervortreten lassen; die kleineren Arten haben dieses Schutzmittel nicht, ebensowenig irgend eine Lema. Diesen Fall hofft Poulton ${ }^{1}$ ) durch spätere (!) Beobachtungen als Synaposem erwiesen zu sehen und knüpft daran die Prophezeiung, daß künftig die I üllersche Erklärung mimetischer Ähnlichkeiten ungleich ausgedehntere Anwendung finden werde als die Bates sche.

4. Von der Nachäffung von Marienkäfern (Coccinellidae) durch Spinnen war bereits S.78 die Rede gewesen. Diese können nach vielen ihrer Eigenschaften, nämlich der grellen Farbe, sichtbaren Lebensweise und Langsamkeit, besonders aber wegen der Absonderung ihres übelriechenden, scharfen Blutes auf Reiz hin allgemein als immun gelten. In der Tat wurden sie nach Versuchen von J. Weir, Poulton und Wallace von Kaltblütern verschmäht, und von freilebenden Vögeln darf man dasselbe annehmen, da nach Rey ${ }^{2}$ ) die Coccinellen nur 3,4 Proz. von deren Käfernahrung ausmachen; die Ausnahmen stellen in allen Zonen zumeist die Kuckucke ${ }^{3}$ ), die ja überhaupt am wenigsten heikel sind. Unter den Nachahmern, deren in den neueren englischen Arbeiten viele aufgestellt wurden, ist besonders die Beteiligung der Schaben (Blattoidea) bemerkenswert, weil sie mit einer völligen Aufgabe der gewöhnlichen Lebensweise dieser altertümlichen Geradflügler einhergeht. Während die überwiegende Zahỉ düsterbraun gefärbt ist und ein sehr verborgenes Leben führt, gibt es auch solche, die in bunten, scharf verteilten Farben prangen und sich furchtlos im Tageslicht zeigen. Wie schon

1) 1898 , S. 573. - ${ }^{2}$ ) 1909 , S. $26 .{ }^{3}$ ) Fowler 1901, S. 41; Dahl, S. 172,173 . 
Semper ${ }^{1}$ ) an der philippinischen Cassidodes ligata und Shelf or ${ }^{2}$ ) an reicherem Tropenmaterial zeigten, wird die Nachäffung nicht allein in der Zeichnung - die aber nur ein Durchschnittsmodell wiedergibt - , sondern in sehr feiner Weise auch in der Körperform, in der Umbildung und entsprechenden Faltung der Flugorgane zu dem dicht schließenden Gewölbe der Coccinellen und in anderen Einzelheiten bewirkt. Die Blattiden haben gewöhnlich einen aus Drüsen stammenden, für uns Menschen unangenehmen Geruch, der aber z. B. kein Hindernis für die Vögel ist, diese Finsterlinge als Leckerbissen zu verspeisen. Wenn dieser Geruch aber nach Shelford bei jenen abweichend gearteten Schaben der Gattung Prosoplecta zu fehlen scheint, so darf man pseudaposematische Nachäffung annehmen, zumal diese Formen wieder recht selten sind.

5. Eine bei uns spärlich und nur unscheinbar vertretene Familie, die Erotylidae, zählt in den südamerikanischen Tropen viel größere und in der bunten Tracht den Marienkäfern nicht unähnliche Formen; auch ihr Wesen ist ein ähnliches, denn sie sind Tagtiere, die sich oft zu kurzem Fluge erheben. Daß die stärkeren Vertreter einen für uns sehr wahrnehmbaren Geruch von sich geben, wäre an sich keine Nötigung für Käferfresser die Erotylen zu verschmähen, aber den Geruch mit den anderen körperlichen und biologischen Eigenschaften zusammengefaßt läßt sich eine Immunität wohl annehmen, die für andere Käfer zur mimetischen Anlehnung geführt hätte. Solcher Fälle finden sich eine Anzahl bei $\mathrm{Haas} \mathrm{s}^{3}$ ) erläutert, von denen ich zwei als Beispiele auswähle. Von der Laufkäfergattung Lia Esch. ähneln einige brasilianische Arten durch weibliche Binden auf lohfarbigem Grunde durchaus gewissen Erotyliden, mit denen sie, man beachte, auch das engere Vorkommen auf Pilzen teilen. Andere haben zur feineren Angleichung an die Vorbilder noch eine Familieneigenschaft der Carabiden, die Längsfurchung der Flügeldecken, verloren und zeigen die glatte Oberfläche der ersteren. Die Fälle gruppieren sich so:
Lia scripta
$\rightarrow$ Priotelus vigintipunctatus
Lia elegans
$\rightarrow$ Megaprotus ephippium
Lia albosinuata
$\rightarrow$ Iphicles flavosinuatus.

$\left.{ }^{1}\right)$ Die natürlichen Existenzbedingungen der Tiere 2, 236 (1880). ${ }^{2}$ ) Proc. Zool. Soc. 1912, S. 358-376; Taf. 48. - ${ }^{3}$ ) S. $14-18$. Jacobi, Mimikry. 
Eine andere mimetische Vereinigung wird in Fig. 13 gezeigt. Ausgangspunkt ist ein sehr häufiger Erotylide Brasiliens, der Erotylus histrio, dessen Kopf und Halsschild schwarz, die Flügeldecken auf schwarzem Grunde mit ockergelben Zickzackbinden geschmückt sind, während deren Schulterecken ein leuchtend orangerotes Mal tragen. Dieselbe Färbung, einschließlich der roten Flecke, hat der zu den Lamiinen gehörende Bockkäfer

\section{Fig. 13.}
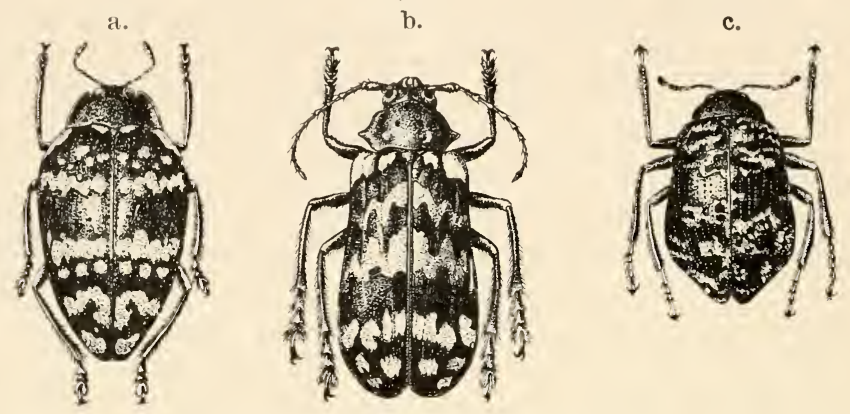

a. Erotylus histrio (Erotylidae),

Vorbild zu b. und c

b. Poecilopeplus corallifir (Cerambycidae).

c. Cuphotes marmoratus (Tenebrionidae).

Original, natürl. Größe.

Poecilopeplus corallifer, während sie dem Schattenkäfer Cuphotes marmoratus bei sonstiger Ähnlichkeit fehlen (der Eindruck würde bei farbiger Wiedergabe viel täuschender sein).

6. Eine Familie, deren Immunität keinem Zweifel unterliegt, bilden die Weichkäfer (Malacodermata). Keiner von ihnen besitzt eine ausgesprochen kryptische, viele aber eine auffallende Färbung, deren aposematische Bedeutung sich auf die ätzende Leibesflüssigkeit oder ebensolche Drüsensäfte stützt. Es sei nur an unsere sehr häufigen, leuchtend grün und rot gezeichneten Warzenkäfer (Malachius aeneus und bipustulatus) erinnert, die bei Berührung ganze Gruppen von Hautdrüsen aus den Seiten des Leibes herausstülpen. Dem entspricht die bereits hervorgehobene offensichtliche Lebensweise z. B. unserer Telephorus, und den Beweis, daß wenigstens die Vögel sie gänzlich verschmähen, haben wir darin, daß sie in deren Mägen noch nicht einmal 0,2 Proz. 
der Käfernahrung stellen ${ }^{1}$ ); Newstead fand überhaupt keine darin ${ }^{2}$ ).

Von den Weichkäfern ist die wesentlich tropische Unterfamilie der Lycinae der Mittelpunkt einer ebenso vielseitig wie scharf ausgeprägten Mimikry, die Haase geradezu die lyciforme nennt. Nach seiner Schilderung ${ }^{3}$ ) macht sich die Erscheinung der Lycinen (vgl. Fig. 14a, 15a, 16a) geltend in der Form der Flügeldecken, die dem Körper meistens nur flach aufliegen, ohne ihn zu umschließen, vier starke Längsrippen besitzen und sich nach hinten erweitern; die Fühlerglieder sind gewöhnlich rom vierten Gliede an verbreitert und schwach gesägt. Die Färbung ist von einem sehr gleichförmigen Muster, was die Bedeutung als Warnfärbung stützt: ein helles, in der Mitte dunkleres Halsschild und gelb- bis rotbraune Flügeldecken, darauf ein grund- und ein endständiges dunkleres Querband. Diese Zeichnung kann einerseits den hellen Grundton ganz verdrängen, andererseits mehr oder weniger schwinden, z. B. innerhalb neotropischer Gattungen. Für die Lebensweise und besonderen Eigenschaften dienen uns Narshalls ${ }^{4}$ ) Angaben aus Südafrika, wo die typische Gattung Lycus nach Arten- wie Individuenzahl stark verbreitet ist. Die Käfer leben zumeist auf Blüten und fallen sehr auf; sie sind sehr träge und langsamen, schweren Fluges, lassen beim Angreifen aus den Hinterschenkeln einen sehr stinkenden, weißen Saft austreten und stellen sich gern tot, sind aber trotz ihrer weichen Haut äußerst zählebig - alles bezeichnende Merkmale von Unangreifbarkeit. Diese Eigenschaft sah Shelford ${ }^{5}$ ) sich bewähren, wenn Lyciden versuchsweise von Vögeln gepackt wurden, denn sie liefen auch nach mehrmaligen Angriffen ungestört weiter. Nach Belt ${ }^{6}$ ) heben und senken sie beim Kriechen die Flügeldecken in besonderer Weise.

Was die Erscheinung der lyciformen Nachahmer zunächst im allgemeinen belangt, so hat uns Gounelle ${ }^{\tau}$ ) gezeigt, daß die bemerkenswerte Gleichförmigkeit der Lycinen sowohl innerhalb der großen Tiergebiete wie in deren Unterbezirken bei den Mimetikern ganz denselben Ausdruck findet, daß also die besondere Tracht einer Gattung von den am gleichen Orte lebenden lyciformen

$\left.{ }^{1}\right)$ Rey, 1909, S. 26. - ${ }^{2}$ ) Nach Fowler, S. 42. - ${ }^{3}$ ) S. 12. $\left.{ }^{4}\right)$ 1902, S. 517. - ${ }^{5}$ ) 1902, S. 267. - ${ }^{6}$ ) Natural. in Nicaragua, 1874, S. $317 .-{ }^{7}$ ) Bull. Soc. Entom. France 1905, S. 132. 
Insekten kopiert wird. In Südbrasilien sind die Lycinen im Stromgebiet des San Francisco schwarz gefärbt, an der Küste und in den Regenwäldern von São Paulo bis Pernambuco mischt sich Gelb in das Schwarz, während sich in der Provinz Goyaz und in der Republik Paraguay Übergänge nach Grau hin einstellen. Jedesmal haben sich die örtlichen Nachäffer aus mehreren Käfer- und Schmetterlingsfamilien dem betreffenden Färbungscharakter angepaßt. Um im neotropischen Gebiet zu bleiben, so findet sich unter den Coleopteren diese Mimikry bei weichhäutigen Buntkäfern (Cleridae), Fadenkäfern (Oedemeridae), dünnschaligen

a.

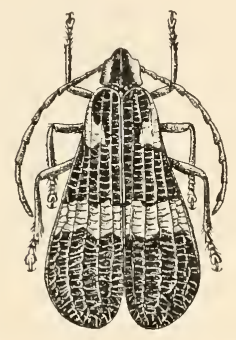

Fig. 14.

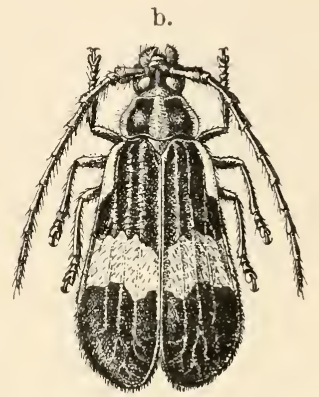

a. Calopteron torquatum, Peru (Lycinae).

b. I'teroplatıs sp., Peru (Cerambycidae).

Original.

Rüßlern (Curcutionidae), namentlich aber bei Böcken aus den Unterfamilien der Cerambycinae und Lamiinae. Vielfach haben letztere ganz den typischen Umriß ihrer Sippe aufgegeben und machen den Eindruck ganz fernstehender Familien, wie denn die Gattung Lycidola ihren Namen von der Lycusmaske bekommen hat. Sie zeigen auch im Gehaben die fortgeschrittenste Anpassung an ihre Modelle, indem z. B. Evander nobilis das Zucken mit dem Hinterleibe in derselben Weise übt, wie sein Modell Calopteron basale. So häufig freilich die Lycinen aufzutreten pflegen, so selten sind im Verhältnis dazu wieder die ausgesprochen lyciformen Cerambyciden. Unsere Figuren (Fig. 14 bis 15) zeigen zwei typische Lycus mit schwarzgelber Zeichnung aus Südamerika mit ihren in Größe, Gestalt und Färbung sehr ähnlichen Cerambycidennachäffern (Calopteron torquatum $\longleftarrow$ Pteroplatus sp.; C. lim- 
batum « Pteroplutus lyciformis), doch würde auch hier eine farbige Wiedergabe den Eindruck weit täuschender machen.

Bei den Cleriden war die Ursache zur Nachäffung vielleicht in der Weichheit der Flügeldecken mancher Formen gegeben, sie neigen sogar dazu, die hintere Verbreiterung dieser Organe anzunehmen, die bei der kopierten Familie so häufig ist; auch das gemeinsame Leben auf Blüten kann zu den Anlässen dieser Umbildung gerechnet werden. Die Nachahmer sind zwar nach der Kopfzahl innerhalb ihrer Art selten, aber es haben ganze Gattungen das lyciforme Kleid angelegt, so das mittelamerikanische Genus

Fig. 15.

a.

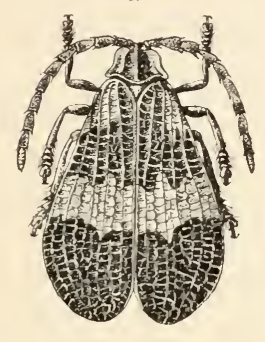

b.

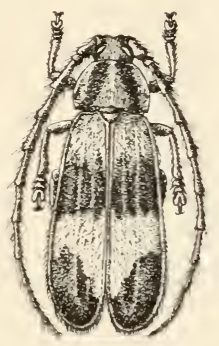

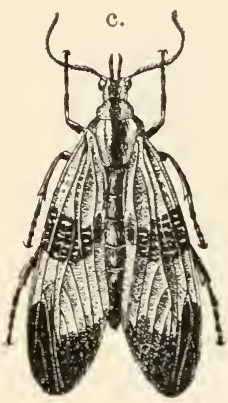

a. Calopteron Timbatum, Brasilien (Lycinae).

b. I'teroplatus lyciformis, desgl. (Ceramb.).

c. Correbia lycoides, desgl. (Syntomidae).

Original.

Ichnea und die im Orinokogebiet verbreiteten Pelonium und Platynoptera, die sich an Lycinen mit leuchtend roten, am Ende tiefblauen Flïgeldecken und in diesen Farben gemustertem Halsschild anschließen. Fig. 16 stellt ein solches Paar aus Venezuela dar.

Auch in Afrika hat die lyciforme Mimikry nicht wenige Nachäffer aus den Cleridae, Metyridae, Canthuridae, Cerambycidae und anderen Familien, wovon Marshall und Poulton ${ }^{1}$ ) lehrreiche und schön illustrierte Zusammenstellungen geben; da manche der Mimetiker, z. B. Canthariden, selber abschreckende Besonderheiten haben, so deuten die Forscher auch hier manche dieser Paarungen als synaposematisch.

1) Marshall, 1902, S. 517; Taf. 18. 
Wenn ferner gewisse Schaben der Gattung Paratropa in Südamerika eine ausgesprochen lyciforme Tracht angelegt haben, so ist dies im Hinblick auf die schon behandelte mimetische Angleichung an Coccinelliden bemerkenswert, verlangt aber auch den Hinweis, daß die Körperform der Blattoideen die Annäherung an Lyciden erleichtert, insofern beide Gruppen das kapuzenförmige, den Kopf überdachende Halsschild haben. Viel auffälliger ist, daß auch Schmetterlinge die lyciforme Mimikry eingehen, da ihre Flügelbildung und -haltung der Nachäffung von Käfern nicht gerade die Wege ebnet. Allerdings kommt sie nur bei

Fig. 16. a.

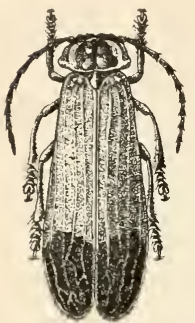

b.

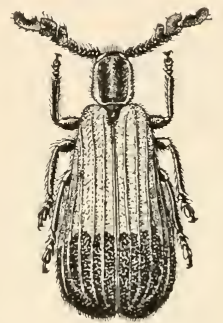

a. Lygistopterus eximius, Venezuela

b. Platynoptera lycoides, desgl. (Lycinae). Original. Heteroceren, "Nachtfaltern", vor, die ja ihre Flügel in der Ruhestellung dachförmig nach hinten zusammenlegen, so daß nur das vordere Paar sichtbar bleibt, wie bei Käfern. Eine besondere morphologische Annäherung besteht darin, daß die äußeren Längsadern der Vorderflügel stark kantig hervortreten, wie es für die Lycinen bezeichnend ist ( $\mathrm{vgl}$. Fig. 15́a und c), auch können die Fühler nach Art dieser seitlich zusammengedrückt sein. Von den Nachahmern, die rein neotropisch sind, gehört eine Gattung (Pionia) zu den Bären (Arctiidae), die andere zu der an sphecoiden Mimetikern schon so reichen Familie der Syntomidae - beide natürlich Tagtiere. Die lyciformen Syntomiden gehören zu den Gattungen Correbia und Lycomorpha und schließen sich in der Färbung bestimmten Arten von Calopteron an, die wir schon als Modelle für Cerambyciden kennen lernten. Bald haben sie dann die Erscheinung der gelb und schwarz gebänderten Typen, wie Correbia lycoides, die mit den gemeinen Cal. limbatum, reticulatum, serratum Brasiliens zusammenlebt (Fig. 15c), oder sie sind ganz stahlblau wie Correbia oberthuiri $\rightarrow$ Cal. cyaneum. Hier ist zu beachten, daß dieser dunkelblaue Farbenton bei den Syntomiden überhaupt vorwiegt, also mimetische Annäherung an ebenso gefärbte immune Insekten — dort Wespen, hier Käfer - erleichtert. 


\section{Nachäffung unter Schmetterlingen.}

Die mimetischen Ähnlichkeiten zwischen Schmetterlingen sind für Bates, Wallace und J. Müller der Ausgangspunkt der Theorie gewesen und sind später an einer sehr großen Zahl von Fällen festgestellt worden, was eine immer genauere Untersuchung der Vergleichspunkte und der Verwandtschaftsbeziehungen zur Folge hatte. Dadurch liefert die Ordnung Lepidoptera den reichsten Stoff für die Erörterung von Mimikryerscheinungen, und gewisse Beispiele daraus werden in jeder Schrift über darwinistische Entwickelungslehre vorgebracht. Trotzdem ist nach dem heutigen Stande der Kenntnisse von der Stellung der Schmetterlinge im Naturganzen die Frage, ob die gegenseitigen Ïhnlichkeiten dieser Kerfe wirklich als schützende Anpassungen, erworben durch natürliche Zuchtwahl, zu betrachten sind, mehr als je umstritten, und es liegen - neben zahlreichen oberflächlichen Beanstandungen mehrere ernst zu nehmende Werke vor, die den mimetischen Erscheinungen eine ganz andere Bedeutung zu unterlegen suchen. Ich halte es für zweckmäßig, zunächst einen Überblick über das Material von systematischen Tatsachen, biologischen Beobachtungen und Schlüssen zu geben, die zur Begründung und Verteidigung des Mimikrygedankens zusammengetragen worden sind, und erst dann die gegnerischen Einwände vorzubringen und $\mathrm{zu}$ würdigen. In beiden Richtungen muß ich mich darauf beschränken, für jede Tatsachengruppe das Wichtigste, Bezeichnende anzuführen, denjenigen Lesern aber, welche tiefer in den Stoff eindringen wollen, die jeweils einschlägigen Spezialwerke namhaft zu machen.

Um dem mit der Schmetterlingskunde nicht Vertrauten die Verwandtschaftsbeziehungen der häufiger zu nennenden System- 
gruppen etwas deutlicher zu machen, sei eine Übersicht') davon mit Anführung der auffallendsten Merkmale gegeben, die auch einige für die Beurteilung mimetischer Angleichungen wichtige, kleinere Gruppen namhaft macht.

\section{Ordnung Lepidoptera.}

I. Unterordnung Rhopalocera, Tagfalter.

1. Familie Nymphatidae. Tarsen (Füße) der Vorderbeine in beiden Geschlechtern verkümmert, beim Männchen eingliedrig, beim Weibchen fünfgliedrig, aber ohne Endklauen. Puppen kopfunter befestigt.

a) Unterfam. Danainae. Vordertarsen des Weibchens in ein unebenes Knöpfchen endigend. Raupen glatt, hier und da lange Fleischzapfen tragend. Im ganzen wärmeren Erdgürtel. Modelle. Hierher gehören aus Amerika die wichtigen Gattungen Ituna und Lycorea.

b) Unterfam. Ithomiinae (bei Bates und Wallace "Danaoid Heliconidae", unter Einschluß von Ituna und Lycorea, von Haase und manchen anderen Systematiker'n "Neotropinae" benannt). Vordertarsen des Weibchens vollständig, wenn auch manchmal verkürzt. Raupen ohne Fleischzapfen, anscheinend nur an den giftigen Solanaceen lebend. Nur in Amerika. Modelle.

c) Unterfam. Satyrinae („Äugler"). Mimetiker (Elymnias, Zethera).

d) Unterfam. Morphinae. Bisweilen Modelle (Tenaris).

e) Unterfam. Acraeinae. Vorwiegend afrikanische Modelle.

f) Unterfam. Heliconiinae. Vordertarsen des Männchens ungegliedert, aber verlängert, die des Weibchens viergliedrig. Die Raupen haben verzweigte Dornen, leben auf den giftigen Passifloren. Neotropische Modelle.

g) Unterfam. Nymphalinae. Kosmopoliten. Mimetiker.

2. Fam. Erycinidae. Hauptsächlich neotropisch. Mimetiker.

1) In Anlehnung an D. Sharp, ${ }_{n}$ Insects, Pt. II $^{u}$ in The Cambridge Natural History 6, $341 \mathrm{f}$. (1901). 


\section{$-137$}

3. Fam. Lycaenidae ("Bläulinge"). Kosmopoliten. Mimetiker.

4. Fam. Pieridae ("Weißlinge"). Vordertarsen bei beiden Geschlechtern normal, Klauen gespalten oder mit Zahn, mit Haftlappen. Raupen glatt bis fein behaart. Puppen mit dem Kopf nach oben befestigt. Kosmopoliten. Mimetiker, selten Modelle (Gattungen Detias, Mylothris).

5. Fam. Papilionidae ("Schwalbenschwänze"). Alle Tarsen vollständig, Klauen einfach, ohne Haftlappen. Die Raupen haben eine vorstülpbare Fleischgabel am ersten Brustring. Kosmopoliten. Modelle und Mimetiker.

II. Unterordnung Heterocera, Nachtfalter.

1. Fam. Castniidae. Wesentlich neotropisch und australisch. Mimetiker.

2. Fam. Sesiidae („Glasflügelschwärmer"). Meist sphecoide Mimetiker.

3. Fam. Syntomidlae. Nur sphecoid.

4. Fam. Zygaenidae ("Widderchen"). Bisweilen Modelle; in der Unterfam. Chalcosiinae Mimetiker.

5. Fam. Lymantriidae („Wollspinner"). Selten Mimetiker.

6. Fam. Arctiidae ("Bären").

a) Unterfam. Pericopinae. Amerikanische Mimetiker.

b) Unterfam. Dioptinae. Amerikanische Mimetiker.

c) Unterfam. Nycthemerinae (Aletis Nodell).

7. Fam. Agaristidae. Außerhalb Europas weit verbreitet. Mimetiker, selten Modelle.

8. Fam. Geometridae. Bisweilen Modelle und Mimetiker.

9. Fam. Epicopeiidae. Nur wenige Arten im indischen Tiergebiete. Mimetiker.

10. Fam. Uraniidae. Selten Modelle.

Da für Mimikryerscheinungen nur tagfliegende Heteroceren in Betracht kommen können, würde die Anwendung des deutschen Wortes "Nachtfalter" ein Widerspruch sein. Wir wollen deshalb dem volkstümlichen Ausdruck "Motten" dieselbe Anwendung, wie sie im Englischen das Wort "Moth" hat, geben und weiterhin von "Tagmotten" sprechen.

Den zu behandelnden Stoff will ich möglichst unter die systematischen Gruppen bringen, welche als gemieden gelten und 
Modelle für Nachäffung liefern; nach dem sollen die allgemein naturgeschichtlichen Gesichtspunkte, die sich aus der Einzeluntersuchung ziehen lassen, und das sich daran knüpfende Für und Wider der Mimikryfrage bei Schmetterlingen behandelt werden.

\section{Danainae.}

Als Musterbild der Unterfamilie Danainae kann nach Artenreichtum und weiter Verbreitung die Gattung Danaus selber angesehen werden; allerdings wird sie jetzt in eine Reihe Untergattungen aufgelöst. Einige davon (Radena, Caduga) haben weißliche, bald mehr ins Grüne, bald ins Safrangelbe spielende Grundfarbe, die von dunklen Adersäumen durchzogen wird; gegen den Außenrand vereinigen sich diese Säume mit Querreihen ${ }^{1}$ ) von Flecken oft derart, daß ein breites, dunkles Außenband entsteht, unterbrochen von ein oder mehreren Reihen von Flecken aus der Grundfarbe. Wie bei vielen Danainen ist die Zeichnung der Flügelunterseite eine fast strichgetreue Kopie des oberseitigen Musters, während bei den meisten anderen Tagfaltern beide Flächen äußerst verschieden sind. Vom Körper sind mindestens Kopf und Brust mit Reihen weißer Tüpfel geziert. Eine solche Danaine, D. (Caduga) tytius hat bei festgehaltenem Muster eine besondere Vertiefung des Farbentons, indem die Vorderflügel grünlichblau getönt, die hinteren aber lebhaft rostrot sind; im nördlichen Indien verbreitet hat sie an den Abhängen des Himalaja zwei äußerst ähnliche Nachahmer, einen Schwalbenschwanz (Papilio agestor), der ihr in Größe, Umriß und Farbe bis in Einzelheiten äußerst ähnlich ist, und eine nur in Tibet ganz selten gefundene Nymphaline, die Neptis imitans (Fig. 17; a. und b. mußten verkleinert werden).

Eine andere Gruppe (Anosia) wird in den Figuren 26 a, 31,1 vorgestellt. Ihr ist ein schwarzes Mal in der Nitte der Hinterflügel eigen, aus besonderen „Duftschuppen" gebildet, ferner ist die Grundfarbe mehr oder weniger ziegel- bis braunrot, und vor der Spitze der Vorderflügel pflegt sich von schwarzer Umgebung ein

1) Die Ansichten sind geteilt, ob man als Längsaderung und -zeichnung auf Insektenflügeln solche auffassen soll, die deren Längsachse parallel sind, oder die senkrecht darauf stehenden nQueradern" usw., die in Flugstellung der Längsachse des Körpers parallel laufen. Ich wende die erste Bezeichnung an. 
Fig. 17 .
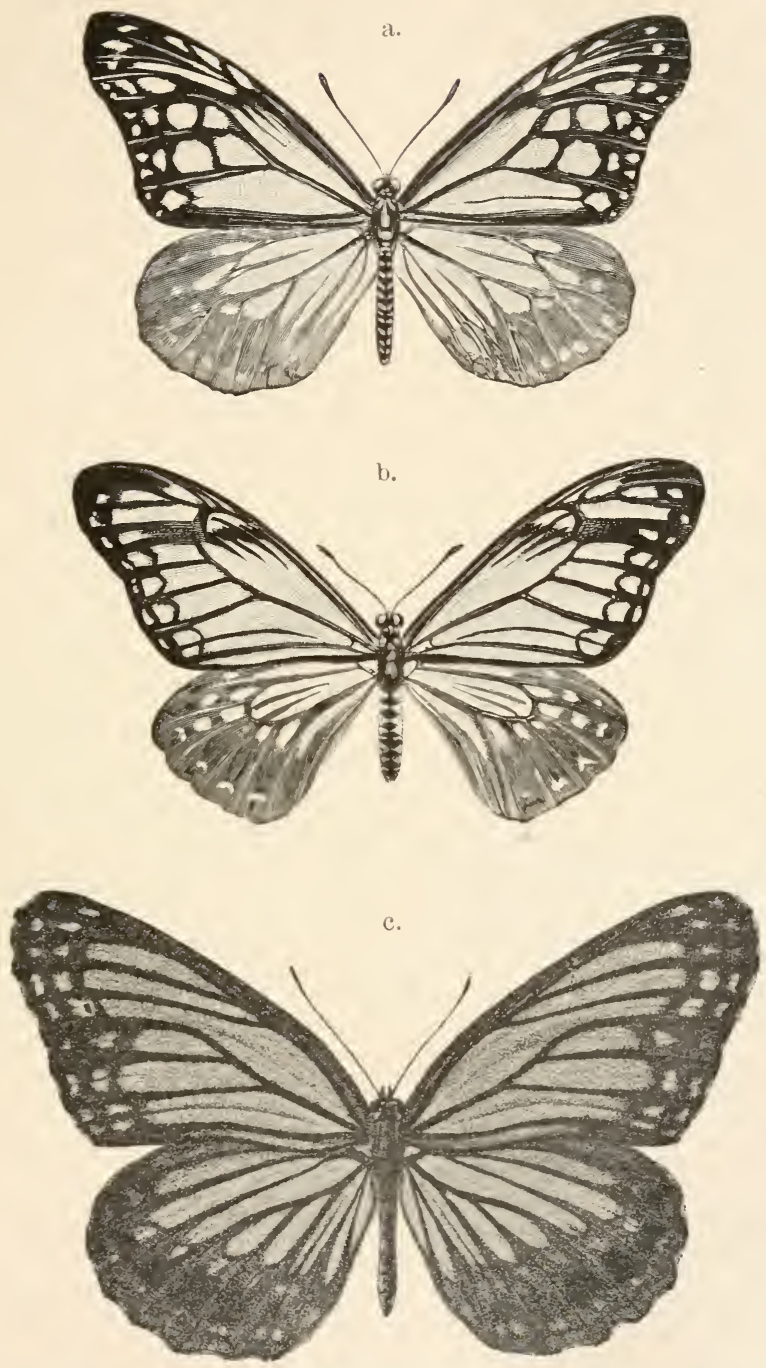

a. Danaus tytius (Danain.). b. Papilio agestor (Papilion.). Original, verkl. c. Neptis imitans (Nymphalin.). Nat. Gr. Aus Oberthür. 
leuchtend weißes Schrägband abzuheben. Die abgebildete A. chrysippus hat weite Verbreitung über Afrika und Indien mit Nachahmern unter den Papilioniden und Nymphalinen, die in besonderen Abschnitten Erwähnung finden sollen; hier sei von der letzteren Unterfamilie außerdem die afrikanische Pseudacraea poggei erwähnt, die eine etwas verkleinerte, sonst täuschende Wiedergabe der gemiedenen Danaine bildet. In Nordamerika hat die sehr stattliche $A$. erippus einen ausgezeichneten Nachäffer in einem "Eisvogel" (Limenitis archippus), dessen eigenartig rostbraune Farbe in seiner Sippe nicht weiter vorkommt; die Ähnlichkeit betrog sogar einen amerikanischen Professor der Entomologie, so daß er für die Abbildung in seinem Lehrbuche den verkehrten Falter benutzte.

Als Euploea faßt man einen Gattungsverband zahlreicher großer und oft sehr gemeiner Falter des indoaustralischen Gebietes (mit einigen Ausläufern ins madagassische) zusammen, die breite Flügel von tiefbrauner bis schwarzer Farbe, oft mit herrlichem blauen Schiller und größeren weißen Feldern bis Randtüpfeln haben (Fig. 28 a, 29 a). In den engeren Verbreitungsgebieten der Euploeen, z. B. in Südindien, auf Neuguinea, den Salomons- und Fidschiinseln ist jedesmal ein besonderes Zeichnungsmuster vorherrschend, von dem innerhalb des Gebietes jede Art wieder eine besondere Ausprägung bildet ${ }^{1}$ ). Die Nachahmer stellen wieder sehr abweichende Erscheinungen der Papilioniden (Papilio paradoxus $\rightarrow$ Euploea Tinnaei); (P. caunus $\rightarrow$ E. rhadamanthus), der Nymphalinen (Euripus hatitherses) und selbst Tagmotten, wie die sehr seltene Chalcosine Mimeuploea rhadamanthe, beide letzteren ebenfalls Kopien von E. rhadamanthus (Fig. 28, 29). Auch auf diese Formen haben wir aus anderen Gesichtspunkten noch zurückzukommen.

\section{Ithomiinae.}

Diese Unterfamilie, die sehr oft unter dem Namen Neotropinae gemeint wird, beschränkt sich auf das tropische Amerika und hat einen bezeichnenden Zug darin, daß die Beschuppung zum Ver-

1) Poulton, Trans. Ent. Soc. 1908, S. 27, dazu Bilder von Moultou auf Taf. 34. 
schwinden neigt, so daß manche Arten durchsichtige Fenster tragen, bei noch anderen die Flügel fast ganz glasig geworden sind, die Zeichnung sich auf schmale Randsäume und Binden von schwarzer und gelber Farbe beschränkt. Letztere Erscheinung hat die typische Gattung Ithomia (Fig. $18 \mathrm{a}, \mathrm{b}$ ) mit oft kleinen, sehr zarten Angehörigen, die das Urwalddunkel lieben und darin verschwinden. Eine sehr bezeichnende Nachahmung solcher kleinen Waldelfen hat bei dortigen Weißlingen (Pieridae) Platz gegriffen, und zwar bei der Gattung Dismorphia, die ja (unter dem Namen Leptatis) zu den Beobachtungen von Bates den ersten Anlaß gegeben hat. Die in Fig. 18 c. abgebildete $D$. eumelia hat nicht nur die Blässe der Oberseite und die Durchsichtigkeit zweier Ithomien (I. ellara und eurimedia) angenommen, sondern auch eine orangerote, schwarz eingefaßte Randbinde auf der Unterseite der Hinterflügel.

Eine andere häufig wiederkehrende und von sehr verschiedenen Falterfamilien nachgeäffte Tracht zeigen uns die Gattungen Methona (Fig. 19b) und Thyridia. Dies sehr eindrucksvolle Bild kommt bei Modellen wie Nachahmern so zustande, daf der größte Teil der Flügelfläche durchscheinend gelblichweif bis weingelb wird, das ursprünglich deckende Schwarz sich aber auf Fig. 18.
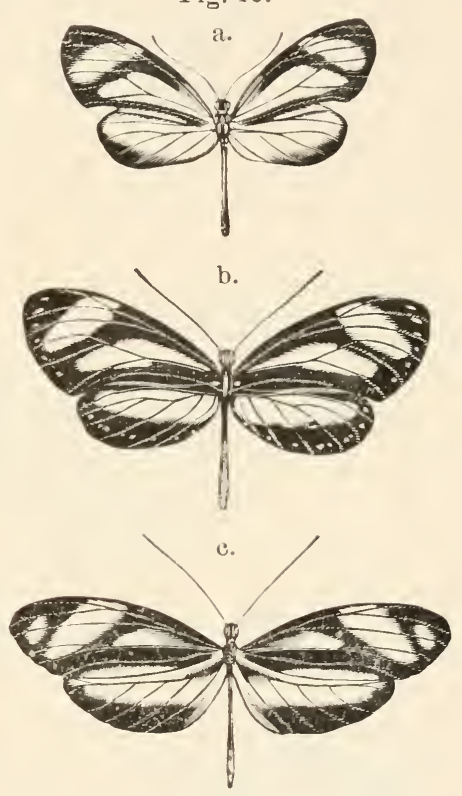

a. Ithomia ellara.

b. Ithomia enrimeilia.

c. Dismorphia enmelia.

Original. die Ränder zurïckzieht. Vorder- und Hinterrand bleiben jedoch derart in Verbindung, daß auf dem vorderen Paar Flügel zwei schwarze Querbinden entstehen und damit diese durchsichtige Fläche in drei Felder teilen; auf den Hinterflügeln ist die Zeichnung ähnlich, nur auf eine Binde und demgemäß zwei Felder beschränkt. Um jene Vorbilder gruppiert sich ein ganzer „Nimikry- 
- 142 -

Fig. 19.
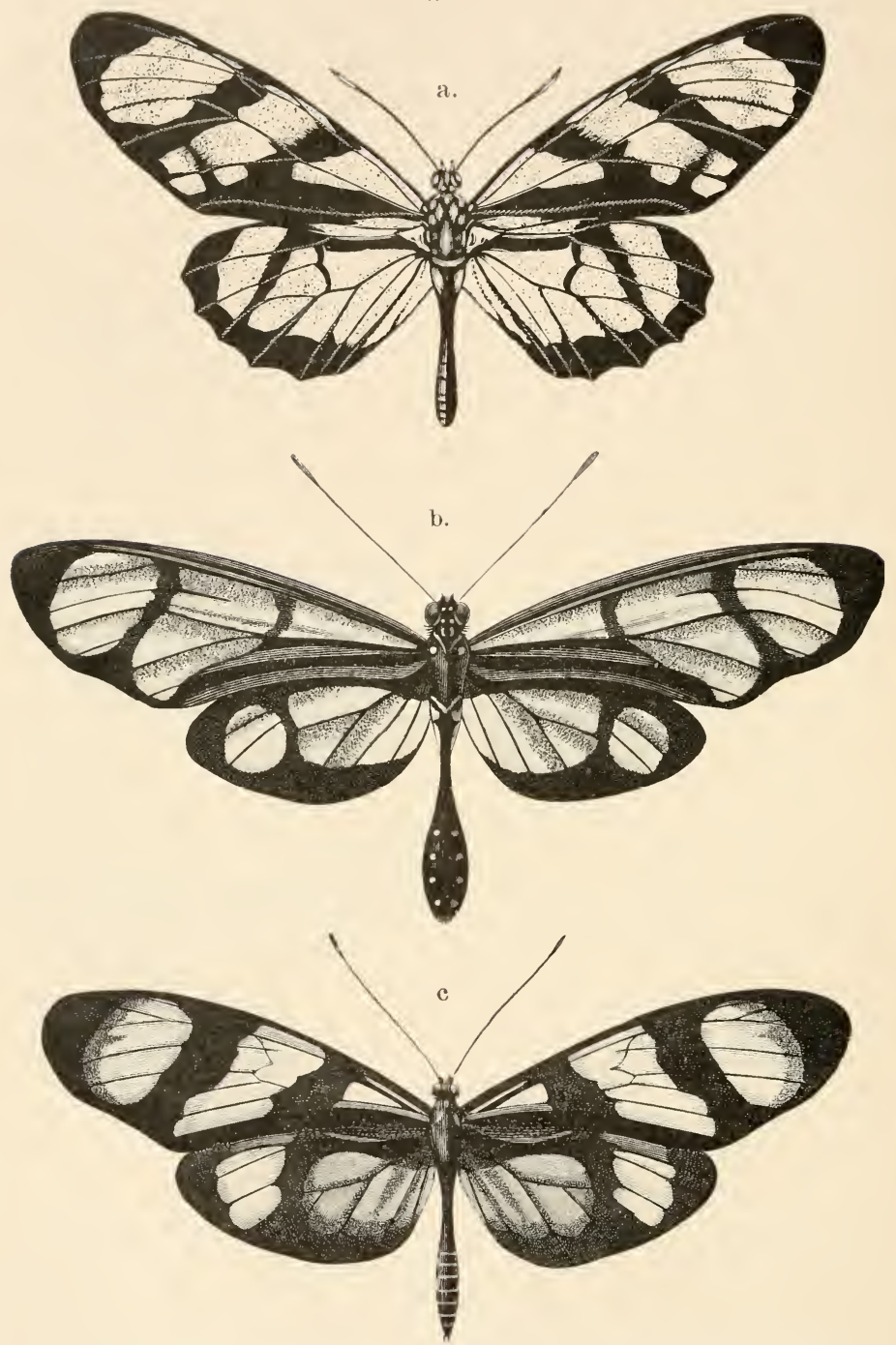

a. Ituna ilione (Danainae). b. Methona confusa (Ithomiinae). c. Dismorphia orise (Pieridae).

a. Original, b.-c. aus Wallace. 
ring"1) von Nachahmern, die alle das Wesentliche dieser Tracht an sich haben und die mimetischen Danainen belangend sogar zu an sich immunen Sippen gehören; da jedoch Haases Vergleichungen ${ }^{2}$ ) es sehr wahrscheinlich machen, daß es sich in der Gattung Ituna um eine Form handelt, die von dem ursprünglichen Danainentypus abgezweigt ist, so wird deren Zeichnung wirklich mimetisch, und zwar nach allem synaposematisch zu erklären sein. In unserem Methona-Ring vereinigen sich nicht weniger als sechs Familien von Tagfaltern und -motten, zum Teil mit mehreren Gattungen und zahlreichen Arten; dieser Formenreichtum ist uns erst allmählich offenbar geworden, denn Bates ${ }^{3}$ ) konnte dazu nur sechs Gattungen mit sieben Arten anführen. Nanche Teilnehmer, namentlich aus den Ithomiinen, Papilioniden und Castniiden, sind außerordentlich selten. Die Zusammensetzung ist folgende:

A. Ithomiinae: Methona confusa (Fig. 19 b), themista, megisto; Thyridia psidii, pytho und zwei andere Arten; Eutresis imitatrix, hispa; Athesis clearista, acrisione; Olyras insignis, praestans; Ithomia eupompe.

B. Danainae: Ituna ilione (Fig. 19 a), phaenarete.

C. Pieridae: Dismorphia orise (Fig. $19 \mathrm{c}$ ).

D. Papilionidae: Papitio hahneli.

E. Arctiidae, Unterfam. Pericopinae: Hyelosia tiresia, Anthomyza heticonioides und vier andere Arten.

F. Castniidae: Castria linus, heliconioides, dodona, micha.

Wesentlich anders und mit etwas Spuren des alten Zusammenlanges mit den ursprünglicher gezeichneten Danainen der Alten Welt ist die Tracht der Gattungen Melinaea und Mechanitis (Fig. 20a, 21 a), und es liegt geradezu ein neotropisches Muster darin, das wieder ein Anziehungszentrum für die Farbenentwickelung anderer Gruppen, besonders der Heliconier, darstellt. Die Grundfarbe ist in der Innenhälfte ein sattes Rotbraun, nach außen aber schwefel- bis safrangelb, das auf den Vorderflügeln durch eingeschaltete schwarze Bänder selber wieder zu Binden und Flecken wird; das Schwarz tritt dort als ein basales, ein die große Mittelzelle besetzendes und als einige Endbänder auf, die zur

1) Poulton 1898 , S. $\left.598 .-{ }^{2}\right)$ S. 49 u. $51 .-{ }^{3}$ ) 1861, S. 503. 

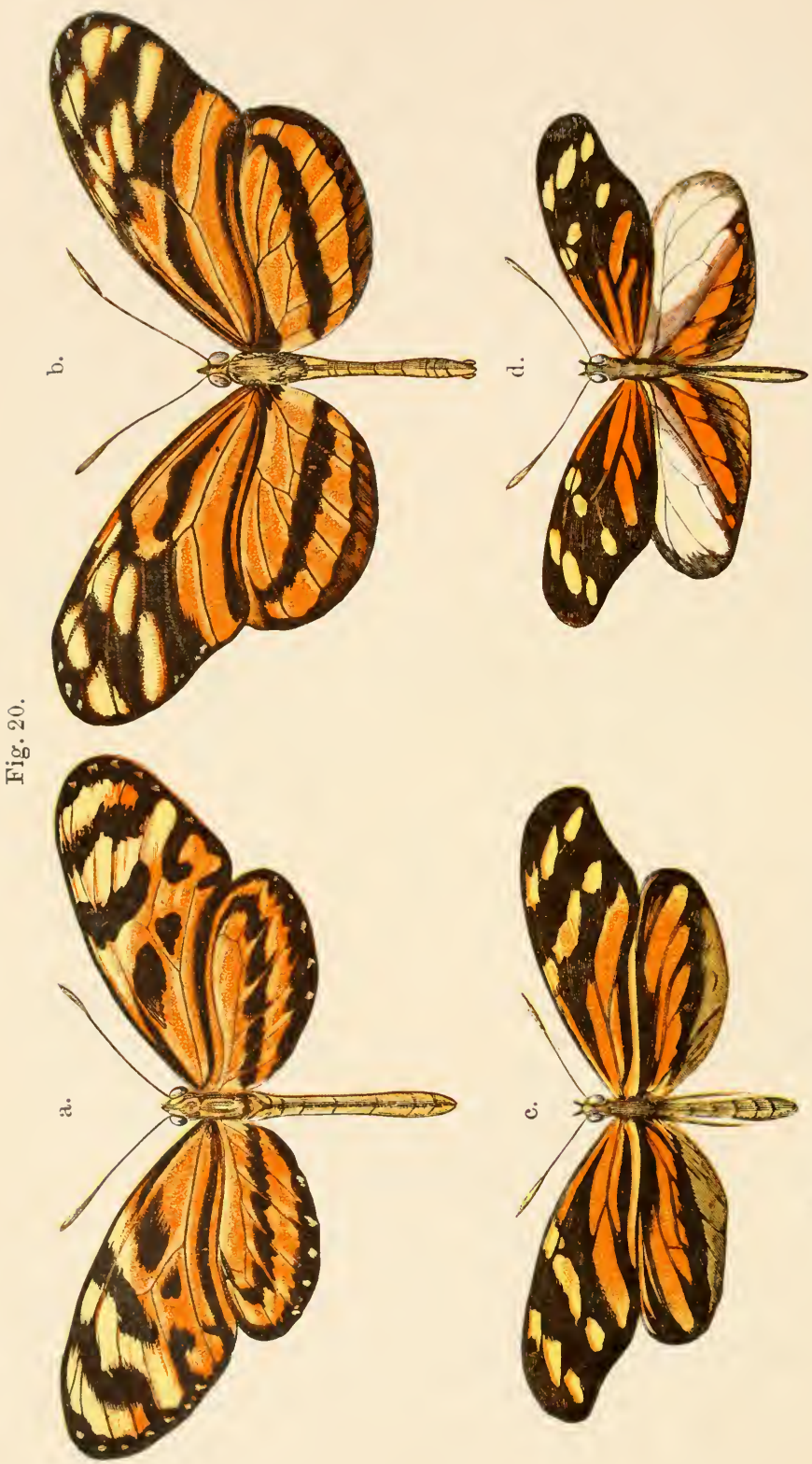

官 . 5 ฮิ ․ํำ ङ $\stackrel{\infty}{*}$

ธิ

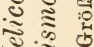

$\approx$ 尺

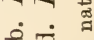

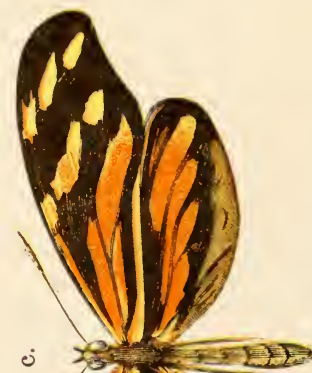

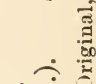

घี 앙 $\pm$

क

क ธิ s :

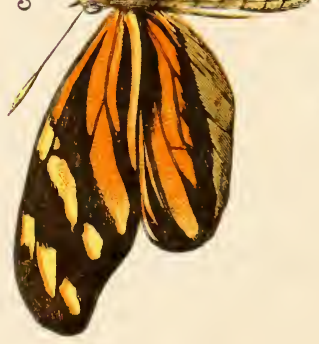

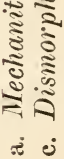


Fig. 21.
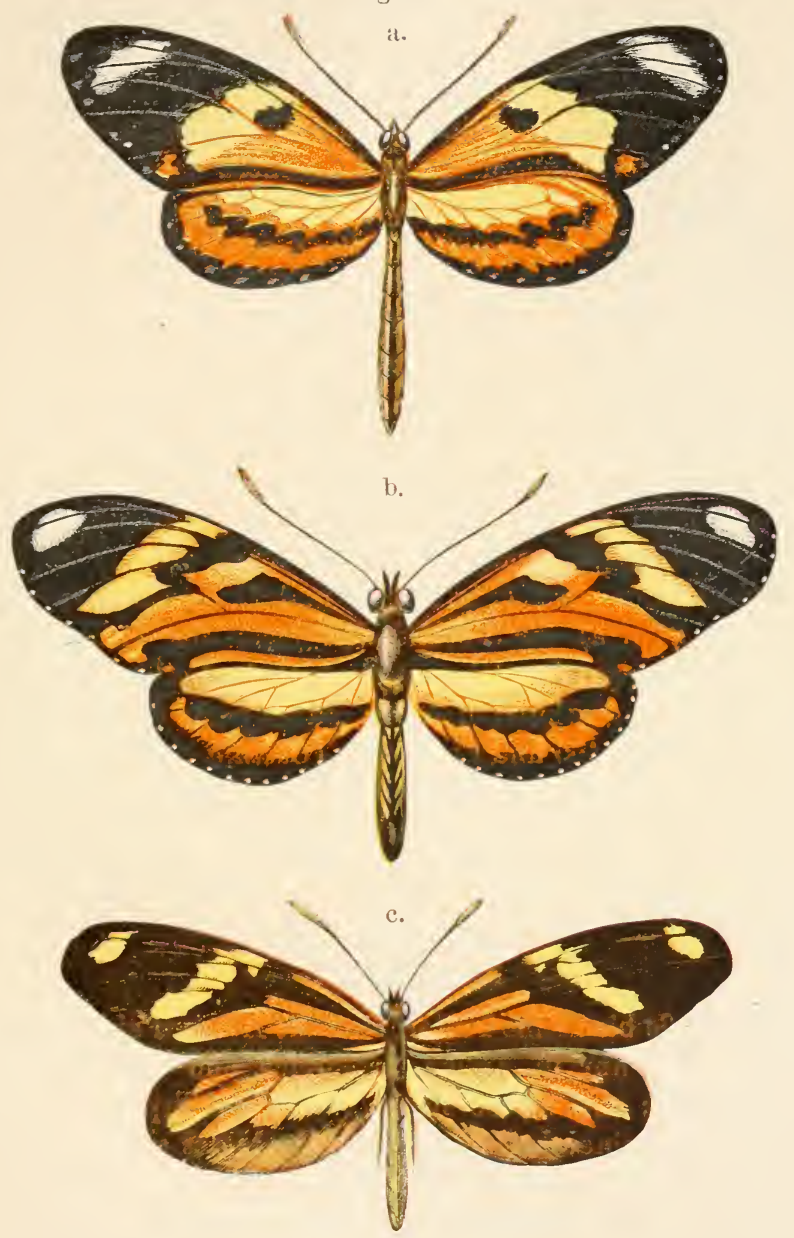

a. Mechanitis lysimniai(Ithomiin.).

b. Heliconius narcaea narcaea (Heliconiin.).

c. Dismorphia astynome (Pierid.).

Original. 
Verschmelzung neigen (Fig. 21 a). Für die Zeichnung der Hinterflügel ist ein mehr oder weniger hufeisenförmiges braunes Band bezeichnend, das nach innen offen ist („Schleifenband“). In diese "Melinaeentracht" gehen manche Pieriden als pseudaposematische Nimetiker gekleidet, allerdings in vollkommnerer Nachäffung nur die Weibchen, was wir als eine häufige dimorphistische Besonderheit der Schmetterlingsmimikry zu betrachten haben. Diesen geschlechtlich gesonderten Grad der Nachbildung zeigen in der Unterfamilie der echten Weiflinge (Pierinae) das Genus I'errhybris (P. Torena, pyrrha) und bei den Dismorphiinae die schon erwähnte Gattung Dismorphia, die man an den schmalen Flügeln, oft mit hakenartiger Zuspitzung der vorderen, leicht von den anderen Pieriden unterscheidet. So sehen wir in Fig. 20d, wie das Männchen von 1$)$. arsinoides vorn schon deutliche Hinneigung zur Melinaeentracht zeigt, während auf den Hinterflügeln das ursprüngliche Weiß noch nicht ganz von dem nachgeäfften Muster verdrängt ist. Dagegen spiegeln die Weibchen von $D$. arsinoides $\longrightarrow$ Mechanitis doryssus (Fig. $20 \mathrm{c}$, a) und D. astynome $\rightarrow M$. Iysimnia (Fig. 21c, a) ihr Vorbild viel mehr ins einzelne wider. Auch diese Gruppe der Ithomiinen tritt in Verbände desselben Aussehens mit ungeschützten Arten, außer jenen Dismorphien mit Eryciniden (Stalachtis) und Castniiden (Castnia simulans, Pericopis ithomia und histrio), weiterhin wieder zu synaposematischer "gemeinsamer Warnfärbung" (Poulton) mit Tithorea aus derselben Unterfamilie, Lycorea (Danaine) und manchen IIeliconius (Fig. 20 b, 21 b).

\section{Acraeinae.}

Mittelgroße bis kleine Falter, sind die Acraeen zirkumtropisch verbreitet, aber nur in Afrika artenreich und dort als Modelle von Bedeutung; als solche haben wir zwei Typen zu berücksichtigen. Der eine, bei Acraea i. e. S., bildet eine echt afrikanische Gestalt mit etwas durchscheinenden Flügeln, deren vordere ziemlich langgestreckt sind; die Fläche ist, wenigstens bei den Männchen, häufig lebhaft ziegelrot mit zahlreichen, etwas regellos darauf gestreuten Flecken und von großen schwarzen Feldern unterbrochen und begrenzt. Dieses kontrastierende Rot und Schwarz der gemiedenen Acraeen finden wir hier und da in anderen Familien nachgeäfft, wo es dann ein wirkliches Fremd- 
kleid unter dem allgemeinen Sippenmuster vorstellt. In dieser Hinsicht fällt der seltene westafrikanische Segelfalter Cosmodesmus ridleyanus $\rightarrow$ Acraea euryta mit seinem Kleide aus Schwarz und Ziegelrot völlig aus dem Habitus der Papilioniden heraus, er hat auch die Unterseite des Modells in ziemlich treuer Wiedergabe. Ferner hat die Nymphalinengattung Pseudacraea in mehreren Arten jene zerstreuten schwarzen Flecke des acraeoiden Typus angenommen, eine davon $(P$. boisduvali) hat sich für Ober- und Unterseite an $A$. egina angepalt, und dieses zu der ähnlichen Verschmälerung der Torderflügel tretende Signal macht es noch Bowker wenigstens für Schmetterlingssammler unmöglich, Modell und

Fig. 22.

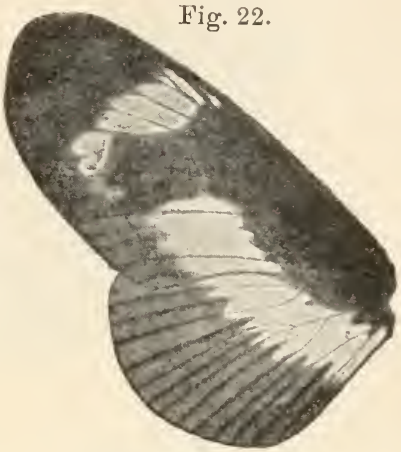

Planema gaca. Aus Eimer.

Nachahmer im Fluge oder sitzend zu unterscheiden. Andere Pseudacraeen kopieren den zweiten afrikanischen Acraeentyp, den die Gattung Planema vorstellt. Oberseits braun, sind ihre Mitglieder durch eine breite, auf den Vorderflügeln quergeteilte Binde von gelber $\left(\sigma^{\pi}\right)$ und weißlicher ( + ) Tönung gezeichnet, während dies unterseits der sienafarbene Flügelgrund mit den bekannten Flecken und außerdem sehr eigene schwarze Streifen zwischen den Adern tun. Dieser von $P$. gaea (Fig. 22) vertretenen Erscheinung folgen in Westafrika Pseudacraea hirce, die Satyride Elymnias phegea und das Weibchen von Papilio (s. str.) cynorta, letzteres durch entsprechende Ober- und Unteransicht sowohl dem sitzenden wie dem fliegenden Modell gleich.

\section{Heliconiinae.}

Die Heliconier nähern sich in der Gestalt sehr den Ithomiinen, haben wie diese sehr schlanke Körper, dünne Fühler und langgestreckte Flügel, deren Zeichnung aber im allgemeinen viel bunter ist; alle sind höchstens mittelgroß. Das Muster besteht am häufigsten aus gelben, roten oder weißen Flecken und Binden auf schwarzem, braunem oder blauem Untergrunde; häufig kommt 
Fig. 23.
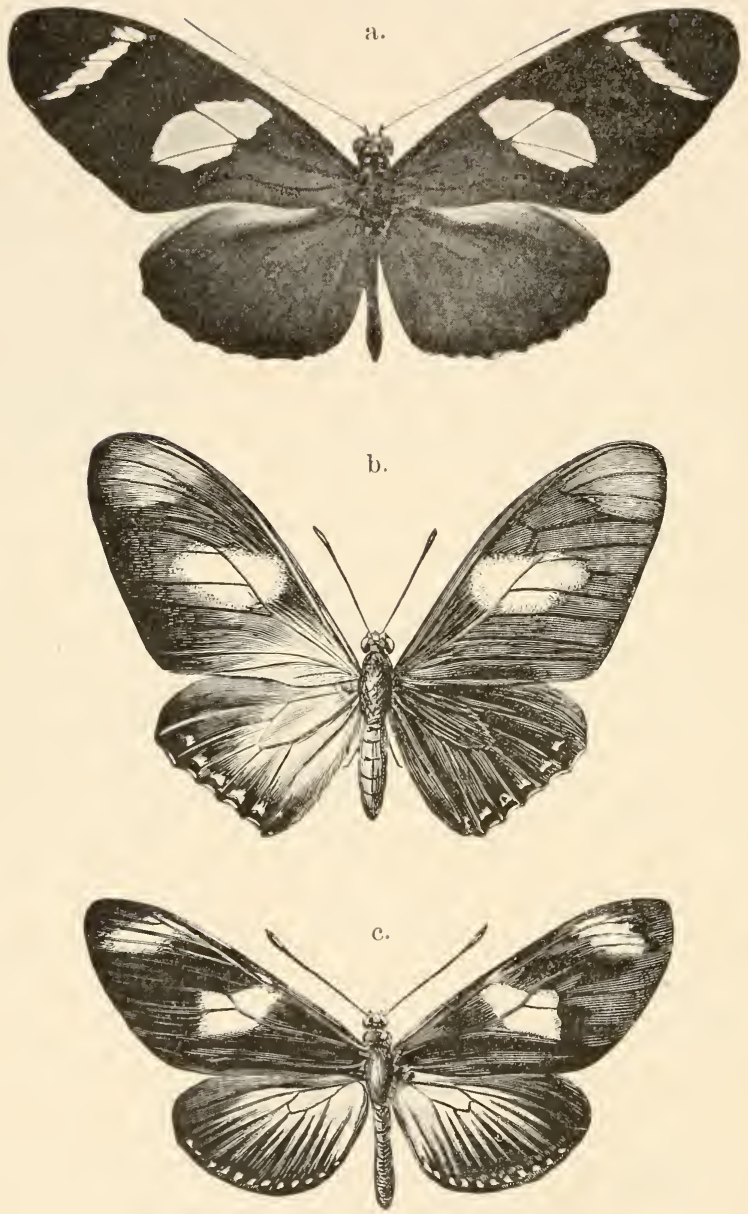

a. Heliconius uallucei colon (Heliconiin.).

b. Papilio pausanias (Papilionid.).

c. Heliconius doris (forma coerulea).

b. Nachahmer von a. und c.

a. Aus Stichel und Riffarth, b. und e. Original. 
es vor, daß ein farbiger, zumal roter, Fleck auf den Hinterflügeln sich strahlenartig nach außen fortsetzt. (Fig. 23 c.) Wie bei den Danainen entspricht sich sehr oft die Zeichnung der Ober- und Unterseite genau. Bei manchen Arten ist die Veränderlichkeit erheblich, so daß man früher viele Spezies unterschieden hat, die wir jetzt für Formen einer einzigen erklären: z. B. kann die helle Zeichnung der Hinterflügel bei den Geschwistern einer Brut von H. doris (Fig. $23 \mathrm{c}$ ) blau, grün und rot ausfallen. Die Unterfamilie umfaßt nur zwei Gattungen (Heliconius und Euides), die sich nur in unscheinbaren körperlichen Merkmalen unterscheiden. Die viel umfangreichere Gattung Heliconius hat zwei Artengruppen, für die ein sehr verstecktes Merkmal der Männchen den Unterschied abgibt, nämlich die verschiedene Ausdehnung eines Streifens von "Duftschuppen“ auf der Unterseite der Vorderflügel. Dabei sind sich manche Angehörige der einen und der anderen Gruppe so ähnlich, daß sie Doppelgänger darstellen, zumal sie dieselben Gebiete des tropischen Amerika bewohnen. Solche Paare sind beispielsweise $H$. pachinus und $H$. hewitsoni von Panama oder II. hydarus und H. amaryllis subsp. euryades des nördlichen Südamerika. Da jenes Unterscheidungsmerkmal trotz seiner Unscheinbarkeit eine ursprünglich getrennte Abstammung beider Gruppen bedeutet, so liegt für die parallele Entwickelung der Färbung die Annahme nahe, daß sie durch synaposematische Annäherung seltenerer Arten der einen Reihe an häufige der anderen entstanden ist ${ }^{1}$ ). Beide Gattungen liefern aber auch Synaposeme mit anderen Unterfamilien, z. B. den näher verwandten Ithomiinae, von denen wir der Melinaeentracht sowohl bei Euides begegnen (E. isabella) wie bei Heliconius. Zu der dort geschilderten Mimikry nach Mechanitisarten gesellt sich beispielsweise Ilel. narcaea $\longrightarrow$ Mech. Tysimnia (Fig. 21) und Hel.ismene telchinia $\rightarrow$ Mechanitis doryssus, wobei letzteres Paar besonders ähnliche Zeichnung bis auf die Ausbildung des Schleifenbandes besitzt. (Fig. 20.)

Indessen sind auch einfache mimetische Anpassungen ungeschützter Falter an die gemiedenen Heliconier häufig, auch von Tagmotten (Pericopinen); besonders verbreitet ist sie unter den Dismorphia-Weißlingen, was ja Bates so auffiel. Unsere Fig. 23 zeigt uns einen nicht immunen Segelfalter, Cosmodesmus pausanias

1) Kaye, Proc. Ent. Soc. 1910, p. 14. 
von Ecuador, als Mimetiker gleich von zwei Heliconius aus dem Andengebiete, aber in verschiedenem Grade der Angleichung. H. wallacei colon hat stahlblau schillemde Grundfarbe mit feinen weißen Randmonden der Hinterflügel und zwei schwefelgelbe Schrägbinden auf den vorderen; dem entspricht der Schwalbenschwanz mit der Abänderung, daß das gelbe Spitzenband nur durch eine helle Stelle im Stahlblau angedeutet ist. Der H. doris (forma coerulea) hat kein metallisches Blau, sondern eine hellblaue Pigmentfarbe in der schon erwähuten Strahlenfigur der Hinterflügel, sonst aber dieselben Abzeichen wie sein Verwandter.

\section{Papilionidae.}

Von der an Gattungen armen, an Arten desto reicheren Familie der Papilioniden liefern nur die Schwalbenschwänze (Papitio s. 1.), die eben jenen Artenreichtum bedingen, Modelle. Diese sind aber durch gemeinsame Merkmale vereinigt und bilden eine der drei Untergattungen, die $\mathrm{H}$ a a s e durch seine tiefgründigen Untersuchungen ${ }^{1}$ ) an dem alten Genus Papitio L. herausfand, die aber vorteilhaft auf den Gattungsrang erhoben werden dürfen, weil sie eine übersichtliche Einteilung der Artenfülle erleichtern. Diese Subgenera besitzen nach $\mathrm{Haase}^{2}$ ) Kennzeichen, deren folgende am leichtesten wahrnehmbar sind:

1. Aristolochienfalter (Pharmacophagus). Fühler undeutlich geringelt, ganz allmählich verdickt; an Kopf, Hals, Brust und Hinterleib rote Warnsignale, die fast nur einer südamerikanischen Gruppe fehlen (Fig. 4 u. 24); am Innenteil der Hinterflügel ist die sogenannte Analfalte deutlich entwickelt, und in den meist nach oben umgeschlagenen zwei letzten Randfeldern der ersteren sind beim Männchen pelzartige Anhäufungen von Duftschuppen ${ }^{3}$ ). Die schwarzen, mit roten Fleischzapfen besetzten Raupen leben auf den Giftstoffe enthaltenden Aristolochiaceen (woher der deutsche und der wissenschaftliche Name); die Puppen sind dick, plump, oben unit sattelartigen Höckern. $\mathrm{Zu}$ den Aristolochienfaltern gehören auch die riesigen Schwalbenschwänze, die man früher unter die besondere Gattung Troides (Ornithoptera) stellte ${ }^{4}$ ).

1) Von E. Reuter 1896 durch andere Nerkmale bestätigt. 2) 1, 15. - ${ }^{3}$ ) In Fig. 24 a ist das Duftfeld zurückgeschlagen und ausgebreitet wiedergegeben. - ${ }^{4}$ ) Neuerdings noch von Rothschild und Jordan, Novitat. Zool. உ (1895), geschehen. 


\section{Fig. 24.}

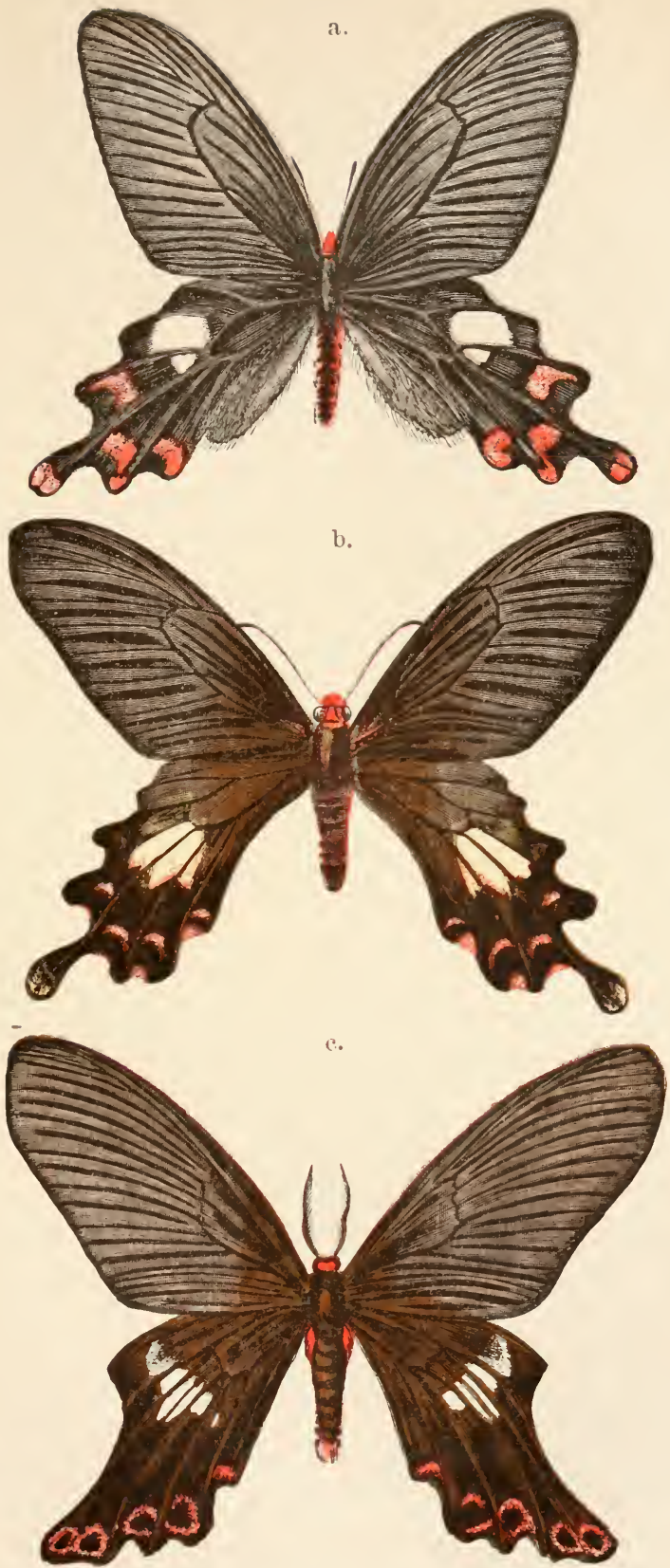

a. Pharmacophagus dasarada (Papilionid.). b. Papilio janalia (desgl.). c. Epicopeia polydorus (Epicopeiid.). 
2. Segelfalter (Cosmodesmus), der ersten Gattung näher verwandt als der folgenden. Fühlerkeule kurz eiförmig, oft platt; Stirn stark behaart. Hinterflügel wie bei 1 gebildet, aber die Dufteinrichtung aus kurzen Schuppen. Zeichnung oft in Querbinden ausgeprägt. Raupen am Hinterende verschmälert, oft in zwei Spitzen ausgezogen und mit blassen Streifen gezeichnet, leben besonder's von Anonaceen.

3. Rinnenfalter (Pupitio s. str.). Das Subanalfeld der Hinterflügel, d. h. der von den beiden innersten Längsadern eiıgeschlossene Flächenteil, ist zu einer tiefen, gebogenen Rinne zusammengeschlagen, in deren Grunde die undeutliche Analfalte liegt.

Modelle liefert nur die immune Untergattung Pharmacophagus, und die Nachäffung beschränkt sich ganz überwiegend auf die beiden anderen. Nachahmer aus anderen Familien sind selır selten. Auch die Mimikry der Schwalbenschwänze nach anderen Schmetterlingen, wovon mehrere Fälle behandelt wurden, geht nur von den nichtgemiedenen Segel- und Rinnenfaltern aus. Bei diesen bringt sie dann Umwandlungen der Zeichnung hervor, welche die Gattungszugehörigkeit ohne nähere Untersuchung ganz verhüllen und die Erkenntnis der natürlichen Verwandtschaft zwischen den Schwalbenschwänzen vielfach gehindert haben. Hier hinein brachten zuerst Wallaces schöne Unter'suchungen ${ }^{1)}$ über die indoaustralischen Papilios Licht, was Haase in einer allen bisherigen Versuchen überlegenen Weise weiter führte und vollendete. Leider hat sein großes Werk, weil es teuer und nicht gerade leicht zu verarbeiten ist, noch nicht den ihm sicherlich gebührenden Einfluß auf die Systematik der Schmetterlinge gewonnen.

Beispiele für Nachäffung von Pharmacoplıagus soll uns das indische Faunengebiet liefern. Die dortigen nachgeahmten Aristolochienfalter haben nicht selten aufs äußerste verschmälerte Flugwerkzeuge (Fig. 27 d), deren vorderes Paar abgestumpft, graubraun mit dunkeln Streifen zwischen den Rippen ist; das hintere ist gewöhnlich geschwärzt und mit großen weißen, bindenartig gereihten Flecken verziert, eine Anzahl karminroter Halbmonde tritt auf der Unterseite besonders grell hervor und vereinigt sich mit der roten Zeichnung des Rumpfes zu einer auch im Sitzen sehr auffallenden Warnfarbe (Fig.4), die bei wenigen Arten, wie Ph. priapus, doubledayi, coon (Fig. 27 d), durch Gelb oder Weiß

1) 1865 . 
ersetzt sein kann. Der ganze Habitus eines solchen immunen Falters aus Nordindien (Ph.dasarada) kehrt bei dem nachahmenden Rinnenfalter (Papilio janaka) unserer Fig. 24 wieder, der, von ungeschwänzten Vorfahren abgezweigt, die verschmälerten Hinterflügel 1) mit gestieltem Schwänzchen, die stumpfen Vorderflügel und die roten Warnsignale an Leib und Hinterflügeln des Vorbildes übernommen hat, während die gelbweißen Fleckenreihen der Gattung durch Grauschwarz verdeckt sind. So macht er in jeder Stellung und bei jeder Bewegung den Eindruck eines widrigen Aristolochienfalters. Wenn nun die Umwandlung des Vertreters einer immerhin nahe verwandten Gattung durch mimetische Anpassung denkbar ist, so muß doch dieselbe Verwandlung bei Heteroceren, also einer ganz fernstehenden Familie, befremden. Wir haben jedoch die Tatsache, daß die nur aus einer Gattung mit etwa zehn, sehr seltenen Arten bestehenden Epicopeiidae insgesamt aussehen wie schwarzweißrote Pharmacophagusarten. Eine dieser mimetischen Tagmotten, und allenfalls noch die häufigste, ist Epicopeia polydorus (Fig. 24c), die sich durch eine gewisse Veränderlichkeit in der Zeichnung bald an Arten mit einfarbig dunkeln Vorderflügeln wie eben $P h$. janaka, bald an solche mit weißer Aufhellung darauf, wie z. B. P. polydorus, anschließt. Ein anderer dieser seltenen Fälle betrifft die mit unseren Zygaenen verwandte Chalcosiine Histia rhodope, die nicht nur in der Färbung, sondern auch im Fluge den gemeinen indischen Pharm. aristolochiae nachahmt ${ }^{2}$ ). Das Gemeinsame im Fluge liegt darin, daß nur die Yorderflügel bewegt, die hinteren aber schräg nach dem Rücken zu ausgestreckt werden. Freilich meint der Beobachter, daß Mimikry ausgeschlossen sei, weil der Schwalbenschwanz bei Canton, wo Mell die Histia fand, nicht mehr vorkäme, aber das tut der Tatsach $\Theta$ keinen Eintrag, daß beide in einem ungeheuren Areal Indiens zusammen leben, womit die Voraussetzung für die schützende Bedeutung der Ähnlichkeit gegeben ist.

\section{Uraniidae.}

Die eigentümlich zerstreut vorkommende Tagmottenfamilie der Uraniidae umfaßt einige Dutzend Arten, die alle die Größe

1) Nach Fig. 24 a sehen diese scheinbar beim Modell breiter aus, weil das Analfeld zurückgeschlagen dargestellt ist. - ${ }^{2}$ ) R. Mlell, Deutsche Entom. Nationalbibliothek 2, 77 (1911). 
Fig. 25 .
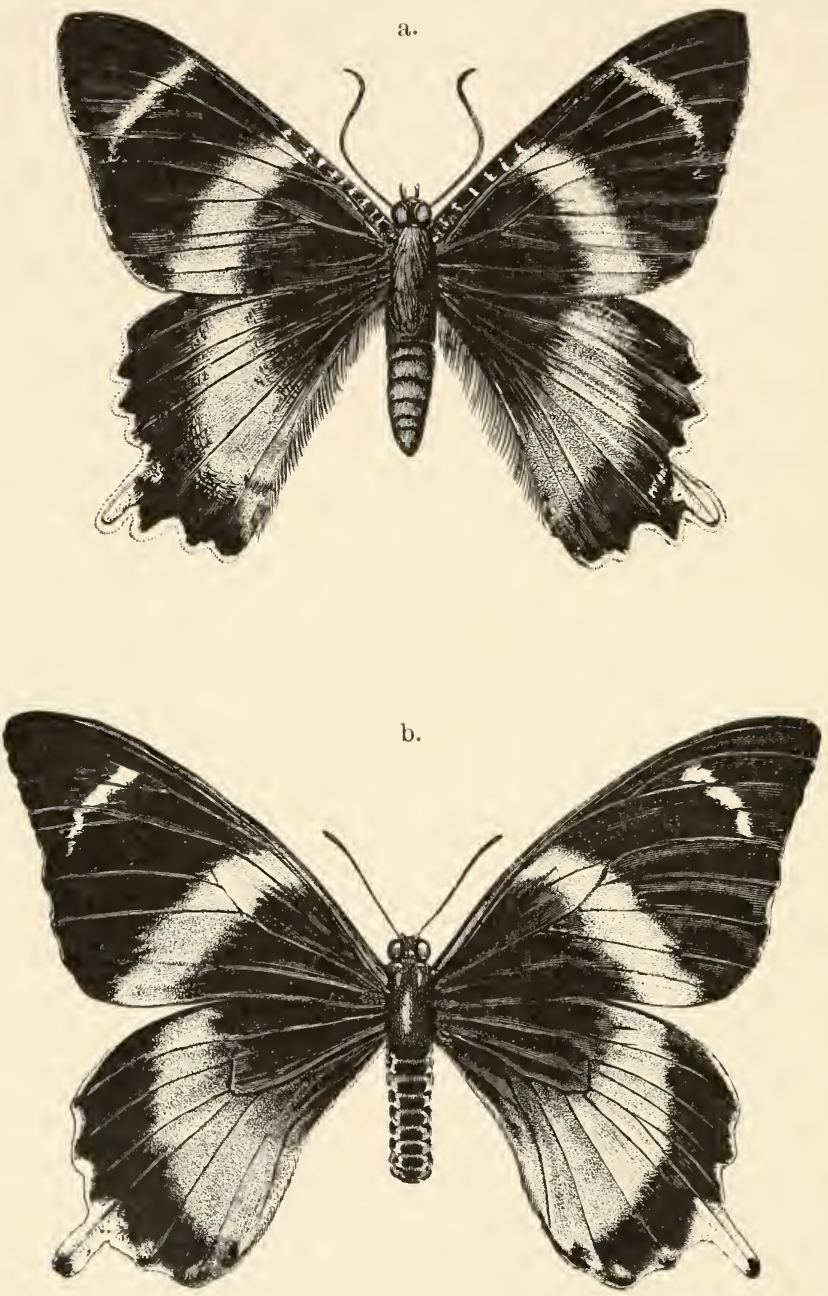

a. Alcides agathyrsus (Urann̊d.). b. Papilio laglaizei (Papilion.). Original. 
und Flügelform stattlicher Papilioniden, aber keineswegs deren Farbmuster haben. Ein Mitglied, Alcides agathyrsus, von Neuguinea und Aru wird in seiner eigenartig schönen Erscheinung von einem echten Schwalbenschwanz (Papilio laglaizei) derselben Gegenden mit der Oberseite und Körperfärbung derartig getreu nachgeäfft, daß letzterer ein völlig von den Sippengenossen verschiedenes Bild vorführt. Beide sehen matt stahlblau aus mit zartem silbrigen Glanze, tragen vor der Flügelspitze eine schmale aufgehellte Binde und quer über beide Flügel ein breites weißlichgrünes Band, die Hinterflügel haben einen feinen silberweißen Saum (Fig. 25). Etwas verschiedener ist die Unterseite, doch sorgt auch dort eine Einzelheit des Papilio für die Ähnlichkeit mit dem Modell, indem nämlich die gelben Flanken des letzteren durch einen länglichen Orangefleck an der Innenkante der Hinterflügel beim Tagfalter vorgetäuscht werden, natürlich nur, wenn dieser sitzt. Zwar haben die Heteroceren eine völlig andere Ruhehaltung der Flügel als jene, sie klappen sie dachförmig nach hinten übereinander, während die Rhopaloceren die Flügel senkrecht nach oben stellen, aber die Uraniiden - eine sehr alte Familie - scheinen auch hierin mehr Tagfalter geworden zu sein. Hahnel ${ }^{1}$ ) berichtet wenigstens von den südamerikanischen Vertretern, daß sie sich vor der Sonne schützen, indem sie ihre Flügel wie die Tagfalter zusammenschließen. Alcides agathyrsus ist häufig und fliegt in Trupps um Baumkronen, worunter sich gelegentlich, im Leben nicht unterscheidbar, der sehr seltene Papilio befindet ${ }^{2}$ ).

\section{Dimorphismus}

\section{und Polymorphismus in der Lepidopterenmimikry.}

Wie bei so vielen Tieren sind auch bei manchen Schmetterlingen die Geschlechter nicht nur durch die Fortpflanzungswerkzeuge unterschieden, sondern auch durch äußerliche Merkmale der Gestalt und Farbe. Mannigmal ist dieser "Dimorphismus" von Männchen und Weibchen so groß, daß lange Zeit jedes Geschlecht als besondere Art beschrieben wurde; bisweilen gibt es sogar in einem Geschlecht mehrere verschiedene Formen, was den "Polymorphismus" bedingt. Als Beispiel für weiblichen mimetischen

1) Iris 3, $\left.277(1890) .{ }^{2}{ }^{2}\right)$ Ribbe, Iris 1, 79 (1886). 
Dimorphismus empfiehlt sich durch seine Häufigkeit der indischafrikanische Hypolimnas misippus(Nymphal., Fig. 26). Das Männchen

Fig. 26.
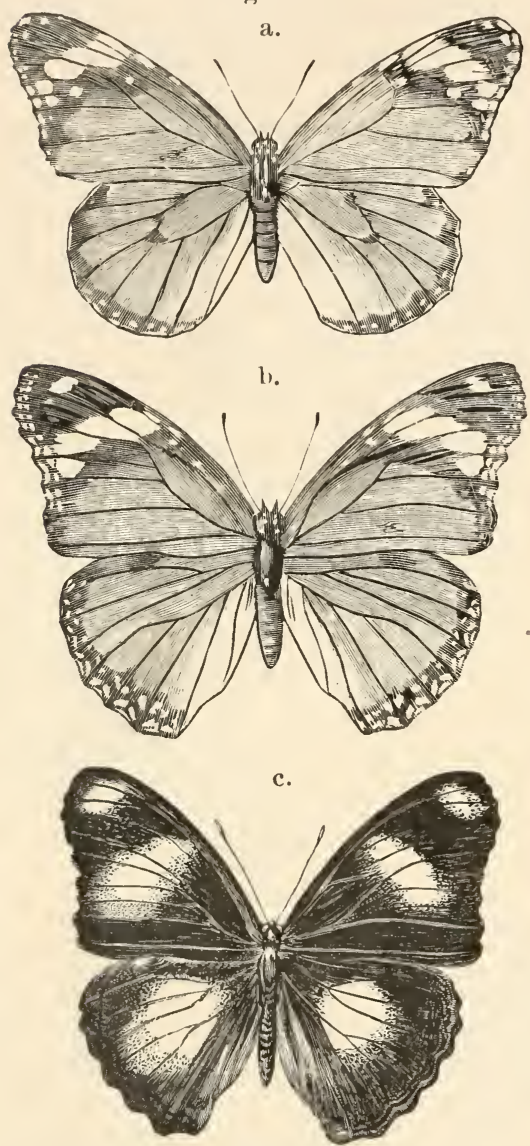

a. Danaus chrysippus (Danain.).

b. Hypolimnas misippus o (Nymphalin.).

c. Hypolimnas misippus ơ (desgl.).

Original $2 / 3$.

hat die Färbung seiner meisten Gattungsgenossen: tiefschwarz auf der Oberseite mit drei weißen, mit herrlichem Blauschiller umsäumten Spiegeln, während die Unterseite ein Gemisch von Weiß, Schwarz und abgestuftem Braun zeigt. Dagegen äfft das Weibchen in ganz vollendeter Weise den fuchsroten, am Rande schwarzweiß gezeichneten Danaus chrysippus (Fig. 26 a) nach, sogar in dem Familienmerkmal der Danainen, daß Ober - und Unterseite gleich aussehen. Als eins der vielen Seitenstücke hierzu möchte ich den Papilio mayo von den Andamaneninseln erwähnen. Im männlichen Geschlecht fast ungeschwänzt, tief schwarzbraun mit himmelblauem Querbande der Hinterflügel, ist sein Weibchen die Wiedergabe eines dortigen typischen Aristolochienfalters Pharmac. rhodifer mit Spatelschwanz, weißer und blutroter Zeichnung der Hinterflügel, ähnlich wie Fig. 24 a.

Den Polymorphismus soll uns ein Schwalbenschwanz, Papilio memnon, verdeutlichen, dessen mimetische Weibchenformen zuerst 


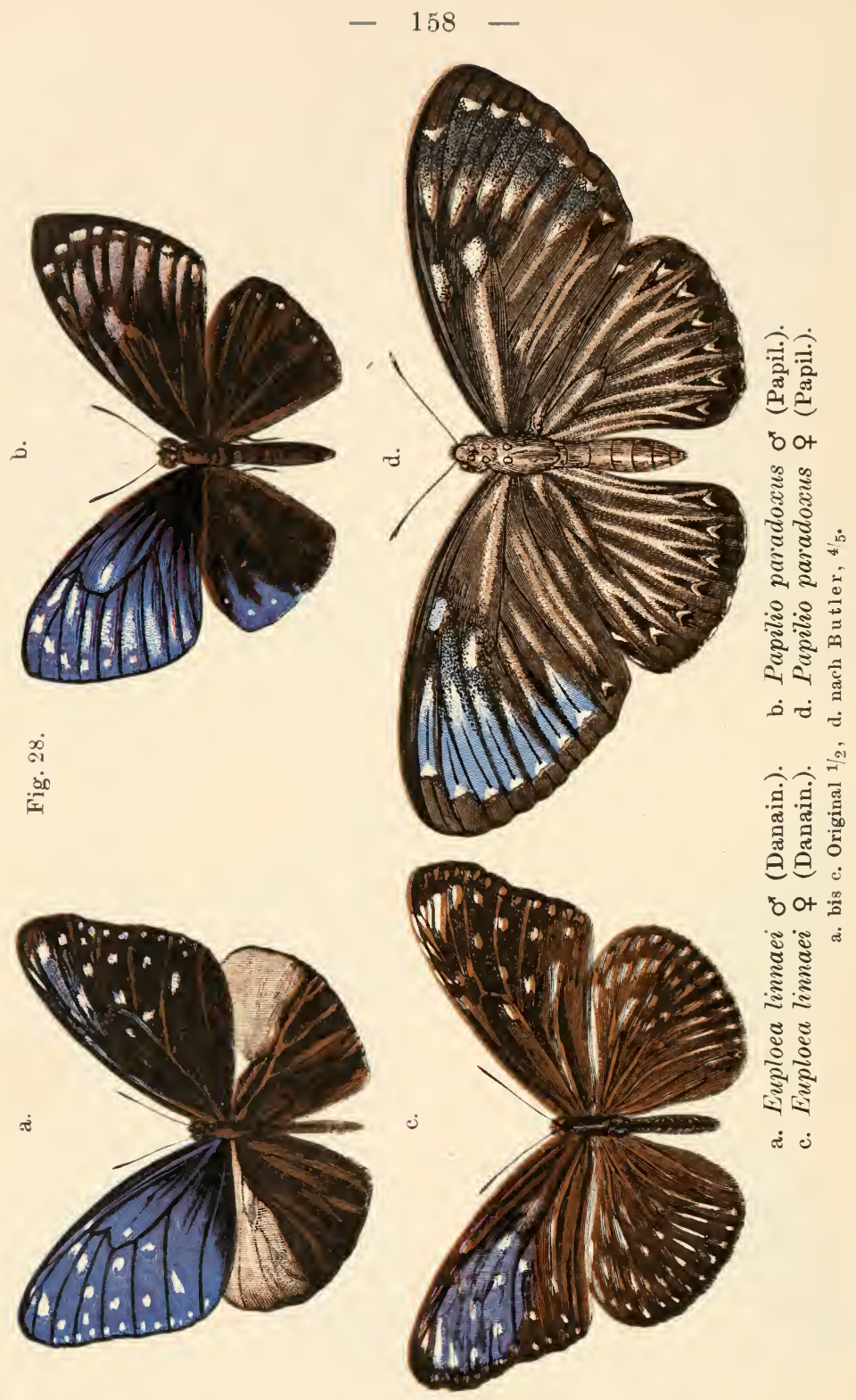


von Vallace ${ }^{1}$ ) als bestes Beispiel für die Herausbildung einer Angleichung beschrieben wurden. Er ist der auf den Großen Sundainseln beheimatete Vertreter einer Artengruppe, die in Hinterindien in einer Menge übergangsreicher Formen vertreten ist (Fig. 27). Diese schwer zu übersehende Veränderlichkeit abgerechnet, ist das Männchen oben dunkel stahlblau mit schwarzen Strichen zwischen den Adern, unten mit einigen ziegelroten Flecken an den Flügelbasen und ebensolcher Einfassung um mehrere tiefschwarze Flecke am Analrande der Hinterflügel. Die Weibchen unterscheiden sich durch eine in sehr verschiedener Ausdehnung vorkommende Aufhellung der Oberseite nach Gelbgrau hin und darin, daß der vorderste rote Basalfleck der Unterseite auch oben ausgeprägt ist. Diese gewöhnlichen Weibchen (Fig. 27 b) haben ebensowenig wie die Männchen Schwänze. An den gleichen Orten findet man aber eine seltenere Weibchenform (f. achates), die wesentlich anders gebildet ist. Sie ist kräftig geschwänzt und hat völlig aufgehellte Vorderflügel mit gelben, nicht roten, Schulterflecken; die hinteren führen oben und unten ein breites, weißes Innenband, das von schwarzen Adersäumen geteilt wird, und der Hinterrand ist ebenso wie die Körperseiten gelb (Fig. 27 c). In der Achatesform - die nicht etwa eine besondere Art, sondern mit der gewöhnlichen verschwistert ist - haben wir die Nachahmung des javanischen Pharmacophagus coon (Fig. $27 \mathrm{~d}$ ), von dem sie sich in der Färbung nur durch die gelben Epauletten, sonst freilich in der erheblich größeren und plumperen Figur unterscheidet.

Besonders verwickelt werden die Beziehungen der Anpassung, wenn jedes Geschlecht einer dimorphen Art sein eigenes Vorbild hat. Das gewählte Beispiel ist noch dadurch besonders anziehend, daß auch die nachgeäffte Art dimorph ist, wobei die Angleichung von Geschlecht zu Geschlecht vor sich gegangen ist. Das Modell ist Euploea linnaei, eine der gemeinsten Danainen des malaiischen Archipels, ihr Nachäffer Papilio paradoxus, eine seltene Art aus einer Gruppe stark zur Euploeenform umgewandelter Rinnenfalter von gleichem Vorkommen. Fig. 28 zeigt, wie das Männchen in allen Zügen der tiefschwarzen, blau schillernden Euploee gleichkommt, ebenso das Weibchen dem entsprechenden Geschlecht des Vorbildes mit dem matteren Braun, den strahlenförmigen hellen Streifen und dem spärlichen Blau.

1) 1865 . 
Fig. 29.
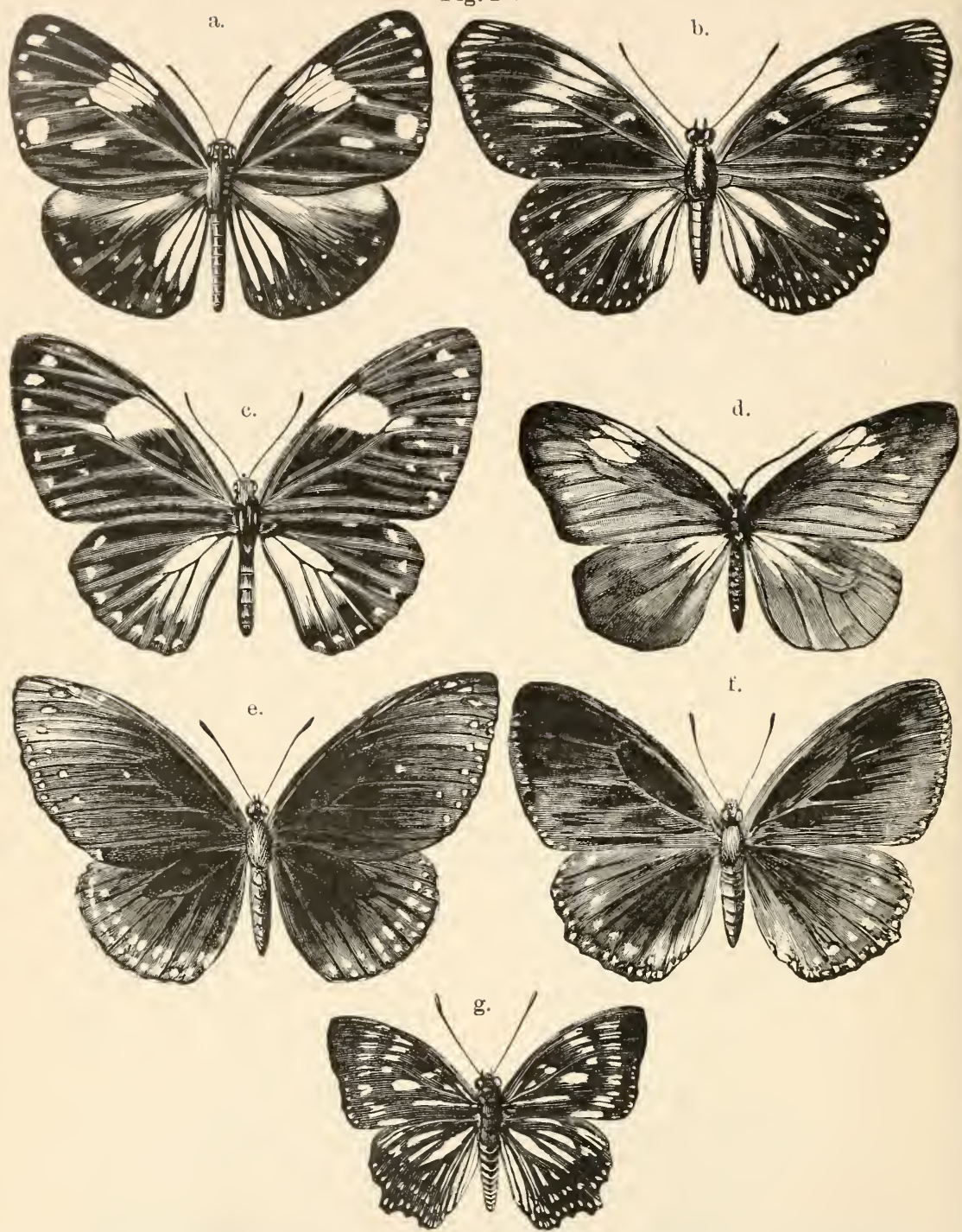

a. Euploea rhadamanthus (Danain.).

c. Papilio caunus (Papilion.).

b. Euripus halitherses + (Nymphalin.).

e. Euploea godarti (Danain.).

d. Mimeuploea rhadamanthe (Chalcosiin.).

f. Euripus halitherses $q$ (Nymphal.).

g. Euripus halitherses $\sigma^{\star}$.

a. Modell zu b. - d., e. Modell zu f. Original $1 / 2$, d. $4 / 5$. 


\section{Nachäffung mehrerer Vorbilder durch eine Art.}

Die nordafrikanische Sesia seitzi ahmt nicht wie die europäischen Glasflügelschwärmer irgend eine Stechimme nach, sondern Widderchen, Zygaenen. Durch ihr Auftreten in drei Formen, mit hellrotem, rotberingtem und schwarzem Hinterleibe kopiert sie gleich drei Modelle: Zygaena cedri, loyseli und algira. Nach Seitz ${ }^{1}$ ) erlangt sie hierdurch Schutz gegen eine Raubfliege (Asilus), die dort geradezu vernichtend unter den Faltern haust. Die Raubgier der Fliege läßt sie sogar Bienen verfolgen, macht aber vor den unschmackhaften Zygaenen Halt. Somit bringt es dem Schmetterling mehr Sicherheit, daß er einen anderen schwachen, aber widrigen Genossen nachäfft, als einen der an sich wehrhaften Hautflügler.

Eine häufige Nymphaline der malaiischen Inselwelt ist Euripus hatitherses (Fig. 29), deren Männchen im ganzen Verbreitungsgebiete gleich aussehen: auf schwarzbraunem Grunde mit weißen Streifen und gereihten Tüpfeln. Bedeutend größer und in der Zeichnung viel veränderlicher sind die Weibchen, welche eine Anzahl Rassen, öfters unter mimetischer Anlehnung an dortige Euploeen, bilden. Eine hier abgebildete (Fig. 29) ist die Wiedergabe der indischen Euploea godarti (Fig. 29), eine andere (Fig. 29) gleicht der schönen, mit weißen Spiegelflecken und bläulichen Tüpfeln gezeichneten E. rhadamanthus (Fig. 29). Wie schon berührt, hat dieses häufige Tier noch auf eine andere Art jener oben erwähnten euploeiformen Schwalbenschwänze eine mimetische Anziehungskraft ausgeübt, den Papitio caunus (Fig. 29), ja sogar eine Heterocere (Mimeuploea rhadamanthe) schließt sich an (Fig. 29).

Zur Berühmtheit als ein Paradestück der Mimikrylehre ist der afrikanische Rinnenfalter Papilio dardanus ${ }^{2}$ ) gelangt, den ich in diesem Zusammenhang vorführen möchte (Fig. 30). Die Ähnlichkeit einer seiner polymorphen Formen mit anderen äthiopischen Rhopaloceren war eine der "Analogien", die bereits Boisduval 3) auffielen, seitdem hat man immer mehr Einblicke in seine beispiellose Veränderlichkeit getan, ohne ihre Beziehung zu Vorkommen, Klima und Vererbungsregeln noch völlig zu durchschauen. Ich

1) Deutsche Entom. Nationalbibliothek 1, 47 (1910). — $\left.{ }^{2}\right)$ Der gültige wissenschaftliche Name ist $P$. darclanus, der sonst für eine amerikanische Art gebraucht wurde; bisher war er als $P$. merope bekannt. $-{ }^{3}$ ) Hist. Nat. des Insectes, Lépid. 1, 373 (1836) ( $P$. westermanni ${ }^{*}$ ).

Jacobi, Mimikry. 


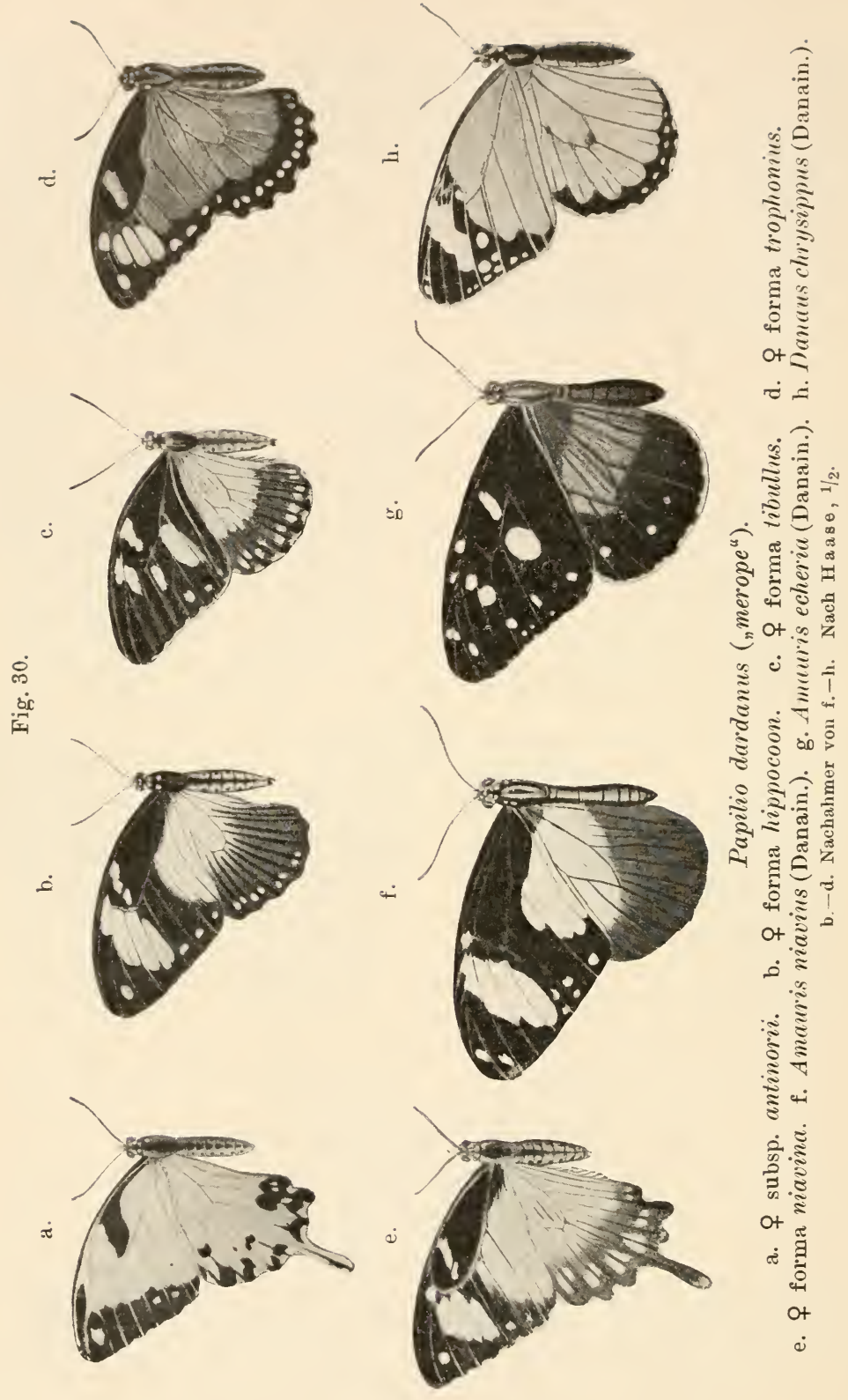


halte mich in der Darstellung dieses Problems an das große Werk Eltringhams ${ }^{1}$ ) über die afrikanischen Mimikryschmetterlinge, werde sie aber zum leichteren Verständnis für den Fernerstehenden möglichst vereinfachen. Auf Madagaskar gibt es nur Unterarten von $P$. dardanus, von denen sich beide Geschlechter in der Gestalt und so ziemlich auch in der Farbe gleich sind: Männchen und Weibchen zeigen einen gewöhnlichen, geschwänzten Rinnenfalter wie Fig. a von schwefelgelbem Grundton mit schwarzer Fleckund Bindenzeichnung ( $P$. dardanus meriones und $d$. humbloti). Auch in Abessinien ist der ganz ähnlich aussehende $P$. d. antinorii (Fig.a) für gewöhnlich eingestaltig, aber es kommen daneben, freilich höchst selten, Ausartungen des Weibchens vor, die zwar geschwänzt, aber anders gefärbt sind und in dieser Beziehung einigen der nachher erwähnten schwanzlosen Weibchenformen nahe kommen: 1. P. d. antinorii, forma niavina (Fig.e), die der forma hippocoon entspricht, daher weißen Grundton statt des gelben führt; 2. P. $d$. antinorii, forma ruspinae, die mit dem ziegelroten Unterton an die Form trophonius (Fig.d) gemahnt. Im übrigen tropischen Afrika ist der männliche $P$. dardanus überall von der gleichen, schon bekannten Erscheinung, hat aber eine ganze Reihe verschiedenartiger, und zwar mimetischer Weibchenformen; diesen gehen die Schwänzchen bis auf gelegentlich vorkommende Andeutungen (forma trimeni) ab. Systematisch werden alle unter $P$. d. dardanus einbegriffen. Ton den dimorphen Weibchenformen sind folgende die häufigsten: 3. forma hippocoon (Fig. b), der weiße Grund durch schwarzbraune Verdunkelung auf die Flügelbasis und randständige Flecke eingeengt; sie hat eine in Westafrika häufige Danaine, die Amauris niavius (Fig. f), zum Vorbild. 4. Forma cenea ähnlich 3., aber mit fortgeschrittener Schwärzung der Vorderflügel und gelber Tönung des Inneren der Hinterflügel, entspricht der ebenfalls westafrikanischen Amauris echeria (Fig.c und g). 5. Forma trophonius (Fig. d) mit größtenteils zinnoberroten Flügeln, lebt in Ostafrika und kann als Nachahmer des so weit verbreiteten, gemeinen Danaus chrysippus gelten (Fig.d und h). 6. Forma planemoides mit breiter, rostgelber Querbinde auf den Vorderflügeln und weißer Basis der Hinterflügel, Mimetiker der Acraeine Planema poggei.

1) 1910 . 
Fast hundert Jahr lang hatte man diese Phasen für ebensoviel verschiedene Arten gehalten, und, wie Eltringham sagt, die Wiedergabe der allmählichen Entschleierung des Geheimnisses liest sich fast wie ein naturgeschichtlicher Roman. Zuerst machte Trimen 1866 in Südafrika die Erfahrung, daß von dem typischen Papitio "merope" nur Männchen zu erlangen waren; nach England zurückgekehrt fand er dies an allen Exemplaren der Sammlungen bestätigt, während $P$. cenea, trophonius, dionysos, hippocoon usf. ebenso unabänderlich Weibchen waren. Daraus zog er den kühnen und zunächst viel bekämpften Schluß, daß alle ungeschwänzten Stücke nur die Weibchen des langgeschwänzten, schwarz-weißen P. merope seien. Für diese Artenvereinigung lieferte zuerst Weale die tatsächliche Bestätigung, indem er aus ein und derselben Brut sowohl merope-Männchen wie auch Weibchen von cenea, trophonius und hippocoon züchtete, was auch Späteren wiederholt gelungen ist. Diese Versuche ergaben auch, daß die Seltenheit der Weibchen im Freien nur scheinbar ist, vielmehr entwickeln sich beide Geschlechter ungefähr in gleicher Zahl, aber die Männchen fallen draußen durch ihr lebhafteres Wesen mehr auf.

Mit der Zeit hat man, namentlich durch umfangreiche Zuchtversuche und genauere Beachtung des Vorkommens in Süd- und Ostafrika eine noch viel größere Veränderlichkeit der dardanusWeibchen und nicht wenige Übergangsformen wahrgenommen und ihre mimetischen Beziehungen zu den Lokalformen immuner Danainen und Acraeinen herauszudeuten gesucht, was freilich nicht wenige Widersprüche ergeben hat.

Während im vorstehenden Falle eine einzige Art durch ihre Vielgestalt die Ähnlichkeit mit mehreren Arten von Modellen erreicht, können auch einzelne Arten das Modell für mehrere Nachahmer oder ganzer verschiedener Gruppen von solchen sein; die Modelle pflegen dann weiter verbreitet und häufig zu sein. So wird die gemeine indische Euploea linnaei von einer der veränderlichen Weibchenformen des schon erwähnten Euripus halitherses und einer anderen Nymphaline Hypolimnas anomala, der Satyride Elymnias 7eucocyma, dem Papilio paradoxus und der Chalcosiine Cyclosia midamus kopiert. Ton Aristolochienfaltern wird Pharmacophagus polydorus Angehörigen mehrerer Gruppen der Rinnenfalter und der Epicopeiide Epicopeia polydorus zum Vorbild usw. 


\section{Mimikry ausgestorbener Modelle}

scheint eine Ableitung zu sein, die den Gipfel von Kühnheit in unserem an Vermutungen schon so reichen Forschungsgebiete bedeutet; sie hat aber einige tatsächliche Unterlagen, die dem Gedanken wenigstens das Recht auf Erwähnung geben. Der oft genannte Danaus chrysippus tritt in Ostafrika und Torderindien teils in der gewöhnlichen orangeroten Form auf, teils, aber ungleich seltener, in einer weißlich aufgehellten Abart [forma dorippus $\left.{ }^{1}\right)$ ], während sein Nachahmer Hypolimnas chrysippus o ziemlich häufig ein der letzteren entsprechendes Kleid trägt. Swinhoe ${ }^{2}$ ) wirft deshalb die Frage auf, ob die dorippus-Form vielleicht - von der typischen chrysippus verdrängt - im Aussterben begriffen sei, während die nachäffende Art ihr Vorbild überlebt. Ferner gibt es im indoaustralischen Gebiete sehr große Danaiden, die Gattungen Hestia und Ideopsis, von weißer Farbe und wie Seidenpapier durchscheinend mit braunen bis schwarzen Zeichnungen und Flecken darauf, die von Papilios, Satyrinen und anderen Familien nachgeäfft werden. Nun hat ein vorzüglicher Beobachter der indonesischen Schmetterlingswelt, Martin, allerlei angedeutet ${ }^{3}$ ), daf diese oft gigantischen Falter ihre Rolle in der heutigen Fauna ausgespielt haben. An den Urwald ebenso gebunden wie die Menschenaffen verschwinden sie samt diesen, wo er gerodet wird, für immer. Auf dem stark bevölkerten Java, wo er zum Zwecke der Reis- und Tabakkultur bereits zum größten Teile gefallen ist, sind zwei der stattlichsten Hestien im Aussterben begriffen oder schon erloschen: von Hestia belia sind nur wenige Stücke, von $H$. javana gar nur eins bekannt.

Endlich ist eine in ihrer bei keinen Verwandten wiederkehrenden Form und Zeichnung ganz eigenartige riesige Papilionide Afrikas unter diesem Gesichtspunkte betrachtet worden. Drurya antimachus hat den Umriß der Flügel, nur noch mehr ausgezogen, und auch die Grundlagen der Zeichnung von einer Acraea, ist sehr selten und hat auch ganz den Flug ${ }^{4}$ ): „er schwebt

1) Der richtige Name ist klugii. - $\left.{ }^{2}\right)$ 1895, S. 341. - ${ }^{3}$ ) Deutsche Ent. Nat.-Bibliothek 2, 22 (1911). - - ${ }^{4}$ ) Infolge einer Verwechslung, die Donovan vor fast 100 Jahren beging und die, wie so oft, einer em anderen nachschrieb, bis Trimen sie aufdeckte, wird der Drurya 
langsam segelnd dahin, ganz nach Art der größeren Acraeen, durchaus nicht ungestüm und in hastigem Fluge wie andere Papilios", berichtet uns E. Baumann ${ }^{1}$ ). Wenn man sich überhaupt um die Erklärung fremdartiger Naturerscheinungen bemühen will, hat deshalb Trimens ${ }^{2}$ ) Frage ihre Berechtigung, ob der Falter vielleicht der überlebende Nachahmer von großen ausgestorbenen Acraeinen sei.

\section{Beispiele für Müllersche oder synaposematische Mimikry.}

Wie schon erwähnt (S. 62), hatte Fritz Müller gewisse Zweifel in der Batesschen Mimikrytheorie, wonach auch zwei an sich geschützte Schmetterlinge verschiedener Gattungen mimetische Ähnlichkeit zeigen können, durch eine Erweiterung dieser Theorie beseitigt. Später stellte es sich mehr und mehr heraus, daß solche "synaposematischen" Trachten (Poulton) durch ganze Gattungen hindurch vorkommen; man kann aus Mitgliedern dieser Gattungen ganze synaposematische "Ringe" zusammenstellen, die alle gemeinsamen Färbungstypus haben und am gleichen Orte und zu derselben Jahreszeit fliegen. Überhaupt zeigen in vielen Gegenden die gemiedenen Insekten aus ganz verschiedenen Gruppen oft reihenweise dasselbe äußere Trachtenbild, was bei schmackhaften nicht annähernd so vorkommt. Poulton fand darin eine Erscheinung, die sich mit dem ursprünglichen Begriffe der Mimikry nach Bates und Wallace nicht mehr recht deckte, und tritt in seinen neueren Schriften dafür ein, sie als ,gemeinsame IVarnfarben" zu bezeichnen. Die als Synaposeme sich ähnelnden Schmetterlinge sind besonders in Südamerika in umgrenzten Bezirken heimisch, und zwar am reichsten bei den Ithomiinae und Heliconiinae vertreten. Auf S. 140 führte ich mehrere solche Paare aus der ersten Familie, S. 147 solche unter den Heliconiern vor, zu denen man sehr oft noch, wie eben dort, die nicht gemiedenen, pseudaposematischen Partner beibringen kann. Einen bei Bahia vorkommenden viergliedrigen Ring kann man in schönen farbigen Abbildungen aus Weismanns neuesten Büchern ${ }^{3}$ ) kennen lernen;

meistens ein reißend schneller Flug angedichtet, worauf ihre Erscheinung, wie letzterer meint (1868, S. 503, Anm. $\dagger$ ), gar nicht paßt.

1) Berl. Ent.-Zeitschr. 39, 16 (1894). — ) 1868, S. 503, Anm. †. 3) 1904, S. 94 , Taf. 2, Fig. 1-4; Die Selektionstheorie 1909, S. 58, Taf. 
er besteht aus Lycorea halia (Dan.), Mechanitis lysimmia und Ielinaea ethra (Ithom.), Heliconius eucrate(Helic.). Bei Pará fliegen nach Bates ${ }^{1}$ ) zusammen: Melinaea egina, M. mneme, Mechanitis polymia (Ithom.), Heliconius silvanus und mumata.

Auch Heteroceren sollen sich als Synaposeme solchen im Naturbild auffallenden, gemiedenen Vorbildern anpassen, wenigstens glaubt Haase ${ }^{2}$ ) nach einer sehr bezeichnenden Angabe Hahnels den Pericopinae widrig machende Eigenschaften zusprechen zu dürfen. Die schöne, seltene Fericopis phoebe gleicht besonders als Weibchen durch die Verteilung des Rot auf beiden Flügelpaaren dem gemeinen Heliconius doris (Fig. 25c), forma rubra, dessen leuchtende gelbe Binden und Außentüpfel sie auch führt, und die colombianische P. mimica entspricht Hel. lindigii.

Wo die englischen Entomologen im Geiste Poultons schon in der Natur genaue statistisch-ökologische Aufnahmen gemacht haben, belehren sie uns, daß in dergleichen Verbänden ein Mitglied durch überwiegende Häufigkeit sozusagen den Mittelpunkt einer Anziehungskraft vorstellt, der die übrigen folgen, indem sie als Gleiche sich zu Gleichen gesellen. Beispielsweise machte Kaye ${ }^{3}$ ) in Britisch-Guiana im Laufe eines Tages auf demselben kleinen Fleck eine Ausbeute von 323 Tagfaltern. Daraus hob sich ein Synaposementypus von Angehörigen der immunen "Danaiformen " heraus mit auffallend verdunkelten Hinterflügeln als Merkmal. Ihm gehörten nicht weniger als 295 der gefangenen Schmetterlinge an, und zwar stellte davon Melinaea mneme allein 25ૅ, während die übrigen aus zwei anderen Melinaea, zwei Arten Mechanitis, zwei Lycorea und zwei Heliconius bestanden, jede aber nur mit höchstens zehn Stück vertreten.

Mit dieser Betrachtung schließe ich die rein systematischen Darlegungen über die Schmetterlinge, halte es jedoch für nützlich, die vielen Einzelheiten mit Hinzunahme alles dessen, was in der Literatur als mimetische Anpassung innerhalb der Ordnung

1) 1861 , S. 550 (die Namen von Ha a se S. 127 berichtigt). - ${ }^{2}$ ) S. 71. - ${ }^{3}$ ) Nach Nitteilung an Poulton: Proc. Entom. Soc. 1903, S. 54; Weiteres bei Kaye 1906 mit vorzüglichen Abbildungen. 
i.epidopter a gedeutet worden ist, übersichtlich zusammenzufassen ${ }^{1}$ ), indem ich die Familien und Unterfamilien in ihren Rollen als Modelle und Nachäffer einander gegenüberstelle.

a) Rhopaloceren, nachgeäft von anderen Rhopaloceren:

1. Danainae mit Neotropinae, nachgeäfft von Mitgliedern ihrer eigenen Unterfamilie, ferner von Satyrinen, Heliconiinen, Nymphalinen, Eryciniden, Pieriden, Papilioniden.

2. Einige Morphinae von Satyrinen und Papilioniden.

3. Acraeinae von Nymphalinen, Lycaeniden, Pieriden, Papilioniden.

4. Heliconiinae von Heliconiinen, Nymphalinen, Pieriden, Papilioniden.

๖. Pieridae von Pieriden und sehr selten von Satyrinen.

6. Papilionidae von Papilioniden und Pieriden.

b) Rhopaloceren, nachgeäft von Heteroceren (viel weniger Fälle):

1. Danainae mit Neotropinae von Castniiden, Chalcosiinen, Arctiiden und Geometriden.

2. Papilionidae von Castniiden, Chalcosiinen, Pericopinen, Epicopeiiden.

c) Heteroceren, nachgeäft von Rhopaloceren (sehr selten):

1. Uraniidae von Papilioniden.

2. Agaristidae von Nymphalinen.

3. Nycthemerinae von Nymphalinen, Lycaeniden (Agaristiden).

d) Heteroceren, nachgeäft von Heteroceren (ebenso selten):

1. Agaristidae von Lipariden.

2. Nycthemerinae von Agaristiden.

Diese Übersicht kann in bedeutendem Umfange erweitert oder eingeschränkt werden, je nach dem Geschmacke des einzelnen, welche Ähnlichkeiten er für mimetische ansieht oder nicht. S. 83 .

$\left.{ }^{1}\right)$ Unter Benutzung einer älteren Aufstellung von Trimen 1897, 


\section{Allgemeine Eigenschaften der mimetischen Schmetterlinge.}

\section{Eigenschaften, die gemieden machen.}

Der Begriff "Immunität" ist bei den Lepidopteren etwas bestimmter als bei anderen Kerbtieren, weil die tierischen Feinde, gegen die sich die Eigenschaft der Widrigkeit richtet, wesentlich nur Vögel sein können, da die in Betracht kommenden Schmetterlinge als große, verhältnismäßig rasch und hoch fliegende Wesen im allgemeinen nur von diesen erbentet werden können. Ich will nämlich, so wie bisher, annehmen, daß der Verfolgung durch Vögel eine Bedeutung innewohnt, die für Entstehung und Vorteil der Nachäffung immuner Arten durch andere den Anreiz gibt, und folge darin sowohl den Begründern der Mimikrylehre wie denjenigen, welche an ihrer späteren Ausgestaltung wesentlich gearbeitet haben. Erst in einem späteren Abschnitte soll untersucht werden, ob die Vögel in der Lebensökonomie der Falter wirklich den Ausschlag geben, der für so bedeutende Umgestaltungen des Körpers und auch für ökologische Anpassungen die Voraussetzung bilden muß. Aber dies selbst zugegeben hat die Immunität einen weiten Spielraum. Wenn sie bei gewissen, eben den immunen, Arten, deren es in den Augen der englischen Verfechter anscheinend immer mehr werden, so weit ginge, daß die Besitzer überhaupt für Kerbtierfresser ungenießbar wären, so würde sie den vertilgenden Angriffen, welchen die anderen Entwickelungsstände der Lepidopteren ausgesetzt sind, in einem Umfange die Wage halten, der zur Übervölkerung mit solchen Arten führen müßte. Es blieben damn den übrigen Arten der an sich wehrlosen Schmetterlinge nur die drei Auswege, entweder sich auch widrige Eigenschaften anzueignen, oder schützende An- 
passungen, kryptische oder mimetische, zu erwerben, oder auszusterbeı. Dadurch käme dieses Gebiet des Naturhaushalts völlig aus dem Gleichgewicht; aber wir können weder jene Ursache noch diese Folgen wahrnehmen. Immunität hat vielmehr nur die Wirkung, daß manche Arten weniger Verminderung durch die besonderen Feinde der Ordnung erleiden als andere. Auch sie bleiben aber nicht frei von Verfolgung durch bestimmte Feinde, denen die Widrigkeit nichts anhat, z. B. nennt Werner ${ }^{1}$ ) einen Sporenkuckuck (Centropus) als gewohnheitsmäßigen Verzehrer von Danaern und Acraeen. IVas die widrigen Eigenschaften bewirken, hat $\mathrm{Haase}$ mit gewohnter Belesenheit und auf Grund eigener Beobachtungen bis etwa 1890 zusammengetragen; ich kann hieraus und aus späteren Schriften nur eine Auswahl bezeichnender Stichproben vorlegen.

Die "Heliconier" - im Sinne der älteren Mimikryforscher" als eine biologisch zulässige Zusammenfassung der Danainen, Ithomiinen und Heliconiinen genommen - rechnete Bates ${ }^{2}$ ) zu den Faltern, die das sicherste Leben führen, denn er beobachtete weder eine Verfolgung der fliegenden durch Vögel und Libellen, noch eine solche durch Eidechsen oder Raubfliegen, denen sitzende Falter sonst zur häufigen Beute werden. Belt ${ }^{3}$ ) stellte fest, da f wenigstens einige Vögel sie in Ruhe ließen, obwohl das Brutgeschäft großen Nahrungsbedarf mit sich brachte. Ebensowenig hat Poeppig wahrgenommen, daß unter den vielen Schmetterlingen, welche die Vogelfamilie der Bucconiden zur Nahrung verwendet, Heliconier waren, auch haben diese Naturforscher niemals abgebissene Flügel von ihnen auf dem Waldboden liegen gesehen, was sonst die Schmetterlingsmahlzeiten von Vögeln und Eidechsen nachweist. Für die Danaiden der Alten Welt bestätigen dies andere Beobachter wie Boyd Alexander, E.L.Arnold, Aitken, Bingham, und zwar selbst für die Bienenfresser, welche eifrige Schmetterlingsjäger sind ${ }^{4}$ ). Marshall ${ }^{5}$ ) stellt aus der Literatur fest, daß unter 71 Beobachtungen von Vogelangriffen nur viermal Danainen betroffen waren; ein Gewährsmann Eimers ${ }^{6}$ ) sah auf Java nur einmal die Verfolgung eines Tagfalters durch einen Vogel - es war ein Danaide und der Vogel ließ von ihm ab, als

1) 1908 , S. $\left.569 .-{ }^{2}\right)$ 1861, S. 510. - ${ }^{3}$ ) A Naturalist in Nicaragua 1888 , S. 316 (nach Haase). - ${ }^{4}$ ) Eltringham 1910, S. 122. - ${ }^{5}$ ) 1909, S. 335 u. f. - ${ }^{6}$ ) 1897 , S. 277 , Anm. 
er ihn nach jenes Meinung erkannt hatte. Hampson ${ }^{1}$ ) glaubt in Indien ebensoviel Danaer wie Arten nicht gemiedener Familien als Beute von Tögeln gesehen $\mathrm{zu}$ haben, allein erstere kamen wieder davon "dank der Zähigkeit ihrer Haut", wie er meint, aber sie wurden wohl infolge ihres Ekelgeschmackes sofort freigegeben. Haase erlebte einen besonders lehrreichen Fall, wo ein Drongowürger, die besondere Schmetterlingsjäger sind, bis auf zwei Fuß an einen Danaus septentrionis heranschoß, ihn fliegend besichtigte und Kehrt machte ${ }^{2}$ ).

Die Acraeen würden, wie Seitz bemerkt ${ }^{3}$ ), bei ihrer ungeheuren Menge und Unbeholfenheit „eine wahre Mast für die insektenfressenden Vögel sein, an denen in den Tropen ein großer Überfluß ist", doch konnte er nie eine Nachstellung bemerken, noch einzelne Acraeenflügel auf der Erde finden. - Eine zu den gemiedenen Pieriden gerechnete Mylothris sah Swynnerton von einem Fliegenschnäpper verfolgt ${ }^{4}$, doch kehrte der Vogel dicht davor um.

Leichter und daher häufiger verzeichnet sind die an Hausgeflügel und Käfigtieren gewonnenen Feststellungen. Hühner, die sich um andere vorgeworfene Falter streiten, lassen Danaus vulgaris und chrysippus nach Erprobung und ohne solche liegen ${ }^{5}$, ebenso Ithomiinen, Heliconier und Pharmacophagus in Südamerika ${ }^{6}$ ) und Indien ${ }^{7}$ ). Ähnliches hat man für diese und andere als Nodelle betrachtete Arten bei Singvögeln und Affen festgestellt, worüber Näheres in den inhaltreichen Abhandlungen von Finn ${ }^{8}$ ) und Marshall ${ }^{9}$ ) zu finden ist. Daß solche Tersuche an Tieren, die ihren natürlichen Neigungen nicht frei nachgehen können, oft der langen Weile folgen, bei Hunger oder Sättigung verschiedene Eindrücke empfangen usw., nur bedingten Wert haben und durch Naturbeobachtung ergänzt werden müssen, wird auch von den Berichterstattern zugegeben ${ }^{10}$ ).

Auch an räuberischen Gliederfüßern, wie Spinnen, Libellen, Mantis, Raubfliegen, sind ähnliche, wenn auch nicht widerspruchs-

$\left.{ }^{1}\right)$ Proc. Ent. Soc. 1897, S. 38. - ${ }^{2}$ ) S. 102. - ${ }^{3}$ ) Nach Haase, S. 54. - ${ }^{4}$ ) Nach Marshall 1909, S. 379. - ${ }^{5}$ ) Haase, S. 23. ${ }^{6}$ ) Hahnel in Iris 3, 161 (1890). - ${ }^{7}$ ) Fruhstorfer in Iris 19, 177 (1909). - ${ }^{8}$ ) 1897. $\left.-{ }^{9}\right)$ 1902. - ${ }^{10}$ ) Marshall 1908, S. 140-142. 
freie Wahrnehmungen zu verzeichnen ${ }^{1}$ ), doch kommt ihnen für unsere Fragen nicht die Bedeutung zu wie den Wirbeltieren. Für letztere steht jedenfalls fest, da@ sie eine Anzahl Schmetterlingsarten im ganzen unbehelligt lassen, weil sie sie an ihrem Äußeren als unschmackhaft bis ungenießbar erkennen.

Worauf die Widrigkeit solcher Schmetterlinge für Insektenfresser beruht, ist dunkel. Die Körpersäfte der allgemein für geschützt gehaltenen Euploea linnaei sind, wie Longstaff an sich selbst probierte ${ }^{2}$ ), für den Menschen gesckmacklos; afrikanische Danainen und Acraeen schmeckten IIarshall ${ }^{3}$ ) teils ganz nüchtern, teils in geringem Grade bitter oder seifig. Auch unser als Raupe und Falter von Vögeln, Fröschen und manchen Spinnen durchaus gemiedener Harlekinspanner (Abraxas grossulariata) hat nach Plateau ${ }^{4}$ ) in beiden Ständen durchaus nichts Abstoßendes für die menschliche Zunge. Ob der vielen Immunen eigene, besonders beim Ergreifen aus vorgestülpten „Duftpinseln" usw. entwickelte und für uns oft, aber durchaus nicht immer, widerwärtige Geruch mitwirkt, ist sehr zweifelhaft, obgleich Haase ihm für das Ansprechen immuner Arten viel Wert beilegte. Solche Düfte, die ebenfalls von Dixey und Longstaff im Freien geprüft worden sind ${ }^{5}$ ), scheinen an erster Stelle der Fortpflanzung als geschlechtliche Lockmittel $\mathrm{zu}$ dienen, was freilich nicht ausschließt, daß andere Tiere davon abgestoßen werden. Ist doch jener der menschlichen Nase so ekelhafte Wanzengeruch, der sicherlich ein Schutzmittel sein soll, weil ihn auch die Larven in besonderen Drüsen erzeugen, für manche Vögel durchaus kein Hindernis, große und kleine Baumwanzen zu verzehren. Um es zusammenzufassen - die Tatsache der Immunität besteht, aber ihre Wirkung hat schwankende Grenzen, und wir haben vorläufig keine sichere Kenntnis, worauf sie beruht.

\section{Weitere Eigenschaften der gemiedenen Falter.}

Von den meisten immunen Gruppen wird berichtet, daß ihre Vertreter einen langsamen, unsicheren, sich in geringer Höhe

$\left.{ }^{1}\right)$ Doherty in Journ. As. Soc. 2, 14-15 (1891); Hahnel in Iris 3, 161 (1890); Seitz in Deutsche Ent. Nat.-Biblioth. 1, 47 (1910); Poulton 1906, S. $362-364$ u. a. m. — ${ }^{2}$ ) Trans. Ent. Soc. 1908, S. 623. — ${ }^{3}$ ) Daselbst 1902, S. 313-314. - ${ }^{4}$ ) Mém. Soc. Zool. France $\mathbf{~}, 375$ (1044). - ${ }^{5}$ ) Proc. Ent. Soc. 1906, S. 2-3. 
bewegenden Flug haben und eine Furchtlosigkeit zur Schau tragen, die von der sonstigen Vorsicht tagliebender Schmetterlinge sehr absticht. Nach Ha ses Zusammenstellungen fliegen die Danainen aufgestört in langsamem, klappendem Fluge davon und zeigen keine Scheu; die afrikanischen Amauris gleiten bedächtig einher, machen lange in der Luft Halt und sind leicht zu fangen; die Euploeen fliegen langsam und schwer dahin, oft in großen Schwärmen. Ganz ähnlich ist das Benehmen der Acraeen, die keinerlei Trieb zeigen, sich zu verstecken, und der neotropischen "Heliconier", die meist in ganzen, von mehreren Familien gestellten Gesellschaften auf Waldblößen, an Flußufern u.dgl. herumschweben; die Schwäche ihrer Flugmuskeln fiel Hahnel immer auf. Auch die immunen Schwalbenschwänze (Pharmacophagus) sind im auffälligsten Gegensatze zu der bekannten schenen Flüchtigkeit der anderen Papilionen bedächtig und vertrauensselig; Ph. aristolochiae, ein sehr langsamer, träger Flieger, machte auf Longstaff ${ }^{1}$ ) mit diesen Bewegungen ganz den Eindruck, als ob er sich seiner Gemiedenheit bewußt wäre. Doflein ${ }^{2}$ ) hebt für Ceylon den langsamen, fast schwerfälligen Flug des von Vögeln unbehelligten Ph. ("Omithoptera“) darsius gegenüber den eilfertigen Pap. agamemnon, pammon, montanus hervor, die stark verfolgt werden; freilich rechnet er zu den letzteren auch Pharm. hector, was einen Widerspruch bedeuten würde, wenn nicht vielleicht eine Verwechselung mit dem Weibchen von Pap. pammon romulus vorgekommen ist, das jenem mimetisch gleicht.

Ein weiteres Merkmal der immunen Modelle ist ihre große Lebenszähigkeit, verbunden mit einer Festigkeit der Flügelmembranen und besonders der Rumpfhaut, die sie viel schwerer verletzbar macht, als man es bei den zarten Tagfaltern gewohnt ist. Die Brustringe sind so fest gefügt, daß der Sammler die Gefangenen kaum auf die gewöhnliche Weise durch Druck zwischen den Fingern lähmen kann, und noch mit halbzerquetschtem Thorax fliegen sie weiter, als wäre ihnen nichts geschehen. Wenn man gleichzeitig eine Acraea und eine der ihr so täuschend gleichenden Pseudacraea fängt, merkt man zwischen Daumen und Zeigefinger sofort den Unterschied in der Nachgiebigkeit der Körperbedeckung,

1) Trans. Ent. Soc. 1907, S. 640. - ${ }^{2}$ ) Ostasienfahrt 1906, S. 444. 
infolgedessen die letztere sofort stirbt, während man die Acraea beliebig fest und lange drücken kann; erst die Giftflasche bringt sie um. Danaus erippus schlüpfte noch aus einer mit der Nadel durchbohrten Puppe; einen Pharmac. philenor, dessen Thorax Haase durch längeren Druck vollkommen gesprengt hatte, sah er nach einiger Zeit wieder herumfliegen ${ }^{1}$ ). Longstaff ${ }^{2}$ ) ist einmal in Indien diesem Unterschied zwischen widrigen und ungeschützten Arten zahlenmäßig nachgegangen, indem er am Abend eines Fangtages feststellte, wieviel der in Düten verwahrten Stücke jeder Art noch Lebenszeichen aufwiesen; bei den Danainen war es mehr als die Hälfte der Artenzahl, ebenso bei den Aristolochienfaltern, während Rinnenfalter, Nymphalinen und Pieriden so gut wie alle abgestorben waren.

Welche Bedeutung die geschilderten Eigenschaften für die immunen Schmetterlinge haben, ist im Anschauungskreise der Nimikry leicht verständlich. Der langsame, pausenreiche Flug und das ganze auffallende Gebahren müssen das Auge von Feinden geradezu auf sie lenken, aber nicht zu ihrem Verderben, sondern kehrt die in deutlichen Einzelzügen oder als Ganzes aposematische Erscheinung so viel wie möglich hervor, um mit ihr zu warnen. Dadurch prägt sie sich immer wieder dem Gedächtnis des Verfolgers ein und zeigt ihm möglichst früh, wenn er eine Beute zu sehen glaubt, daß er ein ungeeignetes Ziel verfolgt. Durch die selteneren Flügelschläge und das oftmalige Stillhalten auf einem Punkt in der Luft kommen die Warnsignale zur Geltung, die bei schnellem Rhythmus der Bewegung und bei größerer Geschwindigkeit undeutlich werden würden. Dazu hilft der meistens beobachtete Aufenthalt nahe dem Boden mit, weil die gewöhnlich schärfer durchgezeichnete Oberseite des Falters hierbei den höher sitzenden oder herumfliegenden Verfolgern öfter zugekehrt wird. Nebenbei ist es natürlich ein Vorteil für den Stoffhaushalt eines Tieres, wenn es im Verhältnis zu anderen seines Stammes weniger Kraft für die Ortsbewegung aufzuwenden braucht; dieser Umstand mag an der starken Vermehrung dieser Art Insekten, die sich in der Häufigkeit mit kundgibt, einen gewissen Anteil haben. Was die Lebenskraft und Widerstandsfähigkeit angeht, so geht ihr Nutzen daraus hervor, wenn man an

$\left.{ }^{1}\right)$ Haase, S. 47. $-{ }^{2}$ ) Trans. Ent. Soc. 1908, S. 626. 
der Voraussetzung festhält, daß jeder Feind erst Erfahrungen über die Genießbarkeit von Schmetterlingen sammeln muß. Wenn ein widrig schmeckender Falter etwa von einem jungen Vogel erfaßt und alsbald verworfen wird, so nutzt ihm die Freigabe nur, wenn er dabei keine lebensgefährliche Verletzung bekommen hat. Erst dadurch, daf die Hautbedeckung des Rumpfes derb genug ist, um dem Schnabeldruck Widerstand zu leisten, und daß die Flugmuskeln bei dieser Kraftprobe leistungsfähig bleiben, zieht das Einzelwesen Vorteil aus seiner Schutzwaffe und kann seine Art fortpflanzen. Würden die immunen Falter ebenso hinfällig sein wie die übrigen, so wäre die Vermehrung viel geringer, weil ein bedeutender Anteil jenen Kostversuchen zum Opfer fallen müßte.

Den durchweg immunen Gruppen sind gewisse körperliche Züge gemeinsam. Die Flügel neigen zur Verlängerung mit stumpfer Spitze, die gelegentlich etwas nach hinten umbiegt, wie dies viele asiatische Danaus-Verwandte, die Ithomiinen Amerikas und die Aristolochienfalter zeigen; man vergleiche die hierher gehörenden Abbildungen! Wan hat diese Erscheinung darauf zurückgeführt, daß dadurch die aposematische Erscheinung mehr hervortritt und einheitlicher erscheint, daß ferner dem als Warnzeichen dienenden Farbmuster mehr Ausdehnung vergönnt wird; sie mag freilich auch rein physiologisch als Folge der beschränkten Flugleistung entstanden und erblich gesteigert worden sein. Weiterhin herrscht unter denjenigen systematischen Einheiten, welche viele immune Mitglieder besitzen, im Verhältnis zur Artenzahl eine auffallende Einförmigkeit in den Farben und ihrer Anbringung - ich erinnere an das "Acraeenrot", die vorwiegend schwarzbraunen Euploeen, das Schwarz-Gelb-Braun der neotropischen Danaiformen, die immer wiederkehrende Zeichnung der Heliconier usf. G. G. Ma yer ${ }^{1}$ ) hat ausgerechnet, daß sich bei den etwa 200 südamerikanischen Papilioniden 36 verschiedene Farben finden, bei den $4 \check{5} 0$ Arten von Ithomiinen nur 15, wobei noch die starke individuelle Veränderlichkeit der letzteren $\mathrm{zu}$ bedenken ist. Dieser Mangel an Abwechselung hat selbstverständlich den Nutzen im Gefolge, daß sich daraus leichter gemeinsame Typen von Färbung ergeben, die als "gemeinsame Warnfarben" (s. o.)

1) Bull. Mus. Comp. Zool. Harward C. 30, 224 (1897). 
den Verfolgern die Verschonung widriger Arten erleichtern. Endlich fehlt den immunen Faltern so gut wie jede Andeutung von Besonderheiten der Form und der Färbung, die ihnen zum Verbergen dienen könnten, d. h. eine kryptische Erscheinung.

Um es zusammenzufassen, besitzen die als Modelle der Nachäffung anzusehenden Lepidopteren gewöhnlich folgende Merkmale:

1. Sie gehören in geschlossene Gruppen von naher systematischer Verwandtschaft, die eine ähnliche Tracht führen.

2. Das Äußere der Immunen besitzt gewisse Züge, die sie unter anderen Schmetterlingen leicht herauskennen lassen.

3. Sie besitzen innere Eigenschaften, die sie für Verfolger von Schmetterlingen widrig und deshalb gemieden machen.

4. Sie haben einen langsamen, unterbrochenen Flug und eine Art sich zu zeigen, durch die sie sehr auffallen.

5. Sie sind wenig scheu.

6. Die Körperbedeckung der Immunen ist sehr widerstandsfähig, und die Träger sind gegen Verletzungen äußerst unempfindlich.

7. Die immunen Arten sind im allgemeinen häufig, ja gemein, und halten sich gern in größeren Flügen ihrer eigenen Art oder solcher von ähnlicher Erscheinung zusammen.

\section{Eigenschaiten der Nachahmer.}

1. Die mimetische Tracht weicht vom durchschnittlichen Aussehen der Gruppe, der die Nachahmer angehören, erheblich ab. Mimikry bedeutet ja mittelbar das Vertauschen von Familienzügen, die von ungeschützten Formen getragen werden, mit einer Maske, die das wahre Wesen so wenig wie möglich durchscheinen läßt. Wie gut die Verkleidung wirken kann, zeigen die vielen Fälle, welche von den alten Systematikern an falscher Stelle untergebracht worden waren, weil sie ganz anders aussahen, als die Schar ihrer nächsten, aber nicht mimetischen Verwandten. Auf Grund dieser Regel kann man bei einem mimetischen Paare, wenn man von den Lebensumständen nichts weiß, Vorbild und Kopie unterscheiden, z. B. bei Danaus chrysippus $\leftarrow$ Hypolimnas misippus o (Fig.26). Ihre gemeinsame Erscheinung ist in der Gattung Danaus etwas Alltägliches, und zwar in beiden Geschlechtern. Dagegen ist das Kleid des weiblichen misippus 
ober- und unterseits etwas ganz Fremdes für die Gattung und die Nymphalinen überhaupt und hat nicht einmal mit dem eigenen Männchen etwas gemein. Daraus ergibt sich, daß die Färbung des Danaus die normale, die von misippus eine neuartige, ihm eigentlich wesensfremde ist, mithin der erstere als das Vorbild der geborgten Maske des letzteren angesehen werden darf. Unter den Satyrinen ist die Gattung Elymmias durch die vielseitige Nachäffung aller möglichen Vorbilder gegenüber den anderen Gattungen bemerkenswert. Darunter ist wieder eine - sehr seltene - Art E. masoura von Madagaskar, die den Weißling Mylothris philaris kopiert und dadurch eine bei Elymnias ganz ungewohnte Tracht hat.

2. Iodell und Nachahmer stehen in keinem engen Verwandtschaftsverhältnis. Gewöhnlich sind beide aus verschiedenen Unterfamilien und Familien, ja selbst bis zur Unterordnung geht die Trennung bei der gegenseitigen Angleichung von Rhopaloceren und Heteroceren. Sehr oft gleicht ein Heliconius einer Melinaea oder anderen Ithomiine seiner Heimat (vgl. Fig. 20, 21), während er unter der nahe verwandten Gattung Euides und die Melinaea unter den übrigen Ithomiinengattungen keinen Doppelgänger hat. Die nächsten systematischen Beziehungen haben noch die Aristolochienfalter zu dell sie nachäffenden Papilios, aber auch da ist des Trennenden ${ }^{1}$ ) genug, um beide Parteien nicht als Blutsverwandte zu rechnen.

3. Die Nachäffung ist nur oberflächlich. Auch die täuschendste Ähnlichkeit wird nur durch Züge geschaffen, die auf das Auge berechnet sind und namentlich im Flugbilde zur Geltung kommen. Wichtige Züge in der Zeichnung des Modells können vollständig fehlen, wenn sie für den Zweck der Täuschung eines Feindes nebensächlich sind. So haben die Uraniiden, denen Alcidis agathyrsus (Fig. 25) angehört, großenteils am Vorderrande der Flügel eine Reihe feiner Querstrichelchen, aber dieses wenig auffallende Merkmal vermissen wir völlig bei Papitio laglaizei, wie weit er auch sonst in der Nachäffung des ersteren gegangen ist.

4. Die Nachahmer sind nicht durch widrige Eigenschaften geschützt. Hierbei muß die Müllersche Mimikry

1) Außer den S. 150 angegebenen Merkmalen ist die andersartige Palpenbildung nach O. M. Reuter sehr bezeichnend.

Jacobi, Mimikry. 
außer Betracht bleiben, wo beide sich ähnelnden Teilhaber eines Paares oder die Mitglieder eines "Ringes" gemieden werden, und wo man aus bestimmten Andeutungen den einen für den Nachäffer zu erklären sucht. Diese Beziehungen laufen aber nicht auf die Täuschung anderer Tiere über die wahre Natur, nämlich die Genießbarkeit, des einen Partners hinaus, sondern auf eine Steigerung der Wirkung von Warnfarben, dadurch, daß diese möglichst oft gezeigt werden.

う. In ihren Lebensäußerungen weichen die Nachahmer oft von den Vorbildern ab, sie bewahren darin mehr die Charakterzüge ihrer Verwandten. Daher sind sie hinfällig ${ }^{1}$ ) und weit scheuer als immune Schmetterlinge. Eine zur Gattung Actinote zählende Acraeine von Ecuador ist sehr gleichgültig gegen jede Nachstellung, man kann ganze Trupps davon mit den Fingern von Gewächsen wegnehmen, während die nachäffende Nymphaline Phyciodes actinote, welche darunter vorkommt, sehr auf ihrer Hut bleibt ${ }^{2}$ ). Ebenso verhalten sich in Afrika Amauris echeria (Dan.) und Hypolimnas dubius, f. mima ${ }^{3}$ ). Im Fluge unterscheidet sich das hippocoon o des Pap. dardanus deutlich von dem matt und niedrig ziehenden Dan. chrysippus ${ }^{4}$ ), und der bekannte Nachahmer des letzteren, Hypol.misippus o, nimmt sich zwar für gewöhnlich auch dessen Gemächlichkeit zum Muster, aber auf Beunruhigung schießt er wie ein Pfeil davon und meidet den Fleck weiterhin, während chrysippus sich nicht groß stören läßt ${ }^{5}$ ). Nan könnte es daher als eine fortgeschrittene, auf das Lebensgebiet übergreifende Angleichung deuten, wenn von einzelnen Mimetikern auch für das Betragen die Übereinstimmung berichtet wird ${ }^{6}$ ), zumal wenn nur dimorphe Weibchen sie aufweisen, wie die von Elymnias undularis und Argynnis hyperbius $\rightarrow$ Dan. chrysippus ${ }^{7}$ ) oder von Euripus halitherses $\longrightarrow$ Euploea. Außerdem stößt man für diese Frage auf vollkommene Widersprüche der Beobachter, z. B. in den Außerungen von Marshall ${ }^{5}$ ) und Neave ${ }^{8}$ ) über Pseudacruea.

6. Die Nachahmer kommen mit den Vorbildern zusammen in deren Wohngebiet und an denselben Stand-

1) Haase, S. 29, 43. - ${ }^{2}$ ) Rosen ber g, Proc. Ent. Soc. 1909, S. 59. - ${ }^{3}$ ) Eltringham 1910, S. 21. - ${ }^{4}$ ) Roger, Trans. Ent. Soc. 1908, S. 522. - ${ }^{5}$ ) Marshall 1902, S. 504. - ${ }^{6}$ ) Haase 1903, S. 70. $\left.{ }^{7}\right)$ T. B. Fletcher, Proc. Ent. Soc. 1909, S.26. - ${ }^{8}$ ) Daselbst 1908, S. 15. 
orten vor. Die Lebensgemeinschaft der beiden Teilhaber des Mimikryverhältnisses ist eine der ältesten Erfahrungen, die man bei der Untersuchung dieses Anpassungsbeispieles gemacht hat, und sie wiederholt sich immer wieder, indem reisende Sammler die meistens seltenen und wertvolleren Nachahmer unbeachtet zu den Torbildern legen, unter denen sie sie unabsichtlich fingen. Diesen Zufällen weichen englische Lepidopterologen aus, indem sie planmäßig in ganz engen Bezirken eines Tropenlandes alle Falter gleichen Aussehens einheimsen, um daraus belehrende Aufschlüsse über die Zusammensetzung solcher gleichfarbigen Schwärme zu erhalten. Beispielsweise enthielt eine Sammlung von 23 Schmetterlingen, die C. A. Wiggins am Ukerewesee in einer halben Stunde machte, 17 Danaus chrysippus, 3 Hyp. misippus +, 2 Acraea encedon und 1 Acraea terpsichore rougeti, welch letztere allerdings nur als unvollkommen mimetisch betrachtet wurde ${ }^{1}$ ).

7. Die Nachahmer sind gewöhnlich viel seltener als ihre Modelle. Auch dieser Umstand fiel von jeher auf; Bates ${ }^{2}$ ) schätzte das Zahlenverhältnis der Dismorphiinen zu den Ithomiinen auf $1: 1000$. Einen gewissen Maßstab geben die Preislisten der Naturalienhändler, so kostete der vorzüglich mimetische Cosmodesmus idaeoides vor 20 Jahren das 40 fache, heute noch das 30 fache seines Modells Hestia leuconoe, aber nur das Männchen, denn das noch ähnlichere Weibchen kommt überhaupt nicht in den freien Handel. Ton Papilio caunus o gilt dasselbe, und von nicht wenigen Arten kennt man nur einige wenige Stücke. Freilich sind Ausnahmen zu verzeichnen, deren bekannteste Hyp. misippus als ein in Ostafrika und Indien häufiges Insekt ist. Da die Flugzeiten von Modellen und Nachäffern nicht immer völlig zusammenfallen, so kann es kommen, daß letzterer zeitweise gemeiner ist als sein Modell, was für die erwähnte Art an mehreren Punkten des britischen Innerafrika bemerkt wurde ${ }^{3}$ ). Freilich bietet sie vom Mimikrystandpunkt aus überhaupt einige Rätsel, namentlich ihre Einwanderung nach Amerika, wo das Nodell nicht vorkommt, also keine Deckung bieten kann. Man könnte aber noch mehr Fälle anführen, sogar solche, wo sich das Verhältnis umkehrt' ${ }^{4}$ ).

1) Proc. Ent. Soc. 1908, S. 80. - $\left.{ }^{2}\right)$ 1861, S. 505. - ${ }^{3}$ ) Proc. Ent. Soc. 1903, S. 29. - $\left.{ }^{4}\right)$ Fr. Müller, 1879, S. 104; Haase, S. 130; Shelford, 1902, S. 256-257 u. a. m. 


\section{Biologische Bedeutung der Müllerschen Mimikry.}

Die einleitungsweise ${ }^{1}$ ) skizzierte Mimikry zwischen beiderseits immunen Arten fordert noch eine ausführlichere Darlegung, in der ich mich wesentlich an Fritz Müllers erste, aber noch immer mustergültige Mitteilung ${ }^{2}$ ) halten kann. Die sein Beispiel bildenden Arten, die Danaine Ituna itione (Fig. 19) und die Ithomiine Thyridia megisto sind sich bis auf ganz feine, nur dem Systematiker verständliche Unterschiede so ähnlich, daß man sie früher für ganz nahe Verwandte gehalten hat, und sie leben zusammen in denselben Gegenden Südbrasiliens. Da beide immuı sind, so entsteht die Frage, welchen Nutzen ihnen die Ähnlichkeit bringt? Wenn die Insektenfresser die Kenntnis des Unterschiedes zwischen genießbaren und ungenießbaren Arten mit auf die Welt brächten, so läge offenbar kein Anlaß vor, daß zwei solche Schmetterlinge das gleiche Warngewand trügen. Wenn aber z. B. der einzelne junge Vogel sich erst durch eigene Erfahrung, durch eine Anzahl Kostproben, diesen Unterschied einprägen muß, so wird ihm zunächst immer eine Reihe ungenießbarer Falter zum Opfer fallen. Wenn jedoch zwei solche Arten einander zum Terwechseln ähneln, so wird die an einer von ihnen gemachte Erfahrung auch der anderen zugute kommen; beide werden zusammen dieselbe Zahl von Opfern zu stellen haben, die jede einzeln bringen müßte, wenn sie anders aussähe. Sind beide Arten gleich häufig, so werden beide aus ihrer Ähnlichkeit den gleichen Nutzen ziehen, jede kann die Hälfte des Tributs sparen, den sie der jugendlichen Unerfahrenheit ihrer Feinde zu bringen hat. Ist aber eine häufiger, so wird sich der Nutzen ungleich verteilen, und zwar wird der verhältnismäßige Vorteil, der für jede aus ihrer Ähnlichkeit erwächst, sich umgekehrt verhalten wie das Quadrat ihrer Häufigkeit, was $M$ üller rechnerisch nachweist $\left.{ }^{3}\right)$. Es soll beispielsweise angenommen werden, daß in einem gewissen Bezirk während der Flugzeit 1200 Träger eines ungenießbaren Zeichnungstypus vertilgt werden, bis sie als solche

$\left.{ }^{1}\right)$ S. 62. - ${ }^{2}$ ) 1879. - ${ }^{3}$ ) Das Zahlenergebnis haben Blakiston und Alexander noch mit stärkerem algebraischen Rüstzeug nachgeprüft und bestätigt, was die beteiligten Insekten beruhigen darf [Nature 29, 405-406 (1884)]. 
fest bekannt sind, und daß weiterhin daselbst 2000 Stück einer ungenießbaren Art, 10000 von einer zweiten leben. Wenn die beiden ganz verschieden aussehen, so wird jede 1200 Angehörige verlieren, wenn aber täuschend ähnlich, so wird sich der Verlust im Verhältnis ihrer Häufigkeit auf sie verteilen, die erste wird 200, die zweite 1000 verlieren. Erstere gewinnt also durch die Ähnlichkeit 1000 Leben oder 50 Proz. der Gesamtzahl, letztere nur 200 oder 2 Proz. ihrer Gesamtzahl. Während also die Häufigkeit der beiden Arten sich verhält wie $1: 5$, verhält sich der Vorteil, den sie von ihrer Ähnlichkeit haben, wie $25: 1$.

Handelt es sich um zwei Arten, von denen die eine sehr häufig, die andere sehr selten ist, so fällt der Vorteil so gut wie ganz auf die Seite der seltenen. Sind dagegen zwei oder auch mehrere ungenießbare Arten nahezu gleich häufig, so wird die Ähnlichkeit ihnen fast gleichen Vorteil bringen. Nüller glaubte, daß man in solchem Falle von gleich häufigen synaposematischen Arten nicht mehr wissen könnte, welche von ihnen der anderen als Vorbild gedient hätte, weil jede stammesgeschichtlich vorgekommene Variation, die zur Gleichheit hinführte, sich im Daseinskampf als vorteilhaft erhalten hätte, allein die von ITallace, Haase u. a. gebildete Methode der genetischen Ableitung gibt auch in solchen Fällen gewöhnlich Andeutung, welche Art älter und damit vorbildlich ist.

Während Müllers Beobachtungen sich auf Südamerika beschränkten, konnte Moore $\left.{ }^{1}\right) 1883$ darauf linweisen, daß auch unter altweltlichen Danainen synaposematische Verbände vorkommen, doch machte er weder Erklärungsversuche, noch gedachte er des Müllerschen, obwohl dieser gleich nach der Veröffentlichung in Eng]and bekannt geworden war.

Erste Voraussetzung für M 1 üllers Erklärung muß die Richtigkeit der Annahme sein, daß die jungen Verfolger von Schmetterlingen keinen instinktiven Unterschied zwischen ekelhaften und genießbaren machen, sondern ihn aus Erfahrung ziehen lernen. Eimer tritt nach seinen Versuchen mit jungen Hühnern für das Gegenteil des ersteren ein, während J.Weir, Poulton, Finn und neuerdings Lloyd Morgan das zweite festgestellt haben. Eine mittelbare Bestätigung der letzteren Lösung gibt Trimen ${ }^{2}$ ) mit dem Hinweis

$\left.{ }^{1}\right)$ Proc. Zool. Soc. 1883 , S. 201 f. $-{ }^{2}$ ) 1897 , S. 94. 
auf die häufigen Verletzungen an den Flügeln tropischer Tagfalter, die nur von Bissen der Eidechsen und Vögel herrühren können. Er führt eine Reihe Beobachtungen aus der Literatur ${ }^{1}$ ) an, wonach Vögel erfolglos Danainen, Euploen usw. gepackt haben (was mehrere Berichterstatter als Beweis gegen die Mimikrylehre hervorgehoben haben), und zwar bisweilen ebensoviel solche wie immune Arten; man vergleiche dazu von Fig. 31 die Bilder 1 und 1 a, welche Danaus plexippus wiedergeben ${ }^{2}$ ).

Neuerdings hat Dixey die Müllersche Theorie für gewisse Fälle, zunächst unter den Pieriden, fortgebildet ${ }^{3}$ ). Er meint, wenn zwei synaposematische Arten annähernd gleiche Kopfzahl haben, so werden die ihnen zufallenden Vorteile der Erhaltung vielleicht durch eine Art Gegenseitigkeit erworben, indem die beiden ihr Ähnlichwerden dadurch beschleunigen, daß sie einander nachahmen, d. h. einander wichtige Bestandteile ihrer Zeichnung mitteilen ${ }^{4}$ ). Poulton hat hierfür den Ausdruck Diaposem vorgeschlagen ${ }^{5}$ ). Zwischen Dixey und Marshall hat sich über die Möglichkeit solcher Beeinflussung ein Federstreit entwickelt, in dem auf beiden Seiten scharfsinnige Berechnungen über Individuenzahl und Wahrscheinlichkeit des Überlebens ins Feld geführt worden sind - freilich reine Studierstubenbeweise. Mit Marshall möchte ich mich dahin bekennen, daß wir an der M üllerschen Erklärung genug des Theoretischen haben, als daß wir sie in noch künstlichere Theorien weiter zu entwickeln brauchtelı.

\section{Beweise für die Richtigkeit der Schmetterlingsmimikry.}

In meiner Darstellung der Mimikryerscheinungen bei Lepidopteren habe ich bisher so viel wie möglich Erörterungen über das Für und Wider ausgelassen, um zunächst das Bild möglichst

$\left.{ }^{1}\right)$ Von Müller selber, Distant, Skertchley, Hampson, Piepers. - ${ }^{2}$ ) Diese leicht zu vermehrenden Beispiele entkräften Werners Behauptung, daß die von Vögeln gepackten Danainen verloren seien, weil ihre feste Flügelsubstanz kein Losreißen gestatte (1908, S. 569); sie sind nach Marshall, der über reichere Erfahrung verfügt als Werner, oft viel stärker verstümmelt, als schmackhafte Arten (1902, S. 367). - ${ }^{3}$ ) Trans. Ent. Soc. 1894, S. 249-334; ausführlich 1896. - ${ }^{4}$ ) Durchgeführte Beispiele daselbst S. 66 und in Proc. Ent. Soc. 1897, S. 20, 21. $-{ }^{5}$ ) Daselbst, S. 29. 
einheitlich zu gestalten; es sind also die Voraussetzungen für den Mimikrygedanken und die aus den Erscheinungen gezogenen Schlüsse vorläufig als richtig betrachtet worden. Nunmehr will ich versuchen, die Gründe, welche dem Lehrgebäude zur Stütze gereichen, kurzgefaßt aufzuzählen, damit der Leser daran den Wert der nachher behandelten Einwände leichter beurteilen kann. Diese Beweise, richtiger Nachweise, gelten vielfach in sinngemäßer Abänderung auch für andere Gebiete der Mimikry, so daß ich auf die Terteidigung der Theorie als Ganzes verzichten darf.

a) Die mimetische Tracht ist wesentlich anders als diejenige der nächstverwandten, aber nicht nachäffenden Formen, von der sie eine Umbildung darstellt. Für diese Umbildungen gibt der Mimikrygedanke eine verständliche Erklärung.

b) Die mimetisch veränderten $Z$ üge sind nur solche, welche für die Täuschung eines Gegners in Betracht kommen, während dafür nebensächliche Merkmale von der Umbildung nicht ergriffen werden.

c) Wo weit verbreitete Vorbilder in engeren Unterbezirken ihres Gebietes deutliche Unterarten bilden, pflegen die Nachahmer eben solche örtliche Sonderausprägungen zu zeigen und schließen sich auch hierin den ersteren eng an. Hierfür wären unter den indischen Papilioniden und den neotropischen Danaiformen viele Beispiele zu nennen; als besonders einleuchtend nenne ich den ostafrikanischen Papilio rex (nebst $P$. mimeticus), einen sehr seltenen Falter, der in mimetischer Anlehnung an die Lokalformen seiner Modelle, der Danainengattung Melinda, ganz erstaunliche Parallelen bietet ${ }^{1}$ ), oder die parallele Abänderung von Argynnis diana $\rightarrow$ Pharm. philenor (Nordamerika).

d) Die Mimikry ist nicht regellos, sondern zeigt systematische Beziehungen von besonderer Gesetzmäßigkeit, sie hält sich an bestimmte Familien, Gattungs- und Gruppenverbände.

e) Nachäffung ist nur in solchen Gruppen ausgebildet, die am Tage fliegen, was ihre Beziehung zur Sichtbarkeit beweist; sie fehlt unter den Rhopaloceren gänzlich bei den dämmerungs-

1) Neave, 1906, S. 216-218, mit Abb.; dazu Marshall, 1908, S. 125. 
liebenden Brassolinen. Wo bei echten Nachfaltern übereinstimmende Erscheinung vorkommt ${ }^{1}$ ), bleiben andere Bedingungen, besonders Punkt a), unerfüllt.

f) Auch die Verbreitung der mimetischen Gruppen ist gesetzmäßig, nicht sprunghaft bald in dieser, bald in jener Region und Familie. In der gemäßigten Zone fehlt Mimikry unter Schmetterlingen, ausgenommen zwei Fälle im wärmeren Nordamerika. Dies läßt sich aus dem sehr spärlichen Vorkommen von Wirbeltieren, die auf größere fliegende Taginsekten jagen, ableiten. Eidechsen kommen nur in Südeuropa auf Bäumen vor, und der Vogelfamilien von solcher Ernährungsweise sind im Vergleich zu den Tropen äußerst wenige, und auch diese haben nur ganz wenige Vertreter. Was die Verbreitung der Mimikryfalter nach Familien belangt, so gehören beispielsweise sämtliche mimetische Satyrinen, mit Ausnahme der afrikanischen Elymnias phegea, nur drei Gattungen von über 30 des indoaustralischen Gebietes an; die mimetischen Lycaeniden beschränken sich auf Afrika, obwohl die Familie kosmopolitisch ist, und die Eryciniden auf ihren Hauptherd Südamerika. Die Aristolochienfalter des Ostens werden nur von Rinnenfaltern, die amerikanischen auch von Segelfaltern kopiert usw.

g) Modelle und Nachahmer leben örtlich und jahreszeitlich eng beieinander. Man hat zwar eine kleine Anzahl Fälle zusammengetragen ${ }^{2}$ ), wo zwei geographisch weit getrennte Arten sich ungemein ähneln, aber es sind im Verhältnis zur Zahl der regelrechten Mimikrybeispiele ganz wenige; sie gehören einerseits niemals zu einer der immunen Gruppen und zeigen meines Wissens anderer'seits keine jener eingreifenden Umwandlungen des Familientypus, welche die mimetischen Arten verkörpern. Wir dürfen sie deshalb als zufällige Ähnlichkeiten, durch Zusammentreffen auf parallelem Entwickelungswege entstanden denken, wie solche auch in anderen Tierklassen gelegentlich vorkommen, z. B. zwischen den Vögeln Macronyx capensis von Südafrika und Sturnella ludoviciana der Vereinigten Staaten.

h) Die Nachäffung bildet sich vorwiegend an denjenigen Körperstellen aus, die bei den Modellen die Warnfarben oder,

1) Z. B. zwischen dem Eulenfalter Agrotis pronuba und der Motte Roeslerstammia pronubella. — ${ }^{2}$ ) Besonders dem gegnerischen Eifer von Piepers (1903, S. 236-238) zu danken. 
allgemeiner gesagt, die Merkzeichen tragen. Wo dies bei den Iodellen die Oberseite tut, folgen darin die Nachahmer zuerst, während ihre Unterseite ganz andere Zeichnung behalten kann. Bei gewissen Arten ron Delias, einer nachweislich immunen Gattung der indischen Pieriden, hat nur die Unterseite eine auffallende, schwarze, gelbe und feuerrote Zeichnung, während sie oben unscheinbarer sind; dieselbe Verteilung haben deren Mimetiker aus der Gattung Elymnias (Satyrinen).

i) Bei geschlechtlichem Dimorphismus mimetischer Schmetterlinge geht das Weibchen zuerst zur Nachäffung über. Daher das viel häufigere Vorkommen von Nimikry bei diesem Geschlecht und als Steigerung dessen der Umstand, daß bei verschieden ausgeprägter Anlehnung beider Geschlechter an ein Modell das weibliche weiter fortgeschritten ist. Ferner sind Arten mit nur mimetischen Weibchen ungemein häufig, während das Gegenteil fast nicht vorkommt; durch ganze Artenreihen hindurch, z. B. der indoaustralischen Papilioniden, haben die Männchen ziemlich die gleiche Erscheinung, während die Weibchen nach allen möglichen Iodellen hin mimetisch verändert sind. Als Veranlassung zu dieser weiblichen Präponderanz hat man seit Wallace ${ }^{1}$ ) das größere Schutzbedürfnis des Weibchens erklärt. Zunächst sind letztere an Zahl spärlicher als das andere Geschlecht [nach Standfuss 2) im Verhältnis 100:105-107], namentlich aber fällt dem Weibchen die Hervorbringung der Eier und ihre Ablage an den richtigen Nährpflanzen für die Raupen allein zu. Während der Trächtigkeit muß es, trotzdem die wachsende Eierlast es unbehilflicher macht, seine Geschwindigkeit hemmt, sich besonders viel bewegen, um Stellen für Eier zu finden. In diesem, für die Erhaltung der Art wichtigen Lebensabschnitte ist es Verfolgungen besonders ausgesetzt ${ }^{3}$ ). Es ist also erklärlich, wenn der Erhaltungstrieb der Natur die täuschende Ähnlichkeit als ein Schutzmittel verwendet und es am meisten und am frühesten demjenigen Geschlechte zukommen läßt, das für den Fortbestand der Art am wichtigsten ist.

1) 1870 , S. 128 . - $\left.{ }^{2}\right)$ Handb. der paläarkt. Großschmetterlinge 1896, S. 192. - 3) Marshall (1902, S. 367) berichtet, daß fünf von Vögeln ergriffene Danaus chrysippus sämtlich Weibchen waren. 


\section{Einwände gegen die Schmetterlingsmimikry.}

\section{Unerhebliche, auf Unkenntnis oder Mißverständnis beruhende Einwände.}

Da Nimikry eine auf Voraussetzungen beruhende Deutung an sich nicht verständlicher Beobachtungen, also eine theoretische Naturerklärung ist, so haben sich Stimmen gefunden, die jene Deutung für unrichtig erklären. An sich wie jede Erörterung wissenschaftlicher Aufgaben nur willkommen und nötig, sind manche dieser Einwände völlige Fehlgriffe, weil ihre Urheber es nicht einmal für nötig fanden, sich über die Grundlagen der Theorie an der Hand dessen, was ihre Begründer darüber gesagt haben, zu unterrichten. Nan braucht dazu nicht die, allerdings ziemlich versteckten, ersten Quellen von Bates, Wallace und Fr. Müller zu benutzen, vielmehr sind gemeinverständliche und weit verbreitete Bücher genug da (Wallaces Darwinismus, Darwins Werke, C. Sterne, Weismann, selbst Konversationslexika), die das Nötige sagen. Die Unklarheit über das Wesentliche des Gegenstandes ist um so schärfer zu verurteilen, wenn solche Gegner oft mit einem Selbstbewußtsein auftreten, das sich umgekehrt wie ihre eigenen Leistungen und Kenntnisse verhält. Als abschreckendes Beispiel dieser Schriftsteller, die sich auf weiter nichts als auf ihre - im übrigen oft sehr achtungswerten und fruchtbringenden - Kenntnisse eines kleinen Sondergebietes hin über eine schwierige biologische Frage und über große Naturforscher ein Urteil anmaßen, kann J. Schilde gelten, dessen Aufsätze in den Titeln ${ }^{1}$ ) wie in der halb burschikosen, halb langatmigen, mit überflüssigen Fremdwörtern und afterphilosophischen Umschreibungen gespickten Darstellung gleich schwülstig und in der letzteren völlig ungenießbar sind. Aus ähnlichen Gründen unbeachtlich sind die Einwürfe von $\mathrm{Auel}^{2}$ ), Rothe ${ }^{3}$ ), A. Schulz ${ }^{4}$ ), die z. B. vor allen Dingen Experimente, Naturbeobachtung u. a.m.

1) "Gregen pseudodoxische Transmutationslehre" (1879); „Antidarwinistische Skizzen" (1884); "Schach dem Darwinismus" (1890). 2) Zeitschr. f. wiss. Insektenbiol. 4, 39, 41 (1908). — ${ }^{\text {s) }}$ ) Daselbst :, 221 (1907), 4, 266 (1908). — 4) Berl. Ent. Zeitschr. 48, 261 (1903); Compt. rend. 6me Congr. Intern. Zool., S. 585 (1904). 
zur Begründung der Mimikrylehre fordern, ohne eine Ahnung zu haben, was darin schon von englischen Forschern geleistet worden ist. Sehr bedauerlich ist es jedoch, wenn auch Forscher, die in ihren sonstigen Leistungen allen Anspruch auf Geltung haben, durch mangelhafte Vertrautheit mit dem Gegenstande oder in leidenschaftlicher Voreingenommenheit mit ihren Gegengründen arg daneben greifen. So wäre Hahnel, der über lange sammlerische Erfahrung im Ursprungsgebiete des Mimikrygedankens und vorzügliche Beobachtungsgabe verfügte, am ersten imstande gewesen, dessen Stützen und Schwächen zu beurteilen, aber ihm waren nicht einmal die biologischen Unterlagen, geschweige denn das Müllersche Prinzip geläufig ${ }^{1}$ ). Auch A. S. Packard hat letzteres gänzlich mißverstanden, weil er es nur in Gestalt einer früheren, von M üller dann selbst aufgegebenen Hypothese kannte ${ }^{2}$ ). Unbekanntschaft mit den Grundlinien der Lehre verriet selbst der hervorragende Schmetterlingskenner Dr. Staudinger, als er die Seltenheit der Nachahmer für einen Widerspruch dazu erklärte ${ }^{3}$ ). Auch kann ich es nur für einen Mangel an nötiger Vorbereitung erklären, wenn man die Theorie zu widerlegen unternimmt, ohne die Fundamentalwerke von Trimen, Haase u. a. $\mathrm{zu}$ berücksichtigen, woran es bei Piepers ${ }^{4}$ ) und Schröder ${ }^{5}$ ) augenscheinlich fehlt. In summa, möchten die Kritiker erst prüfen, dann urteilen!

\section{Sachliche Einwände.}

A. Mimikry beruht nur a uf menschlicher Vorstellung. Dieser öfter erhobene Vorwurf ist insofern begründet, als zur Wirkung von Mimikry die Täuschung von Sinneswahrnehmungen gehört, also die Bildung von Assoziationen, die dem auslösenden Reiz nicht entsprechen; über diese können wir uns jedoch nicht durch direkte Beobachtung, also einwandfrei, Kenntnis verschaffen, sondern sie nur aus Begleiterscheinungen schließen. Wenn diese jedoch zahlreich und gleichartig auftreten, so gewinnen die gezogenen Schlußfolgerungen an Wahrscheinlichkeit. Mit anderen Worten: die Gegner leugnen, daß Vögel und andere Verfolger

1) Iris 3, 310 f. (1890). — ${ }^{2}$ ) Proc. Amer. Phil. Soc. 43, 393-450 (1904). - ${ }^{3}$ ) Exotische Tagfalter 1, 6 (1888). — $\left.{ }^{4}\right)$ 1903. - ${ }^{5}$ ) 1904; eine scharfe, aber nicht unberechtigte Kritik darüber lieferte v. W a gn er, Arch. f. Rassen- u. Gesellschaftsbiol. 6, 138-140 (1906). 
durch die $̈$ hnlichkeit zweier verschiedener Tierarten irregeführt werden könnten, nur dem Menschen mit seinem minderwertigen Wahrnehmungsvermögen könne das passieren. Hiergegen spricht doch eine ganze Anzahl von Versuchen und Beobachtungen in der Natur, wenngleich ich bekenne, daß die Zahl der letzteren auch mir noch zu klein scheinen will, um allen Zweifeln zu begegnen.

$\mathrm{Zu}$ der gegnerischen Skepsis müssen zweifellos auch die unleugbaren, bisweilen hart ans Krankhafte streifenden Übertreibungen des Mimikrytheorems durch solche beitragen, die an allen Ecken und Enden, bei jeder ungefähren Farbenübereinstimmung von Tieren derselben Gegend eine Mimikry sehen. So ungern ich Poulton nahetrete, der auf die Erforschung der biologischen Bedeutung tierischer Färbungen ein Leben regster Arbeit verwendet hat, der durch sein Vorbild und durch eifrige Anregung die weitere Erforschung des Gegenstandes durch Engländer (leider nicht ebenso durch Deutsche) in Heimat und Fremde im Gange hält, so muß ich doch bedauernd feststellen, daß gar mancher solcher Fehlgriffe ihm zur Last fällt. Ganz in die Vorstellung verstrickt, daß der Weiterbestand jeder (uns!) etwas auffallenden Insektenart durch zahlreiche Feinde bedroht sei, läßt er keinen bunten Schmetterling, Raupe, Käfer, Wanze von einiger Häufigkeit bestehen, der nicht irgend einen geheimen Schutz haben muß. Daraus werden dann immer mehr synaposematische "Ringe" konstruiert, und Poulton läßt durchblicken, daß in unseren zoologischen Anschauungen die einfache Nimikry nach Bates wohl dereinst den Platz so gut wie ganz an die Müllersche werde abtreten müssen. Darf man z. B. nicht darüber den Kopf schütteln, daß eine Falterart das halbe Jahr hindurch kryptisch, während der anderen Hälfte aposematisch geschützt sein soll ${ }^{1}$ ), eine Deutung, die sogar sein Schüler Marshall ${ }^{2}$ ) als rein aus dem Sammlungskasten geschöpft erklären muß. Freilich steht auch dieser gründliche Forscher so im Banne derartiger Grübeleien, daß er sogar umgekehrte Nimikry, d. h. die Nachahmung ungeschützter Arten durch immune, für möglich hält!3) Doch genug solcher Fehlgriffe, sie sind keine Punkte, an denen die sachliche Kritik einzusetzen braucht. S. 502 .

1) Bei Marshall, 1902, S. 424. - ${ }^{2}$ ) 1908, S. 134-136. ${ }^{3}$ ) 1902, 
B. Die mimetische Ähnlichkeit ist zu oberflächlich, um Täuschung zu bewirken. „Die Ähnlichkeit (der sogenannten mimetischen Papilioarten, welche Danais nachahmen) ist aber selten so, daß man diese Art genau anzugeben imstande wäre, meistens wird nur der allgemeine Habitus nachgeahmt ${ }^{1}$ )." Diese, in dem angezogenen Falle übrigens durchaus nicht zutreffende Erweiterung einer der Grundregeln für Mimikry wird von Schröder ${ }^{2}$ ), die Erörterung Speisers über Volucella ${ }^{3}$ ) von Werner ${ }^{4}$ ) angezogen, um von vornherein zu bestreiten, daß Verfolger über die wahre Natur von Nachäffern im unklaren bleiben könnten. Abgesehen von Beobachtungen, die doch sehr für solche Täuschung sprechen, möchte ich hierbei der anthropozentrischen Auffassung recht geben, daß zwei Schmetterlinge ron solcher Ähnlichkeit, daß sie der geschulte Sammler in der Hand verwechselt, beim Herumflattern in der Luft ron keinem tierischen Späher unterschieden werden können, zumal wenn sich Größe und Flugweise einigermaßen entsprechen. Vögel sind keine Entomologen, die auf verkümmerte oder ausgebildete Fußglieder oder die Lage einer gewissen Querader achten; mehr Anhaltspunkte, um eine widrige oder genießbare Beute zu unterscheiden, stehen aber selbst dem Falkenauge in Fällen wie Fig. $19 \mathrm{~b}$ und c nicht zur Verfügung. Am ersten müßten doch wohl die Schmetterlinge selber zu unterscheiden wissen, was ihresgleichen ist, aber auch unter ihnen sind Irrungen der Art nicht selten: das Männchen von Dismorphia melite umwirbt öfters einen anderen, seinem Weibchen ähnlichen Weißling ${ }^{5}$ ), Danaus chrysippus seinen Nachahmer Hyp. misippus ${ }^{6}$ ) und dieser sein Modell 7 ), ebenso leicht verkennt Amauris psyttalea den Hypotimnas dubius $\left.{ }^{8}\right)$. Hiernach könnte Piepers ${ }^{9}$ ) auch seine These XX berichtigen.

C. Warnfärbung und ihre Nachäffung dient nicht dazu, die Träger auffällig zu machen, sondern sie in der Umgebung verschwinden zu lassen. Diese einzig dastehende Deutung hat Thayer ${ }^{10}$ ) ausgesonnen, der sich darauf beruft, daß

1) Staudinger in Staudinger und Schatz, Exotische Tagfalter 1, 6 (1888). — $\left.{ }^{\text {y }) ~ 1904, ~ S . ~ 294 . ~ — ~}{ }^{3}\right)$ S. 92. — 4) 1908, S. 592. -

5) Fr. Müller bei Meldola, Ann. Nat. Hist. (Ser. 5), 1, 158 (1878). -

$\left.{ }^{6}\right)$ Eltringham 1910, S. 31. - ${ }^{7}$ ) Longstaff, Trans. Ent. Soc. 1905, S. 109; Manders, S. 703. - ${ }^{8}$ ) Lamborn, Proc. Ent. Soc. 1911, S. 46. - $\left.{ }^{9}\right) 1903$, S. $221 \mathrm{f.}-{ }^{10}$ ) 1903. 
nicht der in allerlei Voraussetzungen befangene Naturforscher, sondern nur der Maler imstande sei, die Farben und Zeichnungen der Naturkörper in dem richtigen Verhältnis zueinander, wie es da draußen besteht, abzuschätzen. In seinen Augen geben die buntgemusterten Schmetterlinge die Farbengegensätze von Wald und Wiese, Lufttöne, Blüten u. a. m. wieder und werden dadurch unsichtbar. Solchen abstrusen Vorstellungen hat alsbald Poulton ${ }^{1}$ ) eine in dem Falle leichte Widerlegung zuteil werden lassen, und Thayers spätere Wiederholungen seiner Lehrsätze sind von ornithologischer Seite ${ }^{2}$ ) als rein vom grünen Tisch aus erdacht und in vollem Gegensatz zu den Tatsachen der Natur stehend zurückgewiesen worden.

D. Die mimetischen Ähnlichkeiten haben überhaupt keine biologische Beziehung zueinander, sondern sind zufällige Ergebnisse einer gleichgerichteten Entwickelung. Dieser Einwand ist der Kern jener Orthogenesislehre von Eimer und der ähnlichen Versuche Piepers', über die ich schon früher (S. 26-30) das Nötige mitgeteilt habe. Beide behaupten, daß zwei Arten, die sich sehr ähnlich, aber blutsfremd sind, ihre Zeichnung unabhängig voneinander von verschiedenen Ausgangspunkten her entwickelt und dabei gleichzeitig eine Stufe der Abänderung erreicht haben, in der eine die andere nachzuahmen scheint. Die Erklärung wäre nicht von der Hand zu weisen, wenn sie sich nicht auf eine sehr anfechtbare Methodik stützte. Insofern Eimer, Fickert, Piepers u. a. eine Stammesgeschichte der Schmetterlingszeichnung entwerfen, gebrauchen sie nur Merkmale lebender Tiere, denn von der Färbung ausgestorbener Vorfahren unserer Falter, die uns Aufschluß über frühere Stufen geben könnten, ist so gut wie nichts erhalten geblieben. In ähnlichen Fällen helfen sich die Forscher, indem sie das Fehlende aus der Embryonalentwickelung der Einzelwesen ergänzen, die ja nach Haeckels biogenetischem Grundgesetz eine gedrängte Wiederholung der Stammesgeschichte jeder Art ist. Dieses Hilfsmittel fällt jedoch im Hinblick auf die Färbung der Insekten ganz weg, weil ihre Entwickelungsstände völlig abgesonderte Bildungsstufen sind. die weder in der Stammesentwickelung ihre Parallelen noch in der

1) 1903, S. 570-575. - ${ }^{2}$ ) Barbour und Phillips, The Auk 28, 179 (1911). 
Färbung gemeinsame Beziehungen haben. Nan ist also für die Wiederherstellung der Ausgangs - und Zwischenglieder völlig auf Vergleichung der heutigen Bilder angewiesen, und an und für sich ist kein Untersucher zu widerlegen, wenn er die Zeichnungsfolge gerade umgekehrt entwickelt, wie sein Vorgänger. So hat Eimer ${ }^{1}$ ) die volle Überzeugung, daß die Weibchen der „dimorphen Schwalbenschwänze, Nymphaliden, Pieriden usw. einen älteren Entwickelungsgrad bedeuten und die Männchen im Fortschreiten, in der Präponderanz, sind", während Haase das Umgekehrte annimmt. Gegen die erstere Auffassung spricht unter anderen, daß die dimorphen, mimetischen Weibchen einiger Arten gelegentlich männchenfarbig sind. In Anlehnung an solche Vorkommnisse bei anderen Tieren darf man dies als Rückschlag auf eine frühere Entwickelungsstufe betrachten, womit die Männchenzeichnung als die ursprüngliche bewiesen wäre. Ferner ist die Zeichnungsstufe der Männchen bei den Dismorphia (Fig.20d) jedenfalls ungezwungener zu erklären, wenn man sie als ein fast vollendetes Einholen der weiblichen, fertig vorliegenden Entwickelung betrachtet, als wenn man mit Eimer (und Piepers) die Weibchenzeichnung für die ursprüngliche, die männliche für eine Phase der Entwickelung aus Bunt nach einfarbigem Weiß hin erklärt. Unter der Voraussetzung, daß das Weibchen eine an Ithomiinen u.dgl. angelehnte Umbildung des weißen Pieridenkleides zeigt, sehen wir den Vorgang bei den Männchen der Dismorphien bis auf die Vorderhälfte der Hinterflügel vollendet; dies Stück der Flügelfläche ist noch weif und ist gerade dasjenige, welches in der Ruhe von den Vorderflügeln verdeckt wird. Da unbedeckte Teile nun immer zuerst einer Umfärbung unterliegen, so ist jener Fleck ein Rest der alten Musterung. Für das Zurückbleiben des Männchens in der mimetischen Anpassung darf noch angeführt werden, daß seine Hinterflügel die breite Rundung des Pieridentypus beibehalten haben, während beim WVeibchen die schmale Heliconierform erlangt ist.

Eimers Terfahren ist, wie schon bemerkt, mehrfach angefochten worden, namentlich sind seinen eingehend begründeten Arbeiten über die Papilioniden von zwei bedeutenden Kennern dieser Familie schwere Irrtümer über die Verwandtschaftsbezie- 
hungen, durch ungenügendes Naterial verschuldet, vorgeworfen worden ${ }^{1}$. Andererseits haben die auf mimetische Beeinflussung hinauslaufenden Untersuchungen Haases den Vorzug, daß sie die Entwickelung nicht von unbekannten Kräften geleitet hinnehmen, sondern biologische Bedingungen einführen, für deren tatsächliches Walten sich viele Gründe ins Feld führen lassen. Freilich sind gewisse Einzelheiten, die schon Klippen in Haases Fahrwasser bedeuteten, seither noch schwieriger geworden und durch die Behandlung nach seiner Art nicht mehr aus dem Wege zu räumen. Dazu gehört namentlich der Polymorphismus des Papilio memnon und verwandter Arten, dessen Formenreichtum, durch neueste Zuchtergebnisse von Piepers in ein anderes Licht rückt, jedenfalls nicht mehr die glatte, sich so schön lesende Behandlung erlaubt, die wir aus Wallaces Abhandlung über die östlichen Schwalbenschwänze bis heute übernommen haben ${ }^{2}$ ). Abgesehen davon, kann ich aber die Nimikrylehre nicht als ersetzbar durch die Orthogenesis betrachten; diese hat, wie früher hervorgehoben wurde, nur die Bedeutung, daß die Entwickelung der Tierstämme ursprünglich in verhältnismäßig wenigen und geraden Bahnen verlief, von denen aber diese und jene durch andere, mächtigere Beeinflussungen abgelenkt, verschmolzen oder durchkreuzt wurden. Ein solcher Einfluß ist die Mimikry ${ }^{3}$ ).

E. Mimikry ist keine durch natürliche Auslese hervorgerufene und weitergezüchtetenützliche Anpassung, sondern das Ergebnis teils von gleichen inneren Vorgängen im Tierkörper, teils von gleichen unmittelbaren Einflüssen der Umgebung. Auch dieser Einwand läuft darauf hinaus, die mimetischen Ähnlichkeiten zu reinen Konvergenzerscheinungen zu machen, er setzt aber, soweit „innere Ursachen" genannt werden, an die Stelle einer auf Naturbeobachtung fußenden Erklärung die reine Phrase, verdrängt den immerhin mit Mimikı.y verbundenen Begriff durch Worte wie „Ergebnis

1) W. Rothschild und K. Jordan, Novitat. Zoolog. 2, 174 (1895). Eimers Arbeiten über die Entwickelung der Vogelzeichnung sind ebenfalls von den Ornithologen abfällig beurteilt worden. 2) Vgl. Hagen, Deutsche Ent. Zeitschr. 7, 14-16 (1894). - ${ }^{3}$ ) Wertvolle Auseinandersetzungen über diesen Punkt findet man bei Darwin, Entstehung der Arten, übersetzt von H. Schmidt, S. 261; [E. v. Hartmann], Das Unbewußte usw. 1872, S.9-11; Fr. Müller 1876, S. 3-5. 
konstitutioneller Ur'sachen physikalisch-chemischen Inhalts $\left.{ }^{1}\right)^{\text {" }}$ oder "Folge der gleichen physiologischen Bedeutung der Färbung ${ }^{2}$ )". Was die Urheber sich hierbei denken, weiß ich nicht, es möchte auch schwer sein, anzugeben, worin die Gleichheit der Konstitution, etwa im Ablauf des Stoffwechsels, besteht, die zur täuschenden Ähnlichkeit eines Schmetterlings mit einer Wespe führen kann.

(Die eben erschienenen wichtigen Mitteilungen F. Gebhardts über die mechanische Verteilung des Pigments im Schmetterlingsflügel scheinen mir auch noch nicht geeignet zu sein, die transformistische Erklärung durch Mimikry zu widerlegen. - Zusatz bei der Korrektur.)

Der Einfluß der Umwelt in Form von Klima, Feuchtigkeit, Sonnenbestrahlung, Nährstoffen ist zwar auf nahe verwandte Wesen von annähernd gleicher Lebensweise verfolgbar, aber diese Toraussetzungen treffen für viele, und oft gerade sehr "schöne" Mimikryfälle durchaus nicht zu. Die Kerbtiere mit vollständiger Verwandlung (Holometabola) können von jenen Einflüssen doch nur während ihrer Eiruhe und als Larven getroffen werden, nach dem Abschlu@ der Larvenzeit und gleich nach dem Beginn der Puppenruhe ist ihr Äußeres unabänderlich festgelegt. Wie kann demn aber die Ähnlichkeit einer Fliege mit einer Stechimme durch das Yilieu hervorgebracht sein, wenn jene als Larve etwa in und ron Mistjauche, diese in einer sauberen Wachszelle von Blütennektar lebt? Oder die Larve eines Käfers (Lycine) lebt als Tierfresser in dunklen Gängen faulenden Holzes, sein mimetischer Schmetterling (Syntomide) als Raupe von Blättern und im Sonnenlicht. Auch läßt sich gelegentlich ganz bestimmt nachweisen, daß die Ähnlichkeit mehrerer Arten Nachahmer mit ihrem Modell auf sehr verschiedenen Anpassungsweisen beruht, während gleiche „innere und äuœere Ursachen" doch ein und dieselbe Wirkung erzielen müßten. Als Beispiel ${ }^{3}$ ) möge die Verähnlichung der fünf Partner eines Mimikryringes dienen, von denen drei Arten S.141 besprochen und in Fig. 19 abgebildet worden sind. Alle zeigen eine fensterartig verteilte Aufhellung der Flügelfläche, aber bei jeder auf andere Weise erreicht. Bei Methona confusa sind die sonst eine

1) G. Entz, Math. и. naturw. Berichte aus Ungarn 24 (1904) [mir nur aus einem Referat in Zeitschr. f. wiss. Insektenbiol. 3, 60 (1907) bekannt\}. - ${ }^{2}$ ) Schröder 1904, S. 293. - ${ }^{3}$ ) Nach den schönen Untersuchungen von Poulton 1898, S. 578 und 599-601.

Jacobi, Mimikry. 
dichtschließende Lage bildenden Flügelschuppen an den betreffenden Stellen ungemein verkleinert, so daß die glasartige Flügelmembran entblößt ist; bei Ituna ilione ist es durch Ausfallen der meisten Schuppen erzielt, während bei Castnia heliconioides die Deckschuppen weder an Größe noch an Zahl verändert, dagegen des Farbstoffs beraubt und durchsichtig geworden sind. Bei Anthomyza heliconioides ist es ähnlich, aber der Schuppen sind außerdem weniger, und bei Dismorphia orise verlief die Umbildung ungefähr wie bei der Castniide. Ferner sind bei den ithomienähnlichen Pieriden nach F. G. Hopkins ${ }^{1}$ ) die Pigmente der Flügelzeichnung von ganz anderem chemischen Aufbau als bei ihren Modellen. Wie soll man hiermit die obigen Schlagwörter in Einklang bringen?

Alle diese und andere Schwierigkeiten für die Erklärung der Nimikry löst die Einführung der natürlichen Zuchtwahl. Sie tritt in Wirksamkeit, sobald an demselben Platze eine von Feinden gemiedene Art als Vorbild besteht und eine andere, schmackhafte und gewöhnlich seltenere zur Erzeugung von Varietäten neigt, die gewisse Anklänge an die erstere zeigen. Unter den Verfolgungen der Insektenfresser werden zuerst die Stücke rerschwinden, welche am meisten von der immunen Art verschieden sind, und am längsten werden diejenigen überleben, welche am leichtesten mit jener verwechselt werden können. Nach der bekannten Vorstellung des Darwinismus wird sich der Typus der ungeschützten Art von Brut zu Brut einem Durchschnitt nähern, der die beste Wiedergabe des Modells darstellt, und damit die Anpassung vollzogen werden. Die Selektionstheorie gibt meines Erachtens befriedigende Antwort ${ }^{2}$ ) auf jede Frage, die man an die Schilderung der Mimikryerscheinungen in diesem Büchlein knüpfen will, aber sie hat eine Voraussetzung, die der letzte übrige Einwand, zugleich der schwerwiegendste, bestreitet.

F. Die insektenfressenden Vögel sind überhaupt nicht nennenswert an der Vernichtung von Schmetterlingen beteiligt. In den ersten Jahrzehnten nach dem Bekanntwerden unserer Theorie wurde die Voraussetzung ihrer Begründer Bates, Wallace und F. Müller, daß Tagschmetterlinge stark unter der Verfolgung durch Vögel zu leiden hätten, von keiner

$\left.{ }^{1}\right)$ Von Poulton angeführt 1898, S.597. - ${ }^{2}$ ) Eine ausführliche Behandlung bei Poulton 1898, kürzer Derselbe 1902. 
Seite bestritten. Dann meldeten sich Stimmen, welche diese Art Nahrungserwerb der Vögel so gut wie ganz leugneten: Butler, Eimer, Aigner-Abafi für Europa, Blandford, Elwes, Piepers, Walker, Yerbury, Kaye u. a. für die Tropen auf Grund eigener Erfahrungen. Diese für die ganze Beurteilung der Theorie wichtigen Bedenken haben dann vielen Anlaß und Grund gegeben, sie gänzlich zu verwerfen. Dies war nicht angebracht, denn eine genauere Untersuchung der Frage setzt eine gewisse Bedeutung der Tögel außer Zweifel, aber man muß zugestehen, daß bis vor wenigen Jahren jenes Fundament der Theorie bei weitem nicht so ausreichend gestützt war, wie man es verlangen durfte. Dabei ist freilich $\mathrm{zu}$ berücksichtigen, daß die Beobachtung über Verzehren von Schmetterlingen im Vergleich $\mathrm{zu}$ demjenigen anderer Insekten viel schwieriger ist, weil vor dem Verschlingen aller größeren Arten - auf die es uns hier ankommt - die Flügel abgebissen zu werden pflegen; die sonst so zuverlässige Magenuntersuchung läßt dann im Stich, weil die hinfälligen Leiber der Rhopaloceren von den Magensäften in kürzester Frist aufgelöst werden. So erklärt es sich vielleicht, daß Dahl in den Kerbtierfressern Melanesiens nur ganz vereinzelt Reste, und dann von ganz kleinen Tagfaltern, die wohl ganz verschluckt wurden, nachweisen konnte ${ }^{1}$ ), G. L. Bates in 178 Mägen von Kamerunvögeln überhaupt keine Überbleibsel fand ${ }^{2}$ ).

(Daß eine sehr sorgfältige Untersuchung der Mageninhalte das Vorkommen von Schmetterlingen viel öfter ergibt, als bisher angenommen wurde, hat soeben C. Swynnerton ${ }^{3}$ ) für SüdostAfrika nachgewiesen. Die ganze wichtige Streitfrage verlangt also noch eingehende Erörterung, ehe wir uns erlauben dürfen, das Problem der Schmetterlingsmimikry für erledigt zu erklären. - Zusatz bei der Korrektur.)

Da die Beobachtung freilebender Vögel hinsichtlich ihrer Schmetterlingsjagd doch mehr oder weniger vom Zufall abhängig ist, so hat man die Spuren ihrer mißlungenen Angriffe in den sehr bezeichnenden Verletzungen der Flügel lebender Falter gesucht. Schon Fr. Müller bezog sich darauf als Unterlage für seine

1) 1899. - ${ }^{2}$ ) Ibis (Ser. 9) 5, 630-631 (1911). - ${ }^{3}$ ) Ibis (Ser. 9) 6, 635-640 (1912). 


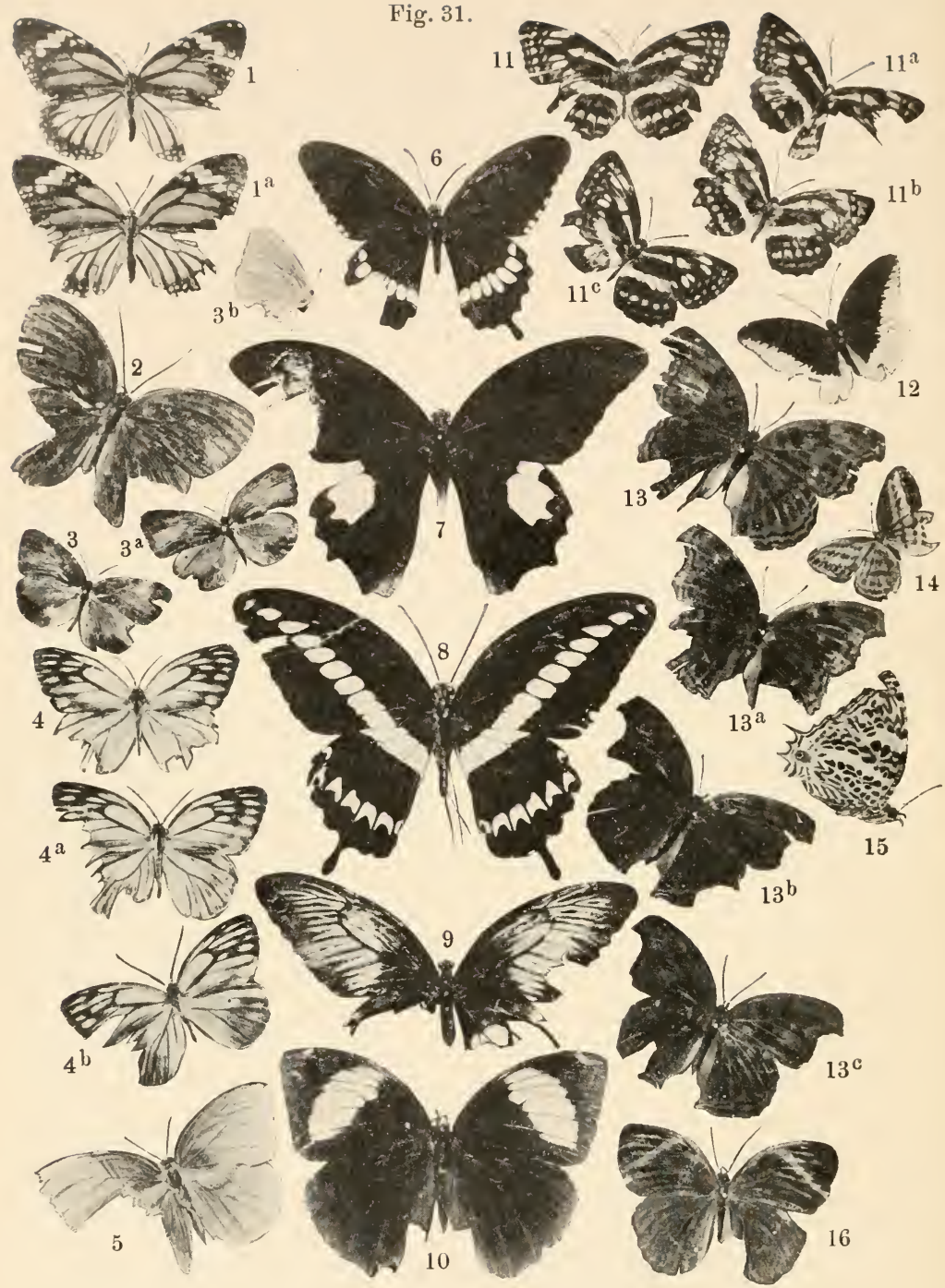

Durch Bisse von Vögeln oder Eidechsen verletzte Tagfalter.

1, 1a Danaus plexippus sumatranus (Sumatra); 2 Clerome chitone (Celebes); 3, 3a-b Terias tilaha (Sum.); 4, 4a-b Huphina timnata (Cel.); 5 Catopsitia crocale (Cel.); 6 Papilio polytes (Sum.); 7 Papilio sataspes (Cel.); 8 Papilio gigon (Cel.); 9 Papitio ascalaphus 우 (Cel.); 10 Thaumantis odana (Sum.); 11,11 $11^{\mathrm{a}-\mathrm{c}}$ Neptis celebensis (Cel.); 12 Euthatia cocytina (Sum.) ; 13,13a-c Precis intermedia (Cel.); 14 Ragadia crisia (Sum.); 15 Megisthanis deucalion (Ecuador); 16 Clerome stomphar (Sum.). 
Annahme von den Probefängen junger Tögel an unschmackhaften Arten und schickte als Beleg 36 so gezeichnete Acraea thatia an Meldola ${ }^{1}$ ). Marshall sammelte in Südafrika eine große Menge solcher Beweismittel, die von Poulton abgebildet und besprochen wurden ${ }^{2}$ ). Auch ich konnte aus großen Schmetterlingsbeständen von Niederländisch-Indien und Südamerika eine Fülle Vergleichsstücke herauslesen, von denen eine Auswahl abgebildet ist (Fig. 31). Wie diese Verluste entstehen, hat Doflein ${ }^{3}$ ) auf Ceylon bemerkt. Sowohl Fliegenschnäpper wie Bienenfresser hatten oft Mißerfolge beim Fang, wobei besonders oft die Schwalbenschwänze sich unter Preisgabe eines Stückes Flügel von dem Feindesschnabel losmachten, um dann in stürmischem Zickzackflug daronzueilen. Nach kurzer Zeit war schließlich im Beobachtungsrevier kein unverletzter Falter mehr vorhanden, alle Colias, Pieris, Papilio, Elymnias. Hypolimnas waren melır oder weniger stark verletzt. Unser Gewährsmann fing öfters solche Exemplare gleich nach dem Ereignis und hob sie auf; dabei ergab sich, dab die Falter fast immer an den Hinterflügeln gepackt worden waren.

Wie die Bilder zeigen, stellen sich die Bißspuren als leicht kenntliche, scharfe Ausschnitte dar; die äußerst starken Verluste, die der Papilio ascalaphus (Bild 9) aufweist, dürften auf wiederholte Angriffe zurückgehen, denn nach Doflein schwächt der Terlust des Schwanzteiles ihrer Hinterflügel das Flugvermögen der Papilios nicht unerheblich. Wenn die Kerben symmetrisch liegen (vgl. Bild 2, 3b, 10, 15), so führt man dies mit Recht auf einen dem sitzenden Falter geltenden Angriff zurück, und zwar soll er dann von einer Eidechse verübt sein. Die Beteiligung dieser Kriechtiere an der Vertilgung ron Tagfaltern ist bisher sicher unterschätzt worden, was z. B. Hahnels und Rosenbergs ${ }^{4}$ ) Erinnerungen aus Südamerika nicht zulassen, aber nach dem Sitze der Verletzung bestimmen zu wollen, ob Eidechse oder Togel der Urheber war, scheint mir nicht angängig, wenigstens sehe ich nicht ein, warum nicht mal ein Togel einen sitzenden Falter an den geschlossenen Flügeln fassen und andererseits nicht eine Eidechse ihn, wenn er ruhend in der bekannten Weise fächelt, an nur einem Flügel erwischen sollte. Ob jedoch die Eidechsen

$\left.{ }^{1}\right)$ Proc. Ent. Soc. 1883, S. 23. - ${ }^{2}$ ) Marshall, 1902, Taf. 9-11. - $\left.{ }^{3}\right)$ 1906, S. 442 u. 443. - ${ }^{4}$ ) Proc. Ent. Soc. 1909, S. 59. 
bei der Entstehung von Mimikryfällen beteiligt sind, scheint mir nach der Behauptung von Manders's), daß auf Ceylon die schmetterlingsfressenden Reptilien keinen Unterschied zwischen widrigen und schmackhaften Arten machen, zweifelhaft, kann aber erst nach Beobachtungen an anderen Orten entschieden werden.

Auch der freien Beobachtungen, welche zur Frage über die Vögel bejahende Antwort geben, sind viel mehr, als man nach der Zahl der erwähnten ablehnenden Stimmen und der Bestimmtheit ihrer Äußerungen glauben müßte. Marshall hat in einer übersichtlichen, große Belesenheit verratenden Abhandlung ${ }^{2}$ ) nachgewiesen, daß solche Vorkommnisse auch in England und Deutschland durchaus nicht selten sind, und für die warme Zone konnte er sich außer vielen positiven Einzelangaben der Literatur auf seine fünfjährige Erfahrung und auf die ganz bestimmten Angaben Dofleins stützen, der uns eine Schilderung von der eifrigen Schmetterlingsjagd der Vögel Ceylons gegeben hat. Daß dagegen Piepers, der jahrzehntelang auf der benachbarten Tropeninsel Java das Naturleben mit offenen Augen beobachtet hat, nur ganze vier solche Vorkommuisse erlebt haben will, ist ein mir unlösbarer Widerspruch. In neuester Zeit hat Manders das noch mehr Klärung gebende Verfahren angewendet, Versuch mit Beobachtung im Freien zu verbinden. Ebenfalls auf Ceylon arbeitend, gab er lebende, aber am Wegfliegen verhinderte Schmetterlinge der immunen wie der ungeschützten Gruppen an gewissen Punkten den dort verkehrenden insektivoren Tögeln preis und verfolgte deren Benehmen. Aus seinen Ergebnissen schließt M anders folgendes ${ }^{3}$ ): 1. Schmetterlinge werden bedeutend mehr von Vögeln verfolgt, als bisher angenommen wurde; 2. Gerade die für besonders gemieden erklärten Danaer und Euploeen fallen ihnen weit häufiger zum Opfer, als die Mitglieder irgend einer anderen Gruppe; dies erklärt sich wohl daraus, daß jene wegen ihrer Häufigkeit und Zutraulichkeit besonders leicht zu erlangen sind.

Wenn diese beiden Feststellungen sich in anderen Gegenden, zu allen Jahreszeiten und auch bei abgeänderter, natürlich aber zweckentsprechender Versuchsanordnung bestätigen sollten, so

1) 1911 , S. $\left.748 .-{ }^{2}\right) 1909 .-{ }^{3}$ ) S. 741. 
würde uns die Entscheidung, ob zwei ausschlaggebende Voraussetzungen der Lehre von der Schmetterlingsmimikry richtig sind, leicht fallen. Manders' erster Satz läßt die übrigens nie beweisbare Möglichkeit zu, daß sich mimetische Ähnlichkeiten unter dem ökologischen Einfluß der Vögel entwickelt haben. Der zweite Satz vernichtet diese Möglichkeit wieder, indem er leugnet, daß die für Vorbilder erklärten Arten von den Vögeln verschmäht werden. Allein so wertvoll, ja bahnbrechend Manders' Versuche auch sind - für ein Endurteil sind sie unzureichend. Sie bedeuten nur den ersten Schritt auf einem langen Wege, den die Naturforschung in tropischen Ländern, besonders in dem daraufhin noch gänzlich brach liegenden Amerika, zu durchmessen hat. Auf die Untersuchung der Schmetterlinge, ihrer Systematik und Abstammung im Hinblick auf Mimikry ist schon eine große Summe von Forscherfleiß verwendet worden, der wohl alle wichtigen Fragen spruchreif gemacht hat; möge man von jetzt ab denselben Eifer der Aufklärung ihres Verhältnisses zur Vogelernährung verwenden! Aber selbst dann, wenn alle weiteren Erfahrungen sich in Übereinstimmung mit jenen vorläufigen, eng begrenzten Ergebnissen befinden sollten, wäre es meiner Überzeugung nach gewagt, die auf Lepidopteren bezogene Mimikrytheorie für eine widerlegte Hypothese, für einen großen, wenn auch wissenschaftlich höchst fruchtbaren Irrtum der Naturforschung zu erklären. Wissen wir denn, ob der Ausschnitt des Daseinskampfes, den wir mimetische Anpassung nennen, noch weitergefochten wird, oder nicht schon mit der endgültigen Niederlage der einen Partei, der Falter, beendet worden ist, wobei der Sieger die weitere Verfolgung nur noch lässig betreibt, weil anderwärts wertvollere Beute mühelos zu gewinnen ist? Ich will hiermit sagen, daß möglicherweise die Entwickelung der mimetischen Anpassungen in einem Zeitabschnitt verlaufen ist, wo die erwachsenen Tagfalter viel mehr von Vögeln begehrt wurden, weil andere Kerbtierkost spärlicher war als heute; dabei konnten gewisse Familien sowohl eine schon vorhandene Geschmackswidrigkeit unter dem Auslesevorgang steigern, wie eine dazu stimmende charakteristische Warnfärbung erlangen. Dieser Entwickelung folgte allmählich die mimetische Anpassung nicht gemiedener Formen und erlangte vielfach jene feine, von uns bewunderte Ausbildung. Mit der Zeit trat jedoch eine Gewöhnung der Tögel an die so häufigen unschmackhaften Arten 
ein, die auch für die Mimetiker verhängnisvoll wurde, weil ihre Iaske nicht mehr als Abschreckungsmittel wirkte - daher vielleicht die große Spärlichkeit der meisten Nachahmer. Indem weiterhin der Tisch des Vogels immer reicher mit anderer, schmackhafterer Kost beschickt wurde, verminderte sich für ihn der Anreiz, sich mit Schmetterlingsfang abzugeben, für die Verfolgten aber mit der Verbesserung ihrer Lage der selektive Drang, in der mimetischen Anpassung Schutz zu suchen: daher die Arten mit unvollkommener Mimikry, die bei der allgemeinen Tracht verharrenden Gatten mimetischer Weibchen usw. Kurz gesagt, wir hätten in der Nachäffung bei Faltern das Ergebnis eines wesentlich abgeschlossenen Abschnittes ihrer Stammesgeschichte vor uns, aus dem viele einst leistungsfähige Unternehmungen sich erhalten haben, während andere in ihren Anfängen stecken geblieben sind, weil die veränderte Wirtschaftslage ihre Weiterführung überflüssig gemacht hat.

Dies sind nur Vermutungen, Erklärungsversuche, wie sie in der Abstammungslehre unentbehrlich sind, ohne daß wir für die Richtigkeit einstehen, noch weniger auf sie schwören dürfen. Jedenfalls möchte ich nochmals hervorheben, daß die Weiterführung von Versuchen der erwähnten Arten durchaus nötig ist, um zu einem annehmbaren Endurteil über das Problem der Schmetterlingsmimikry zu gelangen, und möchte gleichzeitig allen, die schon dazu ablehnende Stellung eingenommen haben, ein vorurteilsfreies Abwarten nahelegen. 


\section{Schriitenverzeichnis.}

Nur solche Schriften sind aufgeführt, die von grundlegender Bedeutung für das Ganze oder einen einzelnen Gegenstand sind oder die im Text öfter angezogen werden.

Aigner-Abafi, L. v. (1902), Über Mimikry. - Allgem. Zeitschr. f. Entom. 7, 368-372, 405-409.

Bates, H. W. (1861), Contributions to an Insect Fauna of the Amazon Valley. Lepidoptera: Heliconidae. - Trans. Linn. Soc. 23, $495-566$, Taf. $55-56$.

Beddard, F. E. (1892), Animal Coloration. - London. $8^{0}$.

Breddin, G. (1896), Nachahmungserscheinungen bei Rhynchoten. - Zeitschr. f. Naturw. 69, 17-45; Taf. 1.

DAHL, F. (1899), Das Leben der Vögel im Bismarckarchipel. Mitteil. d. Zool. Sammlung Berlin 1, 107-222.

Dixey, F. A. (1896), Ou the relation of mimetic patterns to the original form. - Trans. Ent. Soc., S. $65-77$; Truf. $3-5$. Taf. 7 .

- (1897), Mimetic attraction. - Trans. Ent. Soc., S. 317-331;

DofleIN, F. (1908), Über Schutzanpassung durch Ähnlichkeit. (Schutzfärbung und Mimikry.) - Biol. Centralbl. 2S, 243-254.

Doxisthorpe, H. (1901), Cases of protective resemblance, mimicry etc. in the british Coleoptera. - Trans. Ent. Soc., S. 345-377.

Exier, TH. (1888, 1897), Die Entstehung der Arten auf Grund von Vererben erworbener Eigenschaften nach den Gesetzen organischen Wachsens. - 2 Bde., Leipzig. $8^{\circ}$.

Eltringham, H. (1910), African Mimetic Butterflies etc. Oxford, 136 S., 10 Taf., 1 Karte. $4^{0}$.

Fins, F. (1897), Contributions to the theory of warning colours and mimicry. - Journ. Asiatic Soc. of Bengal 66 pt. 2, 613-668.

Fowler, W. (1901) [Protective resemblance and mimicry as affecting the Coleoptera]. - Proc. Ent. Soc., S. XXXVI-LIX. 
GAHAN, C. (1891), Mimetic resemblances between species of the Coleopterous genera Lema and Diabrotica. - Trans. Ent. Soc., S. 367 bis 374 ; Taf. 17 .

Giard, A. (1894), Sur le mimétisme parasitaire. - Annal. Soc. Ent. France 43, 124-126.

Gounelle, E. (1905), Concordance des variations locales de coloration chez les Lycides et les Insects qui les miment. - Bull. Soc. entom. France, S. 132-134.

HAASE, E. (1893), Untersuchungen über die Mimikry auf Grundlage eines natürlichen Systems der Papilioniden. I. Tl.: Entwurf eines natürlichen Systems der Papilioniden. II. Tl.: Untersuchungen über die Mimiki.y. - Stuttgart. $4^{0}$, mit 14 Tafeln (die Seitenzahlen beziehen sich auf Teil II, wenn nicht besonders bemerkt).

JAPHA, A. (1909), Die Trutzstellung des Abendpfauenauges (Smerinthus ocellata L.). - Zool. Jahrb., Abt. f. Syst., 27, 321-328; Taf. 12.

KAYE, W. J. K. (1906), Notes on the dominant Müllerian group of Butterflies from the Potaro District of British Guiana. - Trans. Ent. Soc., S. $411-439$; Taf. $23-27$.

LongstafF, G. B. (1908), Bionomic notes on Butterflies. - Trans. Ent. Soc., S. $607-673$.

Manders, N. (1911), An investigation into the validity of Müllerian and other forms of mimicry, with special reference to the islands of Bourbon, Mauritius and Ceylon. - Proc. Zool. Soc., S. 696-749.

Marshall, G. A. K. [und Poulton, E. B.] (1902), Five year's observations and experiments $(1896-1901)$ on the Bionomics of South African insects etc. - Trans. Ent. Soc., S. 287-584; Taf. 9-23.

- (1908), On Diaposematism, with reference to some limitations of the Müllerian Hypothesis of mimicry. - Trans. Ent. Soc., S. 93-142.

- (1909), Birds as a Factor in the production of mimetic resemblances among the butterflies. - Trans. Ent. Soc., S. 329-383.

Masterman, A. T. (1908), On a possible case of mimicry in the common Sole. - Journ. Linn. Soc., Zool. 30, 239-244.

Melichar, L. (1904), Beitrag zur Kenntnis der Schutzfärbung, Mimikry, bei Homopteren. - Entom. Jahrb. 13, 213-217.

M'Intosh, W. C. (1901), The coloration of marine animals. Ann. Mag. Nat. Hist. (Ser. 7) 7, 221-240.

MÜLlER, F. (1876), Einige Worte über Leptalis. - Jen. Zeitschr. f. Naturw. 10, 1-12; 2 Fig.

- (1879), Ituna und Thyridia. Ein merkwürdiges Beispiel von Mimikry bei Schmetterlingen. - Kosmos 5, 100-108, 4 Fig. 
Neave, S. A. (1906), Some bionomic notes on Butterflies from the Victoria Nyanza. - Trans. Ent. Soc., S. 207-224; Taf. 9-12.

Piepers, M. C. (1903), Mimikry, Selektion, Darwinismus. Leiden. $8^{0}$.

Platead, F. (1892), La ressemblance protectrice dans le règne animal. - Bull. Acad. Roy. Belgique (3. sér.) 23, 89-135.

Pocock, R. J. (1908), Mimicry in Spiders. - Journ. Linn. Soc., Zool. 30, 256-270; Taf. 32 .

Poulton, E. B. (1887), The experimental proof of the protective value of colour and markings in insects in reference to their vertebrate enemies. - Proc. Zool. Soc., S. 191-274.

London. $8^{0}$.

- (1890), The colours of animals, their meaning and use. -

- (1898), Natural selection the cause of mimetic resemblance and common warning colours. - Journ. Linn. Soc., Zool. 26, 558-612; Taf. $40-44$.

- (1902), Mimicry and Natural Selection. - Verhandl. 5. Internat. Zool.-Kongr. 1901, S. 171-179.

- (1903), Suggestions as to the meaning of the shapes and colours of the Membracidae, in the struggle for existence. In: Bucktox, A monograph of the Membracidae, S. 273-385.

- (1906), Predaceous Insects and their Prey. - Trans. Ent. Soc., S. $323-409$.

Prochnow, O. (1907), Die Mimikrytheorie. Internat. ent. Zeitschr., Guben, 1, 2 u. f.

REY, E. (1909), Ein Beitrag zur Beurteilung des wirtschaftlichen Wertes der Insekten fressenden Vögel. - Ornith. Monatsschr. 34, $25-26$.

Schröder, CHr. (1904), Kritische Beiträge zur Mutations-, Selektions- und zur Theorie der Zeichnungsphylogenie bei den Lepidopteren. - Allgem. Zeitschr. f. Ent. 4, 281-297.

Schrotтку, C. (1909), „Mimetische" Lepidopteren. Ein Beitrag zur Kenntnis der Syntomidae Paraguays. - D. Entom. Zeitschr. Iris 2.2, 122-132.

SHELFORD, R. (1902), Observations on some mimetic Insects and Spiders from Borneo and Singapore. - Proc. Zool. Soc., S. 230-284; Taf. $19-23$.

Standfuss, M. (1894), Die Beziehungen zwischen Färbung und Lebensgewohnheit bei den paläarktischen Großschmetterlingen. Vierteljahrsschr. d. naturf. Ges. Zürich 39, 85-119.

Swinhoe, Сн. (1895), On mimicry in Butterflies of the genus Hypotimnas, - Journ. Linn. Soc., Zool. 25, 339-348; Taf. 15-17. 
Thayer, A. H. (1903), Protective Coloration in its relation to Mimicry, Common Warning Colours, and Sexual Selection. - Trans. Ent. Soc., S. $553-569$.

Trimen, R. (1868), On some remarkable Mimetic Analogies among African Butterflies. - Trans. Linn. Soc. 26, 497-521; Taf. 42-43.

- (1897), Mimicry in insects. - Proc. Ent. Soc., S. LXXIV-XCVII.

Vosseler, J. (1903), Beiträge zur Faunistik und Biologie der Orthopteren Algeriens und Tunesiens II. - Zool. Jahrb., Abt. f. Syst., 17, 1-98; Taf. 1-3, 5 Abb.

- (1909), Die Gattung Myrmecophaga Brunner, ihre hypertelische und Ameisennachahmung. - Zool. Jahrb., Abt. f. Syst., 27, 157-210; Taf. 8 und $13 \mathrm{Abb}$. im Text.

WALLACE, A. R. (1865), On the phenomena of variation and geographical distribution as illustrated by the Papilionidae of the Malayan Region. - Trans. Linn. Soc. 25, 1-71; Taf. 1-8.

- (1870), Beiträge zur Theorie der natürlichen Zuchtwahl. Deutsch von A. B. Meyer. - Erlangen. $8^{0}$.

- (1891), Der Darwinismus. Deutsch von D. Brauns. - Braunschweig, Friedr. Vieweg \& Sohn. $8^{0}$.

Wasmann, E. (1903), Zum Mimikrytypus der Dorylinengäste. Zool. Anz. 2:3, 581-590.

- (1909), Die psychischen Fähigkeiten der Ameisen, 2. Autl. Stuttgart. $4^{0}$.

Weismann, A. (1904), Vorträge über Deszendenztheorie. Zweite verbesserte Auflage, 2 Bde. - Jena. Gr. $8^{0}$. Gr. $8^{0}$.

- (1909), Die Selektionstheorie. Eine Untersuchung. - Jena.

Werner, F. (1908), Nochmals Mimikry und Schutzfärbung. Biol. Centralbl. 28, 567-576, 588-601. 


\section{Namenregister.}

Im Namen- und Sachregister bezeichnen die fettgedruckten Ziffern diejenigen seiten. auf denen wichtigere Erörterungen stehen.

Aigner-Abari 39, 195. Aitken 170 .

Alexander 180 .

-, Boyd 170 .

Annandale, N. 16, 47. Armit 47.

Arnold, E. L. 170.

Auel 186.

Austen 87, 90, 94.

Barbour 190.

Bates, G. L. 113, 195.

-, H. I. 60, 61, 62, 64, $143,149,166,167$, $170,179,194$.

Bateson 93.

Baumann, E. 166.

Beddard, F. E. 3à, 51, 92.

Belt 45, 63, 131, 170 .

Bergroth 103.

Bingham 170.

Blakiston 180.

Blandford 195 .

Boettger, O. 74.

Boisduval 161.

Bowker 147.

Breddin 15, 102, 104, 105.

Brues 121.

Brunner von Wattenwyl $107,110$.
Burchell 97 .

Butler, A. G. 92, 195.

Buysson, R. du 82.

Dahl $7,113,126,195$. Darwin $34,44,45,>0$, $186,192$.

Davison 71 .

Distant 68, 182 .

Dixey 63, 172, 15:.

Doflein 39, 173, 197 .

Donovan 165.

Duponchel 125 .

Wimer $21, \mathbf{2} \mathbf{6}, 29,35, \mathbf{3 6}$, 120, 181, 180, 195.

Eisig 51.

Eltringham 63, 16i3), 164.

Elwes 195.

Entz, G. 193.

Escherich 123.

Fickert 190.

Fiebrig 101, $10 \overline{\text {. }}$

Finn 63, 171, 181.

Forbes, H. O. 4, 11.

Fowler, W. 63, 77.

Gahan 107.

Gebhardt, F. 193.

Gerstäcker 61, 94 .

Giard 66, 94.
Gounelle 131.

Green, E. G. 79.

Gregory 15.

Iraase, E. 11, 44, 51, (ii), $67,72,73,82,98$, $129,131,143,150$, $152,167,170,171$, $172,173,174,181$, $191,192$.

Haeckel 190.

Hagen 192.

Hahnel 33, 155, 167 , $173,187,197$.

Hampson 171, 182 .

Handlirsch 94.

Hartert 83.

Hartmann, E. v. 192.

Heller 126.

Hinde 15.

Hopkins, F. G. 51, 194.

Japha 5.j, 57.

Jorda11, K. 150, 192.

Iaye 63, 167, 195.

Kirby 60 .

Kirschbaum 105.

Kittlitz, v. 113.

Tandois 92.

Latter 9:2, 93. 
Linden, Gräfin 30.

Lloyd Morgan 181.

Longstaff $172,173,174$.

II'Intosh 13, 76.

Mac-Leay, W. S. 60.

Manders 19S.

Marshall 54, 57, 63, $131,133,170,171$, $172,178,182,185$, 188, 197, 198.

Martin 165.

Masterman 75 .

Mayer, G. G. 175.

Méhély, L. v. 29.

Meldola 62, 64, 197.

Melichar 15.

Mell 153.

Meyer, A. B. 73.

Moore 181.

Müller, Fritz 62, 166, 180, 192, 194, 195.

一, Herm. 23.

Neave 178.

Newstead 131.

Newton 112.

Nicéville, L. de 106.

Ohaus 106.

Packard, A. S. 187.

Peckham, E. 96, 98, 100.

Phillips 190.

Piepers 23, 24, 26, 30, $33,36,58,59,64$, $121,182,184,187$, $189, \mathbf{1 9 0}, 192,195$, 198.

Plateau 13, 53, 172.
Pocock 78, 96, 101, 107.

Poeppig 170.

Poppius 102.

Poulton, E. B. 15, 23, $24,44,45,49,52$, $62,63,67,68,86,106$, $124,127,128,133$, $166,181,182,158$, 190, 193, 197.

Prochnow 53, 57, 65.

Pryer 83, 84, 86.

Ratzeburg 94.

Reuter, E. 150.

一, O. M. $102,105,177$.

Rey 128.

Ribbe 24, 82.

Ritsema, C. 85 .

Roesel von Rosenhof 56 .

Rosenberg 197.

Rothe 186.

Rothney 103.

Rothschild, W.150, 192.

Sajó 68.

Schilde, J. 186.

Schröder 187, 189, 193.

Sehrottky S5, 89, 90.

Schulz, A. 186.

Seitz 58, S8, 161, 171.

Semper 129.

Shelford $63,83,85,86$, $96,100,129,131$.

Sikora 15.

Simon 96.

Skertchly 37, 182.

Slevogt 57.

Speiser 92, 189.

Spence 60.

Stäger 61 .

Standfuß 5\%, 185.
Staudinger 187, 189.

Stecher 68 .

Sterne, C. 186.

Sternfeld 72.

Swinhoe 63.

Swynnerton, C. 195.

Thallwitz 73.

Thayer 189.

Townsend 94.

Trimen, R. 62, 63, 164, $165,166,181$.

Tristram, H. B. 6 .

Urech 30, 51.

Vosseler 25, 31, 37, 51, 99, 108.

Vuillet, J. 85 .

Wagner, v. 187.

Walker 195 .

Wallace, A. R. 3, 19, $34,44,62,63,70$, $72,113,126,128$, $152, \mathbf{1 5 9}, 181,185$, 192, 194.

Wasmann 95, 114, 120, 12.

Weale 164.

Weir, J. 53, 128, 181.

Weismann 34, 35, 58, 59, 123, 166, 186.

Werner, F. 31, 42, 54, $55,72,109,170$, $182,189$.

Westwood 125 .

Wiggins, C. A. 179.

Wroughton 103.

Yerbury 195. 


\section{Sachregister.}

A bendpfauenauge $\mathbf{5 j}$.

Abraxas grossulariata 172.

Acraea 146, 165, 173.

- egina 147 .

- encedon 179.

- euryta 147.

- terpsichore rougeti 179.

- thalia 197.

Acraeen 171.

Acraeinae 53, 136, 168.

Actinote 178 .

Aculeata 81.

Adeniophis 73 .

- intestinalis 73 .

Agaristidae 137, 168.

Agrotis pronuba 184.

Alcidis agathyrsus 155, 177.

Aletis 137 .

Amathusia 37, 38.

Amauris 173.

- echeria 163, 178.

- niavius 163.

- psyttalea 189.

Ameisen 81.

Ameisenbär 112.

Ameisenbeutler 112.

Ameisendrosseln 112.

Ameisenfeinde 112.

Ameisenfrösche 74 .

Amiciaea lineatipes 100 .
Ammophila 8\%.

Anaea 21.

Anomalon heros 83 .

Anomma 119, 120 .

Anosia 138.

- erippus 140.

Anpassung 65.

-, mechanische 32.

Ant-Thrushes 112.

Anthocharis cardami nes 15 .

Anthomyza heliconioides 143, 194.

Aphaenogaster testaceopilosa 115 .

Apidae 81.

Apocyrtus 126.

Aposem 44.

Aposematisch 44 .

Arachnopus 77.

Arachnothera 77 .

Archidoris tuberculata 12.

Arctiidae 134, 157, 143.

Argiopiden 100.

Argynnis diana 183.

- hyperbius 178.

Argyroeides braco 89.

- sanguinea 89.

Arion empiricorum 47.

Aristolochienfalter 150, 177.

Asilidae 53.
Asilus 161.

Atelopus 74

- varius 74, 75 .

Atemeles 115, 116, 117 .

Athesis acrisione 143 .

- clearista 143.

Atractocerus termiti-

cola 123.

Auerhuhn 7.

Äugler 136.

Aurorafalter 15.

Ballus depressus 77 .

Bären 134, 137.

Bärenspinner 46.

Belts Frosch 75 .

Bembecia hylaeiformis 86.

Bergschaf 5 .

Biene 45, 81 .

Bienenameise 79, 82.

Bienenfresser 54, 81, 197.

Birkhuhn 7.

Bitis arietans 58.

- caudalis 72 .

Blasenkäfer 45, 53.

Blatt, wandelndes 18 .

Blattkäfer 45, 53, 127.

Blattlauslöwe 11 .

Blattnachahmer 18, 38 . Blattnachahmung 36 . Blattoidea 128. 
Blattschmetterlinge $\mathbf{1 9}$, 27.

Blattwespen 45, 54 .

Bläulinge 137 .

Blausieb 44.

Blindwanzen 102, 104 .

Blutströpfchen 46 .

Bockkäfer $77,83,86$, 126, 130, 132.

Bogenfliege 91.

Bombus 92.

- juxtus 92 .

- lapidarius 93.

- muscorum 93.

Brachycephalidae 74 .

Braconidae 81, 89.

Buchenspinner 23.

Buckelzirpen 12, 15, 106.

Buntkäfer 82, 132.

Buntspecht 4 .

Bupalus piniarius 14.

Caduga 138.

Calichrominae 83.

Caligo 58.

Callophis 73, 74 .

- gracilis 73 .

Calopteron 134.

- basale 132.

- cyaneum 134.

- limbatum 133, 134.

- reticulatum 134.

- serratum 134.

- torquatum 132.

Camponotus rufipes 107.

- rufoglaucus 108.

Cantharidae 45, 53, 133.

Capitella 51.

Capsiden 102, 105.

Caria dilata 78 .

Caerois 37.

Cassidodes ligata 129.

Castnia dodona 143.

- heliconioides 143, 194.

- linus 143.

- micha 143.
Castnia simulans 146 .

Castniidae 137, 143, 146.

Catocala 9.

Centropus 170.

Cerambycidae 132, 133 .

Cerambycinae 132.

Cerceris 86 .

Ceria conopsoides 92 .

Cetoniidae 49.

Chalcis emarginata 94.

- punctata 94.

Chalcosiinae 137.

Chamäleon $8,32,34$, 39.

Chaerocampa elpenor $31,57$.

- osiris 57 .

Chilomenes lunata 78 .

Chitosa nigrita 115.

Chlamys pilula 11 .

Chlorophorus annularis 85.

Chrysididae 81.

Chrysomelinae 127.

Chrysopa 11.

Chrysotoxon succinctum 91.

Cicindelidae 125.

Cilix 12.

Cladius 54.

Cleonus 78.

Cleridae 82, 132, 133.

Clerus 82, 83.

- formicarius 83 .

Clubionidae 97.

Clytanthus sumatrensis 85.

Clytinae 85 .

Clytus arietis 85 .

Coccinellidae $45,46,78$, 128.

Colias 197.

Coloborhombus fasciatipennis 83 .

Colubridae 72 .

Combretum gueinzii 22 .

Condylodera 125.

— tricondyloides 125 .
Coenophlebia 37 .

Coenophlebia archidona 21.

Coenoptychus pulchellus 79 .

Cooperastur pileatus 71 .

Coreidae 103.

Coronella laevis 73 .

- tricincta 72 .

Corotoca 123.

Correbia 134.

- lycoides 134.

- oberthüri 134 .

Corrodentia 123.

Cosmolesmus $\mathbf{1 5 2}$.

- idaeoides 179.

- pausanias 149 .

- ridleyanus 147.

Cuphotes marmoratus 130.

Curculionidae 49, 126 , 132.

Cyanopepla 90.

Cyclosa 66.

Cyclosia midamus 164 .

Danainae 53, 136, 138, 143,168 .

Danaus 138, 175, 176.

- chrysippus 140, 156, $163,165,171,176$, $178,179,185,189$.

- - forma dorippus 165.

- erippus 174.

- plexippus 182.

- septentrionis 171.

- tytius 138.

- vulgaris 171 .

Dasypeltis 72 .

Dasypodidae 112.

Delias 137, 185.

Demonax viverra 86 .

Dendrocopus 4.

Dendrolimus 8.

Dendromus 113.

Diabrotica 128.

Diaposem 182. 
Diloba coeruleocephala 44.

Dimorphismus 155 .

-, geschlechtlicher 100.

Dinarda 117.

- dentata 115.

- märkeli 115.

Dinardini 115.

Dioptinae 137.

Diptera 90.

Discophora 38.

Dismorphia 141, 146, 149, 191.

— alsinoides 146.

- astynome 146.

- eumelia 141.

- melite 189.

- orise 143, 194.

Dismorphiinae 146.

Dolchwespen 79, 81, 87, $90,94$.

Doleschallia 21, 28.

Dulichoderinae 96 .

Doliops curculionides 126.

Doris coccinea 12.

Dorylini 117.

Dorylomimus Kohli 121.

Dorylus nigricans 119 .

Dromia vulgaris 11 .

Drongo 171.

Drurya antimachus 165.

Duftpinsel 172.

Dulichius 103.

— inflatus 103.

Echidna 112.

Echthistatus spinosus 77.

Eciton 122.

- burchelli 120.

- praedator 118, 121.

Ecitophya simulans 120.

Ectatorhinus magicus 77.

J a c o bi, MLimikry.
Effektualverhältnis 28 .

Eichhörnchen 70.

Eidechse 40, $19 \overline{7}$.

Eisbär 5.

Eisfuchs 5.

Elaps 72, 73, 75.

- corallinus 72 .

- fulvius 72 .

- lemniscatus 72.

Elymnias $136,177,185$, 197.

- leucocyma 164.

- masoura 177.

- phegea 147, 184.

- undularis 178.

Empusa cyanea 109.

Engmäuler 74 .

Engystomatidae 74 .

Entwickelung, gleichgerichtete $\mathbf{2 6}$.

Entwickelungsgleichheit, unabhängige 27, 121.

Entwickelungsstillstand 27.

Epeiriden 78.

Epicopeia polydorus 153, 164.

Epicopeiidae 137, 153.

Eremobia 25.

Eristalis tenax 92.

Erotylidae 45, 129.

Erotylus histrio 130.

Erycinidae 136, 146.

Erzwespe 94.

Esthesinae 83.

Euchelia jacobaeae L. 46.

Euides 149, 177.

- isabella 149 .

Eulen 8, 31.

Eumolpinae 127.

Euploea 140, 178.

- godarti 161.

- linnaei 120, 159, 164, 172.

- rhadamanthus 140 , 161.
Euripus halitherses 140 , $161,164,178$.

Eurycorypha 108.

- fallax 107.

Eutresis hispa 143.

- imitatrix 143.

Evander nobilis 132.

Fadenkäfer 132.

Faltenwespen 81, 94, 101.

Falter 40.

Fangheuschrecken 16, 53, 54, 106.

Farbenphotographie 24 .

Färbung, kryptische 4 .

-, sympathische $5,6,7$.

Feldheuschrecke 9 .

Feuersalamauder 45.

Feuerwanze 103.

Flatinae 16.

Fliegen 90.

Fliegenschnäpper 171 , 197.

Florfliege 11.

Formica 115.

- fusca 102, 105.

- rufa 102.

- rufibarbis 98 .

- sanguinea 116.

Formicariidae 112.

Formicidae 81.

Formicoris 103.

Fruchttaube 4.

Fulgoridae 9 .

Furchtlosigkeit 173.

Galerucidae 53.

Galerucinae 127.

Gastropacha 8.

- quercifolia 19.

Gazelle 6.

Genepistase 27.

Geometridae 14, 137.

Gerania 77.

Gespenstheuschrecke $14,31$.

Glanzdrossel 112. 
Glasflügelschwärmer s6i, 137.

Glattnatter 73 .

Glaucopiden 87.

Glaucytinae 86.

Goldwespe 81.

Gongylus 17.

Gory tes politus 94.

- robustus 94.

Gottesanbeterinnen 16 .

Grabwespen $81,85,86$, 90, 94, 101, 126.

Gradflügler 101.

Graphosomatinae 49 .

Grillen 107, 125, 126.

Guitelia vuilleti 85 .

Gürteltier 112.

Ilabicht 71 .

Halias prasinana 9.

Halichondria panicea 12.

Halsbandlemming 5 .

Harlekinspanner 172 .

Harpagus diodon 71 .

Hase 7.

Haselhuhn 7.

Heilipus 126.

Heliconiden 61.

Heliconier 170, 171, 173.

Heliconiinae 136, 166, 168.

Heliconius 90, 146, 149, $150,167,177$.

- amaryllis 149 .

- doris 149, 150, 167.

- eucrate 167.

- hewitsoni 149.

- hydarus 149.

- ismene telchinia 149.

- lindigii 167.

- narcaea 149.

- numata 167.

- pachinus 149.

- silvanus 167.

- wallacei colon 150 .

Helioscirtus 38 .
Helioscirtus capsitanus 25.

Heloderma 46 .

Hemaris bombyliformis 86.

Hemerobius 11.

Hemidictya frondosa 18.

Heniconotus 106.

Hermaea 13.

Hermelin 5.

Hestia 165.

- belia 165 .

- javana 165.

- leuconoe 179.

Heterocera 86, 134, 137, $161,167,168$.

Heterodon 53 .

Heteronotus 106.

Heteroptera 101.

Heuschrecken 6, 24, 25, $38,40$.

- der Sahara 37.

Hierococcyx sparverioides 70 .

Hinterkiemerschnecke 12.

Hispa 127.

Hispinae 127.

Histia rhodope 153.

Hochsee, Tiere der 6.

Höckerschnabel 71 .

Holzbiene 87.

Homalocranium semicinctum 72 .

Homoeogenesis 27, 121.

Homoptera 105.

Honigfresser 71 .

Hoplitis phyllocampa 22.

Hornisse 86 .

Hornissenschwärmer 86.

Huechys 47.

Hummelfliegen 60, 67, 92.

Hummelschwärmer 86 . Hyelosia tiresia 143.
Hymenopus bicornis 16 .

Hypolimnas 197.

- anomala 164.

— dubius 178, 189.

- misippus 15(6, 165, $176,178,179,189$.

Ichnea 133.

Ichneumonidae 81 .

Ideopsis 165.

Igelkäfer 127.

Ildibaha mutilloides 100.

- myrmicaeformis 100.

Immunität 44, 169.

Iphicles flavosinuatus 129.

Ithomia 141.

- ellara 141.

- eupompe 143.

- eurimedia 141.

Ithomiinae 6, 136, 143, $166,171$.

Ituna 143.

- ilione 143, 180, 194.

- phaenarete 143 .

Ityraea 15.

- gregoryi 15.

- speciosa 15.

Íallima 19, 21, 24, 27, $28,36,37,38,39$.

- inachis 19, 21.

- paralecta 19.

Kanarienvogel 51 .

Kausalverhältuis 28 .

Kiefernspanner 14.

Knotenameise 106.

Kohlweißling 52.

Kolibri 77.

Korallenschlange 72, 74 .

Körperauflösung 4 .

Kotwanze 11.

Krabbenspinne 11.

Krebs 39.

Kreuzkrautspinner 46 .

Kreuzotter 73 . 
Krustenechse 46 .

Kuckuck 70 .

Kupferglucke 19.

Kurzflügelkäfer 115 .

Lamarckismus 33 .

Lamellicornier 49.

Lamiinae 86, 132.

Landtiere, arktische 36.

Laphria 54.

Lasius 102.

- fuliginosus 104, 116.

Laubfrosch 8.

Laubheuschrecke 9, 18, 125.

Lebenszähigkeit 173 .

Lehmwespen 86, 92.

Lema 127, 128.

Leptaliden 61 .

Leptalis 141.

Leptodira 53.

Leptogorgia virgulata 13.

Lerchen 7 .

Lia 129.

- albosinuata 129.

- elegans 129.

- scripta 129.

Libellen 171.

Limax cinereus 47.

Limenitis archippus 140.

Lindenschwärmer 57 .

Lithinus 15.

Locusta 9.

Lomechusa 115, 117.

- strumosa 116.

Lophyrus 45.

Lycaenidae 137.

Lycidola 132.

Lycinae 45, 131.

Lycomorpha 134.

Lycorea 146, 167.

- halia 167 .

Lycus 131.

Lymantriidae 137.

Lymexyloniden 123.
II acrocneme 87 .

- lades 89.

Iracromeris splendida 85.

Macronyx capensis 184.

Majidae 11.

Malichius aeneus 130 .

- bipustulatus 130 .

Malacodermata 45, 130 .

Malacosoma neustria L. $44,53$.

Ianis 112 .

Mantidae 16, 53, 109.

Mantis 171.

Mantoidea 106.

Marienkäfer 45, 54, 125.

Maskierung 11.

Mechanitis 90, 143, 149, 167.

- doryssus 146, 149.

- lysimnia 146, 149, 167.

- polymnia 167.

Megacanthopus 89.

Megaprotus ephippium 129.

Melanin 32.

Melasoma populi 127.

Melastoma polyanthum 16.

Melinaea 14:, 177.

- egina 167.

- ethra 167.

- mneme 167.

Melinda 183.

Meliphagidae 71.

Melyridae 133.

Membracinae 12, 106.

Mephitis 47.

Meropidae 54, 81.

Methona 141, 143.

- confusa 143, 193.

- megisto 143.

- themisto 143.

Metökie 95 .

Micaria scintillans 98 .
Mimanomma spectrum 119.

Mimeciton pulex 118, $121,122$.

Mimeta 71 .

Mimétisme isotypique 94.

Mimeuploea rhadamanthe 140, 161.

Mimikry, aggressive 67.

-, Batessche 67, 188.

-, Müllersche 67, 124, 126, 188.

-, protektive 67, 68 .

-, synaposematische 68.

一, Wesen der 65.

Mirociona atrosanguinea 12.

Mollusca 76 .

Mooshummel 93.

Morphinae 136, 168.

IIoschusochse 5 .

Mutilla 82.

- europaea 82.

- subintrans 79 .

Iutillinae $\mathbf{7 9}$.

Mydas praegrandis 90 .

- ruficornis 90 .

Mydasidae 90.

Mygnimia anthracina 85.

- aviculus 83.

Mylabris 45 .

Mylothris 137, 171.

- philaris 177.

Myrmarachne 99.

- plataleoides 99.

Myrmecium nigrum 97.

Myrmecobius 112.

Myrmecophaga 112.

Myrmecophana $\mathbf{1 0 S}$.

- fallax 107.

Myrmecophilie 114.

Myrmecophyes albo-

ornatus 102.

Myrmecopsis 88 .

IIyrmecoris gracilis 102 . 
Myrmedonia 116.

Myrmica rubra 116.

Myrmicaria cumenoides 108.

Myrmicidae 106.

Myrmoplasta mira 103.

Tabis lativentris 104, 107.

- myrmicodes 104.

Nachahmung 24.

-, unbewußte 24 .

Nachtfalter 86, 137.

Nachtschwalbe 8 .

Nattern 72.

Naturauslese 34.

Nectariniidae 77.

Necydalinae 83.

Necydalis 83.

Neotropinae 136, 140, 168.

Neptis imitans 138.

Nomada succincta 91.

Nordpolarzone 5 .

Nothopoeus 83, 85.

- fasciatipennis 83 .

- hemipterus 85.

Nucifraga caryocatactes 81 .

Nycthemerinae 137, 168.

Nymphalidae 136.

Nymphalinae 136.

Decophylla smaragdina 99.

Oeda inflata 12.

Oedemeridae 132.

Oedicnemus crepitans 7 .

Oedipoda 9.

Odynerus 86, 101.

- parietum 92.

- parredesi 94.

Olyras insignis 143 .

- praestans 143 .

Onomarchus 18.

Opisthobranchia 12.

Ordensbänder 9 .
Oriolus bouronensis 71 .

- decipiens 71.

- forsteni 71 .

Ornithoptera 150.

Ornithoscatoides decipiens 11.

Orthogenesis 26, 190.

Orthoptera 101, 125.

Otiorrhynchus 78 .

Ovis cervina 5 .

Ovulum uniplicatum 13.

Oxyrrhopus trigeminus 72.

Pachycondyla villosa 97.

Pachymenes ater 89 .

Pachyrhynchus 126.

Papilio 46, 62, 150, 152, 197.

- agamemnon 173.

- agestor 138.

- ascalaphus 197.

- caunus $140,161,179$.

- cynorta 147 .

- dardanus 161.

- - antinorii 163.

- - forma cenea 163.

- - - hippocoon 163,178 .

- - - niavina 163 .

- - - planemoides 163.

- - - ruspinae 163.

- - - trimeni 163 .

- - - trophonius 163.

- Lumbloti 163.

- - meriones 163 .

- hahneli 143.

- janaka 153.

- laglaizei 155, 177.

- mayo 156.

- memnon 156, 192.

- merope 161, 164.

- mimeticus 183.

- montanus 173 .
Papilio pammon 173.

- - romulus 173.

- paradoxus 140, 159, 164.

- polydorus 153.

- rex 183.

- westermanni 161 .

Papilionidae 137, 143, 168.

Paraplectana thorntoni 78.

Paratropa 134.

Parmelia crinita 15.

Peckhamia picata 98 .

Pelonium 133.

Pepsis 88, 89.

- ruficornis 90 .

Pericopinae 137, 143, 149, 167.

Periropis histrio 146.

- itbomia 146.

- mimica 167.

- phoebe 167.

Peridexia fulvipes 126.

Perrhybris 146 .

- lorena 146.

- pyrrha 146.

Petermännchen 75 .

Pflanzen, schützende Ähnlichkeit bei 11 .

Phaneropteriden 107.

Pharmacophagus 46 , 150, 152, 171, 173.

- aristolochiae 153, 173.

- coon 152, 159.

- darsius 173.

- dasalada 153.

- doubledayi 152.

- hector 173.

- philenor 174, 183.

- polydorus 164.

- priapus 152.

- rhodifer 156.

Phasmidae 14, 18, :31.

Phidippus mor'sitans 98.

Philemon 71 .

- moluccensis 71 . 


\section{$-\quad 213$}

Philemon subcorniculatus 71 .

- timorlaoensis 71 .

Phryganistria fruhstorferi 14.

Phryniscus nigricans 75.

- varius 74 .

Phyciodes actinote 178 .

Phyllium 18, 31, 32.

- siccifolium 19.

Phyllodes 22.

- ornata 22.

- verhuelli 22.

Phylloscyrtus 125 .

- macilentus 107.

Phytoeciinae 86.

Phytophaga 45, 127.

Pieridae $30,53,61,137$, $141,143,146,168$.

Pieris 197.

- brassicae L. 52.

Pigment 32.

Pilophorus clavatus 105.

Pimpla 82.

Pionia 134.

Pirol 71.

Pissodes 78 .

Pittas 113.

Pittidae 112.

Plauema 147.

- gaea 147.

- poggei 163.

Plankton 6.

Plattfische 8, 39.

Platynoptera 133.

Pliocercus aequalis 72 .

Poecilopeplus corallifer 130.

Pogonius venustipennis 126.

Polistes testacea 94 .

Polistomorpha surinamensis 94 .

Polybia angulata 89 .

- cayennensis 94.

- chrysothorax 94.
Polybia phthisica 87.

Polymorphismus 155, 156, 192.

Polyrhachis gagates 103.

- spiniger 103.

Pompilidae 81, 83, 94, 101.

Pompilus polistoides 101.

Ponera tarsata 103.

Präponderanz 191.

-, weibliche 185.

Precis-iphita 38.

Priotelus vigintipunctatus 129.

Proctotrupidae 120.

Prosoplecta 129.

Protoparce convolvuli 31.

Pseudacraea 147, 173, 178.

- boisduvali 147 .

- hirce 147.

- poggei 140.

Pseudaposem 67.

Pseudaposematisch 67 .

Pseudepisem 67.

Pseudomimikry 106.

Pseudosphex ichneumonea 89.

- noverca 89.

Psidium guiava 18.

Psophus 9.

Pteroplatus lyciformis 133.

- sp. 132.

Ptilopus cinctus 4.

Puffotter 58, 72.

Pyriglena leucoptera 113.

Pyrrhocoridae 103.

Radena 138.

Randwanzen 103, 105.

Raubfliegen 53,54,161, 171.

Raubwespen 87, 101.
Raupenfliegen 52 .

Rebhuhn 7.

Reduviidae 11.

Reduvius personatus 11 .

Reniera aurantiaca 51.

Rentier 5 .

Rhamphiophis multimaculatus 72 .

Rhinopalpa 21.

Rhinoscapha 126.

Rhinosciurus tupajoides 70.

Rhinotraginae 83 .

Rhopalocera 136, 168.

Rhvnchophorus 126.

Rhynchopyga meisteri 89.

Ringe 166.

-, synaposematische 188.

Ringelspinner 44, 53 .

Rinnenfalter 152, 161.

Riptortus linearis 105 .

Roeslerstammia pronubella 184 .

Rüsselkäfer 15, 126 .

Rüßler 75, 132.

Rutelidae 49.

\$ackspinnen 97.

Salamandra maculosa 45.

Salticidae 79, $9 \overline{7}$.

Sandlaufkäfer 125 .

Satyrinae 136.

Scepastus pachyrrhynchoides 126.

Schaben 128, 134.

Schattenkäfer 130 .

Scheinwarnfärbung 67 .

Schlammfliege 92 .

Schlangenmimikry 58 .

Schlupfwespen 45,52 , $81,82,83,120$.

Schmarotzerinsekten 52.

Schmuckbiene 91 .

Schnabeligel 112. 
Schneeammer 5 .

Schneeeule 5 .

Schneehase 5 .

Schneehuhn 5.

Schreckfärbung 43,55 .

Schreitwanze 11.

Schuppentier 112.

Schutzfärbung 4, 55 .

-, aggressive 4 .

-, protektive 4.

Schwalbenschwänze 46, 62, 137, 155, 173.

Schwämme 12 .

Schwälmer 86 .

Schwebfliegen 91 .

Sciapteron tabaniforme 86.

Scolia hirta 94 ,

Scoliidae 79, 81, 82 .

Seoliomima insignis 87 .

Scutellerinae 49 .

Seezunge 76 .

Segelfalter 152.

Sehmimikry 115.

Selektionstheorie 34, 194.

Sesia asiliformis 86 .

- cynipiformis 86 .

- seitzi 161 .

Sesiidae 86, 137.

Singzikaden 18, 47.

Smerinthus ocellata j.

- tiliae L. 57.

Solea solea 76 .

Somatolyse 4 .

Sonnenvögel 77.

Spanner 14.

Spechtmeise 57.

Sperber 70 .

Sphecosoma 88.

Sphegidae 81, 101.

Sphex cyanea 101.

Sphingidae 86.

Spilomutilla eltola 79 .

Spinnen 6, 47, 66, 171.

Spinnenjäger 77 .

Spinnenkrabben 11.

Spirachtha 123.
Spitzhörnchen 70 .

Sporenkuckuck 170 .

Springmäuse 6 .

Springspinnen 79, 07.

Stabheuschrecken 14, 33.

Stalachtis 146.

Staphylinidae 115.

Stauropus fagi 23.

Stechimmen 81.

Steinhummel 93.

Stielhornfliege 91.

Stinktier 47.

Stizus tridentatus 94 .

Strophosomus 78 .

- faber 78 .

- obesus 77 .

Sturnella ludoviciana 184.

Suberites 11.

Swynnerton 171.

Symphilen 114.

Synageles picata 98 .

Synechthren 114.

Synemosyna formica 98.

Synöken 114.

Syntomidae \$7, 88, 134, 137.

Syrphidae 91.

Syrphus corollae 91.

Systellonotus triguttatus 104.

Tagfalter 136.

Tagmotten 137, 140, 149, 153.

Tagpfauenauge 57.

Tannenhäher 81 .

Tastmimikry 115, 117.

Telephorus 45, 130.

Tenaris 136.

Termiten 112, 123.

Termitoidie 123.

Termitomimus 123.

Thaumantis 38 .

Thyridia 141.

- megisto 180 .
Thyridia psidii 143.

- pytho 143.

Tiger 5 .

Tintenfisch 34 .

Tithorea 146.

Tortrix viridana 9 .

Trachinus draco 75 .

- vipera 75 .

Treiberameisen 119 , 120.

Tricondyla 125.

Triel 7.

Trigonidium cicindeloide 125.

Trisenlia patricialis 87 .

Trochilium apiforme 86.

- spheciforme 86 .

Troides 150.

Tropidonotus 53.

Trutzfärbung 43.

Trutztypus 115.

Truxalis unguiculata 25.

Tupaja ferruginea 70 .

Ultradarwinisten 35 .

Umyebung, Einflüsse der 30 .

Unterschied zwischen schützender Ähnlichkeit und Mimikry 65 .

Uraniidae 137, 168.

Urwaldgebiete, Tiere der 6.

Vanessa io L.: 57 .

Vespidae 81, 89.

- solitariae 101.

Vilpianus galii 15 .

Vipera berus 73 .

Vögel 40 .

Volucella $60,67,92$, 189.

- bombylans $92,93$.

- facialis 92 . 


\section{$-\quad 215$}

Volucella inanis 93.

- inflata 93.

- pellucens 92, 93.

Wachsen, organisches 26.

Waldschnepfe 7 .

Wanderameisen 117 .

Wanzen 49, 101.

Warnfarben, gemeinsame $166,175$.

Warnfärbung, gemeinsame 43, 55, 146.

Warzenkäfer 130 .

Wegböcke 83.

Wegschnecke 47 .

Wegwespen $81,83,88$, $98,101$.
Weichkäfer 45, 130 .

Weichtiere 76.

Weinschwärmer 31 .

-, großer 57.

Weißlinge $30,61,137$, $141,146$.

Wendehals 8.

Wespen 45.

Widderböcke 85 .

Widderchen 44, 46, 137.

Wiedehopf 5 .

Windenschwärmer 31.

Wolf 5 .

Wollkrabbe 11.

Wollspinner 137.

Wüstenfuchs 6 .

Wüstentiere 6,31 .
Tebra 5.

Zethera 136.

Zeuxidia 37.

Ziegenmelker 31 .

Zikaden 9, 12, 15, 18, $40,105$.

Zuchtwahl, natürliche 194.

Zuchtwahllehre 23 .

Zufall 26.

Zygaena 46.

- algira 161.

- cedri 161.

- filipendulae 44, 46.

- loyseli 161.

Zygaenidae 137. 


\section{Druckfehlerverzeichnis.}

\begin{tabular}{|c|c|c|c|c|c|c|c|}
\hline 47 & Zeile & 14 & v. u & sta & Limas & lies & Limax. \\
\hline 79 & $n$ & 14 & v. 0 . & $n$ & Doldwespen & $n$ & Dolchwespen. \\
\hline 106 & $n$ & 2 & v. o. & " & Membracidae & & Membracinae. \\
\hline 106, & $n$ & 5 & v. 0 . & $n$ & Hemiconotus & $"$ & Heniconotus. \\
\hline 115 & $n$ & 20 & v. u. & $n$ & Dinardinen & $n$ & Dinardini. \\
\hline 135 & $n$ & 3 & v. o. & $n$ & J. Müller & $n$ & F. Müller. \\
\hline 154, & $"$ & 2 & v. u. & $n$ & Alcides & & Alcidis. \\
\hline 155 & $"$ & 2 & v. 0 . & $"$ & Alcides & $n$ & Alcidis. \\
\hline 155 , & $n$ & 13 & v. u. & $n$ & Alcides & $n$ & Alcidis. \\
\hline & 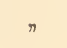 & 9 & v. 0. & $n$ & chrysippus & ” & misippus. \\
\hline
\end{tabular}




\section{DIE WISSENSCHAFT.}

Sammlung nalurwissenschaillicher und mathemalischer Einzeldarstellungen.

\section{Bis jetzt erschienen:}

1. Heft: Untersuchungen über die radioaktiven Substanzen von Mme. S. Curie. Übersetzt und mit Literaturergänzungen versehen von W. Kaufmann. Dritte Auflage. Mit 14 Abbild. Preis 16 3,-, geb. It 3,80.

2. Heft: Die Kathodenstrahlen von Prof. Dr. G. C. Schmidt. Zweite verbesserte u. verm. Auflage. Mit 50 Abbild. Preis $163,-$, geb. 16 3,60.

3. Heft: Elektrizität und Materie von Prof. Dr. J. J. Thomson. Autorisierte Übersetzung von G. Siebert. Z weite verbesserte Auflage. Mit $21 \mathrm{Ab}$ bildungen. Preis $163,-$, geb. 163,60 .

4. Heft: Die physikalischen Eigenschaften der Seen von Dr. Otto Freiherr von und zu Aufsess. Mit 36 Abbild. Preis 16 3,-, geb. 16 3,60.

5. Heft: Die Entwickelung der elektrischen Messungen von Dr. O. Frölich. Mit 124 Abbild. Preis 16 6,-, geb. $166,80$.

6. Heft: Elektromagnetische Schwingungen und Wellen von Prof. Dr. Josef Ritter v. Geitler. Mit 86 Abbild. Preis 16 4,50, geb. 16 5,20.

7. Heft: Die neuere Entwickelung der Kristallographie von Prof. Dr. H. Baum. hauer. Mit 46 Abbild. Preis .16 4,-, geb. 16 4,60.

8. Heft: Neuere Anschauungen auf dem Gebiete der anorganischen Chemie von Prof. Dr. A. Werner. Z weite durchgesehene und vermehrte Auflage. Preis 16 9,-, geb. 16 10,-

9. Heft: Die tierischen Gifte von Dr. Edwin S. Faust. Preis $\mathbb{H}_{6}$ 6,geb. 166,80 .

10. Heft: Die psychischen Maßmethoden von Dr. G. F. Lipps. Mit 6 Abbild. Preis 116 3,50, geb. 16 4,10.

11. Heft: Der Bau des Fixsternsystems von Prof. Dr. Hermann Kobold. Mit 19 Abbild. und 3 Tafeln. Preis 146,50 , geb. 16 7,30.

12. Heft: Die Fortschritte der kinetischen Gastheorie von Prof. Dr. G. Jäger. Mit 8 Abbild. Preis 1163,50 , geb. 16 4,10.

13. Heft: Petrogenesis von Prof. Dr. C. Doelter. Mit 1 Lichtdrucktafel und 5 Abbild. Preis $1167,-$, geb. 167,80 .

14. Heft: Die Grundlagen der Farbenphotographie von Dr. B. Donath. Mit 35 Abbild. u. 1 farb. Ausschlagtafel. Preis $165,-$, geb. 16 5,80.

15. Heft: Höhlenkunde mit Berücksichtigung d. Karstphänomene von Dr. phil. Walther von Knebel. Mit 42 Abbild. Preis 16 5,50, geb. $166,30$. 


\section{Verlag von Friedr. Vieweg \& Sohn in Braunschweig.}

\section{DIE WISSENSCHAFT Sammlung naturvissenschaftlicher u. mathematischer Einzeldarstellungen.}

16. He ft: Die Eiszeit von Prof. Dr. F. E. Geinitz. Mit 25 Abbild., 3 farbigen Tafeln und einer Tabelle. Preis $1 / 67,-$, geb. 167,80 .

17. Heft: Die Anwendung der Interferenzen in der Spektroskopie u. Metrologie von Dr. E. Gehrcke. Mit 73 Abbild. Preis 16 5,50, geb. 16 6,20.

18. Heft: Kinematik organischer Gelenke von Prof. Dr. Otto Fischer. Mit 77 Abbild. Preis $1168,-$, geb. 169 , -

19. Heft: Franz Neumann und sein Wirken als Forscher und Lehrer von Prof. Dr. A. Wangerin. Mit einer Textfigur und einem Bildnis Neumanns in Heliogravüre. Preis $\mathbb{H}_{6}$ 5,50, geb. $166,20$.

20. Heft: Die Zustandsgleichung der Gase u. Flïssigkeiten u. die Kontinuitätstheorie v. Prof. Dr. J. P. Kuenen. Mit 9 Abb. Preis 16 6,50, geb. 16 7,10.

21. Heft: Radioaktive Umwandlungen von Prof. E. Rutherford. Übersetzt von M. Levin. Mit 53 Abbild. Preis 16 8, 一, geb. 16 8,60.

22. Heft: Kant und die Naturwissenschaft von Prof. Dr. Edm. König. Preis geh. $166,-$, geb. 167, -

23. Heft: Synthetisch-organische Chemie d. Neuzeit von Prof. Dr. Jul. Schmidt. Preis 116 5,50, geb. 16 6,20.

24. Heft: Die chemische Affinität und ihre Messung von Dr. Otto Sackur. Mit 5 Abbildungen im Text. Preis $\mathbb{N}_{6} 4,-$, geb. $\mathscr{H}_{6} 4,80$.

25. Heft: Die Korpuskulartheorie der Materie von Prof. Dr. J. J. Thomson. Deutsch von G. Siebert. Mit 29 Abbild. Preis 146 ,-, geb. 16 5,80.

26. Heft: Die Bindung des atmosphärischen Stickstoffs in Natur und Technik von Dr. P. Vageler. Mit 16 Abbildungen im Text und auf 5 Tafeln. Preis $1 / 6$, 50 , geb. 165,20 .

27. Heft: Die Schwerebestimmung an der Erdoberiläche von Prof. Dr. Joh. Bapt. Messerschmitt. Mit 25 Abbildungen. Preis $1 / 6$ 5,-, geb. 16 5,80.

28. Heft: Die Kraftfelder von Prof. V. Bjerknes. Mit 29 Abbildungen. Preis $167,-$, geb. 167,80 .

29. Heft: Physiologie der Stimme und Sprache von Prof. Dr. Hermann Gutzmann. Mit 92 Abbildungen im Text und auf 2 Tafeln, zum Teil in Farbendruck. Preis geh. H6 8,-, geb. 16. 9,-.

30. Heft: Die atmosphärische Elektrizität. Methoden und Ergebnisse der modernen luftelektrischen Forschung von Prof. H. Mache und Prof.

E. v. Schweidler. Mit 20 Abbildungen. Preis $1 / 6$ 6,-, geb. 16 6,80.

31. Heft: Das Klimaproblem der geologischen Vergangenheit und historischen Gegenwart von Dr. Wilh. R. Eckardt. Mit 18 Abbildungen und 4 Karten. Preis 16 6,50, geb. 167,10 . 


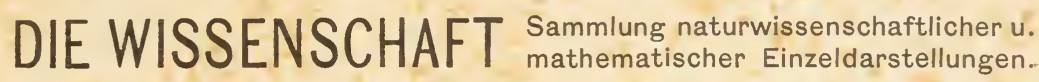

32. Heft: Lichtbiologie. Die experimentellen Grundlagen der modernen Lichtbehandlung, zusammengestellt von Dr. Albert Jesionek, Professor an der Üniversität Gießen. 1910. Preis 116 4,-, geb. 16 4,80.

33. Heft: Die physikalisch-chemischen Eigenschaften der Legierungen. Von Prof. Dr. Bernh. Dessau. Mit 82 Abbild. Preis 16 7,-, geb. 16 8,-.

34. Heft: Die elektrische Fernübertragung von Bildern. Von Dr. Rob. Pohl. Mit 25 Abbildungen. Preis 16 1,80, geb. 16 2,50.

35. Heft: Die elektrischen Erscheinungen in metallischen Leitern. (Leitung, Thermoelektrizität, Galvanomagnetische Effekte, Optik). Von Professor

Dr. K. Baedeker. Mit 25 Abbildungen. Preis 16 4,-, geb. 16 4,80.

36. Heft: Grundlagen der praktischen Metronomie. Von Prof. Dr. K. Scheel. Mit 39 Abbildungen. 1911. Preis 16 5,20, geb. 16 6,-.

37. Heft: Vergleichende Mond- und Erdkunde von Prof. Dr. S. Günther. Mit 23 Abbildungen und 4 Tafeln. 1911. Preis .16 5,-, geb. 16 5,80.

38. Heft: Das Relativitätsprinzip. Von Dr. M. Laue. Zweite vermehrte Auflage. Mit 22 Abbild. 1913. Preis .16 8,-, geb. $168,80$.

39. Heft: Das Problem des absoluten Raumes und seine Beziehung zum allgemeinen Raumproblem. Von Aloys Müller. Preis .16 4,-, geb. 16 4,80.

40. Heft: Die Leuchtgaserzeugung und die moderne Gasbeleuchtung von Ingenieur Fritz Schmidt. Mit 63 Abbildungen. Preis .16 2,50, geb. 16 3,20.

41. Heft: Der Weltäther von Sir Oliver Lodge. Deutsch von H. Barkhausen. Mit 17 Abbildungen im Text und einer Tafel. Preis 16 3,-; geb. 16 3,60.

42. Heft: Wechselstrom-Versuche von Prof. Dr. Anton Lampa. Mit 54 Abbild. Preis $165,-$, geb. 16 5,80.

43. Heft: Die Telephonie ohne Draht von Dr. K. Markau. Mit 103 Abbildungen. Preis 16 4,50, geb. 16 5,20.

44. Heft: Elektrobiologie. Die Lehre von den elektrischen Vorgängen im Organismus auf moderner Grundlage dargestellt von Prof. Dr. Julius Bernstein. Mit 62 Abbildungen. 1912. Preis geh. 16 6,-, geb. 16 6,80.

45. Heft: Die Physik der Röntgenstrahlen. Von Dr. Robert Pohl. Mit 72 Abbild. im Text und auf einer Tafel. 1912. Preis geh. 16 5,-, geb. 16 5,80.

46. Heft. Physikalische Grundlagen der Elektrotechnik. Von Prof. Dr. F. F. Martens. Erster Band: Eigenschaften des magnetischen und elektrischen Feldes. Mit 253 Abbildungen. 1912. Preis geh. 16 7,20, geb. 16 8.- 
a. ins 1 inis:

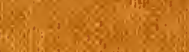

$$
\text { 3. }
$$

\section{3.}

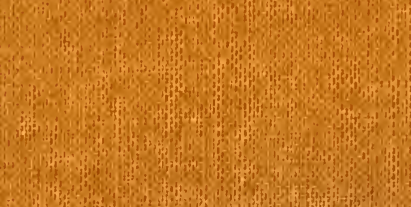

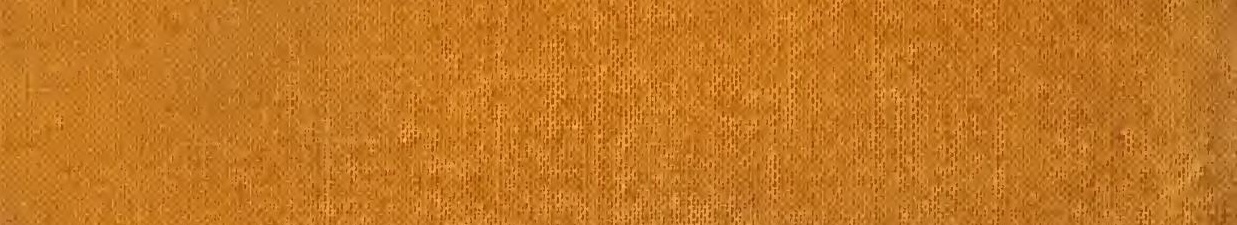

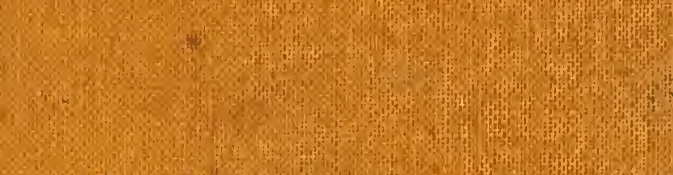

(2)

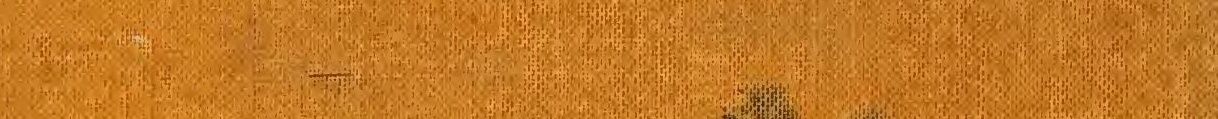

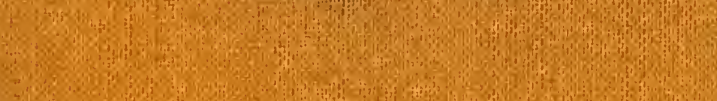

$$
\text { (1) }
$$

Q.

$\lim _{0,0}$

-

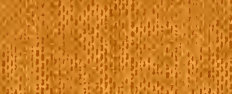

(4)

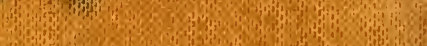

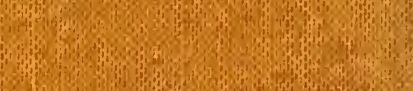
Hon H.

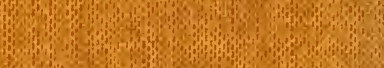

a.

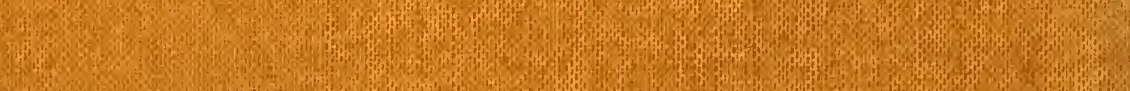

3., 